\title{
AdVANCING RISK AND VULNERABILITY ASSESSMENT FOR \\ DECISION-MAKING AND RESEARCH
}

- Case Study from the German-Indonesian Tsunami EARLY WARNING SYSTEM (GITEWS) PROJECT

\author{
Dissertation \\ zur Erlangung des mathematisch-naturwissenschaftlichen Doktorgrades \\ "Doctor rerum naturalium" \\ der Georg-August-Universität Göttingen
}

im Promotionsprogramm Geowissenschaften / Geographie

der Georg-August University School of Science (GAUSS)

vorgelegt von

Niklas Baumert

Aus Hannover

Göttingen 2015 
Betreuungsausschuss

Referent/in: Prof. Dr. Heiko Faust, Abteilung Humangeographie, Geographisches Institut, Georg-August Universität Göttingen

Korreferent/in: Prof. Dr. Jörn Birkmann, Institut für Raumordnung und Entwicklungsplanung, Universität Stuttgart

Mitglieder der Prüfungskommission

Prof. Dr. Christoph Dittrich, Abteilung Humangeographie, Geographisches Institut, Georg-August Universität Göttingen

Prof. Dr. Jakob Rhyner, United Nations University, Institute for Environment and Human Security

Prof. Dr. Jonas Kley, Abteilung Strukturgeologie und Geodynamik, Geographisches Institut, Georg-August Universität Göttingen

Dr. Markus Keck, Abteilung Humangeographie, Geographisches Institut, Georg-August Universität Göttingen

Tag der mündlichen Prüfung: 30.10.2015 


\section{Abstract}

Opportunities showing how to make use of risk-, and particularly of vulnerability assessment, for risk management decision-making have been less in the focus of contemporary risk and vulnerability research scholars. It has been found that this circumstance is attributable to a) the fact that most contemporary vulnerability assessments are scientific in nature aiming at operationalizing and testing scientific vulnerability concepts and methods, being therefore too limited in scope to provide a precise description of their function and purpose for policy; b) the lack of a common risk and vulnerability terminology shared by vulnerability scholars and risk management practitioners that would allow the smooth and understandable translation of vulnerability assessment results into recommendations for risk management decision-making; c) the widespread perception that risk and vulnerability assessment and reduction refer to a linear process, where the latter comes after the first; and, finally, e) the rare integration of vulnerability assessment research projects into real processes of risk and vulnerability management.

This dissertation charts a course for advancing applied risk and vulnerability assessment aiming at increasing its applicability and utility for processes of risk management. In support of this, a new Framework for Applied Risk and Vulnerability Assessment and Research (FARVAR) has been developed that has spawned a risk and vulnerability causality frame and terminology shared and used as a common frame for action by risk and vulnerability scholars and practitioners. It builds upon the notion that exposure and susceptibility to harm arises from threats, and that the lack of capacity of societies to effectively reduce risks and vulnerabilities to such threats is ascribable to social, economic, and environmental conditions. Consequently, this dissertation argues that applied risk and vulnerability assessment and research needs to focus on societal conditions revealing the lack of effective risk management, and on how such information can support risk management decisions. This challenge has been addressed by defining an iterative risk management process, where for each of the discrete but evolutionary risk management steps, including decisions to invest in risk and vulnerability reduction, then selecting the desired risk and vulnerability reduction domain (prevention, preparedness) as well as the domain specific component (e.g.; accommodation, retreat, early warning system), until finally selecting and implementing component specific tasks and measures - disaggregated, need-based and tailored risk and vulnerability information can support decision-making.

To empirically explore areas of application of risk and vulnerability assessments for risk management decision-making, a case study has contextualized the FARVAR and the risk management process derived thereof in order to setup a Tsunami Early Warning System in Indonesia. The focus of the study has concentrated on assessing tsunami hazard characteristics, exposure patterns, and the conditions of the communities' access to tsunami warnings, their evacuation readiness and physical evacuation capacity, each representing an assessment scheme of its own with different disciplinary foci and methodology. An analysis focused on how such risk and vulnerability information can support each of the sequential risk management steps - elaborating, assessing, selecting, and implementing options for establishing a functioning early warning system - has shown the importance of developing, first and foremost, disaggregated risk and vulnerability information packages. As a result, a variety of diverse application opportunities have emerged providing decision support along the process of risk and vulnerability reduction. They have proven to be beneficial for: a) prioritizing and sequencing options; b) comparative cost-benefit and effectiveness analysis; the identification of spatial areas of intervention and spatial planning; the development of context specific awareness campaigns and education curricula; the rationalization conflicting public and expert debates related to specific risk management challenges; and also for broadening the perspective of R\&V-R from mere technical to social fields of action. 


\section{Zusammenfassung}

Differenzierte Anwendungsmöglichkeiten quantitativer Risiko- und vor allem Vulnerabilitätsanalysen für Risikomanagemententscheidungen sind noch unzureichend entwickelt. Dieser Umstand ist der Situation geschuldet, dass a) aktuelle Vulnerabilitätsanalysen vornehmlich dem Ziel der Prüfung und Weiterentwicklung wissenschaftlicher Vulnerabilitätskonzepte und Methoden dienen und ihre Zweckmäßigkeit für die Risikomanagementpraxis mangelhaft geklärt ist; b) in Ermangelung von durch Forschung und Praxis abgestimmten Konzept und Terminologie bezogenen Standards der gegenseitige Austausch von Erfahrungswissen erschwert wird; c) gängige RisikomanagementKonzeptualisierungen einen Prozess darstellen, bei dem Entscheidungen und die Umsetzung von Risikomanagementoptionen der Risikobewertung linear nachgelagert sind; und d) jenseits von Gefahren- und Expositionsanalysen, eher selten wissenschaftliche Projekte zu Vulnerabilitätsanalysen in realen Prozessen des Risikomanagements integriert werden.

Diese Dissertation beschreitet einen neuen Weg der angewandten Vulnerabilitätsforschung mit dem Ziel, Anwendungsmöglichkeiten von Vulnerabilitätsanalysen für das Risikomanagement und seine einzelnen Prozessetappen zu erkunden und zu diversifizieren. Hierfür dient ein entwickeltes Rahmenkonzept für die angewandte Risiko- und Vulnerabilitätsanalyse (FARVAR) als Grundlage, das im Kern auf eine für Forschung und Praxis gleichermaßen verständliche und handlungsleitende Risikokausalität und -terminologie basiert. Dieses Konzept entspringt der Auffassung, dass Risiko, Exposition und Anfälligkeit eine Folge des Bedrohungspotentials und der mangelhaften Fähigkeit einer Gesellschaft sind, Risiken und Vulnerabilitäten effektiv zu reduzieren. Das bedeutet für die angewandte Risiko- und Vulnerabilitätsbewertung eine Fokussierung auf a) diejenigen gesellschaftlichen Verhältnisse, die das Scheitern eines leistungsfähigen Risikomanagements hervorrufen und b) wie entsprechende Risiko- und Vulnerabilitätsbewertungen Risikomanagemententscheidungen unterstützen können. Um dieser Herausforderung gerecht zu werden, wurde ein iterativer Risikomanagementprozess definiert, der maßgeschneiderte Risiko- und Vulnerabilitätsinformationspakete für jeden der aufeinander aufbauenden und sich ergänzenden Schritte als Entscheidungsunterstützung vorsieht, zum Beispiel für die Feststellung von Risikomanagementbedarf, die Festlegung auf eine präferierte Risikomanagementdomäne (Prävention, Katastrophenvorsorge), auf domänenspezifische Komponenten (z.B. Gefahreneinbindung, Rückzug, Frühwarnsystem) und auf komponentenspezifische Aufgaben und Maßnahmen, sowie deren Implementierung und Überwachung.

Um Anwendungsmöglichkeiten eines entsprechenden Ansatzes empirisch zu ergründen wurde das FARVAR und der daraus abgeleitete Risikomanagementprozess für den Aufbau eines Tsunami Frühwarnsystems in Indonesien (InaTEWS) kontextualisiert. Die Fallstudie zeigt, wie mittels einer Tsunami Gefahren- und Expositionsanalyse und der Bewertung der Fähigkeit betroffener Bevölkerungsteile, rechtzeitigen Zugang zu Warninformationen zu haben, bereit für die unmittelbare Evakuierung zu sein und erfolgreich physisch zu evakuieren, Optionen zur Ausgestaltung eines effektiven Tsunami Frühwarnsystems entwickelt, bewertet, ausgewählt und umgesetzt werden können. Die Ergebnisse zeigen, dass der Nutzen entsprechender Analysen steigt, je aufgeschlüsselter und flexibler sie methodisch und disziplinarisch den Bedarfen einzelner Risikomanagementsequenzen angepasst werden. Die resultierenden vielseitigen Anwendungsmöglichkeiten beinhalten die Priorisierung und Sequenzierung von Optionen, die Anfertigung von Kosten-Nutzen- und Effektivitätsanalysen, die Identifikation von Interventionsräumen für Risikomanagement und Raumplanung, die Entwicklung von Strategien und Inhalten für kontextspezifische Aufklärungskampagnen und Lehrplänen, sowie die Rationalisierung von konfliktträchtigen Fachdebatten und öffentlichen Diskursen. 


\section{TABLE OF CONTENTS}

$\begin{array}{llr}\text { I.1 Motivation } & 1\end{array}$

I.2 Problem Setting 3

I.3 Research ObJectives, Goals and Questions

$\begin{array}{lll}\text { I.4 Methodological OVerview } & 8\end{array}$

$\begin{array}{lll}\text { I.5 StRUCtURE OF THE Dissertation } & 11\end{array}$

II. RISK, VULNERABILITY AND CAPACITY $\quad 15$

$\begin{array}{lll}\text { II.1 INTRODUCTION } & 15\end{array}$

$\begin{array}{lll}\text { II.2 COMPONENTS OF RISK } & 15\end{array}$

II.3 Approaches Towards Understanding the Causal Structure OF VUlnerability 19

$\begin{array}{lll}\text { II.4 CAPACITY } & 23\end{array}$

\begin{tabular}{ll} 
III. & RISK AND VULNERABILITY REDUCTION \\
\hline
\end{tabular}

\begin{tabular}{ll|l} 
III.1 INTRODUCTION & 27
\end{tabular}

III.2 Framing Risk AND VUlnerability Reduction Within a SOCIETAL CONTEXt 27

III.3 Hierarchical Nomenclature OF Risk AND VUlNerability Reduction 30

III.4 The Process OF Risk AND VULNerability Reduction 36

IV. NEW FRAMEWORK FOR APPLIED RISK AND VULNERABILITY ASSESSMENT RESEARCH (FARVAR) 43

$\begin{array}{lll}\text { IV.1 INTRODUCTION } & 43\end{array}$

IV.2 RISK AND VULNERABILITY AS THE OUTCOME OF LACK OF CAPACITY

$\begin{array}{lll}\text { IV.3 THE R\&V-R NOMENCLATURE REPRESENTING TYPES OF CAPACITY } & 48\end{array}$

IV.4 THE RISK AND VULNERABILITY CAUSALITY Frame OF THE FARVAR

$\begin{array}{lll}\text { IV.5 APPLIED RISK AND VULNERABILITY ASSESSMENT } & 60\end{array}$

$\begin{array}{llr}\text { IV.6 CONCLUSION } & 69\end{array}$

V. CASE STUDY PART I - RATIONALE AND OVERVIEW

$\begin{array}{lll}\text { V.1 INTRODUCTION } & 72\end{array}$

V.2 A TSUNAMI EARLY WARNING SYSTEM FOR INDONESIA - A RESPONSE TO THE 2004 INDIAN OCEAN TSUNAMI 73

$\begin{array}{lll}\text { V.3 RESEARCH AREA } & 76\end{array}$ 
VI. CASE STUDY PART 2 - RISK AND VULNERABILITY ASSESSMENT FRAMEWORK IN THE CONTEXT OF \begin{tabular}{ll} 
INATEWS & 82 \\
\hline
\end{tabular}

$\begin{array}{lll}\text { VI.1 INTRODUCTION } & 82\end{array}$

$\begin{array}{lll}\text { VI.2 Risk And Vulnerability Assessment Framework DeVelopment Process } & 82\end{array}$

VI.3 Generic DisASTER RISK AND VULNERABILITY REDUCTION TASKS TO ESTABLISH AN EARLY WARNING SYSTEM 83

VI.4 CONTEXTUALIZEd RISK AND VULNERABILITY Reduction TASKS AND PROCESSES WITHIN INATEWS 86

$\begin{array}{lll}\text { VI.5 RISK AND VULNERABILITY ASSESSMENT IN THE CONTEXT OF INATEWS } & 96\end{array}$

VII. CASE STUDY PART 3 - EMPIRICAL RESEARCH; METHODS AND RESULTS 102

$\begin{array}{llr}\text { VII.1 INTRODUCTION } & 102\end{array}$

Vil.2 OVerview on the Research Process, Research Topics, Methods, and Data Sources 102

$\begin{array}{lll}\text { VII.3 Mapping Warning LeVel SPECIFIC TSUNAMI INUNDATION } & 105\end{array}$

$\begin{array}{lll}\text { VII.4 ASSESSING EXPOSURE } & 110\end{array}$

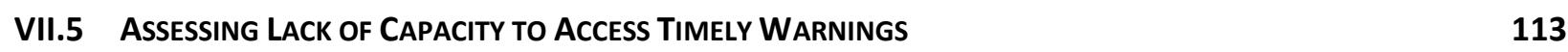

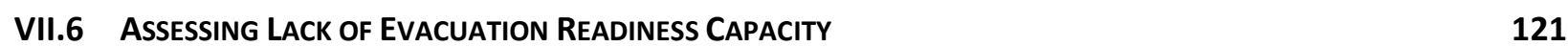

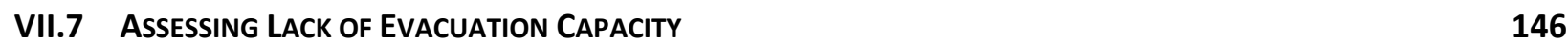

VIII. CASE STUDY PART 4 - THE UTILITY OF RISK AND VULNERABILITY ASSESSMENT RESULTS FOR INATEWS 153

$\begin{array}{llr}\text { VIII.1 INTRODUCTION } & 153\end{array}$

$\begin{array}{lll}\text { VIII.2 Utility EValuation Method } & 153\end{array}$

$\begin{array}{llr}\text { VIII.3 RESULTS } & 155\end{array}$

$\begin{array}{lll}\text { VIII.4 CONCLUSION } & 168\end{array}$

\begin{tabular}{ll} 
IX. SUMMARY AND DISCUSSION & 175 \\
\hline
\end{tabular}

$\begin{array}{lll}\text { IX.1 INTRODUCTION } & 175\end{array}$

IX.2 DeVelopment of A Framework Shared by R\&V-SChOlaRS AND R\&V-R Practitioners to Facilitate APPLIED R\&V-A AND RESEARCH 175

IX.3 WIDENING THE SCOPE AND UTILITY OF R\&V-A FOR R\&V-R IN PROCESSES OF R\&V-R 182

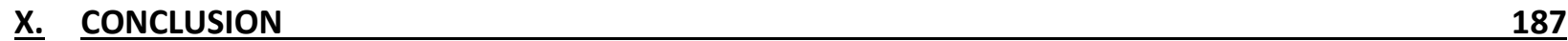


X.1 Advancing Applied R\&V-A for DeCision Making

X.2 The Role Of GEOgRAPHY In APPLIEd RISK AND VULNERABILITY RESEARCH 188

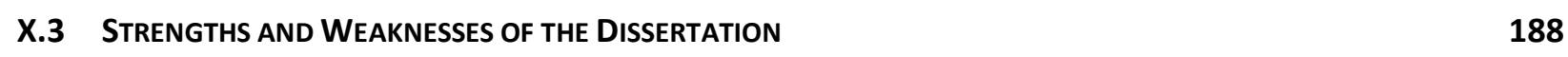

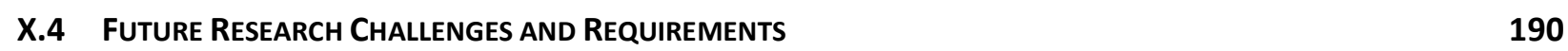

XII. APPENDIX I

XII.1 LOCAL ASSESSMENT RESULTS I

XII.2 HOUSEHOLD QUESTIONNAIRE V

XII.3 ACKNOWLEDGEMENT XXII

XII.4 DeCLARATION OF ORIGINALITY AND CERTIFICATE OF OWNERSHIP XXIII 


\section{LIST OF FIGURES}

Figure 1 Methodological overview of the dissertation

Figure 2 Hazards of natural and socio-natural origin

Figure 3: Analytical framework for poverty-related interventions 20

Figure 4: New perspective on R\&V-R 29

Figure 5: The hierarchical R\&V-R-nomenclature 31

Figure 6: The process of R\&V-R 38

Figure 7: Capacity as the dependent variable of the emergence of vulnerability 45

Figure 8 Framework for Applied Risk and Vulnerability Assessment and Research 52

Figure 9 Overview of the case study approach 81

Figure 10 Early warning systems operating at the interface of society, environment and technology 84

Figure 11 Bathymetry at the coast of West Sumatra in the region of the tsunami-genic earthquake 200486

Figure 12: The InaTEWS response scheme and R\&V-R tasks 87

Figure 13 Linking R\&V-R tasks with the process of R\&V-R 87

Figure 14: Components of R\&V in the context of TEWS in Indonesia 98

Figure 15 Topics of R\&V-A based on the definition of R\&V-R tasks in the context of InaTEWS 100

Figure 16: Assessment of the spatially differentiated likelihoods for the occurrence of an earthquake 107

Figure 17: Process of mapping access to tsunami warnings by the population $\quad 114$

Figure 18: Sound projection for three sirens with different output power 117

Figure 19: Methodological flowchart for constructing and mapping the Evacuation Readiness Index 123

Figure 20: Evacuation readiness sub-indexes and aggregated index 129

Figure 21: Evacuation Readiness Index construction 130

Figure 22: Respondents anticipated response to tsunami warning in Cilacap and Bali 131

Figure 23: Evacuation readiness sub-indexes and aggregated index 138

Figure 24: Evacuation readiness assessment results for communities in Cilacap 143

Figure 25: Evacuation readiness assessment results for all research areas 144

Figure 26: Evacuation time and building capacity as decisive evacuation constraints 149

\section{LIST OF TABLES}

Table 1: The hierarchical R\&V-R-nomenclature (own conceptualization) 32

Table 2 Vulnerability definitions referring to unsafe conditions and capacity as a driver of vulnerability 44

Table 3 Examples for differential risks and vulnerabilities 53

Table 4 R\&V causality pathways based on the provisions of the FARVAR 56

Table 5 R\&V-R process to identify spatial entities for intervention 89

Table 6 R\&V-R process to enhance the effectiveness of warning dissemination 92

Table 7 R\&V-R process to enhance the effectiveness of evacuation readiness 94

Table 8 R\&V-R process and assessment requirements to enhance evacuation capability 95

Table 9 Overview of empirical work - methods, data and division of works 104

Table 10: Defined Warning levels in Ina-TEWS 105 
Table 11: Overview on the criteria selection process

Table 12: Calculation of village level access to indoor mass notification devices in Cilacap

Table 13: Dependent variables in the household questionnaire

Table 14: Overview of the survey parameters

Table 15: Significant variables for all three pilot areas

Table 16: Model fit measures for Cilacap, Bali, and Padang

Table 17: Observed and classified sample cases for Cilacap

Table 18: Model fit measures for top model variables in Cilacap

Table 19: Factors of Evacuation Readiness

Table 20 Overview of the utility evaluation approach

Table 21: Utility of R\&V-A to establish effective warning dissemination chains

Table 22 Utility of R\&V-A for identifying an effective and manageable evacuation zone

Table 23 Utility of R\&V-A for developing people-centred warning infrastructures at the local level

Table 24 Utility of R\&V-A to enhance warning response and the effectiveness of evacuation readiness

Table 25 Utility of R\&V-A for the establishment of effective evacuation infrastructure

\section{LIST OF MAPS}

Map 1: Overview of research locations

Map 2: Detailed tsunami hazard map of Cilacap 1:25 000 (Source: LIPI et al. 2011b)

Map 3: Tsunami exposure map of Cilacap 1. 25000 (Source: LIPI et al. 2011b)

Map 4: Access to warning, of selected communities in the district of Cilacap, Java

Map 5: Selected city wards / villages in Kabupaten Cilacap

Map 6: Evacuation readiness map of selected villages in the district of Cilacap (Java) 140

Map 7: Risk of Evacuation Failure Map, Cilacap (Source: LIPI et al. 2011)

Map 8: Access to tsunami warning in exposed areas in Bali

Map 9: Access to tsunami warning in exposed areas in Padang

Map 10: Degree of evacuation readiness of the populaiton in exposed communities in the district of Badung III

Map 11: Degree of evacuation readiness of the populaiton in exposed communities in the district of Padang

IV 


\section{LIST OF ACRONYMS AND ABBREVIATIONS}

$\begin{array}{ll}\text { EWS } & \text { Early Warning System } \\ \text { ETA } & \text { Estimated Time of Tsunami Arrival } \\ \text { FARVAR } & \text { Framework for Applied Risk and Vulnerability Assessment Research } \\ \text { GITEWS } & \text { German-Indonesian Tsunami Early Warning System } \\ \text { InaTEWS } & \text { Indonesian Tsunami Early Warning System } \\ \text { R\&V } & \text { Risk and Vulnerability } \\ \text { R\&V-A } & \text { Risk and Vulnerability Assessment } \\ \text { R\&V-R } & \text { Risk and Vulnerability Reduction } \\ \text { TEWS } & \text { Tsunami Early Warning System }\end{array}$




\section{Introduction}

\section{I.1 Motivation}

Increases in risk and vulnerability $(\mathrm{R} \& \mathrm{~V})$ and the occurrence of disasters have been in evidence over the last five decades (Munich Re 2012). The IPCC has documented that many groups, sectors, ecosystems and places are highly vulnerable to today's weather and climate (IPCC 2007, 2012). This trend may continue in the future - as a result of the anticipated climate change occurrence on the one hand, and on the other, the increased vulnerability to such changes related to the demographic and socio-economic development pathways humankind is following - unless concerted actions are enacted to reduce vulnerability and to adapt to climate change, including interventions to address disaster risks (Lavell 1999, 2003; ICSU-LAC 2010; UNISDR 2011b). Hence, R\&V research serves an important purpose in political decision-making.

This circumstance was the driving factor fuelling my major motivation to invest substantial effort to advance applied R\&V science through this dissertation, particularly as a geographer. With the emergence of vulnerability science in the past ten years, research on risk and vulnerability assessment (R\&V-A) in the context of socio-natural and natural disasters has become an important research field within geography (Chambers 1989; Pelling 1997; Birkmann 2006a; W. Neil Adger 2006; Bohle 2008; Felgentreff, Glade 2008; Bohle, Glade 2008), a "research field squeezed between the disciplines of the natural and social sciences (...) that deploys a geographically explicit viewpoint on the human-environmental system" (Patt 2009). What are the drivers in the human and natural systems and the consequent spatial conditions causing the emergence of disasters? How do actors shape spatially differentiated risks and vulnerabilities and how do they compare across communities and regions? My intrinsic motivation for this dissertation has not simply something to do with being a geographer feeling enticed to work at the interface of natural and social sciences. Of greater compulsion, the following two major circumstances are even more challenging and motivating:

The first deals with my diagnosis of the situation of the contemporary R\&V-A research seen from the perspective of an applied scientist. Today, many concepts exist aiming to provide guidance on how to conceptualize and assess R\&V; all of them have their inner justification and particular perspective to look at R\&V problems (Cf. Bohle, Glade 2008; Kasperson, Kasperson 
2005; Turner et al. 2003; Wisner et al. 2004; Pelling 1997; Birkmann 2006a; Birkmann et al. 2013a; Welle et al. 2012). Although high quality research on R\&V and how to assess R\&V through contributions of very competent international researchers - such as Bohle, Birkmann, Adger, Wisner, and Pelling- can be found, I am heavily concerned with how such R\&V-A types can inform policy in such a way that knowledge based decisions can be made to reduce R\&V. Having spent considerable time myself with research in this domain, I became very much dissatisfied with the gap between the proliferation of $R \& V-A$ in $R \& V$ science, and the underdeveloped field of scientific R\&V-As informing policy on risk and vulnerability reduction(R\&V-R). This aspect will be elaborated more exhaustively in the "problem setting" chapter (Cf. I.2). I am convinced that science plays an important role in suggesting and justifying policy decisions, and that policy makers need to show that their decisions are supported by sound scientific analysis. Hence, having worked for the United Nations University - Institute for Environment and Human Security (UNU-EHS), I felt very much the appeal to contribute to advance the utility of scientific R\&V-A for decision-making through scientific research. Furthermore, I also gained conviction that the theoretical foundations of R\&V at home in the discipline of geography could contribute to this and thereby advance the role geography science could play for R\&V-R.

The second source of motivation was the circumstance that I had the opportunity to join a very competent team of researchers, notably colleagues from the German Aerospace Center (DLR), to advance policy focused R\&V-A. I was assigned the task - within the frame of the GermanIndonesian Tsunami Early Warning System Project (GITEWS) - to conceptualize and conduct empirical research on R\&V-A to support and enhance the effectiveness of the Indonesian Tsunami Early Warning System (InaTEWS). This select team was dealing precisely with the question of how risk and in particular vulnerability assessment can support decision-making and the establishment and sustainability of a tsunami early warning system as a chosen R\&V-Rstrategy to reduce tsunami R\&V in Indonesia.

Towards the end of the research project I was not satisfied with leaving the results of this much applied and yet innovative research project only in the hands of practitioners who benefitted from our research, but to use the case study as an example and upscale the results to develop a generic perspective on how $R \& V-A$ can serve $R \& V-R$ decision-making. Hence, I felt motivated to streamline and upscale the results into a generic scientific discussion on conceptualizing R\&V in 
conjunction with assessments to advance applied R\&V science. In short, I felt driven to find out how to operationalize the very abstract concept of vulnerability so that it can become a practical tool for decision-making in different processes of R\&V-R.

\section{I.2 Problem Setting}

Many international policies repeatedly state that a basic instrument to engage in Risk and Vulnerability Reduction (R\&V-R) is Risk and Vulnerability Assessment (R\&V-A), (HFA priority area 2, UNISDR 2008, 2005). In fact, much effort has been put into conceptualizing vulnerability, providing explanatory power how vulnerability emerges in a wider societal context, helping to redirect practitioners' attention from hazards towards vulnerability as the key driver of risk in many circumstances (Watts, Bohle 1993; Bohle, Glade 2008; Turner et al. 2003; Wisner et al. 2004). But reports such as the Mid-Term-Review of the Hyogo Framework for Action have revealed that to-date in many countries of the world, little progress has been made about how to utilize the huge potential of R\&V-As, especially how to factor in social and economic vulnerabilities and conduct the respective assessments that could inform R\&V-R policies (UNISDR 2011b). Hence, in many situations, measures and options of R\&V-R are often decided upon and implemented based on $R \& V$ perceptions, interests and priorities of individuals, groups and authorities without scientific evidence of the precise knowledge of the R\&Vs, ultimately leading to unsustainable R\&V-R solutions (Wisner, Walter 2005).

Only recently, the discussion about the utility of R\&V-Assessments - in particular vulnerability assessment - for R\&V-R has sparked off and has been given larger attention (Patt et al. 2009b; Fritzsche et al. 2015). A prominent representative is the research group around Patt, Hinkel and Klein (PROVIA 2013a; Patt et al. 2009b), which has raised a critical voice and expressed some important concerns; most importantly amongst them "that hereto vulnerability assessments are discussed without reference to the specific problems that they are meant to solve" (Hinkel 2011). Of course vulnerability theory has produced vulnerability assessments that pinpoint at societal conditions revealing a risk of loss or damage in case of emergence of extreme events, but they lack adjustment to a specific risk problem that might trigger the identification of specific R\&V-R solutions. 
Based on literature research and own observations during my empirical research within the GITEWS project, some arguments are provided in the following that clearly show why contemporary risk - and in particular vulnerability assessments - do not meet the requirements to provide end-user friendly decision support for processes of R\&V-R and are hardly utilized in those processes:

- There is a tremendous difficulty for decision makers to understand the existing rather confusing and incoherent vulnerability terminology, especially when they have to understand and distinguish terms like sensibility, sensitivity, susceptibility, response capacity, coping capacity, adaptive capacity, resilience etc. How can R\&V-A conducted and based on such fuzzy scientific categories be useful to inform policy-makers (Schellnhuber 2009)? How shall R\&V-R practitioners develop a common understanding if even the science community is suffering from the "Babylonian Confusion of Terms" (Janssen, Ostrom 2006)? Interestingly, the IPCC-SREX report (IPCC 2012) is a prominent example of how the divergent development and coexistence of the two disciplines $R \& V$ research on the one side, $R \& V-R$ on the other- has led to redundancies and overlaps in the conceptualization of capacity related terms (Cf. II.4.1), yielding a scientific landscape full of contradictions, ultimately rendering $R \& V$ assessments less applied than they could be. For example, types of capacity are subject to discourse in both chapters 2 and 5 of the IPCC report. Whereas, in chapter 2 of the report coping and adaptive capacity are defined as "positive features of people's characteristics that may reduce the risk" and are discussed in the context of defining determinants of R\&V, they are discussed as well in chapter 5 of the same report with regard to different options and differing outcomes of R\&V-R (IPCC 2012, p. 72). Thus, both chapters make reference to capacity and R\&V-R simultaneously without explicitly referring to each other, or comparing terms or making a clear distinction. This example from the IPCC report is a prominent representation of the flawed integration of the work conducted by $R \& V$ scholars and R\&V-R practitioners. When applied $R \& V$ research is to provide decision support for $R \& V-R$, resolving differences between the $R \& V$ - related terminology in $R \& V$ science and the $R \& V$ terminology used in $R \& V-R$ is required. Until now, the smallest common denominator that can be discovered is the acknowledgement by the R\&V-R 
community that vulnerability is a distinct driver of risk, implying the need to include $R \& V-A$ into processes of $R \& V-R$.

- Most R\&V-As are conducted within the frame of scientific research, with the goal to develop a general theory that can be "applied in contexts other than where the research took place" (Patt et al. 2009a). Here, R\&V-A is focusing on operationalizing scientific vulnerability concepts and their diversely defined subsequent components (e.g.; exposure, susceptibility, coping capacity, adaptive capacity), aiming at validating and exploring their added value for scientific purposes. This has resulted in a proliferation of aggregated index based assessment types, structured according to such scientific categories (Cutter et al. 2003; Birkmann 2006a; Welle et al. 2012; Cardona 2006b). They barely address specific policy or research problems beyond calling themselves "vulnerability assessment" (Hinkel 2008; Wolf et al. 2013). Dedicating themselves to focus thoroughly on their usefulness for R\&V-R has not been their purpose, yielding less precise utility descriptions such as "appropriate scope", "guiding decision-making", "making right choices" or "triggering political action in order to avoid damage", "identifying vulnerable people, regions, sectors" (Birkmann 2006b; Angela Queste, Peter Lauwe 2006; Patt 2009; Hinkel 2011; Schröter et al. 2005). Still, some more precise utility-related statements does exist, such as acknowledging that there is an R\&V problem, increasing awareness about vulnerability as a larger driver of risk, or providing agencies a justification for the prioritization of spatial areas of intervention and funding. But they remain of little use for the support of a complex process such as R\&V-R.

- As a consequence from the latter, less V\&R-As have been conducted within the frame of applied scientific assessment, where scientific knowledge is processed in order to help decision makers to design strategies of R\&V-R (Farrell et al. 2001). By responding to the needs of end-users (Patt et al. 2009a), applied scientific assessments shall include a social process linking science with policy making (Mitchell et al. 2006). Nevertheless, the described utility is more explicit but remains piecemeal such as the identification of mitigation targets, the allocation of adaptation funds, monitoring the performance of adaptation policy, and determining adaptation options (Hinkel 2011; Füssel, Klein 2006; Barry Smit, Johanna Wandel 2006; Cash 2006; Kates 1985; Carter et al. 1994; Benioff et 
al. 1996; Metzger, Schröter 2006; Fritzsche et al. 2015). Each of the described utilities reflects singular aspects of how they can be used for R\&V-R decisions, but they lack coherence and systematization, such as describing utilities based on well-defined processes of adaptation to climate change or R\&V-A, specifically the elaboration, assessment, selection and implementation of R\&V-R options (Renn 2008; OECD 2009; PROVIA 2013a). No case study could be found so far that has shown how this works.

As consequence of the above outlined points, on the one hand R\&V-R practitioners have barely recognized the innovative potential of the evolution of vulnerability science for processes of $R \& V-R$, and on the other, scientists have yet to put greater effort into developing and empirically testing frameworks, methods and procedures that advance applied R\&V-A, a major objective of this dissertation.

\section{I.3 Research Objectives, Goals and Questions}

After a decade of proliferation of R\&V-As for purposes of advancing R\&V theory and concepts, working harder on a better R\&V theory and its translation into an R\&V-A scheme might not be the appropriate solution. The dissertation is based on the notion that R\&V-A research only proves to be significant if it contributes to increase the capacity of society to constructively deal with risks (Vogel, O'Brien 2004). Bearing this in mind, the dissertation deduces the following research objective:

This dissertation aims to better integrate $R \& V$ research, $R \& V$ assessment and $R \& V$ reduction to advance the conceptualization of applied scientific R\&V-As for promoting research on maximizing the applicability and usefulness for R\&V-As - and in particular vulnerability assessment - for R\&V-R decision-making. Such research shall promote a shift of thinking from operationalizing purely scientific and theoretical $R \& V$ concepts to the development of $R \& V$ information packages tailored to specific $R \& V-R$ requirements in different steps of $R \& V-R$ decision-making and implementation.

To accomplish this main objective of the dissertation two subsequent research goals are presented in the following, each containing two research questions. 
Goal 1: Development of a common conceptual framework for applied R\&V-A research to be shared by R\&V scholars and R\&V practitioners

Ever since 2004 and lately in 2011 it has been stated by well-known R\&V scholars that a comprehensive conceptual framework promoting multidisciplinary R\&V evaluation that focusses on what is needed for decision-making is missing, impeding the effectiveness of R\&V-R (Patt 2011, p. 3; Cardona 2004). Hence, one important goal of the dissertation is the development of a conceptual framework that acts as an interface between R\&V-science and R\&V-R-practice, facilitates a common understanding about how to frame and classify R\&V problems, and provides guidance on how to diversify application areas of R\&V-A for R\&V-R decision-making. The following research questions (RQ) need to be dealt with to obtain valuable results:

RQ 1.1 What could a R\&V framework look like applicable for both R\&V-A scholars as well as $R \& V-R$ practitioners, acting as a reference frame for action, and facilitating a mutual understanding and exchange?

RQ 1.2 How to conceptualize the role of applied R\&V-A for R\&V-R decision-making that promotes and guides the integration of R\&V-As into the different process steps of $R \& V-R$ ?

Goal 2: Testing the new framework for applied R\&V-A to diversify the fields of application of R\&V-A for R\&V-R decision-making and implementation

Most of the state-of-the-art objectives of R\&V-As seem to rather identify appropriate approaches to translate theoretic and conceptual foundations of R\&V into R\&V-A schemes to advance R\&V theory (Cf. I.2). Conversely, the objective of this thesis is to advance scientific $R \& V-A$ to serve as an important instrument for R\&V-R related policy and decision-making. $A$ case study has been chosen - the establishment of an Tsunami Early Warning System in Indonesia - to provide empirical evidence for the strengths of the framework developed and to showcase how applied R\&V-A can be of utility for processes of R\&V-R such as the elaboration, assessment, selection, implementation, and monitoring of $R \& V-R$ options. The following research questions $(\mathrm{RQ})$ need to be dealt with to obtain valuable results: 
RQ 2.1 What could a contextualized framework of applied R\&V-As look like that facilitates the establishment of a tsunami early warning system in Indonesia?

RQ 2.2 What are the areas of application of R\&V-A for different processes for establishing a tsunami early warning system in Indonesia and in general?

\section{I.4 Methodological Overview}

This chapter provides an overview of how the dissertation has evolved, and about the general methodological procedure followed in this dissertation; particularly, how the overarching research objective is being accomplished. The order of the single research steps (Cf. Figure 1) broadly follows the idea of the grounded theory, referred to as "a research style for the elaboration of empirically based conceptualizations" (Strübing 2008). According to Strübing, a key objective of the grounded theory is facilitating the development of a reality-focussedtheory of utility for practical application in order to close the gap between theory and practice, a notion fitting very much the overall research objective laid down in the previous chapter. Accordingly, the dissertation has emerged from an applied research project, in which the assumed innovative theoretical framing of $R \& V-A$ is a result of the empirical work (case study) that aimed at developing "R\&V-A information and components suitable for running a tsunami early warning system such as the InaTEWS supported by the German government. 


\begin{tabular}{|c|c|c|c|c|}
\hline $2006 / 2007$ & 1 & \multicolumn{3}{|c|}{$\begin{array}{l}\text { Elaboration of the case study specific research questions and topics based } \\
\text { on the requirements of GITEWS }\end{array}$} \\
\hline \multirow[t]{3}{*}{$2007 / 2008$} & 2 & \multicolumn{3}{|c|}{$\begin{array}{l}\text { Topic specific data collection in three tsunami exposed case study sites } \\
\text { in Indonesia (Cilacap, Bali, Padang) }\end{array}$} \\
\hline & & $\begin{array}{l}\text { Existing socio - } \\
\text { economic statistics }\end{array}$ & $\begin{array}{l}\text { Land use data / } \\
\text { satellite imagery }\end{array}$ & $\begin{array}{l}\text { Existing spatial } \\
\text { data }\end{array}$ \\
\hline & & \multicolumn{3}{|c|}{ Quantitative household survey (sample size $=2000 \mathrm{hh}$ ) } \\
\hline $2008 / 2009$ & 3. & \multicolumn{3}{|c|}{$\begin{array}{l}\text { Iterative risk and vulnerability information package development and } \\
\text { refinement including data analysis and processing }\end{array}$} \\
\hline 2009 - 2011 & 4 & \multicolumn{3}{|c|}{$\begin{array}{l}\text { Theoretization and upscaling process: Development of the new Framework } \\
\text { for Applied Risk and Vulnerability Assessment and Research (FARVAR) }\end{array}$} \\
\hline $2011 / 2012$ & 5 & \multicolumn{3}{|c|}{$\begin{array}{l}\text { Utility evaluation: Evaluation of empirical results in terms of their utility } \\
\text { for } \mathbf{R} \& \mathbf{V}-\mathbf{R} \text { decision making }\end{array}$} \\
\hline
\end{tabular}

Figure 1 Methodological overview of the dissertation

Accordingly, the generic macro-methodology of this dissertation encompasses the following distinct steps:

1. According to the initial mandate of the GITEWS project, the research has commenced with defining research questions related to how to assess $R \& V$ in support of constructing and running a tsunami early warning system. Further literature research and numerous discussions held have revealed the initial R\&V-A concept linked to the tsunami early warning system (Cf. V.2.3).

2. Based on the identified R\&V-A topics an iterative process of developing $R \& V-A$ information packages has been accomplished (Cf. VII.2.1) dealing in particular with the question how the R\&V information compiled from various sources - such as tsunami hazard-, household-, land use- and remote sensing data - shall be processed and visualized to support R\&V-R practitioners involved in the different areas in setting up 
the Indonesian tsunami early warning system ${ }^{1}$. In a series of workshops on behalf of the official InaTEWS-Working Group and together with stakeholders (national and local representatives of universities, authorities and NGOs) the development of R\&V-A information packages had been discussed and refined. A very detailed description of the methods used to arrive at the predefined R\&V-A information packages is provided in the respective chapters of the case study where the empirical work is laid down (Cf. VII.2.2).

3. The third step dealt with using the experiences made with the case study to enter a new path how to conceptualize $R \& V$ and respective $R \& V-A$ to increase their utility for $R \& V-R$ decision-making. The scientific "upscaling" of the case study has led to the evolution of the new FARVAR framework (Cf. IV), consisting of a restructured R\&V-terminology (Cf. IV.2), the definition of a R\&V causality frame (Cf. IV.4) as well as defining an iterative process of R\&V-A and R\&V-R and how R\&V-A can contribute to R\&V-R decision-making (Cf. IV.5.3).

4. The fourth step dealt with providing more specificity about the utility of R\&V-A for R\&V$R$ (Cf. VIII). Each of the developed R\&V-A information packages within the case study had been discussed with regard to the respective contributions to the elaboration, assessment, selection, implementation, and monitoring of R\&V-R measures, a process of R\&V-R defined in chapter III.4 on the basis of provision as presented by Renn (Renn 2008) and the OECD (OECD 2009).

\footnotetext{
${ }^{1}$ At this point it shall be noted that not all empirical material has been collected by me. The distribution of topics of scientific research amongst the partners of the GITEWS-project guided the division of work. A clear demarcation of who contributed to what is provided in the chapter on the presentation of the case study results (Chapter VII).
} 


\section{I.5 Structure of the Dissertation}

The structure of the dissertation follows the formal logic of presenting the theoretical conception of the research first (chapters II - IV), then providing the empirical evidence (chapters V - VII) and finally, concluding the results within a broader scientific context (chapter VII).

Chapters II - IV: Theoretical part. The theoretical part is meant to culminate in a new Framework for Applied Risk and Vulnerability Assessment Research (FARVAR) to be put to the test.

- Chapter II explores the key determinants of R\&V and how the causal structure of R\&V is framed by different R\&V scholars. First, the lowest common denominator of defining $R \& V$ is presented, by emphasizing the role of vulnerability (Chapter II.2). Thereafter, contemplation follows about how to understand the causal structure of R\&V through the lens of different vulnerability frameworks within the discipline of human geography (Cf. II.4). Finally, the term capacity is defined, including a discussion about how different types of capacity are being distinguished and have been evolving in the scientific literature (Cf. II.4).

- Chapter III provides a comprehensive perspective of R\&V-R. It aims at looking at DRR from a societal perspective to emphasize that actors in R\&V-R are not, as traditionalists in $R \& V-R$ suggest, technicians, engineers or state authorities; but that all the members of society, from the household level to the private sector, non-governmental organizations and state authorities are active agents in R\&V-R (Cf. III.2). Moreover, the chapter includes the definition of a "Hierarchical Nomenclature of Risk and Vulnerability Reduction", to structure integral components and sub-components of R\&V-R in a way nobody has done before (CF. III.3). The last sub-chapter proposes a process of R\&V-R that includes decision-making processes along the "Nomenclature of R\&V-R" (Cf. III.4).

- Chapter IV presents the newly developed Framework for Applied Risk and Vulnerability Assessment Research (FARVAR) and draws from the latter two major chapters II and III. It constitutes a turning point in this dissertation. It starts with identifying differences and commonalities, finally resolving redundancies and conflicting terminologies of the two strains and groups of actors, $R \& V$ scientists and R\&V-R 
practitioners (Cf. IV.2). This is done by mirroring and comparing the different types and definitions of capacity that are common in the R\&V research community (coping, adaptive, response capacity) (Cf. II.4.1) with those that are implicitly or explicitly elaborated and used in discourses about R\&V-R (Cf. III.3). The analytical comparison allows for viewing vulnerability as the outcome of causal processes inherent in the absence of R\&V-R performance. In chapter IV.4 the new FARVAR framework is presented, including the provision of a definition, exploring a systematization of different pathways of how $R \& V$ and unsafe conditions emerge, and finally how R\&V causalities can be structured. Based on the FARVAR framework, Chapter IV.4.4 defines the role of $R \& V-A$ in processes of $R \& V-R$ by describing an iterative process of $R \& V-A$ and $R \& V-R$ while elaborating, assessing, selecting, and implementing $R \& V-R$ measures.

Chapters V and VI, VII and VIII - Empirical part - The case study. The purpose of the case study is to provide empirical evidence for the usefulness of the logic of the new FARVAR framework and its implications for R\&V-A. The case study demonstrates how R\&V-A information packages are being developed for the benefit of establishing a Tsunami Early Warning System in Indonesia. The empirical part is divided into four major chapters.

- Chapter V provides and overall introduction to the case study by dedicating a chapter to its rationale (Chapter V.1.1) and describing the context into which the case is embedded (Cf. V.2), including reasoning why a Tsunami Early Warning System has been chosen as the best strategy for R\&V-R in Indonesia, and what role the working package on R\&V-A had played in the overall context of the GITEWS project (Cf. V.2.1, V.2.2, V.2.3). Finally, a short overview is given about the research area (Cf. V.3) as well as a logical description of how the case study presentation in this thesis is organized (Cf. V.4), including a short summarized methodology of the case.

- Chapter VI presents the R\&V-A framework for the case of InaTEWS. A full chapter is dedicated to explore more in-depth the conceptual foundations of a Tsunami Early Warning System, its integral components and the delineated R\&V-A -framework that represents a contextualised FARVAR framework for the case of InaTEWS (Chapter V.2)

- Chapter VII presents the case study concept, analysis and results. As according to the concept of the FARVAR framework where R\&V-A is defined through the requirements of the specific R\&V-R-domains, -components, -tasks and -measures, the R\&V-A -topics 
and methods vary accordingly. Hence, an own R\&V-A chapter has been dedicated to each of the different R\&V-R-tasks of InaTEWS, composed of defining precisely the R\&V$R$ and assessment requirements, the assessment topics and detailed methodology, as well the presentation and discussion of the results. This complex structure is attributed to the requirements of the newly developed FARVAR framework to develop R\&V-A information packages useful for R\&V-R decision-making at different hierarchical levels, such as at the level of effectively implementing R\&V-R- tasks and -measures.

- Chapter VIII presents the utility evaluation of the R\&V-A results. This chapter discusses the utility of the R\&V-A results using a method specifically developed for this purpose and based on the provisions of different authors that have defined a process of $R \& V-R$ decision-making. The analysis contains a last very important step to showcase how R\&V-A can support the elaboration, assessment, selection, and implementation of overall $R \& V-R$. It shades light on the utility of the FARVAR framework, not only to advance applied R\&V-As but also to advance and structure the future research agenda in this investigative field and the contributing role of geography to this.

Chapter IX: Discussion and Summary. The discussion aims at distilling what the dissertation has achieved to advance the overall applied R\&V-A - and Research.

Chapter X: Conclusions. First, the implications of the research for better integrating R\&V-A Research, --Assessment and -Policy are concluded. Thereafter, the contribution of the dissertation to advance geographic $R \& V$ research is explored, as well as the strengths and weaknesses of the dissertation are addressed, to finally address future research challenges and requirements. 


\section{Risk, Vulnerability and Capacity}

\section{II.1 Introduction}

$R \& V$ research attempts to provide causal evidence of those societal-ecological conditions that influence loss and damage in the course of a hazard event ('potential', 'hypothetical', 'estimated' or 'assumed' R\&V). This section deals with introducing the basic concept of R\&V, therein elaborating the notion that lack of capacity is a driver of R\&V, and in particular of vulnerability. In this context the main schools of thought, particularly those home to geographical development and $R \& V$ research, are discussed with respect to their contribution to understanding processes of capacity formation and obstruction revealing R\&V conditions.

This section is structured as follows: In the beginning, the terms hazard, exposure and vulnerability are elaborated and defined (Cf. II.2). In the following chapter emphasis is put on vulnerability and how different vulnerability frameworks by different R\&V scholars in geography contribute to the understanding of the emergence of R\&V (Cf. II.3). Thereafter, the focus is on defining the term capacity and elaborating different types of capacity in the context of R\&V (Cf. II.4).

\section{II.2 Components of Risk}

Disasters signify unmanaged risks (Westgate, O'Keefe 1976). Thus, a hazard event is not the only driver of disasters. Disasters are to a large part socially constructed, rooted in the exposure and vulnerable conditions of societies to natural phenomena, such as extreme hazardous events (UNISDR 2004; Cardona 2011; Birkmann 2006c). Thus, R\&V research in the context of socio-natural disasters deals on the one side with the spatial and temporal analysis of the physical phenomena of extreme events, and on the other with employing theories, concepts and methods for understanding those conditions in the human and environmental system that determine whether a hazard turns into a disaster. This notion is reflected by the term "vulnerability". It focuses on structures and processes of a socio-ecological system which can increase the magnitude of disaster impact or prevent disasters (Bohle, Glade 2008). Hence, society is viewed as agency of shaping R\&V by contributing to the transformation of physical 
events into hazards that increase the likelihood of adverse effects (Chambers 1989; Wisner et al. 2004). Hence, Weichselgartner (2001) acknowledges that social sciences and natural sciences approaches in disaster research should not only coexist, but be integrated to better understand their mutual causal relationship (Weichselgartner 2001). Thereby, research also shall consider that parameters of hazard characteristics as well as those of vulnerability change dynamically over time, hence, that also $R \& V$ is not fixed but is a continuum in constant evolution (ICSU-LAC 2010). In the following a more detailed description of the constituent elements of risk, namely hazard, exposure, and vulnerability is provided.

\section{II.2.1 Hazard}

A hazard refers to "a dangerous phenomenon, substance, human activity or condition that may cause loss of life, injury or other health impacts, property damage, loss of livelihoods and services, social and economic disruption, or environmental damage" (UNISDR 2009a). Until recently, the term risk was used to pinpoint at the requirement to describe certain hazard characteristics. Today, acknowledging the contributing role of vulnerability to overall disaster risk conditions, hazard is considered only as a component of risk (Cardona et al. 2012, p. 69). Hazard research is dealing with understanding the different physical conditions and processes of hazard generation and their magnitude and frequency / probability of occurrence as well as their spatial and temporal distribution. Specific concerns of hazard research are to determine thresholds, at which a "natural system" alters and significantly increases disaster risk (Bohle 2008). Against the background of humankind's increasing role in degrading ecosystems and exploiting natural resources, hazards are not anymore purely of natural origin, they are socionatural hazards. For example, deforestation can become an important trigger for landslides, floods and droughts (Lavell 1999). The following graph illustrates the "spectrum of hazards" that can be triggered, either by purely natural factors or a mix of human-natural factors and processes (Cf. Figure 2) 


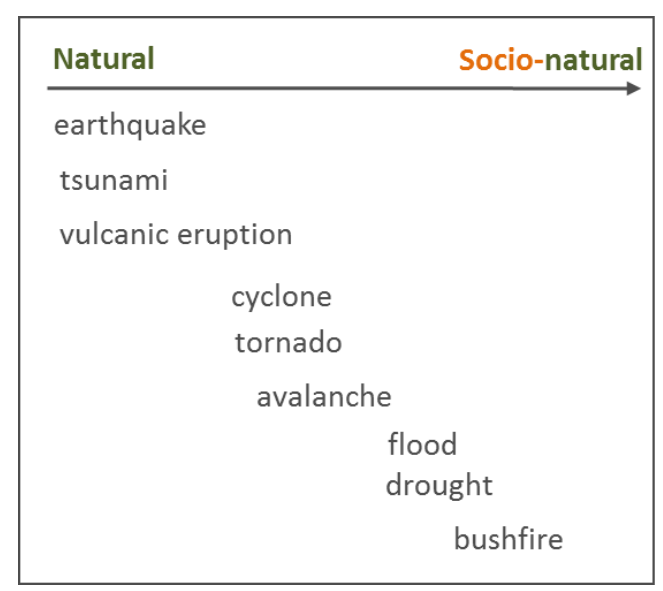

Figure 2 Hazards of natural and socio-natural origin

\section{II.2.2 Exposure}

Exposure can be referred to as a "first order R\&V condition" - defined by UNDP as the "Elements at risk, an inventory of those people or artefacts that are exposed to a hazard" (UNDP 2004) - in which societal structures, people and the environment can potentially be adversely affected by a hazard event simply because they are physically located in a hazardous area. Thus, exposure is a function of both, the hazard potential and the existence of an element of concern in the catchment of the hazard. Without a hazard threat, or a hazard threat without elements of concern in the catchment of a hazard, there is no exposure. Thus, exposure is a precondition for deeming an area as a high risk area, but not a sufficient risk factor. Disaster impacts vary for different elements exposed to a given hazard. Some of those exposed suffer harm, some rather not. The conditions that configure the likelihood of suffering harm are to be found in vulnerable conditions. To conclude, it is possible to be exposed but not vulnerable, but in order to be vulnerable, exposure is a necessary precondition (Cardona et al. 2012). 


\section{II.2.3 Vulnerability}

In its very basic form vulnerability can be described as the likelihood to be wounded (Turner et al. 2003), or more elaborated, the propensity of exposed elements such as physical or capital assets, as well as human beings and their livelihoods, to experience harm and suffer loss and damage by a single or a compound of hazard events (UNDRO 1980; Cutter, Finch 2008; Cutter et al. 2003; Birkmann 2006c; Chambers 1989; Liverman 1990; Timmerman 1981; Birkmann 2006a) Often the terms exposure and vulnerability are used interchangeably (Cardona et al. 2012). This is a serious pitfall (fallacy), because simply looking at exposure may overlook the underlying causes of adverse disaster impacts, the so-called „vulnerabilities“. In its infancy, the research on vulnerability had been limited to understand the lack of physical resistance of engineering structures (UNDHA 1992). But as vulnerability is highly contextual (O'Brien et al. 2007), today`s vulnerability has become multi- and transdisciplinary (IPCC 2012), and is at home in the social sciences, ecology, economy, public health, poverty and development, livelihoods and famine, and climate change adaptation. It focuses on the characteristics of historical and prevailing cultural, physical, social, environmental, political, and economic contexts and processes that lead to societies' vulnerability to environmental threats (Watts, Bohle 1993; Bankoff et al. 2004; UNISDR 2009b; Luers et al. 2003; IPCC 2007, (Schröter et al. 2005)). Because of the multidisciplinary perspective, vulnerability is defined ${ }^{2}$ and conceptualized in many different ways, each claiming to use the most appropriate terms, such as susceptibility, fragility, sensitivity, weaknesses, deficiencies, or lack of capacities (Cardona et al. 2012; Villagrán De León 2006; Füssel 2007; Wisner et al. 2004; Cutter et al. 2003). But all share the view that vulnerability is socially constructed and the outcome of a complex set of drivers and interacting conditions that increase the likelihood of adverse impacts of natural and socionatural hazards on the human or environmental system (UNDRO 1980; Cannon 2006; Wisner et al. 2004; Weichselgartner 2001; Bogardi, Birkmann 2004; UNISDR 2004, 2009b; Birkmann 2006a; Janssen, Ostrom 2007; Thywissen 2006).

\footnotetext{
${ }^{2}$ General definitions and reviews on the issue of vulnerability are provided by Thywissen 2006; Kasperson, Kasperson 2005.
} 


\section{II.3 Approaches Towards Understanding the Causal Structure of Vulnerability}

A diverse set of schools of thought exist that address disaster R\&V causalities. Each of them uses their own theoretical base and emphasizes different factors or the combination of different factors and dimensions. The most relevant ones for this thesis are rooted in sociology, human and development geography, as well as socio-ecological research and include the "Sustainable Livelihoods Framework" (Ashley, Carney 1999), the "Double Structure of Vulnerability" (Bohle 2001), "Structuration"(Tröger 2003; Giddens 1986), "Political Ecology (Blaikie 1995), the "Pressure and Release Model" (Wisner et al. 2004), and Turner's "Vulnerability Analysis Framework" (Turner et al. 2003).

A more or less all uniting feature of these schools of thought is that they work at the interface between constructivism und structuralism, where their frame of analysis is based on the agency in which the actors' scope of actions are embedded in structural framework conditions shaped by cross-scale interactions (Rauch 2003). Thereby, people are not perceived as "helpless victims" (Bohle 2001; Gaillard 2010) but also as active managers of vulnerability (Ribot 1995; Pelling 1997; Pelling 2003). This notion is well reflected in Rauch's essay arguing that "better framework conditions are not sufficient enough to mitigate poverty", but that there is a need to focus on agency (Cf. Figure 3). 


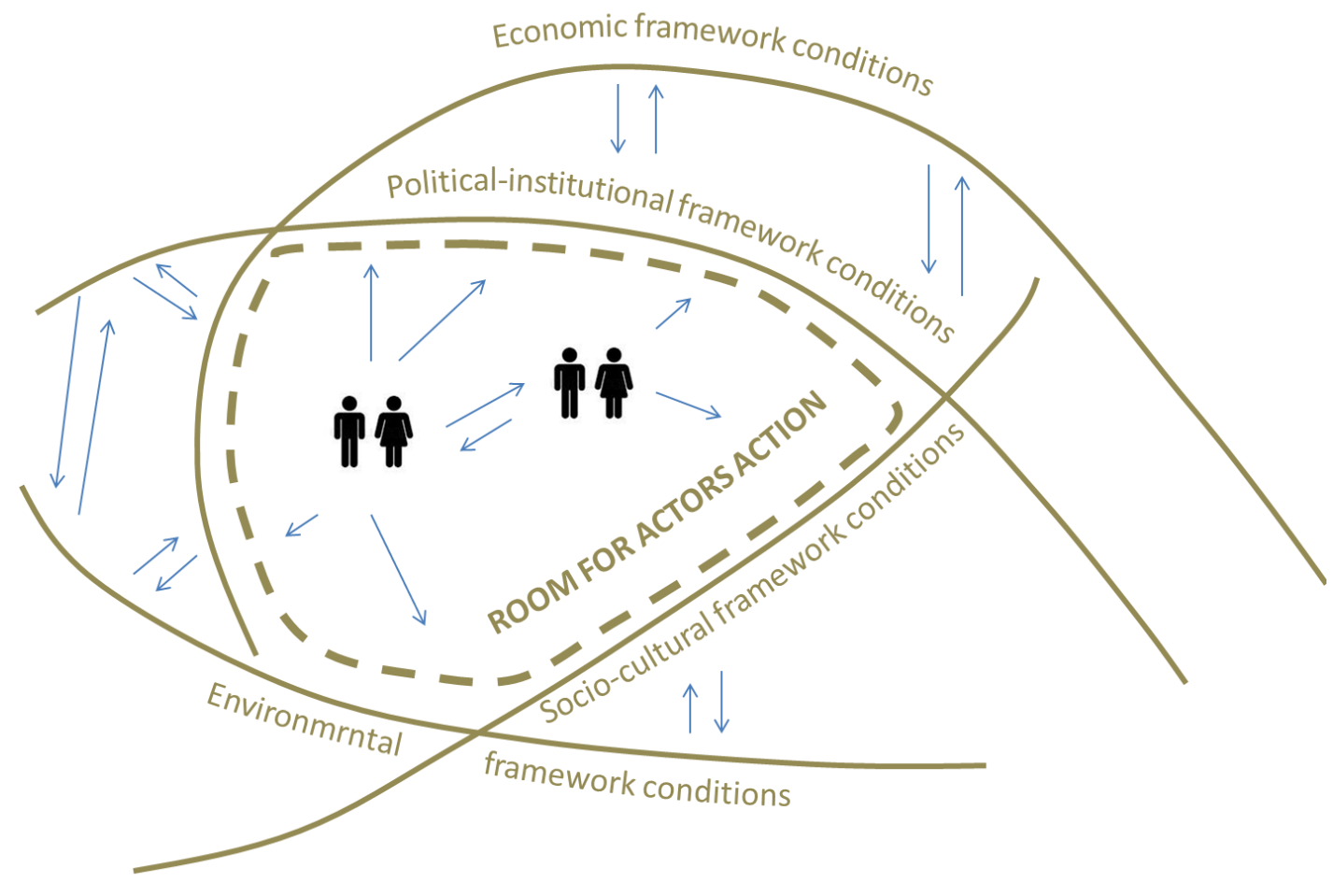

Figure 3: Analytical framework for poverty-related interventions (Source: Rauch 2003)

Thus, vulnerability can be understood as the outcome of multi-dimensional and multi-scalar processes arising from mutual and interdependent reactions between different social units which are households, formal organizations, communities and nations, and the roles, routines and decisions enacted within them that constitute social structure" ((Burns, Dietz 1992)) - and the physical environment.

In the following, three examples are provided relating to how to frame the causal structure of vulnerability. Thereby, the respective theories will not be explained exhaustively, but their short description shall rather show the many different perspectives on how to approach the causal structure of vulnerability.

\section{II.3.1 Agency and Structure}

Structure and agency constitute an enduring core debate in sociology. Essentially the same as in the Marxist conception, "agency" refers to the capacity of individuals to act independently and to make their own free choices, whereas "structure" refers to those factors (such as social class, but also religion, gender, ethnicity, subculture, etc.) that seem to limit or influence the opportunities that individuals have. Action theories rather focus on agency and put the 
emphasis on the individual making of free choices (Giddens 1986). Thereby, agency refers to "the capacity of individuals to play an independent causal role in history" (Paul McLaughlin, Thomas Dietz 2008, p. 105). Werlen was the first geographer to utilize agency focused theories of social science to explain spatial phenomena and the production of space in human geography by shifting the focus from structures to agency (Werlen 1993). Actors interpret their experiences in relation to "frames" which provide "schemata for interpretation" that enable individuals to "perceive, identify and label occurrences within their life space and the world at large" (Snow et al. 1986). This constructivist perspective has been taken up by (Tröger 2003), who translated Giddens' theory of structuration (Giddens 1986) into the context of human geography. The process of structuration puts agency and social structure into a causal relationship by which on the one side actors' actions and decisions are shaped by prevailing socio-spatial structures, whilst they themselves build the platform for actors to reshape sociospatial structures. The so-called "duality of structure" and the conceptualized process of "structuration" emphasize that, particularly in times of transformation, actors are faced with multi-structural conditions that provide a window of opportunity for actors to change their routine practices (Tröger 2003), thus "creating opportunities for doing new things, for innovation and development" (W. Neil Adger 2006, p. 253). Whether such opportunities are taken advantage of depends on the reflective and discursive cognitive capacities of individuals (Tröger 2003).

Translating this constructivist perspective into the context of $R \& V$, the emergence or reduction of vulnerability is a matter of individuals' capacity to make a distinct difference between routine knowledge and the anticipation of what changes are necessary and what options exist to attain a net benefit of what they value as important. Thus, the role of agency is "producing differential vulnerabilities amongst individuals and groups even when they confront seemingly identical risks" (Paul McLaughlin, Thomas Dietz 2008). 


\section{II.3.2 Sustainable Livelihoods Framework}

The Sustainable Livelihoods Framework (Ashley, Carney 1999) can be viewed as translating the very theory focussed action theories into tangible processes of how actors / individuals and households are agents of vulnerability formation. The focus is on a number of livelihood assets (social, financial, physical, environmental, and human capital) that need to be accessed and utilized in pursuit of participating in overall development and R\&V-R. The opportunity or the lack of opportunity to access and utilize resources to reduce R\&V depends on political, social, cultural, economic, and environmental processes (Carreño et al. 2007; Gaillard 2010). These are the so-called "transforming structures and processes" (laws, policies, culture, institutions) that influence individual access to the required assets. For example, the liberalization of international trade has led in many countries to a destruction of the local economy leading to high unemployment rates in the affected sectors such as agriculture. Consequently, the lack of access to financial resources leaves rural households defenceless against hazardous events, when in absence of employment opportunities rural-urban migration pushes impoverished individuals to live in informal settlements exposed to e.g., flooding, landslides, storm surge, and coastal erosion. Many other causality chains can be drafted and examples exist that show how vulnerability is generated leading to unsafe conditions most likely conducive to the emergence of risk. The Sustainable Livelihood Framework provides rather an an alytical frame than a theory for explaining vulnerability causality, which is different from the framework presented in the following sub-chapter.

\section{II.3.3 Double Structure of Vulnerability}

The framework on the Double Structure of Vulnerability (Bohle 2001) is an attempt to link up different schools of thought and theories from different research disciplines (political science, sociology, economy, famine and conflict research) to provide comprehensive and powerful explanatory methods to understand the situation of people living in exposed and unsafe conditions and their dealings with such conditions. It is built upon Chambers', Watts' and Bohle's work documented in their essay on "The space of vulnerability: the causal structure of hunger and famine" (Chambers 1989; Watts, Bohle 1993). The framework emphasizes that people living in precarious conditions are exposed to a diverse and complementary set of R\&Vs 
in everyday life and are urged to cope with them (e.g. rise in food price, insecurity of informal employment, floods). In this framework, vulnerability causality is deemed not explainable by a single theory or concept, but rather by a bundle of interrelated, mutually dependent theoretical approaches. These approaches are selected, simplified and summarized as follows:

- The lack of access resources due to the lack of entitlements resulting in people living in exposed and/or and precarious living conditions leaving them fragile to external shocks (Entitlement Theory, represented by Sen 1983).

- The lack of societal actors - who interfere at different scales - to maintain environmental health and protect natural resources resulting in socio-natural hazards to which the human system is exposed (Human Ecology perspectives, e.g. represented by Blaikie, 1985, Blaikie and Brookfield, 1987).

- The lack of social and political actors to ensure an equity-based and just distribution of resources resulting in fragmentation processes leaving a large proportion of citizens resource-poor (Political Economy approaches represented by e.g. Susman et al. 1984, Wolf and Resnick, 1987)

\section{II.4 Capacity}

The term "capacity" can be defined as "the combination of all the strengths, attributes and resources available within a community, society or organization that can be used to achieve agreed goals" (UNISDR 2009a). For example, capacities include cognitive faculties, physical characteristics, personality factors, financial and other resources, knowledge and experience (Kuban, MacKenzie-Carey 2001). Kuban and MacKenzie-Carey add to this arguing that besides possessing resources (Davis et al. 2004), the "ability to use needed resources" is equally important (Kuban, MacKenzie-Carey 2001). Thereby, capacity describes different types of resources at different scales, accessed to and utilized by an element of concern (institutions, people, and physical structures). In contemporary R\&V literature the term capacity is very much linked to the conception of R\&V, as the "lack of capacity" of an individual or community to protect itself from damaging events, hence as a key driver of $R \& V$, a notion shared by many frameworks (Cf. Birkmann 2006a; Wood et al. 2010). 


\section{II.4.1 Types of Capacity}

A number of terms are used by the $R \& V$ scientists to distinguish between types of capacity. For example, these include "anticipating", "resisting", "responding", "coping", "adapting", and "recovering". In the following the terms response capacity (Cf. II.2.4.1), coping capacity (Cf. II.2.4.2), and adaptive capacity (Cf. II.2.4.3) are explored in detail to provide an understanding of the different types of capacity terminology commonly used in geographical R\&V research. A comparative and critical analysis is done to draw conclusions on the weaknesses and strengths of the terms used. This contributes to the proposal of a new framework for applied R\&V-A (Cf. IV).

\section{II.4.2 Response Capacity}

The term response capacity is defined in various ways and overlaps with other terms in this section, and is therefore susceptible to multiple interpretations. In the following some possible ways of understanding the term in the context of disaster R\&V and R\&V-R are presented.

Response capacity can be referred to as the capacity for accomplishing both ex-ante and expost interventions to reduce disaster and climate $R \& V s$, whereas the ex-ante conception is rather related to the climate change approach and the ex-post to the disaster risk community. By linking both conceptions, response capacity is understood as the capacity to plan and invest in disaster preparedness (ex-ante), to ensure proper disaster management (ex-post), or cope with gradual emerging threats and changes such as climate change (Cardona et al. 2012). One view that recognizes a major distinction between the capacity to respond in the context of expost interventions and the capacity to reduce $R \& V$ is that a purely reactive attitude just responding to occurring losses may lead to new unfavourable conditions leaving societies vulnerable again (Cardona et al. 2012). This perception is contrasted by Turner's concept of the vulnerability of social-ecological systems, in which different types of responses, such as „coping response“, „impact response“ and „adaptation response“, are combined and build up resilience (component of vulnerability) instead of reinforcing vulnerability (Turner et al. 2003). Thereby, Turner's definition of response is closely linked with Bohle's (Bohle 2001) definition of coping as it covers the entire spectrum of possible interventions. 


\section{II.4.3 Coping Capacity}

At least three schools use the term coping simultaneously, but use different approaches and have different perspectives on framing it, causing confusion regarding the term's meaning (Davies 1996). Bohle (2001) and Wisner et al. (2004), both representing the development geography school, have a very broad conception of coping that includes a wide range of options to deal with $R \& V$ that may also include adaptation: Bohle defines coping capacity as the ability " $\{\ldots\}$ to overcome or at least mitigate the negative effects of economic and ecological change $\{\ldots\}$ " that is " $\{\ldots\}$ highly complex, contextual and dynamic $\{\ldots\}$ " (Bohle 2001). He uses a number of theoretical approaches that provide entry points to understand the formation or obstruction of coping capacity, referred to as the internal side of vulnerability (Cf. II.4 "action theories", "models of access to assets", "entitlement theory"). Especially action theories focus on modes and conditions for change and transformation conceptually closely connected to the term "adaptation". Thus, embedding coping into these theoretical approaches proves how broad the term coping is. Also Wisner et al. follow this broader conception by differentiating between different types of coping, such as preventive coping strategies, impact minimizing coping strategies, and post-event coping strategies (Wisner et al. 2004). This view is also shared in psychology science, where coping refers to a strategy on how to deal with an anticipated threat including "defence mechanisms, active ways of solving problems and methods for handling stress" (Murphy, Moriarty 1976; Lazarus, Alfert 1964).

Many scholars, predominantly representing the disaster risk community, provide a more specific definition where coping refers only to short-term response mechanisms to mitigate adverse effects, thus excluding ex-ante measures, such as prevention. According to Turner et al. (2003) coping "takes effect as the impacts of the exposure are experienced (status quo coping) $[\ldots .$.$\} as well as those mechanisms adjusted or created because of the experience" (ex-post$ adapted coping)(Turner et al. 2003). In the words of UNISDR this means the „ability of people, organizations, and systems, using available resources, to face and manage adverse conditions, emergencies, or disasters" (UNISDR 2009a). This view is also shared by (Gaillard 2010) and (Birkmann 2011). Birkmann provides a more abstract definition by stressing that coping aims to maintain the system and its functions in the face of adverse conditions (Birkmann 2011). Hence, Birkmann aims to make an explicit distinction between coping and adaptive capacity (Cf. II.4.4). 
Turner et al. is linking both, "coping" and "adapting", by arguing that coping mechanisms per se give way for adaptation, defined as "system-wide changes in the human-environment conditions" (Turner et al. 2003).

\section{II.4.4 Differences Between Adaptive Capacity and Coping Capacity}

There are little conflicting definitions of adaptive capacity. Thus, this chapter aims at demarking the term from coping capacity, an attempt made by various scientists (Cf. IPCC 2012). Although the term has evolved from the climate change adaptation community, its meaning is also applicable to the R\&V-R community. Representatively, adaptive capacity can be defined as the "vector of resources that represent the asset base from which adaptation actions can be made" (Adger, Vincent 2005), whereby adaptation refers commonly to the accomplishment of "system-wide changes in the human-environment conditions" (Turner et al. 2003) based on strategic decisions that focus on anticipating change and addressing this proactively (Füssel 2007) to also "expand its coping range" (Brooks et al. 2005). The purpose of adaptation emphasized by Brooks (2005) allows for clearly distinguishing between the terms coping and adaptation. Accordingly, coping refers to existing mechanisms in place to deal with disasters and climate R\&Vs as they emerge at a certain point of time, whereas adaptation refers to processes that adjust coping mechanisms with regard to the new challenges faced associated with climate and disaster R\&Vs. This clear distinction, between coping and adaptive capacity is not as clear when comparing the term with how (Bohle 2001) and (Wisner et al. 2004) and others (representing the development geography community) have defined coping (Cf. III.2.1), where the wide conception of coping capacity strongly overlaps with the definition of adaptive capacity and adaptation. 


\section{Risk and Vulnerability Reduction}

\section{III.1 Introduction}

The presentation of a holistic and integrative approach towards Risk \& Vulnerability Reduction (R\&V-R) constitutes a next step towards the conceptualization of the new Framework for Applied Risk and Vulnerability Assessment Research (FARVAR) (Cf. IV). As anticipatory remark, the purpose of this chapter is to pave the way for arguing that a holistic R\&V-R terminology is coherent, precise, and comprehensive and thus preferable in order to distinguish between different types of capacities and to characterize the "positive features of societies that may reduce the risk posed by a certain hazard" (IPCC 2012, p. 72).

In the following the general societal setting in which R\&Vs evolve are explored as a base for how R\&V-R can be defined (Cf. III.2). Thereafter, a holistic R\&V-R Nomenclature is described in detail (Cf. III.3) as well as the process showing how R\&V-R is accomplished (Cf. III.4).

\section{III.2 Framing Risk and Vulnerability Reduction within a Societal Context}

The societal dimension of $R \& V-R$ is closely linked with the discussion on the causality and emergence of $R \& V$. Since, the emergence of $R \& V$ is rooted in societal conditions also the reduction of $R \& V$ has to focus on resolving societal development challenges. Especially, in cases where hazards tend to be in many circumstances not manageable or avoidable, R\&V-R has to widen its scope and focus more on the reduction of vulnerability by addressing capacity obstructing processes within societies. Hence, within processes of R\&V-R, the facilitation of societal processes for enhancing entitlements, freedoms and choices, justice, fairness and equity" is necessary (adapted from Renn 2008; Lavell et al. 2012; Bohle et al. 2009). Taking these considerations into account, Risk and Vulnerability Reduction can be defined as

... "the process of generating, assessing, selecting, implementing and monitoring strategies, policies, options, tasks and measures to address capacity obstructing processes to ensure that societies are capable to anticipate, prevent and prepare for disastrous events and processes to ensure human well-being, quality of life and sustainable development" (own definition based on Renn 2008). 
This definition reflects a recent shift from focussing on disasters and their consequences to their underlying causal structure, altering fundamental concepts of analysis and planning in favour of anticipatory and proactive R\&V prevention and preparedness (Lavell 2003, 2010; UNISDR 2009b, 2011a). Particularly under 'skewed' development conditions (Cuny 1983; Sen 1983; Lavell 1999, 2003; Wisner et al. 2004; Wisner et al. 2012; UNDP 2004; Dulal et al. 2009; UNISDR 2009b, 2011a) R\&V-R requires to focus on the transformational development of societal structures towards reducing hazard and vulnerability (Birkmann et al. 2013a; Nelson et al. 2007), also, because hazards are induced by transformation itself (Beck 1992, p.21). Hence, the transformational character of social-ecological relations in times of globalization and climate change (O'Brien, R.M. Leichenko 2000) poses an additional important challenge for R\&V-R. As with adaptation to climate change, R\&V-R also relates to a longer-term and constantly unfolding process of learning, experimentation and change of systems (Pelling 2011, 2010) in multi-sectorial environments (e.g.; educational, economic, environmental, and social sector). Just as with framing and understanding processes of adaptation, e.g. termed as selforganized, and organized (Pelling 2011, p. 66), (Barry Smit, Johanna Wandel 2006), also the outcome of $R \& V-R$ is the result of a multitude of mutually influential processes in which citizens are on the one hand beneficiaries or even victims of state driven R\&V-R efforts, and on the other hand agents, following their own specific agendas, priorities and strategies to accomplish their individual or collective R\&V-R that might oppose those of formalized strategies and policies employed by government or civil society institutions. Figure 4 generically depicts how $R \& V-R$ is imbedded within wider developmental, institutional, and social settings. 


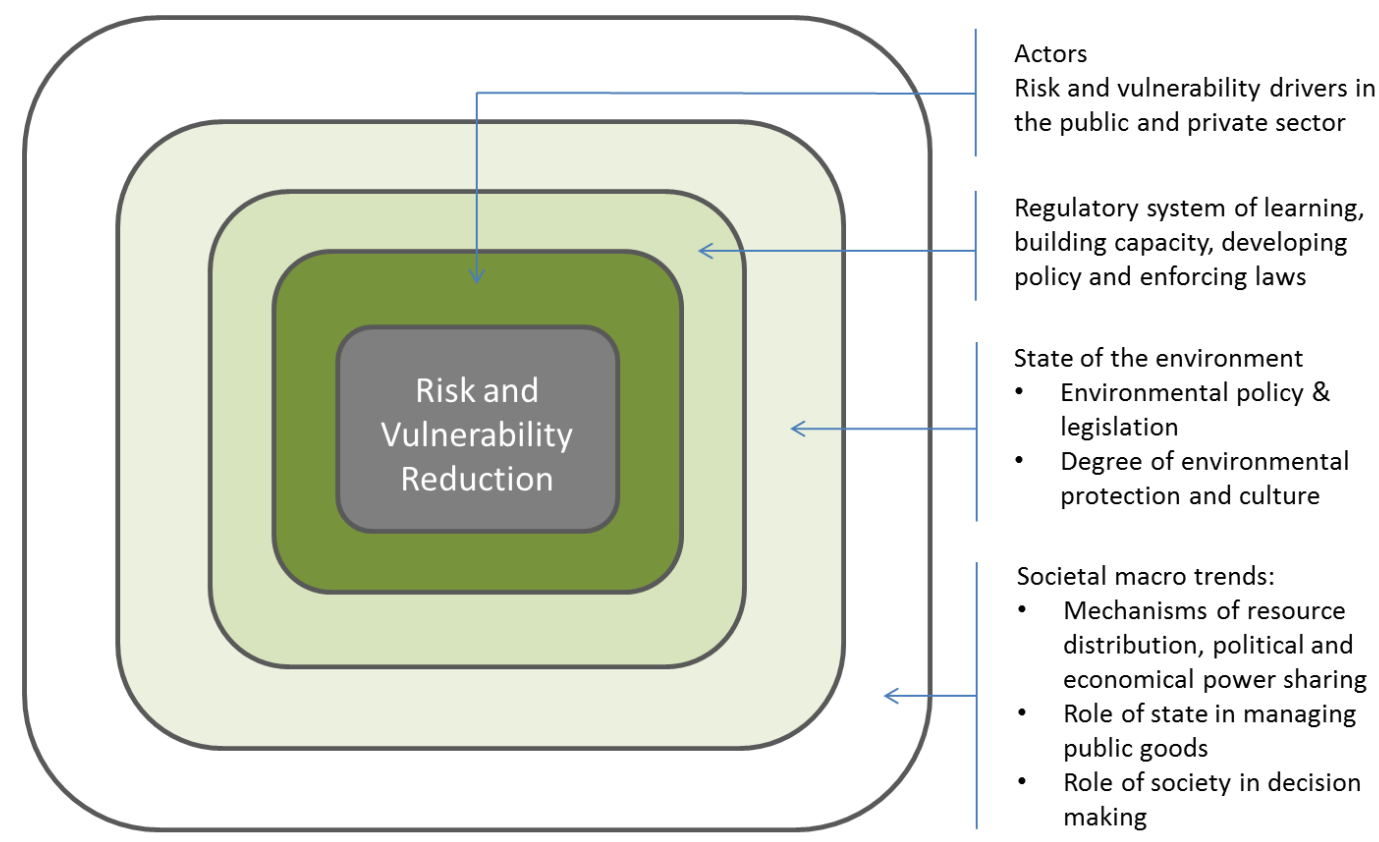

Figure 4: New perspective on R\&V-R embedded in socio-political, socio-economic and socio- environmental conditions and processes (Source: adapted from Renn 2008)

Consequently, one main objective of purposeful and strategic state led R\&V-R is to streamline, to harmonize, and to synchronize differential efforts of societal actors to reduce R\&Vs. This notion is reflected by Renn's (2008) concept of risk governance that "looks at the complex web of actors, rules and conventions, processes and mechanisms concerned with how relevant risk information is collected, analyzed, communicated, and how R\&V-R decisions are taken" (Renn 2008). Thus, compared to the traditional view on R\&V-R, that focusses on disaster response and infrastructure provisions managed by civil protection, defence and public works authorities, the arena for $R \& V-R$ interventions has widened significantly. $R \& V-R$ and its sustainable implementation requires cross-sectorial (horizontal), cross-societal, cross-scale (vertical), and cross institutional coordination between formal state led organizations, civil society, individuals, and the private sector (Lavell et al. 2012; Wisner et al. 2004). In this way R\&V-R should build upon the different existing R\&V schools of thought (Cf. II.3) and provide methods for assessing the contributing role of society towards the formation of R\&V (Bohle et al. 2009; Bohle 2001; Wisner et al. 2004; Blaikie 1995). 


\section{III.3 Hierarchical Nomenclature of Risk and Vulnerability Reduction}

This chapter provides a new systematization of $R \& V-R$ built upon various different sources. The systematization proposed builds upon a number of sources aiming at conceptualizing, classifying and defining R\&V-R (Cf. UNISDR 2009a; UNESCO-IOC 2009; IPCC 2012). For example, UNESCO-IOC differentiates between different $R \& V-R$ Strategies (Protection, Accommodation, and Retreat) and strategy specific Measures (e.g.; dykes, building codes, insurance etc.) (UNESCO-IOC 2009). What these approaches are often missing is to provide a comprehensive scheme for classifying and structuring vertical and hierarchical integrated components of R\&VR.

Hence, the dissertation proposes a comprehensive and systematized "R\&V-R-nomenclature" that is framed by the description of horizontal and vertical and hierarchically integrated components termed R\&V-R-domains, -components, -tasks and -measures. Such a classification provides the baseline for describing the process of R\&V-R (Cf. III.4) and how R\&V-A is integrated into such a process (Cf. IV.5.3).

\section{III.3.1 Overview}

As part of the innovative character of the dissertation, a new classification scheme has been developed that aims to integrate the different approaches towards defining $R \& V-R$ options and proposes four interdependent intervention levels that in their sum constitute R\&V-R (Cf. Figure $5)$.

\begin{tabular}{ll}
\hline R\&V-R-domains & $\begin{array}{l}\text { Four partially non-mutually-exclusive R\&V-R-domains operating in } \\
\text { pre- and post R\&V-R-contexts. The defined domains provide initial } \\
\text { guidance for defining subsequent R\&V-R-components, -tasks, and } \\
\text {-measures. }\end{array}$ \\
\hline R\&V-R-components & $\begin{array}{l}\text { A set of partially non-mutually-exclusive R\&V-R-domain specific } \\
\text { R\&V-R-components. }\end{array}$ \\
\hline R\&V-R-tasks & $\begin{array}{l}\text { A set of domain specific R\&V-R-tasks composed of a number of } \\
\text { measures. }\end{array}$ \\
\hline R\&V-R-measures & $\begin{array}{l}\text { A set of task specific R\&V-R-measures that - if successfully } \\
\text { designed and implemented - contribute to the effective }\end{array}$ \\
\hline
\end{tabular}


implementation of R\&V-R tasks, domains, and strategies.

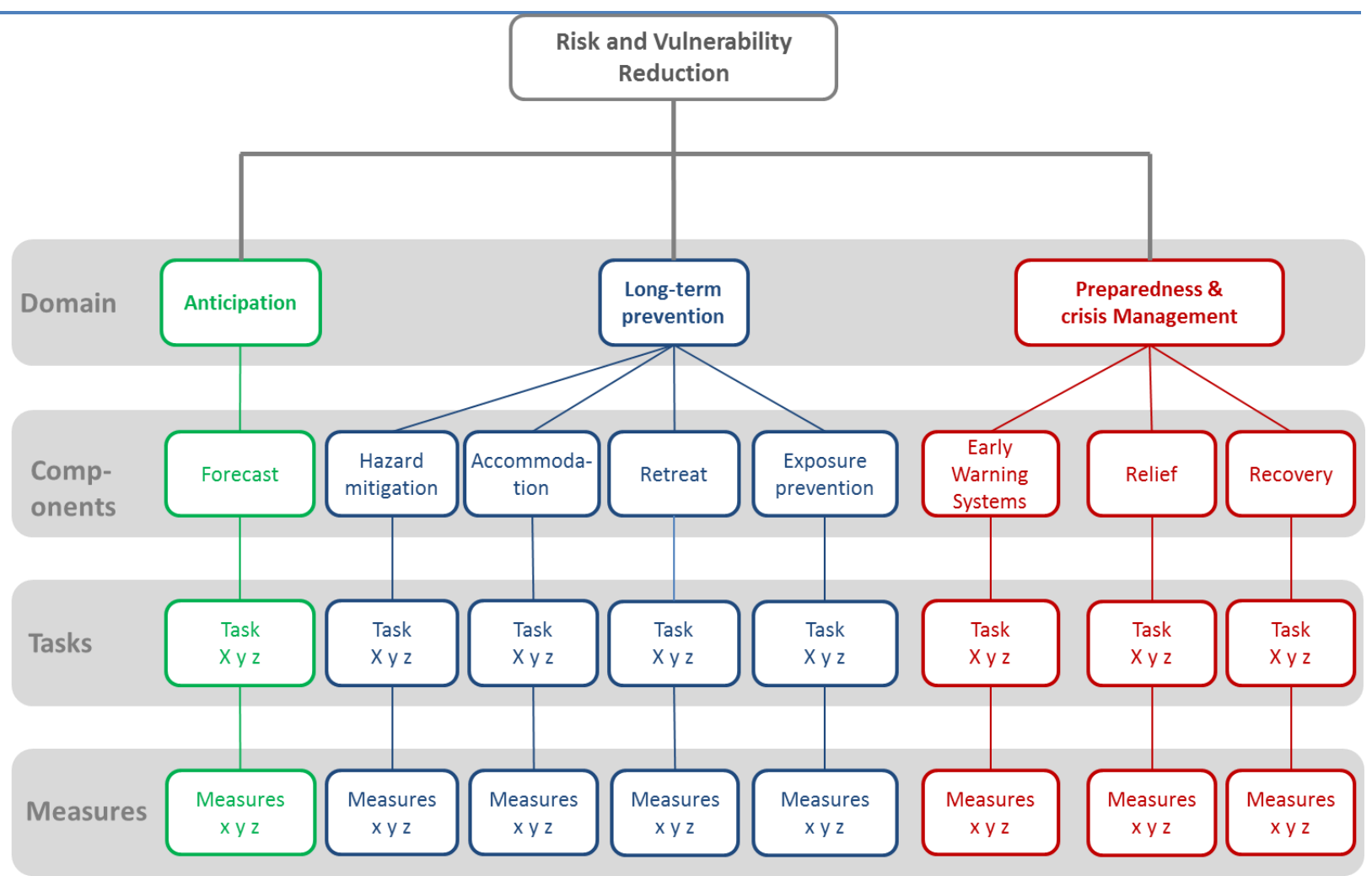

Figure 5: The hierarchical R\&V-R-nomenclature (own conceptualization)

Accordingly, R\&V-R does not refer to the implementation of a single risk reducing measure, but to a diverse set of complementary, vertical and horizontal R\&V-R-domains, -components, -tasks and measures that in their sum lead to R\&V-R. Table 1 provides an overview on defining R\&V-Rdomains and their associated components including possible tasks and measures. 
Table 1: The hierarchical R\&V-R-nomenclature (own conceptualization)

\begin{tabular}{|c|c|c|c|}
\hline R\&V-R-domain & R\&V-R-component & R\&V-R-tasks & R\&V-R-Measures \\
\hline \multirow[t]{2}{*}{ Anticipation } & \multirow[t]{2}{*}{ Forecast } & $\begin{array}{l}\text { Current R\&V and future R\&V } \\
\text { scenarios }\end{array}$ & Technical capacity development, research \\
\hline & & $\begin{array}{l}\text { Institutionalized mechanisms } \\
\text { for anticipating future } R \& V s\end{array}$ & Cross-institutional coordination \\
\hline \multirow[t]{7}{*}{ Prevention } & \multirow[t]{2}{*}{ Hazard mitigation } & $\begin{array}{l}\text { Global Co2 Emission } \\
\text { reduction }\end{array}$ & $\begin{array}{l}\text { Mitigating anthropogenic hazard triggers (green } \\
\text { economy, transport system, energy supply) }\end{array}$ \\
\hline & & $\begin{array}{l}\text { Local / regional hazard } \\
\text { mitigation }\end{array}$ & $\begin{array}{l}\text { Mitigating anthropogenic hazard triggers (land } \\
\text { degradation, pollution, ecosystem changes, land } \\
\text { use change, sealing), retention areas, restoring } \\
\text { ecosystem functions }\end{array}$ \\
\hline & \multirow[t]{2}{*}{ Accommodation } & Protection & $\begin{array}{l}\text { Protected infrastructures and assets, e.g. dykes, } \\
\text { green houses for crops, irrigation systems, } \\
\text { window protection against storms }\end{array}$ \\
\hline & & $\begin{array}{l}\text { Resistance (long-term } \\
\text { functional exposure } \\
\text { reduction) }\end{array}$ & $\begin{array}{l}\text { Multi-hazard building codes for lifelines and } \\
\text { housing, altering farming practices and planting } \\
\text { dates, crop diversification }\end{array}$ \\
\hline & \multirow[t]{2}{*}{ Retreat } & $\begin{array}{l}\text { Redirection of development } \\
\text { away from hazardous places }\end{array}$ & $\begin{array}{l}\text { Incentives (insurance, economic development) } \\
\text { and regulation (land use policies etc.) }\end{array}$ \\
\hline & & $\begin{array}{l}\text { Relocation of settlements, socia } \\
\text { and economic assets }\end{array}$ & $\begin{array}{l}\text { Sustainable livelihood restoration of the affected } \\
\text { population in less risky environments according to } \\
\text { standards }\end{array}$ \\
\hline & $\begin{array}{l}\text { Exposure } \\
\text { prevention }\end{array}$ & $\begin{array}{l}\text { Development restriction } \\
\text { potentially hazardous areas }\end{array}$ & Insurance, land use regulation \\
\hline \multirow{8}{*}{$\begin{array}{l}\text { Preparedness } \\
\text { and } \\
\text { crisis } \\
\text { management }\end{array}$} & \multirow[t]{2}{*}{$\begin{array}{l}\text { Early warning } \\
\text { mechanisms }\end{array}$} & $\begin{array}{l}\text { Real time hazard detection } \\
\text { (time of arrival, magnitude) }\end{array}$ & $\begin{array}{l}\text { Building instrumentation networks, } \\
\text { institutionalization, decision support systems }\end{array}$ \\
\hline & & Warning dissemination & $\begin{array}{l}\text { SOPs: institutionalization and infrastructure } \\
\text { planning, education and socialization }\end{array}$ \\
\hline & \multirow{3}{*}{$\begin{array}{l}\text { Immediate } \\
\text { response } \\
\text { mechanisms to } \\
\text { warnings }\end{array}$} & \multirow{2}{*}{$\begin{array}{l}\text { Short-term exposure } \\
\text { reduction }\end{array}$} & Hazard control mechanisms and measures \\
\hline & & & $\begin{array}{l}\text { Evacuation: SOPs / Evacuation Infrastructure: } \\
\text { Spatial planning, shelter planning, labelling and } \\
\text { socialization, provision of basic services }\end{array}$ \\
\hline & & $\begin{array}{l}\text { Short-term resistance } \\
\text { building }\end{array}$ & $\begin{array}{l}\text { Measures that protect infrastructure and assets in } \\
\text { the short-term from a hazardous event: e.g. } \\
\text { housing protection }\end{array}$ \\
\hline & $\begin{array}{l}\text { Search and Rescue, } \\
\text { Relief }\end{array}$ & Contingencies & $\begin{array}{l}\text { Search and rescue infrastructure provision } \\
\text { (shelter, direct aid, sanitation, food) \& market } \\
\text { interventions }\end{array}$ \\
\hline & \multirow[t]{2}{*}{ Recovery } & Contingencies & $\begin{array}{l}\text { Insurance: } R \& V \text { transfer, micro-insurance for } \\
\text { reconstruction }\end{array}$ \\
\hline & & $\begin{array}{l}\text { Disaster resilient recovery } \\
\text { planning }\end{array}$ & $\begin{array}{l}R \& V \text { zoning, } R \& V-R \text { infrastructure planning, } \\
\text { integration of } R \& V-R \text { in recovery planning to } \\
\text { account for returning and new hazards }\end{array}$ \\
\hline
\end{tabular}




\section{III.3.2 R\&V-R-Domains}

The classifying of R\&V-R-domains is guided by the definition of a temporal sequence of investment opportunities to reduce $R \& V$, which in the disaster context is before, during, and after a disastrous event. Accordingly, mortality and livelihood risks are manifest in these different phases, but also undergo constant change, requiring different modalities of intervention over time (Lavell 2003). By acknowledging the uncertainty of changes in the natural system (despite continuously improving science based knowledge of future hazard trends), and the imperative of accepting a certain level of residual $R \& V$, the continuous reduction of R\&V is largely a function of investing in the following R\&V-R-domains: Anticipation, Prevention, and Preparedness (pre-disaster context) (Twigg 2007; Cardona et al. 2003; UNISDR 2009a). The different domains are closely interrelated. For example, based on the anticipation of future R\&Vs, investments in prevention and preparedness can be conducted. Or, the more prevention can be accomplished, the less preparedness may be necessary (Cardona et al. 2003). All the R\&V-R-domains put together contribute to $R \& V-R$, e.g. prevention aims to reduce $R \& V$ and vulnerabilities ex-ante or ex-post of a disastrous event, and preparedness aims to reduce mortality and livelihood risk during and shortly after a disastrous event. In theory, the different $R \& V$-R-domains are not mutually exclusive (accepting a level of residual $R \& V$ ), but in the face of resource constraints and depending on hazard specificities, investments in preparedness are dominant.

\section{III.3.3 Integral components of R\&V-R-domains}

For each of the three R\&V-R-domains a set of R\&V-R-components exist. Thereby, the term "components" refers to the different options that are available to reduce risks within a specific domain of R\&V-R. The choice of the most efficient, effective, sustainable, fair, and ethically acceptable $^{3}$ R\&V-R-component is a difficult task and requires the utilization of the tools for decision-making employed by key stakeholders involved in risk governance.

\footnotetext{
${ }^{3}$ Criteria inferred from Renn 2008
} 
- The $R \& V-R$ domain "Anticipation" refers to the forecast of future $R \& V s$ by the means of investments into technical capacity to assess current and future R\&Vs, as well as to institutionalize cross-sectorial and vertical mechanisms for creating environments for proper R\&V anticipation. Anticipating $R \& V s$ is a precondition for making decisions about investments into prevention and preparedness strategies. In some cases evidence for emerging R\&Vs can be drawn from past experiences as well as scientific knowledge. But confronted with a changing climate non-linear changes occur in a discontinuous way (Berkes 2007) such high degree of uncertainty of future development in climate, hazards and social systems forces decision makers to utilize strategies of forecast and anticipation that are built upon scenarios and stakeholder judgment. To enhance the capacity to anticipate vertical, horizontal and inter-sectorial coordination is required since $R \& V$ sources and their factors are rooted in cross-sectorial development pathways and domains of governance at different scales (O'Neill et al. 2015; Kloos et al. 2013).

- The R\&V-R domain "Prevention" addresses the elimination of the underlying causes of unsafe conditions that lead to disaster, either in a pre-disaster (anticipatory R\&V-R) or/and in a post-disaster (corrective - reactive R\&V-R) context (Lavell 2003; UNISDR 2011a). This notion presumes that existing and future R\&Vs are preventable (varies depending on the context), particularly those that are human induced (e.g. floods due to deforestation).

The following components of prevention include:

- Hazard mitigation; which means mitigating anthropogenic hazard triggers such as land degradation, pollution, ecosystem destruction, land use change, sealing through measures of emission control, afforestation, and ecosystem based adaptation.

- Accommodation; which means aiming to live with R\&V through enhancing the protection of existing infrastructures and assets as well as, where appropriate, increasing their resistance such as introducing building codes, and disaster tolerant crops. The domain of preparedness is closely linked to accommodation. Living with $R \& V$ requires strong preparedness structures to manage significant amount of tolerated residual $R \& V$.

- Retreat; which means drawing back the human system out of a hazard zone by the means of resettlement or incentives provided by $R \& V$ transfer mechanisms. 
- Exposure prevention; which means development prohibition in potentially hazardous areas, or even on a broader scale e.g.; tackling the root causes of settlement into hazardous areas through poverty reduction, rural development, etc.

- The domain "Preparedness" refers to the establishment of crisis management structures that need to function well in the case of emergency to prevent and mitigate mortality and livelihood risk once a hazard event strikes. Investments into preparedness and adjusting existing preparedness configurations to anticipated emerging R\&Vs are an acknowledgement to limits of prevention (IPCC 2012), or a remaining residual R\&V in R\&VR (UNISDR 2004).

The following components within the preparedness domain include:

- Early warning and response systems, serving the temporary retreat of people (evacuation) and assets (transportable assets) as well as the temporary improvement of the robustness of fixed assets (e.g. house protection against cyclones). Response options can be diverse depending on hazard specifications and exposure levels. E.g. for drought, as warning can be issued long time before drought occurs preventive and disaster management strategies can be simultaneously employed (e.g. food aid to affected populations, setting up irrigation systems, prevention of fire outbreaks, etc.). In this sense, early warning systems are strongly linked to strategies to forecast $R \& V$ to selected threats. The depending variable is available warning time.

- Contingencies for rescue, disaster relief and recovery operations.

- R\&V transfer and coordination mechanisms to ensure sustainable recovery and reconstruction. R\&V transfer refers to the process of formally or informally shifting the financial consequences of particular $R \& V s$ from one party to another, whereby a household, community, enterprise, or state authority will obtain resources from the other party after a disaster occurs, in exchange for ongoing or compensatory social or financial benefits provided to that other party (IPCC 2012). 


\section{III.3.4 R\&V-R-Tasks and -Measures}

The definition of R\&V-R-tasks and measures allows for a classification of the available options for each $R \& V$-R-component. Their function is to define all necessary requirements for a strategy to be effectively implemented. R\&V-R tasks can be defined through referral to internationally accepted frameworks, standards, and best practices (e.g. pre-defined procedures and processes). E.g. relief operations follow standardized procedures regarding e.g. Search and Rescue (SAR) activities, emergency food supply, temporary shelter provisions and international coordination. This also accounts for defined tasks for the implementation of resettlement strategies or early warning systems. Therein, technical standards, procedural prescriptions, economic incentives, physical measures and spatial planning, education and social development are the tools through which R\&V-R-tasks can be defined (Renn 2008, p. 174). Standardized R\&V-R-tasks are often non-negotiable but require contextualization for different hazard and vulnerability specificities influenced by geography (population, infrastructures, environmental conditions, cultural values) and sectorial requirements (e.g. public, financial, agricultural, and industrial). Each R\&V-R-task is accomplished by a set of R\&V-R-measures which are often highly disputable and require negotiation. The definition and selection of measures for implementing transformational requirements and implementing e.g. technical standards, procedural prescriptions, economic incentives, engineering works, spatial planning, education and overall institutional and development requirements need to be done by evaluating each of them according to pre-defined criteria.

\section{III.4 The Process of Risk and Vulnerability Reduction}

Exploring the process of $R \& V-R$ is an important step in this dissertation as it guides the evaluation of the utility of $R \& V-A$ for $R \& V-R$. The process of $R \& V-R$ is a dynamic complex decision-making process, conceptualized in this thesis based on the integration of two major elements:

(1) The vertically and horizontally structured R\&V-R-nomenclature (Cf. III.4.1) through which $R \& V-R$ has to navigate through to arrive at a desired $R \& V-R$ solution. Six steps have been identified; decision on needs for investment into R\&V-R, decision on the appropriate R\&V-R- 
domain, decision on domain specific R\&V-R components, component specific tasks and task specific measures, and the implementation and monitoring of the measures identified.

(2) The definition of a generic process of decision-making based on the provisions of Renn (2008) to navigate through each hierarchical level of the R\&V-R-nomenclature (III.4.2), that includes, the elaboration, assessment, selection of R\&V-options. Figure 6 represents a graphic visualization of the developed $R \& V-R$ process framework described in detail in the following chapters. 


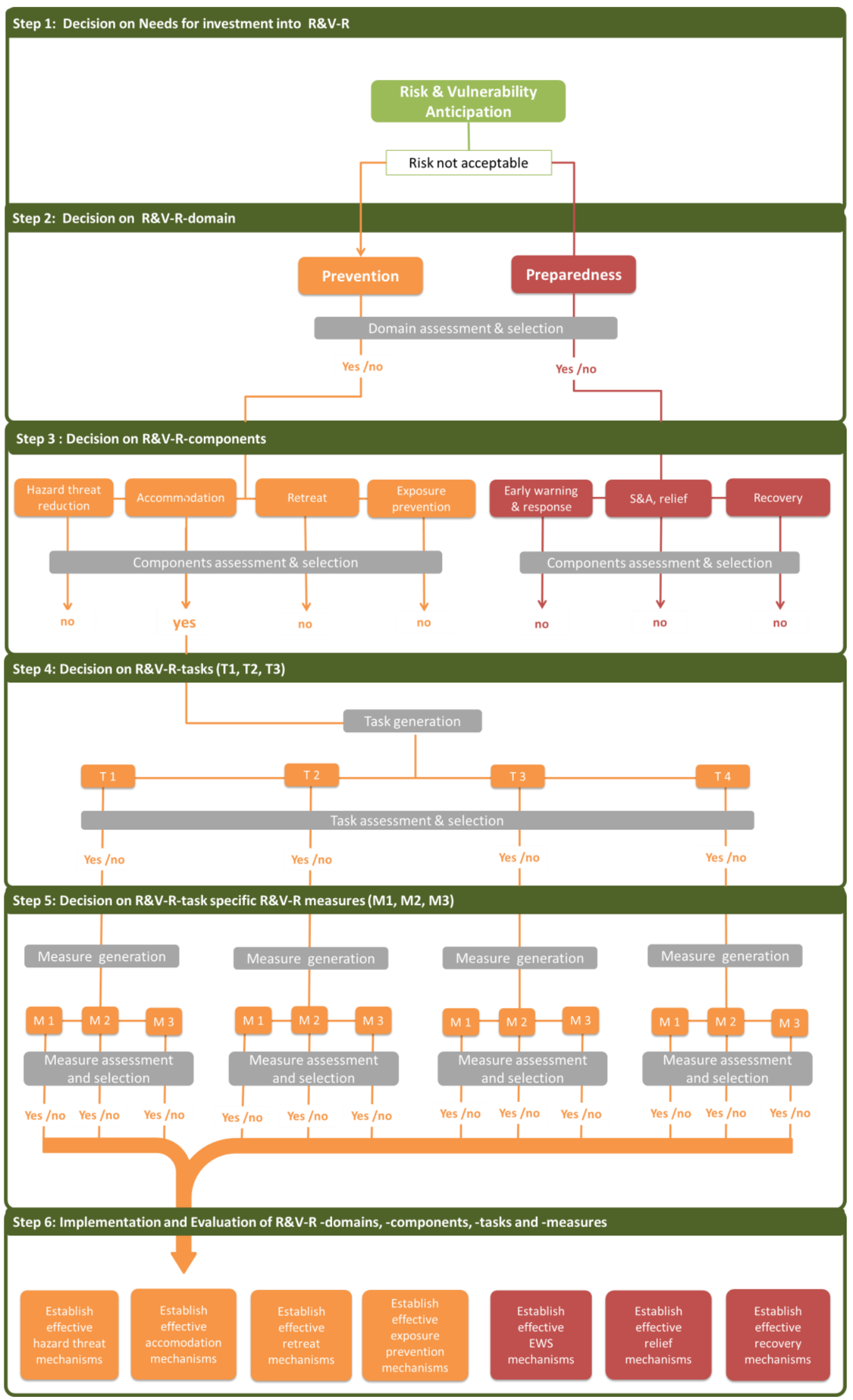

Figure 6: The process of R\&V-R (own conceptualization) 


\section{III.4.1 Risk Reduction Decision Making - Navigating Through the Hierarchical Structure of R\&V-R}

The process of $R \& V-R$ draws from how the definition of the vertically and horizontally structured R\&V-R-nomenclature (Cf. III.3), through which R\&V-R has to navigate to arrive at the most effective, suitable and acceptable R\&V-R domain, component, component specific tasks and measures. The diverse set of options available about how to accomplish R\&V-R (Cf. III.3) for a specific subject of interest at risk (e.g. water resources, agriculture, infrastructures, people and livelihoods) suggests that choices have to be made to arrive at the best suitable option.

Here, the hierarchical ordered R\&V-R-nomenclature (Cf. III.3) provides a comprehensive normative frame to structure and guide an R\&V-R decision-making process, which is composed of six major steps (Cf. Figure 6):

- Step 1: Decision on needs for investment into R\&V-R (can be also referred to tolerability assessment after Renn 2008). This step refers to seeking societal / community census about the need to engage in R\&V-R. The participatory anticipation of future threats and R\&Vs is a key initial step of R\&V-R.

- Step 2: Decision on R\&V-R-domains. If the need to engage in R\&V-R is decided upon, decisions on whether to invest rather in prevention or preparedness have to be taken. A comparative assessment of the two main R\&V-R-domains allows selecting the most appropriate one. In some cases, managing residual $R \& V$ by investing in early warning systems is more effective than relocating entire cities. Hence, although the two R\&V-Rdomains are rather complementary than mutually exclusive, budget constraints require prioritization.

- Step 3: Decisions on R\&V-R-domain specific components. When a domain has been decided upon (Step 2), decisions on domain specific R\&V-R-components have to be taken based on assessing the normatively pre-defined components and finally selecting those that are most appropriate. Is it more efficient, effective, ethically justifiable, manageable, and cheaper to invest in measures to accommodate hazards or to strengthen the resistance of existing structures, or is it better to retreat from a hazardous area? 
- Step 4: Decision on R\&V-R-component specific tasks. Each R\&V-R-component is composed of a set of complementary tasks. They have to be identified and elaborated, assessed and selected, particularly where no normative guidance exists. However, often they do not have to be elaborated from scratch. Many guidelines and well accepted standards exist that define, for example, the core R\&V-R-tasks for early warning systems. But contextualization of the R\&V-R-tasks is often required.

- Step 5: Decisions on R\&V-R-task specific measures. When component specific R\&V-Rtasks are decided upon, task specific measures are to be selected, based on elaborating, assessing, and selecting the most appropriate measures. This step refers to the final decision-making process. Based on the selection of the R\&V-R-domain, R\&V-Rcomponent, R\&V-R-task, and R\&V-R-measures, an R\&V-R strategy can be developed.

- Step 6: Implementation of measures and performance monitoring. The final step of the entire R\&V-R-process is a difficult one, since it affects the entire area of interest. In many instances, implementation is delegated (e.g. when governments take decisions but leave their implementation to other public or private bodies or to the general public). However, the R\&V-R team has, at any rate, the implicit mandate to supervise the implementation process or at least to monitor its outcome.

\section{III.4.2 Generic Steps of Risk and Vulnerability Reduction Decision-Making}

The step by step approach for navigating through the hierarchical structure of R\&V-R (Cf. III.4.1) has shown that each step represents an own decision-making process. How are decisions taken within each step of the proposed R\&V-R process? Guidance for decision-making is provided particularly by Renn (Renn 2008), the OCED (OECD 2009), and the PROVIA project (PROVIA 2013a). Generalized for the dissertation they refer to five generic components: (1) option generation, (2) option assessment, (3) option selection, (4) implementation, and (5) monitoring. Not each component is required for each of the five steps. Whereas in Steps 1 and 2 "option generation" is not necessary - as the normative framework of the R\&V-R-nomenclature already provides them - often decisions upon R\&V-R-tasks and R\&V-R-measures require the elaboration of potential options for selecting R\&V-R-tasks and R\&V-R-measures (Steps 4 and 5). Component 4 is represented by Step 5 in its entirety and refers to the implementation of options, namely 
the respectively selected $R \& V$-R-tasks and $R \& V-R$-measures. Also Step 6 is equivalent to the component 5 of the decision-making process.

In the following a more detailed description of the five components is provided, as they play a pivotal role when assessing the utility of the R\&V-A results for R\&V-R-decision-making.

\section{III.4.2.1 Option generation}

For Steps 4 and 5 options regarding identifying possible R\&V-R-tasks and R\&V-R-measures need to be generated. This stage of decision-making refers to brainstorming within a multistakeholder environment, e.g., representing the private and public sector, about all possible options available and worth to be considered (strategic, task and measure specific options). The open character, meaning putting less concern on feasibility or other aspects when generating options, is relevant to allow multiple perspectives and thinking "out of the box" when identifying potential R\&V-R solutions (Renn 2008; OECD 2009).

\section{III.4.2.2 Option assessment}

The phase of option assessment aims to discover the most appropriate strategy, or task or measure. Each of the options generated can have intended, but also unintended consequences that influence the R\&Vs that they are supposed to reduce. On the other hand, some options are mutually exclusive, others can work complementarily to accomplish even more effective R\&V$R$, and others again represent different approaches for addressing the same R\&V. Here, an assessment is necessary that guides decision makers through a process on how to evaluate alternative options, e.g., whether the options generated are effective, efficient, costly, and sustainable, have side effects, or are fair and ethically acceptable (Renn 2008; OECD 2009). Hence, handling R\&V trade-offs and knowing how to employ decision-analytic tools for dealing with conflicting evidence and values (e. g. cost-benefit and multi-criteria analysis) is an important issue and part of this decision-making stage (Viscusi 1994; Goodwin, Wright 2009). The selection of the assessment criteria is context specific and shall be based on a consensus of the relevant stakeholders. 


\section{III.4.2.3 Option Selection}

Once the different options are assessed, it has to be decided upon which options are to be selected and which rejected. This decision is obvious if one or more options turn out to be dominant (relatively better on all criteria). Otherwise, trade-offs have to be made that require legitimization (Graham and Wiener, 1995). A legitimate decision can be made on the basis of formal balancing tools (such as cost-benefit or multi-criteria decision analysis) by the respective decision-makers (given that their decisions are informed by a holistic view of the problem) or in conjunction with participatory procedures.

\section{III.4.2.4 Option Implementation}

This step relates to overseeing and controlling the implementation process. In many instances, implementation is delegated (e.g., when governments take decisions but leave their implementation to other public or private bodies or to the general public) (Renn 2008).

\section{III.4.2.5 Monitoring of Option Performance}

The final step in the process is to monitor and evaluate the success of the adaptation strategy implemented. Evaluating the success of an adaptation is not a straightforward task and may take a long time because the benefits of some adaptation measures may not be realized until the climate changes significantly. Evaluating the success of an adaptation should be based on measuring the benefits against the policy objectives used in the effectiveness analysis. Quantitative measures of success should be used when available (Smith, Lenhart 1996). 


\section{New Framework for Applied Risk and Vulnerability Assessment Research (FARVAR)}

\section{IV.1 Introduction}

This chapter presents the new Framework for Applied Risk and Vulnerability Assessment Research (FARVAR) and addresses RQ 1.1. The main objective is to provide a common analytic lens for $R \& V$ scholars and $R \& V-R$ practitioners that facilitates the mutual exchange of knowledge, and allows for developing a more applied research agenda with a focus on how to systematically analyse $R \& V$ causalities of utility for $R \& V$ scholars as well as $R \& V-R$ practitioners. Thus, the framework developed acknowledges Birkmann's call for "more comprehensive and holistic approaches $\{. .$.$\} that take into account the underlying causal factors of vulnerability \{. .\}.\}^{\prime \prime}$ (Birkmann 2006b) by providing conceptual guidance for the different schools of thought in R\&V science, as well as for R\&V-R practitioners on how to delineate causal pathways of the emergence of unsafe conditions (Cf. IV.4.4).

In the following the new FARVAR is presented, to which the conceptualization on how R\&V-A can be integrated into processes of R\&V-R is attached (Cf. IV.5.2, IV.5.3). This chapter is structured in such a way as to track back the evolution of the FARVAR revealing the key provisions and different components of the framework:

- First, in chapter IV.2, it is elaborated that capacity is the depending variable that decides upon the emergence of vulnerability, revealing that R\&V conditions are viewed as the results of lack of capacity.

- Second, in chapter IV.3, arguments are made about why the R\&V-R-nomenclature provides a more precise and applicable structure for understanding R\&V causalities than using the contemporary terminology inherent in the $\mathrm{R} \& \mathrm{~V}$ research community.

- Third, in chapter IV.4, the R\&V causality frame of the new Framework for Applied Risk and Vulnerability Assessment and Research (FARVAR) is presented that builds upon the provisions made in chapters IV.2 and IV.3. A new definition of R\&V is provided, as well as a set of R\&V causality frames, enriched with examples of how R\&V causalities emerge.

- Fourth, in chapter IV.5, the utility of R\&V-A for R\&V-R and how R\&V-A shall be integrated into R\&V-R decision-making is conceptualized. 


\section{IV.2 Risk and Vulnerability as the Outcome of Lack of Capacity}

This thesis shares the view with many scholars that the causal structure of R\&V is to be searched in the mechanisms that pose barriers to capacity formation und utilization, creating unsafe conditions such as exposure and susceptibility (Bohle 2001; Moss et al. 2001; Yodmani 2001; Downing, Patwandhan 2004; Brooks et al. 2005; Barry Smit, Johanna Wandel 2006; Gaillard 2010). The examples of vulnerability definitions in Table 2 show how the term capacity is put into relation with the term vulnerability. Implicitly, all of them refer to vulnerability as the result of a "lack of capacity", implying that the degree of vulnerability is a function of the degree of capacity, i.e. that "[....] high vulnerability means low capacity" (Cardona et al. 2012) or vice versa, that high capacity refers to "positive circumstances to offset vulnerability" (ANDERSON, WOODROW 1998).

Table 2 Vulnerability definitions referring to unsafe conditions and capacity as a driver of vulnerability

Vulnerability definitions explicitly referring to capacity as a major driver

"Vulnerability is defined as the propensity or predisposition to be adversely

(Wisner et al. 2004)

affected. Such predisposition constitutes an internal characteristic of the affected

element. In the field of disaster risk, this includes the characteristics of a person or group and their situation that influences their capacity to anticipate, cope with, resist, and recover from the adverse effects of physical events."

"Is the characteristic of a person or a group in terms of their capacity to anticipate,

(Blaikie 1995) cope with, resist, and recover from the impact of a natural disaster".

"Vulnerability is not the same as poverty. It means not lack or want, but (Chambers 1989) defencelessness, insecurity, and exposure to risk, shocks and stress $\{. .$.$\} .$ Vulnerability here refers to exposure to contingencies and stress, and difficulty in coping with them."

"The characteristics of a person or group in terms of their capacity to anticipate, cope with, resist and recover from the impact of a natural or man-made hazard."

(IFRC 1999)

Accordingly, capacity is the depending variable that decides upon whether risky conditions are generated, prevail or are successfully reduced (Cf. Figure 7). The configuration of capacity outcomes for a specific system of interest is determined by the mutual influence of capacity specific criteria embedded in overall economic, social, institutional, and environmental processes and trends. Hence, the degree of capacity varies for different variables and types of capacity and capacity forming and obstructing processes are capacity-type specific. 


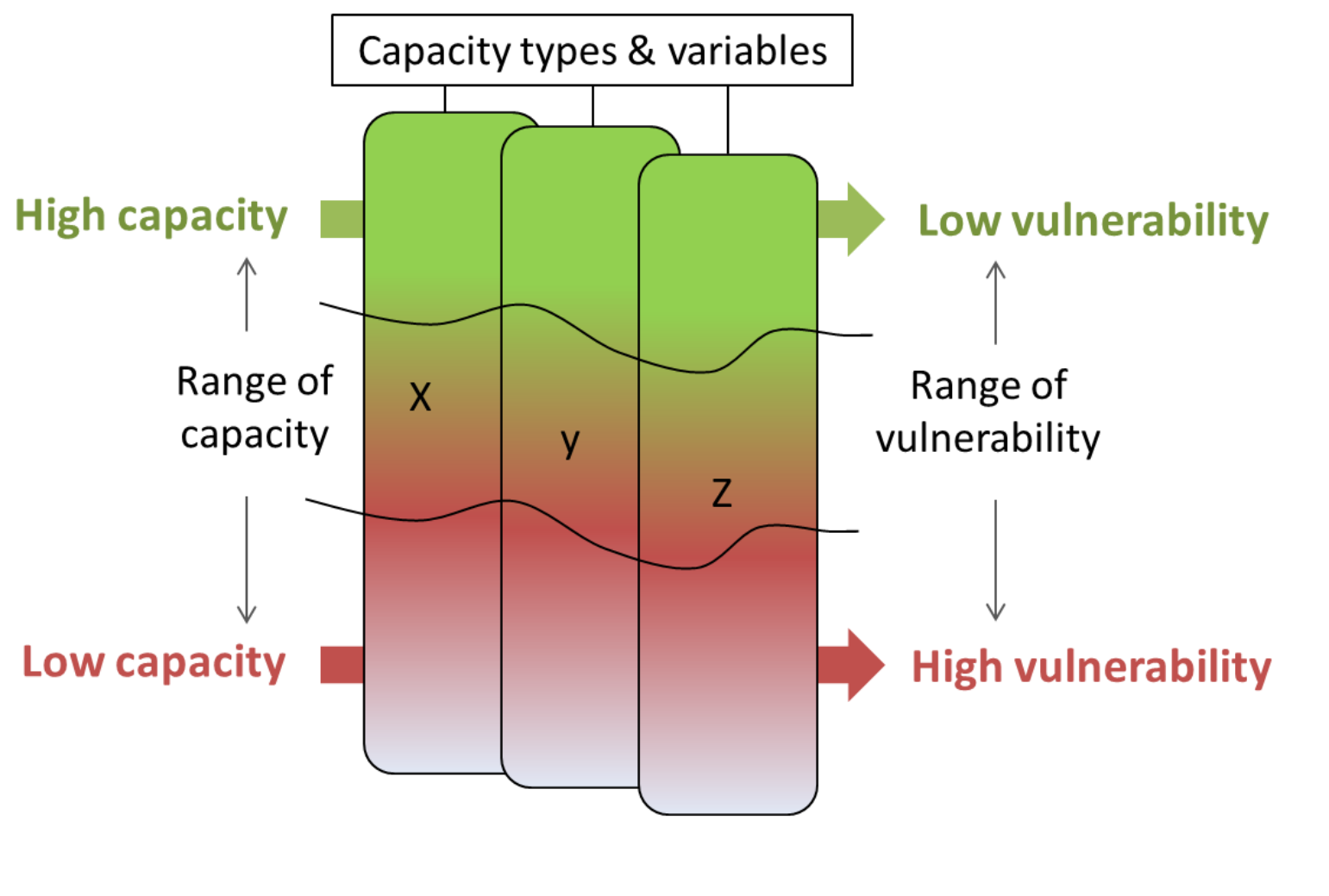

Figure 7: Capacity as the dependent variable of the emergence of vulnerability (own conceptualization)

This means that the commonly described determinants of vulnerability, notably capacity, exposure, susceptibility, are not independent from each other, as often assumed when looking at various attempts to measure vulnerability. The notion that the degree of capacity is the depending variable that decides upon whether risky and vulnerable conditions are generated and prevail or are successfully reduced can be strengthened by inconsistencies observed within the scientific debate on the relationship between vulnerability and capacity. In this sense, the concept of vulnerability cannot be defined as the opposite of capacity, and whether vulnerability and capacity coexist depends on whether parameters of concern have mutual influence within a predefined reference system of analysis. In Box 1 a selection of narratives with regard to the relationship of the two is commented that clearly shows a lack of a consistent and logic relationship between them. Resolving this is an important cornerstone of the dissertation as it lays the foundation for the development of the new Framework for Applied Risk and Vulnerability Assessment Research (FARVAR) that builds upon the notion that $\mathrm{R} \& \mathrm{~V}$ result from lack of capacity. 
- The narrative that vulnerability and risk are the opposite of capacity (Cardona et al. 2012). Such a perspective inherits a dialectic mistake. Capacity rather refers to a resource or an asset, and vulnerability to a condition in which people are likely to face adverse impacts from hazardous events. Thus, capacity might act as a surrogate of the degree of latent vulnerability, but not the opposite. Hence, capacity relates to an observable phenomenon causing possible harm in the future, such as conditions and processes of capacity obstruction (Cf. II.4). The opposite of vulnerability is rather resilience (Miller et al. 2010) and capacity is the mediator between the two ends.

- $\quad$ The narrative that high vulnerability and high capacity can coexist (Davis et al. 2004; Carreño et al. 2007; Gaillard 2010). This message is only partially correct, high vulnerability and high capacity can only coexist for different unconnected variables or different reference frames of interest (e.g. R\&V-R -Strategies, Tasks and -Measures) but not for interrelated variables within a specific reference frame (Figure 7, " $\mathrm{x}, \mathrm{y}$, $\left.z^{\prime \prime}\right)$.

- Example for interrelated variables within a specific reference system: Although an individual or household has sufficient financial resources to resettle, factors such as chronic sickness and lack of labour limits the opportunity to utilize them and decreases the overall capacity thus leaving the household exposed and vulnerable (not able to resettle). The example shows that capacity (sufficient financial resources) and the lack of other resources (health problems) can coexist, but since they are mutually influential, only one outcome in relation to a defined system of interest is possible.

- Example for unconnected variables or different reference frames: Whereas communities or social groups have good established structures to evacuate (low capacity to respond reveals high vulnerability), at the same time they have limited resources to recover from disaster impacts (high capacity to recover reveals low vulnerability), showing that vulnerability and capacity can coexist.

- The narrative that people's abilities are not recognized in the concept of vulnerability (Davis et al. 2004). To the contrary, capacity is a core concept of vulnerability, in which theories and frameworks explore why certain capacities required to reduce $R \& V$ cannot be sufficiently developed leading to loss and damage in the course and the aftermath of a hazardous event. Moreover, the focus on capacity as the mediating variable between vulnerability and attained vulnerability reduction allows for a better linkage between the two communities, namely the R\&V science and the R\&V-R community in practice.

- The observation that in many R\&V-As the relationship between capacity and the other "components" of vulnerability, notably "exposure" and "susceptibility" is not consistently described (Welle et al. 2012; Birkmann 2006a; Bogardi, Birkmann 2004; Turner et al. 2003). Many vulnerability frameworks provide explanations of the differences amongst the components but tell little about their causal relationship. Often, they are only connected through linking the terms by putting them in a temporal or sequential 
order. For example, Davis defines capacity to cope / recover as a response capacity to existing exposure and susceptible conditions (Davis et al. 2004), neglecting ex-ante capacities to prevent the emergence of exposure or susceptibility. The limited acknowledgement of the causal relationship between vulnerability and capacity becomes very obvious when vulnerability is attempted to be assessed through the creation of indices for each of the components that are assumed to be independent (e.g. exposure, susceptibility, coping, adaptive capacity). Indicators for $\mathrm{R} \& \mathrm{~V}-\mathrm{A}$ are selected representing each of the components, without recognizing the logical interference between them. Hence, paradoxically, these indicators representing each component appear to be significantly independent from each other when tested through statistical analysis, but from a logical point of view ( $R \& V$ as a result of lack of capacity) they strongly inter-relate: For example, in the WorldRiskIndex (Welle et al. 2012) the indicator "informal housing" is attributed to the category of "susceptibility" but can be also seen as a result of "lack of capacity".

The notion that R\&V are the result of lack of capacity (Cf. IV.2) allows to redirect the focus of vulnerability research from the phenomena of vulnerability to its causal structure; namely the processes of capacity formation and obstruction. Conceptual approaches towards understanding the causal structure of societal capacity formation and obstruction is well advanced (Cf. II.3). Different vulnerability frameworks demonstrate that the causal structure of societal or individual and collective capacity formation and obstruction is the result of interacting processes between actions of societal actors, institutions and structural framework conditions termed structuration. The complexity of capacity formation and obstruction is best acknowledged by Bohle's concept of the "double structure of vulnerability" (Bohle 2001), by admitting that there is no single theory or concept that provides sufficient explanatory power for understanding capacity formation and obstruction. Instead, Bohle's concept seeks to integrate various theoretical approaches and perspectives; e.g. by linking political economy approaches with human ecology approaches as well as action and entitlement theories (Giddens 1986; Tröger 2003). Others could be added. 


\section{IV.3 The R\&V-R Nomenclature Representing Types of Capacity}

The objective of this chapter is to provide argumentative evidence that the $R \& V-R$ nomenclature (Cf. III.3) better distinguishes between different types of capacity and hence resolves the presumed non-mutually exclusive coexistence of each of the two terminologies. To accomplish this, this chapter draws from the results of the comparative analysis of different types of capacity (Cf. II.4.1) and the exploration of the societal dimension of R\&V-R (Cf. III.2), as well as the Hierarchical Nomenclature of R\&V-R (Cf. III.3).

\section{IV.3.1 Convergence of the Capacity Terminology and the R\&V-R Nomenclature} In the following several arguments can be made about why the capacity terminology and the R\&V-R-nomenclature are increasingly converging, paving the way for the development of a capacity terminology that can be well used by $R \& V$ scholars as well as R\&V-R practitioners.

- Both, the notion of capacity; e.g. to cope, to adapt or to respond, and the notion of disaster R\&V-R share the same objective, namely resolving R\&V conditions. This observed commonality provides a general entry point for initiating a scientific debate about assimilating both terminologies.

- As the conceptualization of R\&V-R has experienced a significant shift from focussing on disasters and the management of their consequences to resolving their underlying causal structure through societal processes, no significant differences between the two terminologies and their focus of debate can be observed anymore. Here, the scientific discourse of adapting, coping, responding, and preventing is very well reflected in the conception of R\&V-R.

- A decisive, but not made explicit reason for making a distinction between the two terminologies is their different type of "agency" in focus. Whereas, in R\&V science, the different types of capacities are rather attributed to individuals, households or communities dealing with $R \& V$ (Cf.II.3), R\&V-R is often perceived as a process that is strategically planned and implemented by organizations and authorities (Carreño et al. 2007). According to the definition of R\&V-R in Chapter III.2, a holistic perspective of $R \& V-R$ suggests that any social unit that is influencing $R \& V$ conditions is also an agent of $R \& V-R$, irrespective of whether it is classified as unconscious, involuntary, purposeful, or intentional. Consequently, the strategies and respective outcomes of R\&V-R of different 
social units also differ, leading to differential impacts in the course of a disastrous event. The investigation of these differences and the factors contributing to them is a core task of vulnerability research (IPCC 2012, p. 313).

\section{IV.3.2 Suggestion to Substitute the Capacity Terminology by the R\&V-R Nomenclature}

The comparison of the different types of capacities as they are defined by the different schools of thought in R\&V science (Cf. II.4.1) has revealed that the labelling of such types of capacity is subject to many possible interpretations, and hence contributes to the widely stated Babylonian confusion of terms used in R\&V science (Cf. Hinkel 2011; Füssel 2007). In the following it is attempted to argue, furthermore, why the R\&V-R nomenclature better differentiates and structures the various types of capacity. Taking the terms "coping", "responding"; and "adapting" as examples, in the following the different types of capacity are compared with the R\&V-R nomenclature:

- What are the implications of the term coping capacity for $R \& V-R$ ? Whereas one could put "coping", as defined; e.g., by Bohle 2001 and Wisner et al. 2004, on the same level as overall R\&V-R, "coping" as defined by for example, by Adger 2000 and Bankoff et al. 2004, it relates only to a specific part of the $R \& V-R$ nomenclature, namely by addressing the domain preparedness and disaster management including warning, relief and rescue as well as sustainable recovery. The variability of how to relate the term "coping" with different elements of the R\&V-R nomenclature shows its fuzziness of meaning (Davis et al. 2004). Its susceptibility to a wide range of possible interpretations is not favourable for scientific discourses.

- What are the implications of the term response capacity for $R \& V-R$ ? As with coping capacity, response is also a very broad term trying to characterize a wide range of options of how to deal with R\&V. A response to an anticipated threat can mean everything, from prevention, to preparedness and disaster management. Thus, it is very difficult to identify what is specifically meant by the term and what kind of topics and processes can be deduced, whereas also here the $R \& V-R$ nomenclature is much more differentiated as it provides a comprehensive classification of response options. 
- What are the implications of the term adaptive capacity for $R \& V-R$ ? Also this term is very broad and provides little guidance for R\&V-R but allows for contextualization within processes of R\&V-R. Adaptive capacity has been defined as the potential for adjusting an existing $R \& V-R$ system to new $R \& V$ challenges to accomplish overall $R \& V-R$ in times of new threats that might lead to system-wide changes in the human-environmental conditions (Turner et al. 2003; Adger et al.). In R\&V-R, the notion of adaptive capacity refers to the capacity to continuously monitor $R \& V s$ and $R \& V-R$ performance, to cyclically accomplish overall R\&V-R in all its defined steps, even in times of altering R\&V patterns. A useful aspect of adaptive capacity is that also R\&V-R has to be viewed in an even much larger context, namely, acting as a system-inherent mechanism for transformational change also addressed in chapter 8 of the IPCC-SREX report, that includes components such as adaptive management, learning, innovation (Cf. IPCC 2012) that are so to say outcomes of cyclic $R \& V-R$ as defined through the process of R\&V-R (Cf. III.4).

To conclude, it could be found that capacity and its different types of capacity can be related to how the R\&V-R community distinguishes different approaches of risk management, R\&V-R, or risk governance. The comparative analysis conducted justifies why the R\&V-R-nomenclature can substitute the differentiation between types of capacity developed by R\&V scholars. The conceptualizations of the different types of capacity by R\&V scholars are rather arbitrarily used without an inner justification and logic. The scientific debate about how to differentiate between different types of capacity is rather fuzzy and confusing due to high levels of abstraction of the terms revealing a lack of specificity and resulting in a lack of coherence of the different research schools using and relating the terms (short-term, long-term) coping-, adaptive-, and response capacity. In contrast, the R\&V-R nomenclature (Cf. III.3) with its horizontally and vertically integrated components provides a more precise, coherent, and comprehensive structure to define and differentiate between types of capacity.

\section{IV.3.3 Implications for Applied R\&V Research}

The demonstrated poor coherence of capacity related terminology used by vulnerability scholars and R\&V-R practitioners reveals the little integration of the two. Such integration has been the objective of this chapter. This dissertation has advanced the scientific debate about how to conceptualize capacity in $R \& V$ sciences to become of relevance for applied $R \& V$ 
research by proposing the use of the $R \& V-R$ nomenclature representing types of capacity. Ultimately, the R\&V-R nomenclature can serve as a well-accepted platform for various scholars and schools of thought for conducting R\&V research, thereby advancing integrative and interdisciplinary R\&V science. The R\&V-R nomenclature increases the mutual understanding of the different schools of thought within the R\&V science community and between R\&V researchers and R\&V-R practitioners, hence facilitating interdisciplinary research and developing applied R\&V-As of utility for R\&V-R decision-making. Thereby, the science community must not fear to become too applied in its approach; to the contrary, it would achieve more precision on what it aims to conduct research for. Moreover, taking over a clear definition of R\&V-R targets on the basis of the R\&V-R nomenclature ensures the definition of coherent policy relevant research lines.

\section{IV.4 The Risk and Vulnerability Causality Frame of the FARVAR}

\section{IV.4.1 Overview on the Generic Risk and Vulnerability Causality Frame}

The FARVAR uses the R\&V-R nomenclature as a classification scheme for differentiating between different types of capacities. Hence, the term capacity - in the context of R\&V research - can be defined as the capacity to accomplish R\&V-R (Cf. IV.3.2). Consequently, R\&V (hazard potential, exposure, susceptibility) is the cumulative result of the lack of capacity (Cf. IV.4) of an individual or community to reduce R\&V by means of R\&V anticipation, prevention, and preparedness (Cf. Figure 8). Vice versa, improving capacity means reducing vulnerability (Thomalla et al. 2006) and risk. Hence, $R \& V$ is the inverse of accomplished R\&V-R rooted in societal outcomes of development paths. A definition and mathematical expression is provided in the following:

"Risk of loss and damage is a product of both, the potential for hazard occurrence and vulnerability (exposure and susceptibility) in a certain point of time resulting from the incapacity of different and mutually dependent social units to anticipate current and future risks and vulnerabilities, and to accomplish effective $R \& V-R$ in pursuit of preventing and preparing for hazardous events to increase the net benefit for individual and societal security". (Own definition, adapted from UNDP 2004; Renn 2008; Wisner et al. 2004). 
The notion of the definition corresponds with the simple statement - but that has never been translated into a framework for R\&V-A - that disasters are the outcome of unmanaged risks (Westgate, O'Keefe 1976) and vulnerabilities. The generic R\&V frame of the FARVAR and its components are visualized in Figure 8 as follows:

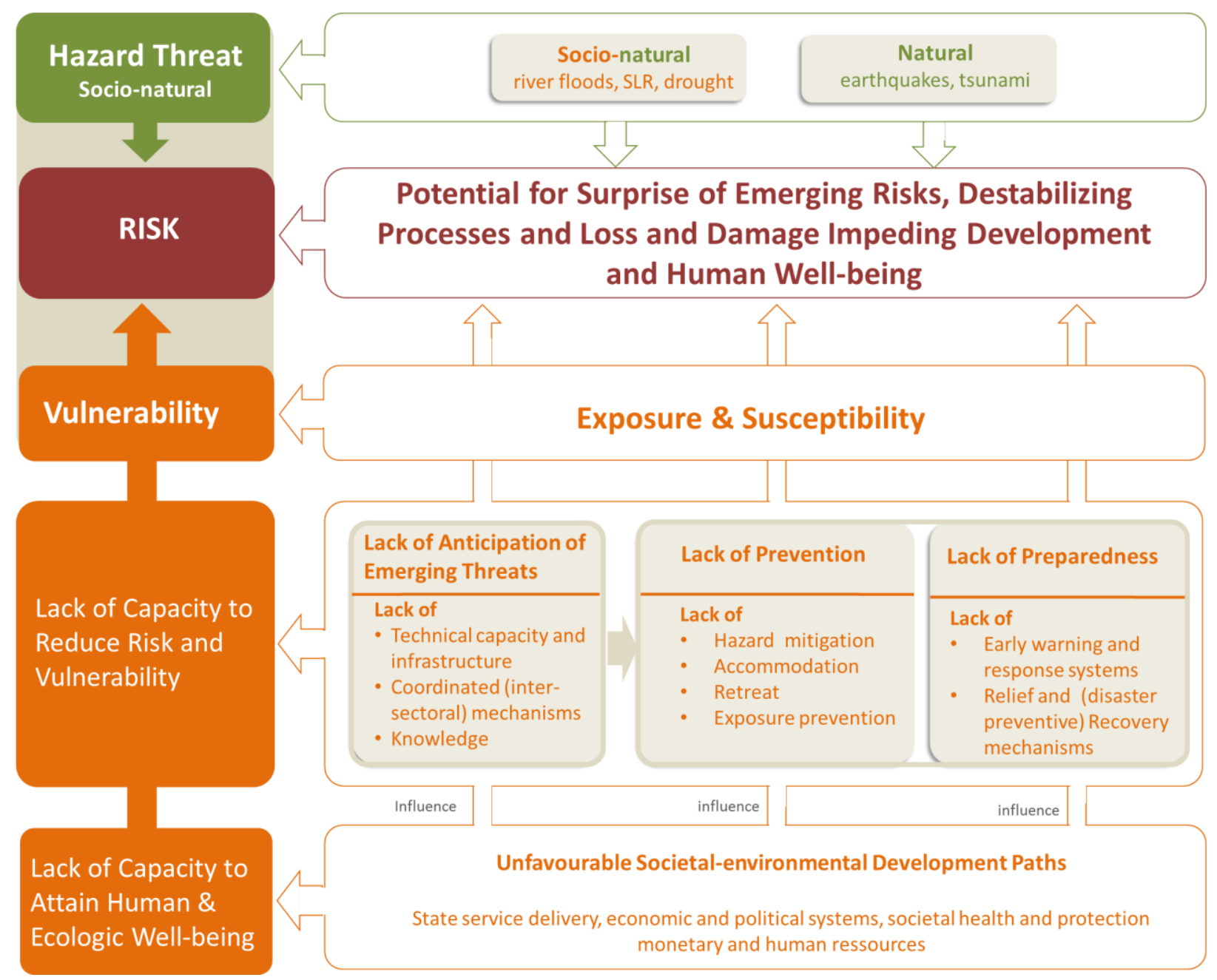

Figure 8 Framework for Applied Risk and Vulnerability Assessment and Research (own conceptualization)

The FARVAR urges $R \& V$ research to focus on understanding societal dynamics causing a deviation from a human system having accomplished sustainable R\&V-R. Other than for example Wisner's "Pressure and Release Model" (PAR) that focuses on generic R\&V causalities (Cf. Wisner et al. 2004), the FARVAR framework promotes the necessity to understand R\&V causalities through a predefined set of R\&V-causality-frames, which are based on the R\&V-R nomenclature. This allows the delineation of frame specific emergent and complex 
hierarchically structured R\&V causalities that include understanding how societalenvironmental development paths influence a society`s capacity to anticipate, prevent, and prepare and how they influence the emergence of socio-natural hazards. Therefore, the FARVAR also focusses on, for example; understanding the conditions of state service delivery, the dynamics of economic and political systems, societal protection and human resource development influencing the evolution and outcome of R\&V-R mechanisms. The FARVAR promotes the analysis of such processes based on the provisions of the different theoretical approaches within the domain of geographic R\&V research outlined in chapter II.3. Particularly, the integration of the R\&V-R nomenclature into a R\&V causality frame, enables the FARVAR to operate as a hinge between R\&V scholars and R\&V-R practitioners, who can benefit from each other's work in progress as they use the same reference frame as a basis of their work, a notion that has been tested in the empirical work of this dissertation.

\section{IV.4.2 Differential Risks and Vulnerability Outcomes}

Anticipated and revealed R\&Vs can take many forms and be contextualized for many different systems of interest, such as agricultural systems, infrastructures, people, nations etc. The framework focuses on R\&Vs for the human system in which loss and damage might be related to injury, mortality, livelihood deprivation, famine, displacement, and other phenomena. They materialize in the course of a hazardous event (or process) and in the aftermath. They can occur simultaneously and in a sequence for the same or for different social units, such as individuals, households, or communities. For example, although an individual, group, or community might be able to survive a hazardous event, the same individual, group, or community might face displacement and difficulties in the aftermath of an event to re-establish livelihoods. Table 3 exemplifies the importance of looking at multiple types of R\&V outcomes in different phases of a hazardous event, and seeks to delineate for each of them differential causal pathways, thus demonstrating that R\&V has multiple causalities and outcomes.

Table 3 Examples for differential risks and vulnerabilities

\begin{tabular}{l|l|l|l|} 
& \multicolumn{1}{|c|}{ Mortality risk } & \multicolumn{1}{|c|}{ Livelihood risk } & \multicolumn{1}{c|}{ Displacement risk } \\
\hline $\begin{array}{l}\text { During hazardous } \\
\text { event / process }\end{array}$ & $\begin{array}{l}\text { Why during a hazardous } \\
\text { event people lose their life }\end{array}$ & $\begin{array}{l}\text { Why during a hazardous } \\
\text { event livelihoods are lost }\end{array}$ & $\begin{array}{l}\text { Why during a hazardous event } \\
\text { displacement occurs }\end{array}$ \\
\hline $\begin{array}{l}\text { After hazardous } \\
\text { event / process }\end{array}$ & $\begin{array}{l}\text { Why after a hazardous } \\
\text { event people lose their life }\end{array}$ & $\begin{array}{l}\text { Why after a hazardous } \\
\text { event livelihoods are lost }\end{array}$ & $\begin{array}{l}\text { Why after a hazardous event } \\
\text { displacement occurs }\end{array}$
\end{tabular}


Risk of loss and damage can only be understood if the causes that lead to impact are understood. Here, the term vulnerability is the key. Vulnerability and the conditions and factors leading to specific disaster impacts on a human system are different within each phase of the risk cycle because the causes for negative impacts are different within each phase.

\section{IV.4.3 Different R\&V Causality Pathways Based on the R\&V-R Nomenclature}

According to the outlined societal dimension of R\&V-R (III.2) and the provisions made by the different existing vulnerability frameworks (Cf. II.3), R\&V research has to focus on understanding the societal dynamics responsible for a society lacking the sustainable accomplishment of $R \& V-R$ through anticipation, prevention, and preparedness. This notion is further elaborated in the following:

- $R \& V$ as the outcome of lack of anticipation capacity: Anticipating R\&V is a precondition for implementing prevention and preparedness measures. The lack of institutional and technical capacities to anticipate leads to a situation in which human systems will be surprised by hazardous events leaving them defenceless and vulnerable. The increasing emergence of R\&Vs shows that the baseline for the safe anticipation and prediction of R\&Vs has been lost. Uncertainty, ambiguity, and incalculability are new experiences und challenges of an ecological R\&V society and pose a threat to capacity (Bohle 2008).

- $R \& V$ as the outcome of lack of prevention capacity: Preventing damage can be accomplished by the means of hazard control or mitigation, exposure prevention, accommodation of hazards, and retreat. But the increasing emergence of R\&Vs shows that societies are increasingly exposed, cannot sufficiently mitigate the occurrence and accommodate a range of types of hazards, or even retreat from dangerous places as they lack the capacities to adequately accomplish these goals rooted in option specific causality paths.

- $R \& V$ as the outcome of lack of preparedness capacity: Mitigating damage can be accomplished by the means of crisis management including warning and response systems, rescue, relief, and recovery. But the increasing emergence of R\&Vs shows that societies are less capable to accomplish adequate crisis management, a failure leading to mortality, livelihood deprivation, and displacement. 
The types of R\&V causalities presented represent the conceptualization of the " $R \& V$-causalityanalysis-frame" of the FARVAR. This framework guides R\&V research with respect to how to structure and approach the analysis of a multitude of mutually influencing capacity obstructing factors, processes and dynamics within human systems, and between different social units. These obstructing elements result in incapacities to anticipate, prevent, and get prepared, leading to varying unsafe conditions and differential risks of loss and damage such as mortality, livelihood deprivation, and displacement (Cf. IV.4.2). Hence, the framework acknowledges that by focussing on frame-specific R\&V causalities, a better targeting of frame-specific solutions for $R \& V-R$ is possible. Depending on how $R \& V-R$ has been framed, research on $R \& V$ causalities also needs to take into account the influence of societal development and transformations whether purposeful, planned, autonomous, or spontaneous - on the capacities of societies to effectively anticipate, prevent, and prepare for prevailing or emergent R\&Vs. The following examples are provided, showing how to work out frame-specific R\&V causality pathways (Cf. Table 4). 


\section{Lack of Anticipation}

People, societies will be surprised by hazardous events and not be able to prevent and get prepared for emergin threats.

\section{Lack of capacity to timely forecast upcoming threats to society}

- Lack of knowledge of future hazards and potential impacts due to lack of integrated governance and inter-sectorial coordination and lack of research that altogether facilitate scenario thinking.

\section{Lack of capacity to reflect on upcoming R\&Vs}

- Lack of local knowledge and awareness with regard to changing patterns of livelihoods due to e.g. high mobility, lack of reflective education, lack of communication, and due to requirements to meet daily livelihood needs.

\section{Lack of Prevention}

\section{Lack of hazard}

\section{mitigation}

Defencelessness, new hazard threats emerge, existing threats prevail and intensify, further endangering exposed settlement areas, infrastructures, assets, and people.

\section{Lack of capacity to mitigate or control hazard occurrence and magnitude}

- Lack of hazard proof land use planning and construction of hazard specific protective infrastructures, or of sustainable natural protective structures.

- Lack of hazard mitigating infrastructures and their maintenance that contribute to limit hazard magnitude and distribution (e.g. drainage systems).

\section{Lack of capacity to enhance / maintain the environment}

- Lack of mechanisms for environmental protection (development at the expense of environmental services) leading to increasing environmental stress / environmental degradation / depletion (e.g. deforestation, diversity, tolerance limits, endemic species).

- Lack of $\mathrm{CO} 2$ neutral economy (lack of technology, financial capacity, political economy) and land use leading to the prevalence of the system and a continuous increase of $\mathrm{CO} 2$ concentration and higher probability of weather extremes (rising air, soil, and water temperatures).

\section{Lack of capacity to mitigate or control hazard occurrence and magnitude}

- Hazard control as it materializes is rather a public responsibility; whereas activities related to prevent hazards from occurring are also a responsibility of individuals (compare below).

\section{Lack of capacity to enhance / maintain the environment}

- Lack of mechanisms to change patterns of livelihoods in favour of the sustainable utilization of environmental services (no livelihood alternative, no incentives, no assets available for transformation), leading to increasing environmental stress / environmental degradation / depletion (e.g. deforestation, diversity, tolerance limits, endemic species).

- Lack of CO2 neutral consumption habits (lack of livelihood maintaining alternatives) leading to the prevalence of the system causing a continuous increase of $\mathrm{CO} 2$ concentration resulting in a higher probability of weather extremes (rising air, soil, water temperatures). 


\section{Lack of \\ accommodation}

Unprotected buildings, infrastructures and livelihood systems, e.g. food, increasing the likelihood of damage in the course of a disastrous event.

\section{Lack of exposure prevention}

Hazardous areas are populated and human activity will prevail.

Lack of retreat

Large areas prevail that are exposed to well-known hazards risking mortality in the course of an event if not capable to evacuate and save assets.

\section{Lack of capacity to protect public and private assets, entities of relevance}

- Lack of sector-specific knowledge and protective capacity (e.g. building codes, protection of crops from heat waves, floods).

- Lack of law enforcement of existing regulations to protect relevant assets.

Lack of capacity to govern transformational change of susceptible elements of human activity to increase their resistance

- Lack of disaster resistant sector-specific infrastructures and land use (lack of "hazard proofing" in different sectors, e.g. construction / building codes, agriculture /drought resistant crops).

\section{Lack of capacity to prevent settlement in exposed areas}

- Lack of instruments and implementation of sector-specific "hazard proofing" (where to allow settlement /economic activity) - (no interest, corruption in land registration etc.), leading to human activities in threatened areas.

- Lack of population control and growth management (socio-economic development deficits, social security provisions, culture), leading to accelerated population growth and urbanization.

- Lack of provision of livelihood security to the population ensuring living in healthy and safe environments (in contrast to marginality), leading to an increase of socially weak parts of the population living in exposed areas.

\section{Lack of capacity to protect privately owned assets and property}

- Lack of the individuals' awareness of the need for protection.

- Lack of access to financial resources to invest in protection infrastructures (e.g. mobile protection of owned property against floods, cyclones, drought).

\section{Lack of capacity of individuals and groups to initiate and engage} and participate in transformational change

- Lack of opportunity to change patterns of livelihoods and property owned physical structures to increase the level of resistance to hazards once they materialize (change cropping systems, planting periods, drought resistant crops).

\section{Lack of capacity to settle in safe areas}

- Lack of hazard knowledge or adequate cost-benefit judgments of exposed living (perceived dominance of opportunities over R\&Vs), leading to investments into livelihood assets in exposed areas.

- Lack of choice not to live or not to settle in exposed areas (marginality, poverty, informal sector employment, dependency on "risky livelihoods"), leading to socially stratified (e.g. gender, age, profession, income) exposure to hazards.

\section{Lack of capacity to manage resettlement}

- Lack of economic and social incentives for resettlement that overweigh the interest to stay in exposed areas (low attractiveness of alternatives), leading to low participation rates in resettlement programmes.
- Lack of alternatives to re-establish livelihoods somewhere else (e.g.; lack of property or adequate employment), leading to low participation rates in resettlement programmes or displacement and livelihood deprivation in the course of 


\section{Governance structures}

- Lack of financial resources to make provisions for communities to resettle, leading to low participation rates in resettlement programmes.

- Lack of strategic and management skills to accomplish resettlement (low level of institutional performance), leading to displacement and livelihood deprivation in the course of resettlement.

\section{Population}

resettlement.

- Lack of willingness to resettle (attachment to place of origin, culture, and dependency on local livelihood and environmental services), leading to low participation rates / resistance to resettle, and conflicts.

\section{Lack of Preparedness}

\section{Lack of early warning} and response

Hazard surprise and lack of response mechanisms will cause damage and mortality.

\section{Lack of rescue and recovery \\ Increases mortality risk, pandemics and long-term livelihood deprivation and displacement.}

\section{Lack of warning and response mechanisms}

- Lack of hazard detection infrastructure (lack of technology, and access thereto), leading to unexpected and unprepared for surprise hazards causing damage / mortality in their course.

- Lack of warning dissemination mechanisms (lack of vertically institutionalized coordinated mechanisms between different authorities), leading to damage / mortality in the course of a hazardous event.

- Lack of hazard-specific response mechanisms (evacuation systems, shelters, stocking facilities), leading to damage / mortality in the course of a hazardous event.

\section{Lack of emergency management and recovery mechanisms}

- Lack of contingencies and equipment.

- Lack of crisis coordination mechanisms.

- Lack of R\&V transfer / insurance mechanisms for compensation and schemes to finance recovery.

\section{Lack of adequate reaction to the occurrence of hazards}

- Lack of accessing warnings (no communication, no infrastructure available at the place where people live and work)

- Lack of knowledge, guidance, and mechanisms for action giving instructions on what to do in case of emergence of a hazardous event.

- Lack of ability to save lives due to unfavourable hazard characteristics, spatial settings of the places, and physical conditions of individuals (age, gender, health).

\section{Lack of capacity to survive and attain livelihood security}

- Lack of physical strength and self-rescue contingencies to survive the physical impact during an extreme event (age, gender, health).

- Lack of physical strength to survive injury after an event without access to basic needs, such as food, shelter, medical treatment (age, gender, health).

- Lack of human and financial resources to manage recovery (poverty, damage, no insurance, land tenure insecurity).

- Underestimation of R\&Vs leading to the neglect of benefits associated with purchasing adequately covered disaster insurance ((IPCC 2012), chapter 5.5.3). 


\section{IV.4.4 Orientation for Applied Research on R\&V Causalities}

In the following some arguments are presented that underscore why applied R\&V research has to focus on frame-specific $R \& V$ causalities, and why these arise from generic and R\&V-R specific societal processes.

- $R \& V$ causality paths are frame-specific: Each of the different causality frames (understanding lack of capacity to anticipate, prevent, prepare) has its own contextspecific (country, culture, institutions, economic and social system) causality path. For instance, causalities leading to the incapacity to prevent exposure manifestation are different from those that lead to the incapacity to develop disaster resistant infrastructures.

- $R \& V$ causality paths are dependent on generic and $R \& V-R$ specific factors: For each causality frame, interdependent generic as well as R\&V-R-specific capacity obstructing and forming conditions and processes play a role. For example, population growth, a key driver of exposure, is a result of lack of family planning and balanced socioeconomic development and if combined with other factors, such as improper R\&V knowledge and R\&V based land use planning, corruption, lack of law enforcement, and environmental degradation, leads to unregulated urban development in hazard zones.

- $R \& V$ causality paths have frame-specific characteristics and attributions of common R\&V factors: Although often similar processes and factors are responsible for the lack of anticipation, prevention, and preparedness (e.g.; failure of state service delivery rooted in corruption, lack of human and financial resources, operational management, law enforcement, efficiency, social learning as well as unfavourable cultural, physical, economic and social conditions such as population growth, demographic imbalances, negative impacts of globalization leading to impoverishment, culturally imposed gender roles, marginalization, lack of education and knowledge), their specific attributes and characteristics are frame-specific. For example, although institutional performance (e.g. good governance) is crucial for both, i.e., managing exposure prevention through proper land registration and land use planning, as well as the establishment of an effective early warning system, the types of capacities required for accomplishing them, and 
therefore the conditions and processes that might obstruct such capacities, differ. Another condition or variable that is often referred to is knowledge. Although generically, knowledge plays a great role in $R \& V-R$, characteristics and features of knowledge that are frame-specific can be identified. For example, the lack of R\&V knowledge can increase mortality risk during a disastrous event, whereas the lack of knowledge with regard to how to access compensation funds for reconstruction increases livelihood deprivation.

- $R \& V$ causality paths are constituted by the combination of frame-specific capacity obstructing factors and processes: The way how they are interlinked is frame-specific. For example, whereas the combination of $R \& V$ knowledge, age, gender and spatial conditions factor the capacity to evacuate in the course of a hazardous event, the incapacity to recover properly from a disastrous event depends on damage patterns, financial capacities, and types of social networks that allow for resource sharing.

The FARVAR framework does not prescribe a specific conceptual or theoretical perspective for the analysis of frame-specific differential R\&V pathways. To the contrary, it provides the opportunity for the integration and application of existing conceptual frameworks and theories of $R \& V$ research in human geography (Cf. II.3). The only prescription the framework makes is to give proper weight to the diversity and mutual influence and interaction between different social units (Cf. II.3, III.2); and the role social structure, human agency, and the environment play in generating or reducing R\&V (Cf. II.3.1).

\section{IV.5 Applied Risk and Vulnerability Assessment}

The FARVAR (Cf. IV.4) paves the way for developing a new perspective on applied R\&V-A (particularly the contributing role of vulnerability assessment) focussing on how to integrate R\&V-A into various stages of decision-making within the process of R\&V-A. Hence, this chapter addresses RQ 1.2 of the dissertation. First, the initial point of departure of the thesis is recalled that diagnosed a considerable lack of applied R\&V-A of utility for R\&V-R (Cf. I.2). Thereafter, the notion of applied R\&V-A is framed (Cf. IV.5.2) to finally propose a procedure how to integrate $R \& V-A$ into $R \& V-R$ decision-making with the aim to increase the utilization of $R \& V-A$ for $R \& V-R$ (Cf. IV.5.3). 


\section{IV.5.1 Shortcomings of State-of-the-Art Approaches Towards Risk and Vulnerability Assessment}

Most of today`s R\&V-As follow the logic of theoretical and scientific models and not the requirements of policy makers. This circumstance traps and brings confusion to policy makers when they try to understand how R\&V can contribute to solving their particular R\&V problems.

In the following the most important arguments are provided that reveal why the current stateof-the-art R\&V-As are of little value for R\&V-R.

- A common definition of R\&V-A defines R\&V-A as " $a$ methodology to determine the nature and extent of risk by analysing potential hazards and evaluating existing conditions of vulnerability that together could potentially harm exposed people, property, services, livelihoods and the environment on which they depend" (UNISDR 2009a). This definition lacks a policy perspective, but based on such a definition research on R\&V-As has sized up over the last decade, as vulnerability has gained wide recognition for being a major driver of risk (Cf. II.2.3). Such assessments barely address specific policy problems and only very simplistically describe their purpose, such as "appropriate scope", "guiding decision-making", and "making right choices" (Birkmann 2006b; Angela Queste, Peter Lauwe 2006; Hinkel 2011; UNISDR 2008; Schröter et al. 2005).

- The many scientific disciplines addressing R\&V in the context of socio-environmental systems led to the emergence of different competing frameworks and their respective R\&V-A types and methodologies that build their assessment logic upon different scientific traditions (Turner et al. 2003; Füssel, Klein 2006; Metzger, Schröter 2006), each suggesting slightly different $R \& V$ causalities and therefore applying different indicators and their combination when conducting R\&V-As (Patt et al. 2009a; PROVIA 2013b). This confuses policy makers, especially when scientists insist on their approach as the most appropriate to guide indicator definition and data aggregation (Patt et al. 2009a).

- From a policy perspective, R\&V-A that are built upon scientific categories and terminology such as susceptibility, coping capacity and adaptive capacity (Wisner et al. 2004), revealing for example separate susceptibilities, coping and adaptive capacity 
indicators and indices (Turner et al. 2003; Marion Damm 2008; Welle et al. 2012; Carreño et al. 2007; Damm 2010; Cardona 2006a; Fekete 2010; Garschagen 2014), cause confusion amongst R\&V-R practitioners. This is because the terminology used in R\&V science is fuzzy (Cf. IV.3.1) and too broad to be meaningful (Schröter et al. 2005).

It can be concluded that the utility of most R\&V-As does not go beyond facilitating R\&V communication about the role risk and vulnerability play in R\&V manifestation, as well as making decisions about the need to invest in R\&V-R (Cf. Step 1 of the R\&V-R-process, III.4), also because most research projects that produce $R \& V-A s$ are not embedded within $R \& V-R$ processes. So far, I have not come across any literature or approach dedicated to elaborate on the role risk and in particular vulnerability assessment can play for the process of R\&V-R, providing guidance on how, specifically, R\&V-A can support the elaboration, assessment, selection, and implementation of R\&V-R measures. Only Hinkel makes an important point by saying that many R\&V-As are lacking a clear definition of their scope, paying little attention to how the different determinants of R\&V interact or are connected (Hinkel 2011), often confusing scientists in determining which indicators to assign to which category, thus limiting its use for $R \& V-R$ in practice.

\section{IV.5.2 Framing Applied Risk and Vulnerability Assessment based on the FARVAR Framework}

The FARVAR (Cf. IV.4) represents a vehicle for resolving the stated mismatch between the proliferation of scientific R\&V-As and their little utility for R\&V-R (Cf. I.2 and IV.5.1). The FARVAR fully dedicates its objective to the conceptualization of R\&V-A in such a way as to provide scientific decision support for practitioners to effectively minimize potential impacts, ideally prior to the anticipated occurrence of a natural hazard (Farrell et al. 2001). The following three cornerstones of the FARVAR underpin its utility to act as a hub for all types of policy focussed scientific R\&V-As:

- The FARVAR provides normative guidance for structuring applied R\&V-A based on the tangible R\&V-R-nomenclature (Cf. III.3). It facilitates the need to assess those causalities and pathways within the social and environmental systems that reveal a lack of effective R\&V-R performance, whether in the context of anticipation, preparedness, or prevention and their subsequent components, tasks and measures. For quantitative 
assessments this means measuring the gap between desired and factual accomplished R\&V-R performance (IV.4.1). Qualitative assessments focus more on the factors and contexts that reveal such gaps.

- The FARVAR facilitates multidisciplinary scientific research by accommodating the different schools of thought in R\&V science (Cf. II.3) when aiming to understand R\&V causalities (Cf. II.3 and IV.2) for a specific R\&V-R domain, component, task, or measure. For example, for understanding the lack of hazard mitigation as a result of environmental degradation, the provisions of Turner et al. 2003 can be valuable that look at social-ecological interacting factors. Or, for example, for understanding the rural households' lack of capacity to invest in protective infrastructure, the provisions of the livelihood framework or structuration theory (Cf. II.3) that focus on actors might be helpful.

- The FARVAR facilitates the integration of R\&V-A into R\&V-R decision-making. Based on the FARVAR and the R\&V-R decision-making process (Cf. III.4), an iterative process of applied scientific R\&V-As and R\&V-R decision-making can be framed. Many scholars suggest that R\&V-A is done prior to R\&V-R decision-making, thus implying a linear process of R\&V-A and R\&V-R (Birkmann et al. 2013a; Bogardi, Birkmann 2004; Abarquez, Murshed; UNISDR 2009a)(ISO 31000 - risk management ${ }^{4}$ ). But what increases the utility of applied R\&V-A is that it is embedded within the proposed R\&V-R-process (Cf. III.4). For each step of R\&V-R decision-making R\&V-A plays a valuable role as will be shown in Chapter IV.5.3. Hence, the decision about how R\&V should be assessed is determined by the requirements of decision-making within the R\&V-R process, whether taking decisions about which $R \& V-R$ domain or component to invest in, or to elaborate, assess, select, implement, and monitor selected R\&V-R tasks and measures. Hence, R\&V-A provides decision support to iteratively navigate through the different steps of the R\&V$\mathrm{R}$ process. This means that $\mathrm{R} \& \mathrm{~V}$ s are assessed and decisions about options taken to reach the next level of $R \& V-R$ decision-making, where again different $R \& V$-As are required for taking the corresponding subsequent decisions.

\footnotetext{
${ }^{4}$ See: http://www.iso.org/iso/home/standards/iso31000.htm
} 
To conclude, the FARVAR promotes applied scientific R\&V-A that responds to the needs of the particular end-user applying it (Farrell, Jäger 2005). Consequently, it promotes a social process that links scientific knowledge to policy making (Mitchell et al. 2006). Thereby, R\&V-A and R\&V$\mathrm{R}$ refer to an iterative process, in which the development of R\&V-A -methods, -indicators, and information packages follow the specific needs for accomplishing the different stages of the R\&V-R-decision-making process and for fulfilling user requirements (Cf. IV.5.3). Therefore, it is not the goal of applied R\&V-A to develop a methodology and an R\&V-A information package for a specific scientifically determined R\&V component (might it be a single vulnerability, hazard or risk product), but to process, assemble, and transform the results into information packages (aggregated and disaggregated, mapped and documented) tailored to comply with R\&V-R practitioners requirements and capacities. This includes the validation of assessment methods and products through multi-stakeholder dialogues and institutionalized feedback mechanisms on the basis of R\&V-R experiences.

\section{IV.5.3 Integrating Risk and Vulnerability Assessment into R\&V-Reduction Decision-making}

The key particularity of the proposed applied R\&V-A approach is that for every step in the process of $R \& V-R, R \& V-A$ is different by purpose, content (e.g. indicators), and type of the respective $R \& V-A$ information package (way of presentation, semblance of information and data), designed according to the specific requirements of each $R \& V-R$ step aiming at taking knowledge based decisions. Thereby, the main assumed purpose and utility of R\&V-A in the process of $R \& V-R$ is

to provide decision support for elaborating, assessing, selecting, and implementing the most effective $R \& V$ - $R$-domain, $R \& V$ - $R$-component, $R \& V$ - $R$-task, and $R \& V$ - $R$-measure to increase the effectiveness of $R \& V-R$ performance ${ }^{5}$.

\footnotetext{
${ }^{5}$ For example, for the development of efficient recovery instruments such as compensation schemes for impacted households, the knowledge of those having unusual difficulties to recover is required. Detailed damage assessments on the household level as well as generating knowledge of their socio-economic conditions (e.g. income, land
} 
How exactly such an approach towards $R \& V-A$ contributes to more effective $R \& V-R$ is subject to empirical testing in the case study and final conceptualization.

\section{IV.5.3.1 R\&V-A Serving the Anticipation of R\&V for Taking Decisions About the Need for Investment in Disaster R\&V-R}

This step refers to seeking consensus about the need to engage in R\&V-R and about determining whether the anticipated $R \& V s$ are tolerable or not. Anticipating $R \& V s$ is an important precondition for entering an R\&V-R process, based on the assessment of subjective concerns and R\&V perceptions of stakeholders as well as scientific R\&V-A (Renn 2008; Kloos et al. 2013). It is the responsibility of key social actors (e.g. authorities, NGOs etc.) to continuously search for early warning signs about emerging or future R\&Vs. Thereby, various R\&V-A approaches "on the market" are useful to raise awareness about emerging R\&V conditions and factors, identify areas where interventions are needed, and support responsible entities to allocate budget and resources for investments in R\&V-R in the short and long-term. Although not made explicit, most R\&V-As at present can be attributed to this type of utility. For example, indicator and index based assessment types (Welle et al. 2012; Cutter et al. 2003; Cardona 2006a) focus the discussion on generic factors of $R \& V$, thereby facilitating $R \& V$ communication and raising the awareness about the role hazard, exposure, and vulnerability play, and showing regions where urgent intervention is needed. Another R\&V-A approach is to conduct impact assessments based on past experiences (damage and losses) to locate most vulnerable or risky areas in regions of the world (Dilley 2006), or based on current generic and hazardindependent sensitivity assessments (baseline) to estimate the impact of a defined hazard. A step forward for anticipating future R\&Vs is the development of future R\&V, vulnerability, and impact scenarios (Birkmann et al. 2013b; O'Neill et al. 2015) by also taking into account the effectiveness of potential $R \& V-R$ adjustments and adaptations to prevent an under or overestimation of residual impacts and vulnerabilities (Reilly, Schimmelpfennig 2000; Risbey et al. 1999; Smith et al. 2000). But also single assessments and modelling of environmental system behaviour indicating tipping points, hazard occurrence probabilities, magnitudes and 
geographic distribution, as well as exposure, can contribute to support the search for "early warning signs" and support decisions about the tolerability of emerging and future R\&Vs.

Often such assessments remain in the scientific arena. To increase their utility for policy, institutionalized mechanisms are required, e.g. within and between authorities, that enable the regular exchange of data to discover trends in specific areas such as sectors, and discuss the results for decisions about whether to invest in R\&V-R (Kloos et al. 2013). Hence, a type of R\&VA focussing on institutions and their performance can also address the causal structure of such conditions at different administrative levels, providing decision-making support on how to improve the systematic and coordinated anticipation of emerging R\&Vs.

\section{IV.5.3.2 R\&V-A Supporting Decisions on the Appropriate R\&V-R-Domain}

Once the need for $R \& V-R$ is decided upon, the most feasible and appropriate $R \& V-R-d o m a i n$ has to be explored enabling to identify and decide on an acceptable level of protection. In some cases implementing good preparedness structures might be sufficient; in others investment in prevention and transformational change is more appropriate. Ideally, the two domains preparedness and prevention are not mutually exclusive and shall not be played out against each other; in most cases however they have to be understood as complementary and interdependent requiring simultaneous adjustments in cases potential threat and vulnerability parameters undergo significant change. It is the uncertainty in forecasting the magnitude and distribution of hazard events that requires strategies on how to accommodate unforeseen possible threats and potential disastrous events.

But in reality, decisions are often made under conditions of limited resources and feasibility constraints requiring the prioritization of investments in $R \& V-R$ which are subject to political negotiation about protection goals (in the area of preventing loss of life, loss of livelihood, maintaining ecosystems health, sector specific goals, etc.), and to identify the best feasible, most effective and less costly R\&V-R solution.

In support of this "cost-effectiveness" and "multi-criteria", assessments can be useful (UNFCCC 2011) for which R\&V-A can play an important role. R\&V-A provides the baseline to define R\&VR-goals and to estimate social and monetary costs as well as the effectiveness of a specific strategy. For example, saving people's lives in coastal Indonesia by means of establishing an 
early warning system is less costly than resettling large parts of the coastal population due to low tsunami occurrence probability, high magnitude/high degree of exposure of cities and communities to tsunamis, as well as relatively low costs to ensure safe evacuation. Whereas, investments in protection and resistance mechanisms might not be feasible for many local communities where the geographic and social setting is unfavourable, and where protection and livelihood infrastructures have not the capacity to resist the destructive power of tsunamis. For other threat contexts, such as sea level rise or flooding, exposure and capacity conditions might be different and call for other solutions, where, for example, investing in dyke infrastructures or elevating settlements has a better cost-effectiveness ratio than resettlement.

The examples presented indicate that the role of R\&V-A, by assessing the difference between desired and accomplished R\&V-R performance for a specific strategy, allows for comparing and assessing the feasibility and costs of each optional R\&V-R-strategy. Often, hazard and exposure data are used for such evaluations, but rarely the function of vulnerability.

\section{IV.5.3.3 R\&V-A Serving the Decision About Appropriate R\&V-R-Tasks}

Following the logic of the R\&V-R-process, decisions on strategy-specific R\&V-R-tasks are to be taken (Cf. III.3). They are often reflected by existing pre-defined standards such as they exist in the different components of preparedness (e.g. early warning, relief, recovery) and prevention (retreat: principles and guidelines for resettlement; protection; building codes). But in many cases, they require hazard and exposure dependent contextualization; e.g., building codes are different for earthquakes or for cyclones or flooding. This accounts for many other R\&V-R-tasks, such as the establishment of warning dissemination systems and evacuation infrastructure, where hazard arrival times determine the speed and means of warning communication. Anticipated impacts, often as a measure of exposed monetarily valued assets and social conditions (e.g., number of people exposed), can help to define how R\&V insurance and transfer schemes (enhancing recovery) need to look like. The knowledge of such high resolution parameters fosters also the mutual understanding of the different institutions' perspective on how to define R\&V-R-tasks, especially when the elaboration of efficient tasks heavily depends on cross-scale institutional cooperation (national to local), such as the development of Standing Operational Procedures (SOPs) for warning dissemination, or developing criteria for identifying relocation sites, etc. 
IV.5.3.4 Risk and Vulnerability Assessment Serving the Elaboration, Assessment, Selection, and Implementation of R\&V-R-Measures

When strategy-specific R\&V-R-tasks have been selected, decisions on task-specific measures are to be taken and implemented. Often it is not known what the bundle of task-specific effective measures shall consist of for achieving a defined R\&V-R-task-specific goal, as the most effective types of capacities a system of interest requires are also unknown. For example, what are the factors and conditions that pose an obstacle or facilitate people's participation in relocation programmes, investment in drought resistant crops, implementation of building codes, participation of people in R\&V insurance schemes, responses to tsunami warnings and successful evacuation? When these factors are known, measures can be defined to develop and enhance capacity. By circumstance, capacity parameters that are effective are not generic but highly contextual. For example, in some cases the successful investment in drought resistant crops depends rather on monetary capacities, in other cases, it is a matter of how farmers value their crops. Also, the implementation of building codes is rather a matter of skill than law enforcement or corruption, or vice versa. Hence, R\&V-A can support such decisions by assessing the degree to which the identified capacity requirements fail to perform effectively and efficiently, which, according to the R\&V-R-Framework, reflects the degree of vulnerability and risk. Based on the results, also the costs of the required investments can be calculated. Thus, risk and particularly vulnerability assessments can contribute to calculate the monetary, but also the non-monetary costs of implementing specific R\&V-R-measures, thus contributing to the cost-effectiveness analysis. This also helps to choose the most efficient among a set of different effective measures available.

IV.5.3.5 Risk and Vulnerability Assessment Serving the Monitoring and Evaluation of Risk and Vulnerability Reduction

After $R \& V-R$ measures have been implemented, $R \& V$ patterns might change as they are dynamic over time, the same as society (MOVE 2010). Moreover, nonlinearity, complexity, and emergence are key characteristics of disaster risk systems (Birkmann et al. 2013a), requiring adjustment in the R\&V-R system that addresses both traditional and emerging topics (Fritzsche et al. 2015). Hence, next to anticipating future R\&Vs, the continuous monitoring and evaluation of overall R\&V-R performance is necessary (PROVIA 2013b). Here R\&V-A can play an important 
role (Fritzsche et al. 2015) by measuring, based on the provisions of the FARVAR, the residual gap between factual and required R\&V-R performance. Such assessment can be done based on the assessment framework, data sources, and information package design already available. However, changes in vulnerability factors can occur when R\&V-R solutions are changed to satisfy new requirements.

\section{IV.6 Conclusion}

The major goal of the FARVAR as developed here is - without losing scientific ground - to redirect the $R \& V$ assessors' focus from translating scientific vulnerability frameworks into assessment schemes of utility for processes of R\&V-R. Being first of its kind, the FARVAR strives to bridge the gap between scientific R\&V-A (e.g.; measuring risks based on their determents such as susceptibility or coping capacity) and the requirements for applied R\&V-As in order to advance overall $R \& V-R$ in practice. It links $R \& V-A$ with $R \& V-R$ and is the result of a comparative compatibility analysis of terms and causalities used by R\&V scholars and practitioners (Cf. IV.2). In the following, the major concluding points regarding this carefully developed framework are presented:

- The FARVAR framework stresses that unsafe conditions in which societies live in are the outcome of lack of capacity, whereas capacity is strongly linked to the capacity to anticipate, prevent, and prepare for damaging events and processes. In their absence, exposure and susceptibility to harm can evolve.

- The framework explicitly delineates different causality paths of vulnerability which lead to cumulative $R \& V$. These causality paths are streamlined and normatively framed by the R\&V-R nomenclature (Cf. III.3), a purposeful and grounded substitution of the inconsistent capacity terminology in contemporary R\&V science (Cf. II.4.1, IV.3.1). It provides guidance on how to trace back those factors and processes that constitute vulnerability and risk (Cf. IV.4.3).

- To be more specific, the failure or absence of R\&V-R performance unfolding unsafe conditions is rooted in R\&V-R specific and generic development patterns in a specific societal and environmental setting. Hence, the framework acknowledges the pivotal role of 
societal configurations that influence R\&V-R-performance as a whole, including options for reducing $R \& V$ in the long-term (Cf. III.2).

- Hence, the framework promotes types of R\&V-As that help to identify the prevailing factors and conditions that constitute the lack of effectiveness of a range of potentially envisaged R\&V-R domains, -components, -tasks, and -measures most likely revealing loss and damage in the course of future hazardous events. By putting emphasis on searching and assessing factors that result in lack of $R \& V-R, R \& V-A s$ focus on those physical, spatial, and social phenomena and conditions that determine the effectiveness of R\&V-R performance, hence becoming useful for R\&V-R (Cf. IV.4.4). 
New Framework for Applied Risk and Vulnerability Assessment Research (FARVAR) 


\section{Case Study Part I - Rationale and Overview}

\section{V.1 Introduction}

This chapter introduces the case study research presented in the following three chapters: the R\&V-A framework development process (chapter VI), the empirical research results (chapter VII), and finally the evaluation of the utility of the conducted R\&V-A for different processes of R\&V-R (chapter VIII).

The rationale of the case study is to act as a test-bed to demonstrate that the developed FARVAR framework (Cf. IV) has a distinct value in promoting types of applied R\&V-As that are useful for R\&V-R (Cf. I.3, IV.4.4). Hence, it addresses RQ 2.1 of the dissertation, and aims to show how the FARVAR can be translated into any context of R\&V-R. Moreover, the case study aims to showcase - through providing empirical evidence - the utility of R\&V-A for effectively navigating through different stages of decision-making within the elaborated R\&V-R-process (Cf. III.4, IV.5.3), and hence also addresses RQ 2.2.

The case study does not cover the entire R\&V-R process (1-7), but steps 4 -5 (Cf. III.4, Step $1-5$, Figure 6), a phase of $R \& V-R$ decision-making where both the $R \& V-R$ domain and its respective component have already been decided upon: namely the establishment of a tsunami early warning system in Indonesia. The decision of Indonesia to invest in the R\&V-R-domain "preparedness" and its corresponding preparedness component "Early warning system" was purely political, not based on the provisions of the iterative process of R\&V-A and R\&V-R proposed in chapter IV.5.3.2. Nevertheless, the case study is unique, as it presents a full and integrated bundle of "R\&V-A-information packages" covering the entire range of complementary R\&V-R-tasks for establishing a people-centred end-to-end tsunami early warning system. Hence, the transferability of the approach onto other R\&V-R-decision-making steps becomes more obvious and allows for discussing its results on a broader level in the conclusions of this dissertation (Cf. IX.).

In the following the context of the case study is described, which is the establishment of the Tsunami Early Warning System in Indonesia (Cf. V.2), as well as the case study sites in Indonesia (Cf. V.3) and the structure of the case study (Cf. V.4) are being presented. 


\section{V.2 A Tsunami Early Warning System for Indonesia - A Response to the 2004 Indian Ocean Tsunami}

\section{V.2.1 Response to Tsunami Threat in Indonesia}

Tsunamis pose a tremendous threat to societies. Their destructive power has been well shown in the past 30 years. Worldwide, nearly 250.000 people have been killed, of which Indonesia shares the largest amount (Emdat, $\left.2013^{6}\right)$. Since the early $19^{\text {th }}$ century, earthquakes in Indonesia unleashed around 100 tsunamis $\left(\mathrm{BNBP}^{7}\right.$ and Hidayati 2012), amongst them the devastating 2004 Indian Ocean tsunami that left in its wake more than 170,000 casualties and 500,000 displaced people. Frequent earthquakes and tsunamis followed.

Although, on average, every three years small and medium size tsunamis occur in the Indonesian archipelago and a large and growing proportion of Indonesian citizens live exposed to tsunamis (Latief Hamza et al. 2000). It has been estimated that approximately 4.35 million Indonesians live in tsunami exposed areas (Post et al. 2009). Achieving long term exposure reduction by means of retreat (resettlement) is the less favourable R\&V-R-component to be selected. In fact, although the number of exposed Indonesians is very high the low probabilities of tsunamis occurring in certain specific localities along the Indonesian coastline (all the tsunamis occurred so far have impacted different locations), do not justify to remove, for example, large coastal cities even if they are located in zones potentially exposed to coastal tsunamis.

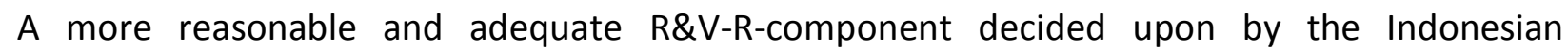
government was the establishment of a Tsunami Early Warning System (TEWS) in order to at least reduce the mortality risks of tsunami events. Indeed, Early Warning Systems (EWS) play a key role for reducing mortality risk. "If an effective tsunami early warning system had been in place in the Indian Ocean region, thousands of lives could have been saved" (UNISDR-PPEW).

\footnotetext{
${ }^{6}$ EM-DAT: The International Disaster Database, available at http://www.emdat.be/ (accessed 18.8.2013)

7 Indonesian National Disaster Management Agency (BNPB), “Data and Information about Disasters in Indonesia”, available at: http://www.dbi.bnpb.go.id, accessed 18.8.2013
} 
For example, in Bangladesh the establishment of a cyclone warning system reduced the amount of cyclone victims in the period 1970-2007 from half a million to a few thousands ${ }^{8}$.

A consortium of German research institutions under the leadership of the GeoForschungsZentrum Potsdam (GFZ) proposed to the German government the installation of a Tsunami Early Warning System in Indonesia. In March 2005, the governments of Germany and Indonesia signed a joint declaration to collaborate for the establishment of such a system. The cooperation included the development of a Tsunami Decision Support System as well as technical developing national and local capacities to disseminate warnings and to adequately respond to them Rudloff et al. 2009; Lauterjung et al. 2010b; Lauterjung et al. 2010a; Hanka et al. 2010; Roessler et al. 2010; Boebel et al. 2010; Gayer et al. 2010; H. Spahn et al. 2010; Denis Chang Seng 2010)

\section{V.2.2 People Centred and End-to-End Warning Systems}

In 2006, a global survey of early warning systems found that while some warning systems were well advanced, there were many gaps and shortcomings, especially in developing countries and in terms of effectively reaching and serving the needs of those at risk. In 2007, many countries reported good progress in developing early warning systems. However, the reports submitted also showed gaps between the development of regional and national hazard warning capacities and the development of effective local capacities to receive and use early warnings to save lives (UNISDR-PPEW). This observation applies very well to the case of Indonesia.

Although Indonesia had received a tsunami warning from the Pacific Tsunami Warning Centre on 26th December 2004 and in May 2007, why was it not passed on to the local communities through the Indonesian authorities? It became evident that the national authorities were lacking adequate institutionalized mechanisms to handle warnings received from the international community. Moreover, local communities were not prepared to respond to warnings.

\footnotetext{
${ }^{8}$ British Red Cross: Early warning saves lives, 2009, Available at: http://www.redcross.org.uk/news.asp?id=95271 (17.12.2009)
} 
Therefore, the German contribution to the Indonesian Tsunami Early Warning System (InaTEWS) was not only designed to provide the technology to detect tsunami events in due time but also to support the development of an InaTEWS ensuring that warnings reach communities exposed and that these communities know how to respond adequately to them. Putting more emphasis on efficient response capabilities has been promoted by UN/ISDR and been identified as one of the priorities of the Hyogo Framework for Action (UNISDR 2005).

\section{V.2.3 R\&V-A for Establishing an Efficient Indonesian Tsunami Early Warning System}

For the development of knowledge-based response capabilities of organizations and the identification of population vulnerability, R\&V-A plays a key role. Hence, one Working Package of the German-Indonesian research and development project has been dedicated to R\&V-A. The research aimed at developing $R \& V-A$ products that support the development of effective response structures. Hence, the case study presented in this chapter is the result of the efforts made by the German science community to contribute to the establishment of InaTEWS. The entire assessment process has been accompanied by the involvement of a range of stakeholders as proposed by (Renn 2008). Throughout the entire assessment process five multistakeholder workshops were held funded and organized by the GITEWS project, conceptualized and implemented to large parts by the author of this dissertation. The workshop participants were members of the "Joint German-Indonesian Working Group on R\&V-A" on behalf of the scientific community, as well as representatives from national and local authorities and from local NGOs. 


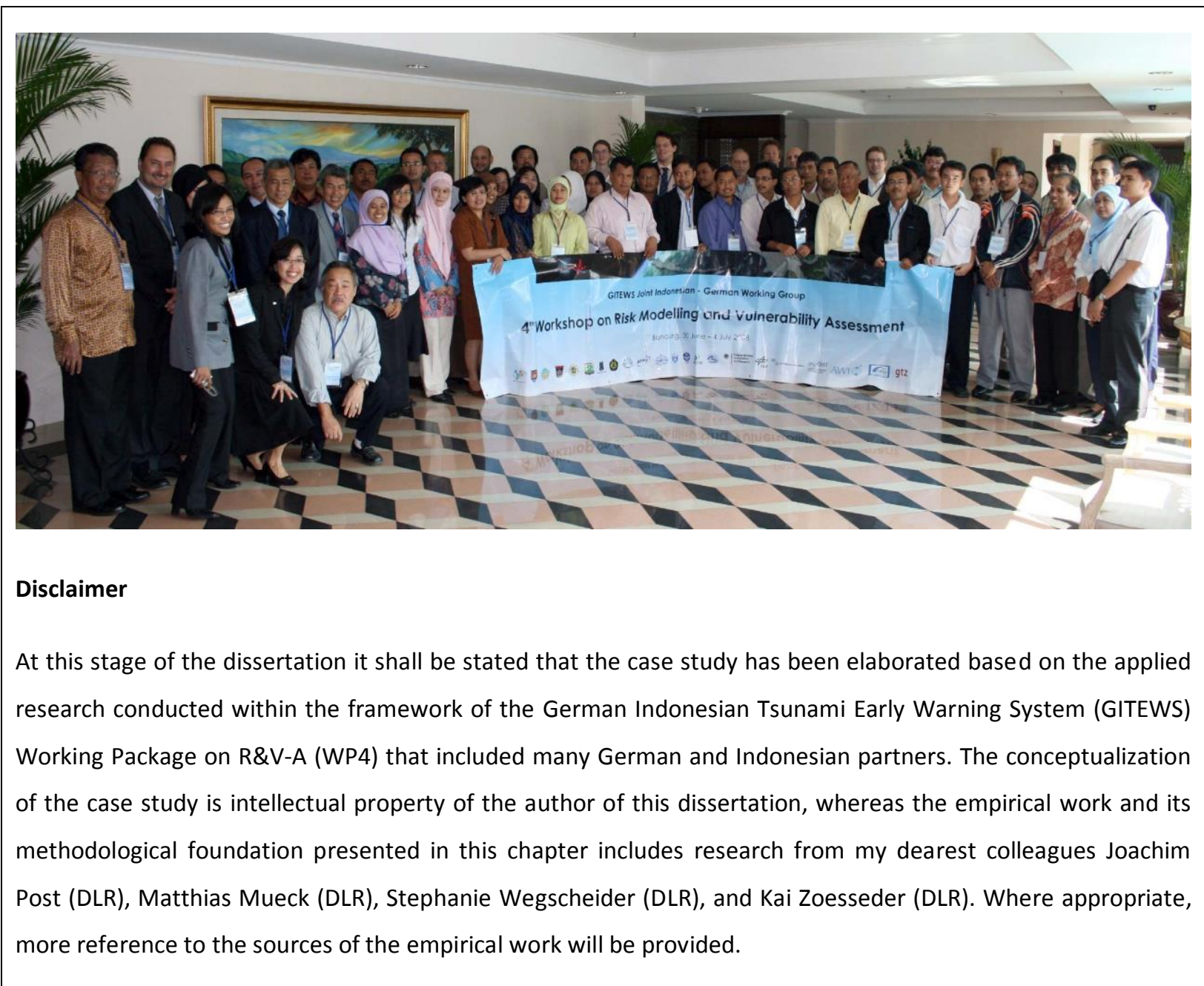

\section{V.3 Research Area}

Indonesia, a tropical country with more than 13,000 islands and 3.2 million $\mathrm{km}_{2}$ of sea water lies on three crustal plates (the Eurasian, the Pacific, and the Indian-Australian plates), so that earthquake zones are found in almost all parts of the country $\left({ }^{9} \&^{10}\right)$. The regions / districts for the case study had been defined by the GITEWS consortium, who selected priority areas for establishing an effective end-to-end TEWS in Indonesia, arguing that the district of Padang (Province West Sumatra) has comparably high probability of tsunami R\&V and that the district

\footnotetext{
${ }^{9}$ Indonesian National Disaster Management Agency (BNPB), "Data and Information about Disaster in Indonesia, available at: "http://www.dbi.bnpb.go.id
}

${ }^{10}$ http://en.wikipedia.org/wiki/Geography_of_Indonesia 
of Cilacap (Province Central Java) and Badung (Province Bali) account for hotspots of exposure along the Sunda Trench. Most potential tsunamis are classified as local in scale and their travel time is approximately $10-30 \mathrm{~min}$ (Permana 2005). That tsunamis and earthquakes pose a threat to the Indonesian population is obvious. With about 237.6 million people (BPS ${ }^{11}$ ) Indonesia has the fifth-largest population in the world. In 2003 the largest share of the population was living in low lying coastal areas (60\%), and about $17 \%$ in rural coastal areas (BPS ${ }^{12}$ ). In the following, all three case study areas will be briefly introduced.
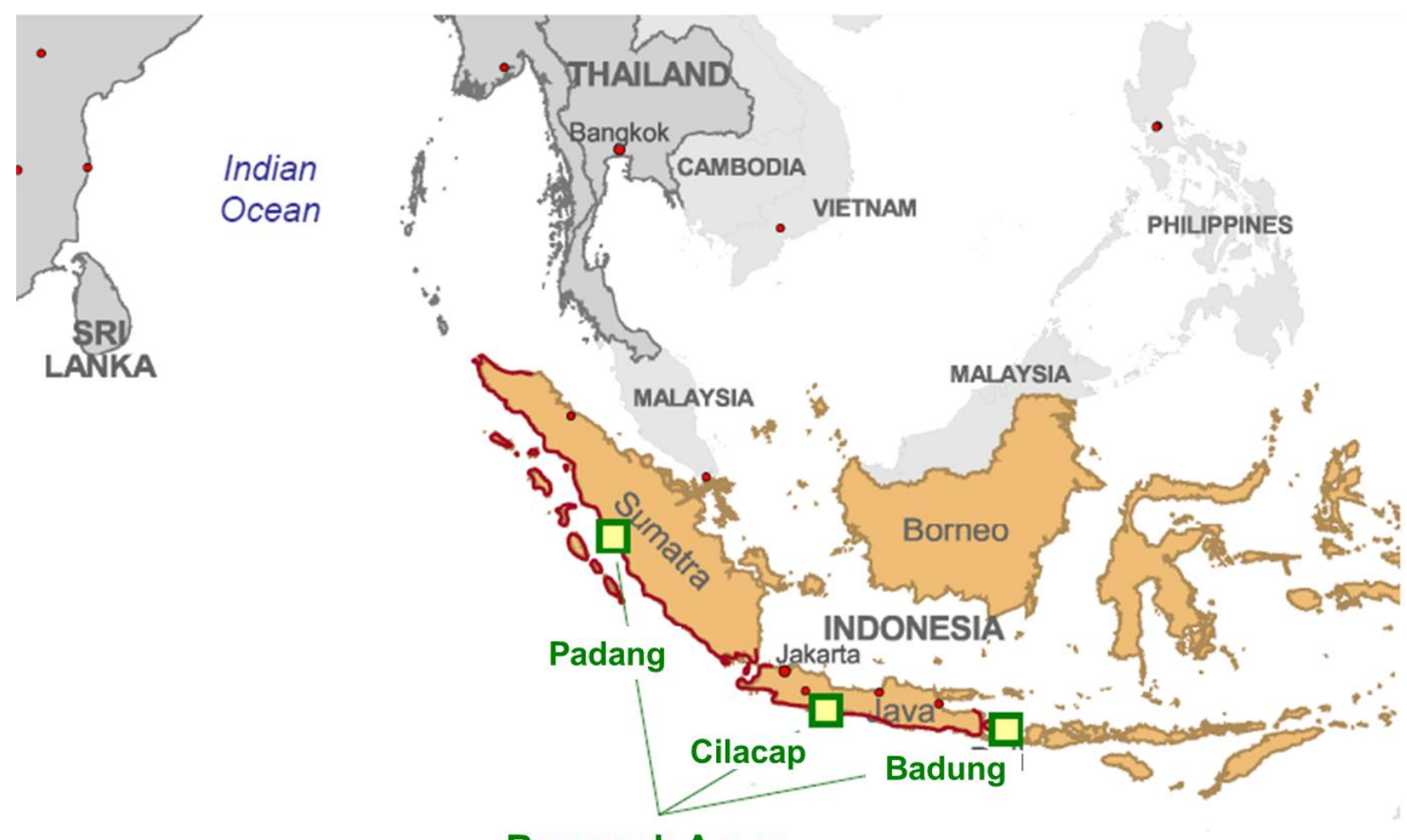

Research Areas

Map 1: Overview of research locations

\footnotetext{
${ }^{11}$ Badan Pusat Statistik Indonesia (BPS), available at www.bps.go.id/eng

${ }^{12}$ Badan Pusat Statistik Indonesia (BPS), available at www.bps.go.id/eng
} 


\section{V.3.1 District of Cilacap, Java}

Cilacap is a district in the south-western part of the Central Java province. Its capital is Cilacap, which is a municipality (town) in its own right. Cilacap has a relatively flat topographical terrain and the highest population in the south coast of Java (Kongo, W. et al. $2009^{13}$ ). Cilacap has experienced major earthquakes and tsunamis in the past. This is due to its location at geological plate boundaries between the Australian and the Eurasian plates that represent a subduction zone with high seismic activity and hence, a major source of tsunamis that might affect Cilacap also in the future. A tsunami event in 2005 - known as the Pangandaran tsunami - occurred as a result of thrust-faulting on the boundary between these geological plates and generated subsequent three to five meter high tsunami waves. It took 147 lives, devastated beaches, damaged 435 fishing boats, inflicting material losses to the amount of about 9 million US\$ (Cousins et al. 2007). Due to the area's proximity to the subduction zone and its seismic history, the science community presumes that tsunamis will affect Cilacap again in the future, although a precise prediction is not possible.

\section{V.3.2 District of Badung, Bali}

Badung is a low laying coastal district of Bali. It has an area of $418.52 \mathrm{~km} 2$ and a population of 543,332 with a density of $1,293.37$ inhabitants per square kilometre according to the 2010 BPS census survey ${ }^{14}$. It has undergone a population boom in the last decade, becoming the largest suburban area of Greater Denpasar. It is one of the most popular destinations in Indonesia for domestic and international tourists. Badung is considered the center of tourism activities in Bali. An estimated number of $60.000-70.000$ people visit this area on average every month. As with Cilacap, Badung is also starkly exposed to tsunamis located close to the Sunda Trench, the subduction zone where the Indian-Australian plate slides under the Eurasian Plate. Realistic analysis allows no better prognosis than to anticipate that tsunami waves would need only 20 to 80 minutes to reach the coast (Post et al. 2009).

\footnotetext{
${ }^{13}$ Available at: http://adsabs.harvard.edu//abs/2009AGUFMNH31B1114K

${ }^{14}$ Census 2010 Indonesia, available at: http://sp2010.bps.go.id/
} 


\section{V.3.3 District of Padang, Sumatra}

Padang is the largest city in the western coast of Sumatra and the capital of the West Sumatra province. It has an area of 694.96 square kilometres and a population of over 1,024.906 people according to the 2010 BPS census survey ${ }^{15}$. The settlement is concentrated in the low laying coastal area, occupying about 3-5 km from coastline to hinterland. Padang is considered as highly exposed to tsunami threats. Along offshore of the Sumatra coastline the boundaries of the Indian plate are forced beneath the Australian plate. The plates are sliding north-eastward at about $7 \mathrm{~cm}$ per year and dipping under the Sunda plate, which Sumatra and Singapore are part of and are well known as the Sunda megathrust. It is widely acknowledged that the region of the Mentawai Islands along the Sunda megathrust and adjacent areas are proven to have a huge seismic moment deficit which has been progressively accumulating since the last recorded major earthquakes in 1797 and 1833 (McCloskey et al. 2008). Hence, various authors draw attention to the substantial tsunami hazard potential in the Indonesian densely populated urban agglomerations such as the city of Padang, with about 850.000 inhabitants located on the western shore of Sumatra. It is well acknowledged amongst numerous scientists that the Sunda megathrust is well advanced in its seismic cycle and may be ready for another large earthquake setting forth the sequence of a series of major earthquakes that had occurred in the late 1300s, in about 1600, and again in the early 1800s (Borrero et al. 2006; McCloskey et al. 2007).

\footnotetext{
${ }^{15}$ Census 2010 Indonesia, available at: http://sp2010.bps.go.id/
} 


\section{V.4 Structure of the Case Study}

This chapter broadly describes the different elements of the case study that represent the macro-methodological approach for testing and evaluating the conceptualized role of R\&V for R\&V-R decision-making. Each of the different elements includes a detailed description of the specific methods and procedure used and presents the results. The first deals with the contextualizing the FARVAR for setting up an tsunami early warning system in Indonesia (Cf. VI), the second provides the empirical work (Cf. VII), and the third, evaluates the utility of the R\&VA results for the elaboration, assessment, selection, and implementation of R\&V-R-tasks and measures in the context of InaTEWS (Cf. VIII).

- Chapter VI: Case Study - Contextualized FARVAR for InaTEWS. Chapter IV.4.4 has elaborated that applied R\&V-A does not build upon one distinct framework defining measurement categories, criteria and indicators, but that the new Framework for Applied Risk and Vulnerability Assessment and Research (FARVAR) (Cf. IV) has the function to guide the process of how R\&V-A requirements are defined and integrated into processes of R\&VR. Accordingly, the challenge of this part of the case study was to showcase how the generically described role of R\&V-A for R\&V-R (Cf. IV.5.3), and particularly the iterative process of R\&V-A and R\&V-R (Cf. IV.5.3), could be translated into the context of the establishment of an effective TEWS in Indonesia (Cf. VI.3). Hence, the R\&V-A framework developed is a result of such a process that includes the definition of R\&V-R-tasks in the context of InaTEWS and of how disaggregated R\&V-information can by concept support the establishment of an effective TEWS.

- Chapter VII Case Study - Empirical Research. This chapter showcases the single steps of the assessment procedure necessary, indicating how to arrive at disaggregated R\&V-Ainformation of assumed utility for accomplishing the defined R\&V-R-tasks in the context of InaTEWS. Results are presented for each of the R\&V-R-tasks, namely (1) the R\&V-A concept; (2) the respective R\&V-A -methods; and (3) the R\&V-A.

- Chapter VIII Assessing the Utility of R\&V-A -Results. In this chapter the empirical results are evaluated according to which degree they are of utility to effectively manage tsunami $R \& V$ in the context of InaTEWS. Thereby, the guiding question is dedicated to enquire into the precise utility of the R\&V-A results for processes of R\&V-R such as the elaboration, assessment, selection, and implementation of R\&V-R-tasks and measures in the context of 
a Tsunami Early Warning System (Cf. VI.3). Figure 9 provides an overview of the logical set up of the case study.

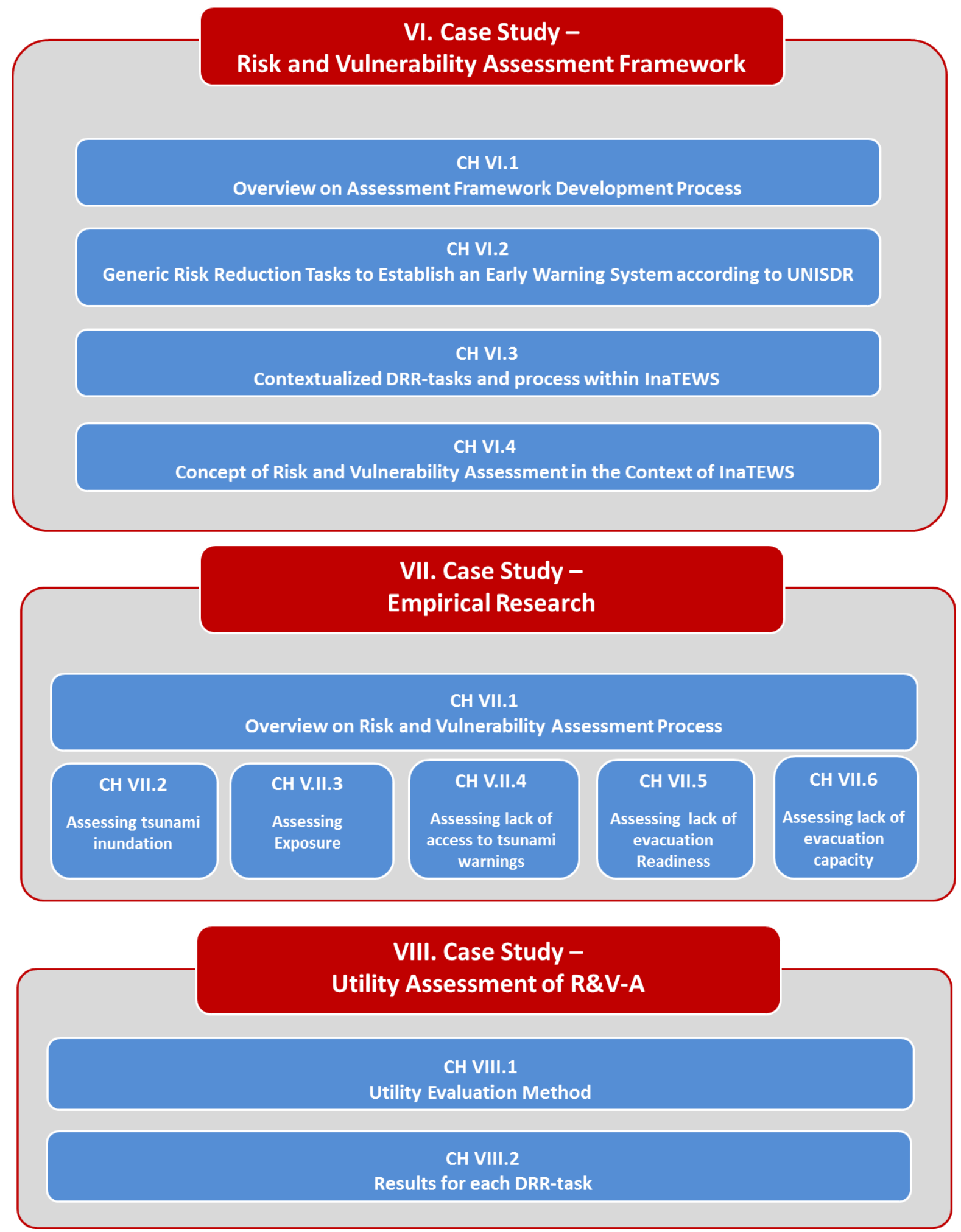

Figure 9 Overview of the case study approach 


\section{Case Study Part 2 - Risk and Vulnerability Assessment Framework in the Context of InaTEWS}

\section{VI.1 Introduction}

The FARVAR framework postulates that applied R\&V-A measures the divide between desired $R \& V-R$ outcomes and current $R \& V-R$ performance and its underlying factors, hence measuring the degree to which a specific R\&V-R-domain, -component, -task and -measure is successfully implemented revealing a certain level of R\&V (Cf. IV.4). Hence, any R\&V-A process starts with defining an R\&V-A framework based on the single domains, components and tasks of the hierarchical R\&V-R nomenclature. The framework has to define whether R\&V-A shall be conducted for the entire process of R\&V-R from the decision upon the need to invest in $R \& V-R$ to the implementation of selected R\&V-R domains, component, tasks and measures, or only parts of it. In this case, the framing and definition of R\&V is done in relation to a TEWS in Indonesia, which will be elaborated in detail in the following chapters (Cf. VI.2VI.3VI.40).

\section{VI.2 Risk and Vulnerability Assessment Framework Development Process}

The framework development process commenced with literature research and a set of qualitative pre-assessments within a multi-stakeholder environment to precisely define the different R\&V-R tasks and measures to set up an effective and people-centred tsunami early warning system in Indonesia and to delineate respective $R \& V$ definitions and $R \& V-A$ requirements. The single steps of the assessment framework construction include the following:

- Defining the R\&V-R tasks of an Early Warning System (Cf. VI.3). By concept, o defining EWS-related hierarchically structured effective R\&V-R-tasks and measures is a precondition for defining R\&V-A requirements. Thereby, the term effectiveness is understood as "the capability of producing a desired result. When something is deemed 
effective, it means it has an intended or expected outcome ${ }^{\prime 16}$. In the context of R\&V-R this means that effectiveness relates to the accomplishment of different objectives included in the diverse set of option-specific R\&V-R-tasks and -measures. Generic R\&V-R tasks are provided by well-known conceptualizations of Early Warning Systems such as the one proposed by (UNISDR-PPEW).

- Defining R\&V-R tasks of a Tsunami Early Warning System in Indonesia (Cf. VI.4). By considering the specific tsunami hazard characteristics in Indonesia (Tsunami Arrival Time, ETA), as well as socio-cultural and spatial settings, the UNISDR-EWS-framework has been modified, resulting in contextualised and complementary R\&V-R tasks, also termed the "tsunami warning reaction scheme".

- Delineating an R\&V-A framework adapted to the specificities of an Indonesian tsunami early warning system (Cf. 0). This step required the definition of R\&V factors that might cause mortality in the course of a tsunami event, categorized according to the different $R \& V-R$ tasks of the tsunami reaction scheme. The process of arriving at a common definition of $R \& V$ and identifying respective $R \& V$ factors had been accompanied by the GITEWS “Joint German-Indonesian Working Group on R\&V-A".

\section{VI.3 Generic Disaster Risk and Vulnerability Reduction Tasks to Establish an Early Warning System}

How to establish an efficient TEWS that covers and protects all exposed communities at the coastline? UNISDR has defined four elements of a people-centred EWS (UNISDR-PPEW), which can, according to the R\&V-R-nomenclature (Cf. III.3.2), be termed R\&V-R tasks. They are generic, and act as a basis for contextualizing R\&V-R tasks and measures for the establishment of an effective people-centred tsunami early warning system in Indonesia (InaTEWS). They reflect the internationally well accepted perspective of UNISDR (UNISDR-PPEW) on early warning systems. To introduce, the establishment of Early Warning Systems requires R\&V-R at the interface of social, technological, and environmental systems (Cf. Figure 10).

\footnotetext{
${ }^{16}$ WIKIPEDIA, available at http://en.wikipedia.org/wiki/Effectiveness (accessed 24.6.2013)
} 


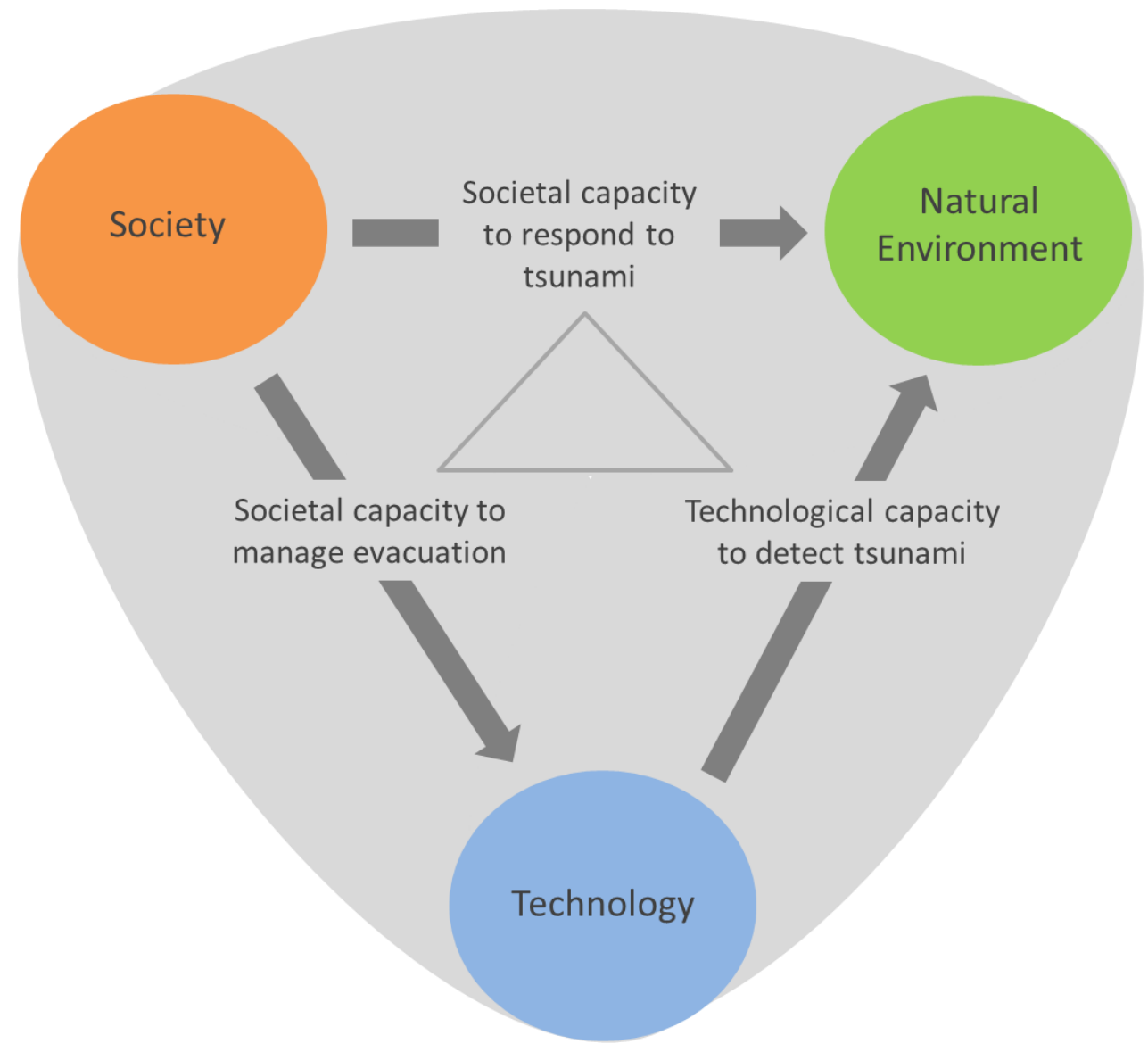

Figure 10 Early warning systems operating at the interface of society, environment and technology

Thereby, the focus is on the social and technological capacities to anticipate threats and establish effective response capacities:

- Hazard Monitoring and Decision Support. This component relates to the development of the hazard detection infrastructure, which includes sensor networks (e.g. for the case of tsunami GPS stations, seismographs, Ocean Bottom Units) and a warning centre in which all the different data are compiled and processed to derive meaningful information on whether a tsunami is going to happen or not. If properly constructed and managed, the event detection infrastructure provides real-time decision support for responsible stakeholders to decide whether to warn or not. The process of decision support provisions and warning decisions by stakeholders is subject to the development of Standing Operational Procedures (SOP) that clearly defines roles and responsibilities. In this respect also local authorities need to be engaged because they also share the responsibility with national stakeholders to warn their citizens. R\&V information can significantly contribute to effective warning decision and SOP development. 
- Dissemination and Coordination. Once a warning is issued, it needs to be communicated to the exposed populations in due time and in a for a layperson understandable manner. Therefore, also here national, regional, and local Standing Operational Procedures (SOP) are to be developed that define modes of warning dissemination amongst authorities and to the general public. Thereby, questions arise such as: How is the public media engaged in the process of warning? Are warnings communicated directly to the general public, or must they first pass through all the levels of governance according to the institutional setup and power system? Who are the authorities that are engaged in the warning process; do they possess the capacities to provide 24-hour emergency services? Which devices are the most effective ones to warn citizens in due time?

- Response Capacities. Response capacities can be diverse depending on hazard specifications, such as hazard type, exposure levels, and the time left from the moment of warning until the hazard occurs. E.g. for drought, if the warning is issued long time before the drought occurs, there are a lot of measures that can be implemented to prevent or mitigate the damage (e.g. food aid to affected populations, setting up irrigation systems, prevention of fire outbreak etc.). In other hazard cases, response mechanisms are required that save lives within a few minutes or hours.

- $R \& V$ Knowledge. R\&V knowledge within this framework specifically refers to the knowledge of probabilities of hazard distribution on land and the question whether elements are exposed to the hazard. In the case of a tsunami, knowledge of the area it has inundated by is necessary for defining the evacuation zone and the deployment of warning dissemination infrastructures such as sirens. But R\&V knowledge is not limited to hazard and exposure assessment. As already defined, vulnerability assessment refers to analysing the underlying factors that determine the likelihood of damage and loss of life during and after an extreme event. In the view of the authors of this guideline, R\&V knowledge is important to increase also the effectiveness of the other elements of a EWS.

In the following, a contextualization of these generic elements for the case of the Indonesian Tsunami Early Warning System is provided. 


\section{VI.4 Contextualized Risk and Vulnerability Reduction Tasks and Processes within InaTEWS}

How shall a tsunami early warning system in Indonesia be established? What are the specificities to be taken into consideration when defining $R \& V-R$ tasks and measures in the context of InaTEWS? This chapter defines and provides an overview of R\&V-R tasks to be accomplished for establishing an effective Tsunami Early Warning System in Indonesia.

In case of a tsunami-genic earthquake along the Indonesian fault-line, tsunamis are anticipated to arrive at the coast between 10 and 70 minutes (Post et al. 2009) posing an extraordinary challenge for the development of efficient event detection and response structures.

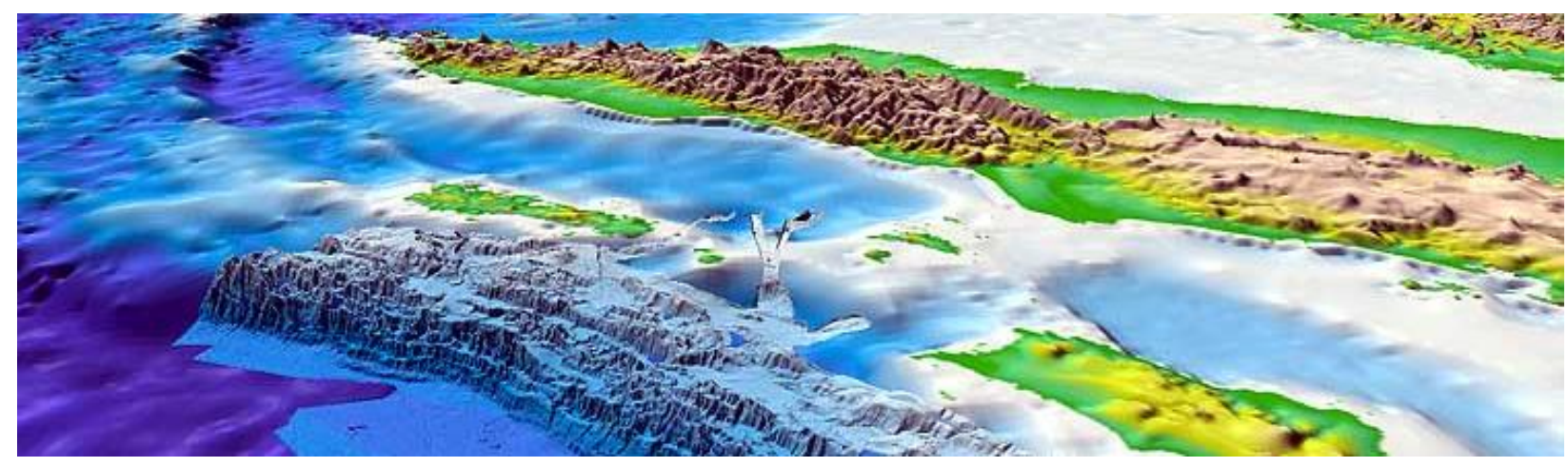

Figure 11 Bathymetry at the coast of West Sumatra in the region of the tsunami-genic earthquake 2004 (Source: GEOMAR Helmholtz-Zentrum für Ozeanforschung Kiel / GITEWS)

Hence, as the available response time to tsunami in Indonesia is not sufficient to safe livelihood assets in due time, the overall goal of InaTEWS is to reduce mortality risk by providing timely access to warnings to the entire exposed population and ensure their safe evacuation. InaTEWS has defined a tsunami early warning and response scheme that represents a sequence of institutionalized actions necessary to accomplish full evacuation before a tsunami hits the exposed communities (H. Spahn et al. 2010). Figure 4 schematically illustrates its sequential order: (1) Event detection, warning decision and dissemination; (2) warning access by the population; (3) evacuation decision; and (4) physical evacuation. 


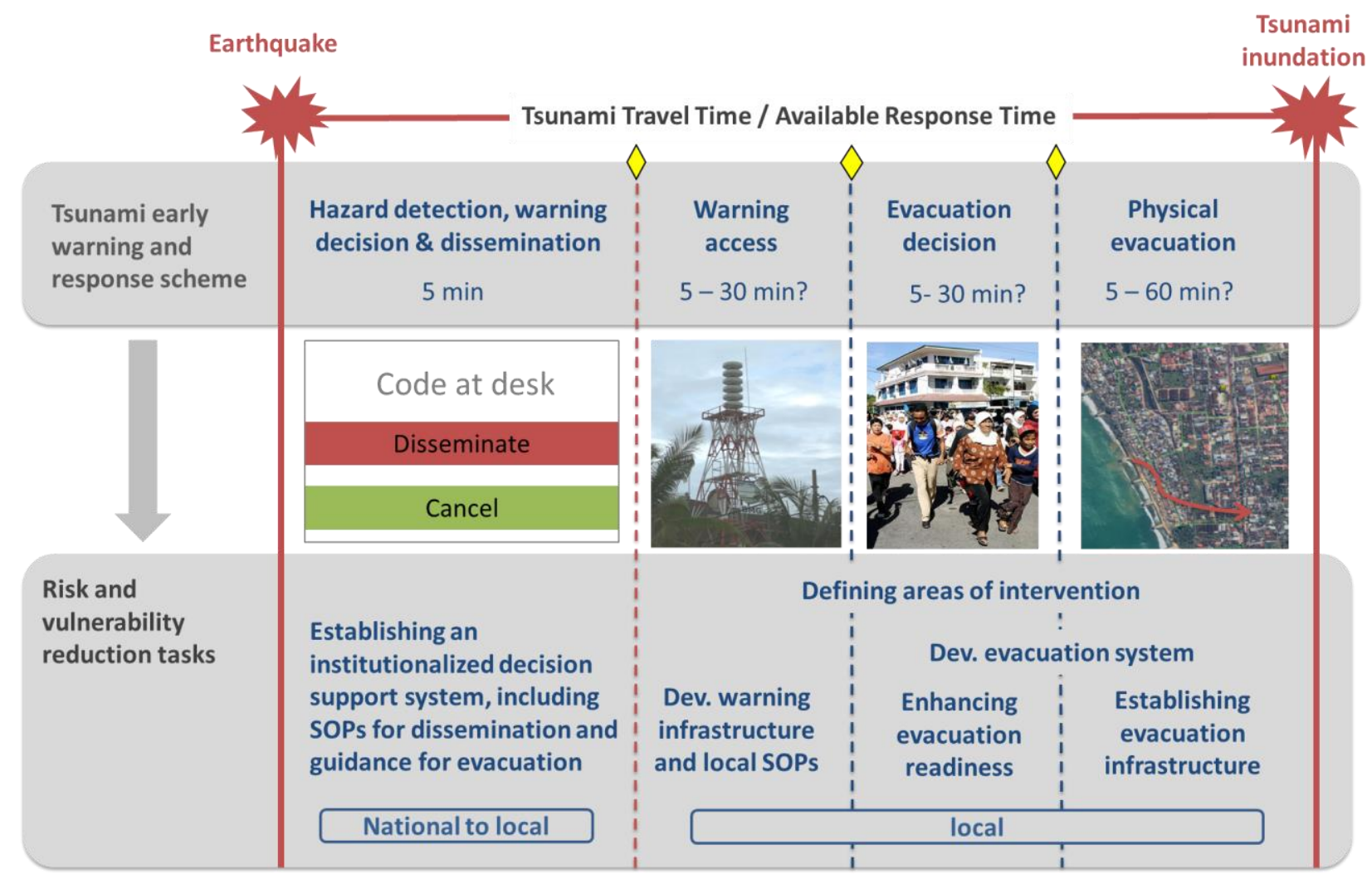

Figure 12: The InaTEWS response scheme and R\&V-R tasks (own conceptualization)

To accomplish this, decisions about and the implementation of response scheme-specific R\&VR-tasks and measures is necessary (Cf. Figure 12, bottom row). The implementation of each of the R\&V-R-tasks is guided by the decision-making process of how to elaborate, assess, select, implement and monitor R\&V-R tasks specific measures (Cf. III.4), adapted to the case of InaTEWS as shown in Figure 13 below.

\begin{tabular}{|c|c|c|c|c|c|}
\hline & \multirow[t]{2}{*}{ Decision support system } & \multirow{2}{*}{$\begin{array}{l}\text { Identifying areas of } \\
\text { intervention }\end{array}$} & \multirow{2}{*}{$\begin{array}{l}\text { Warning } \\
\text { dissemination SOPs } \\
\text { and infrastructure }\end{array}$} & \multicolumn{2}{|c|}{ Evacuation system } \\
\hline & & & & $\begin{array}{l}\text { Evacuation } \\
\text { readiness }\end{array}$ & $\begin{array}{l}\text { Evacuation } \\
\text { infrastructure }\end{array}$ \\
\hline 1 & $\begin{array}{l}\text { Measure } \\
\text { generation }\end{array}$ & $\begin{array}{l}\text { Measure } \\
\text { generation }\end{array}$ & $\begin{array}{l}\text { Measure } \\
\text { generation }\end{array}$ & $\begin{array}{l}\text { Measure } \\
\text { generation }\end{array}$ & $\begin{array}{l}\text { Measure } \\
\text { generation }\end{array}$ \\
\hline 2. & Measure assessment & $\begin{array}{l}\text { Measure } \\
\text { assessment }\end{array}$ & $\begin{array}{l}\text { Measure } \\
\text { assessment }\end{array}$ & $\begin{array}{l}\text { Measure } \\
\text { assessment }\end{array}$ & $\begin{array}{l}\text { Measure } \\
\text { assessment }\end{array}$ \\
\hline 3. & $\begin{array}{l}\text { Measure } \\
\text { selection }\end{array}$ & $\begin{array}{l}\text { Measure } \\
\text { selection }\end{array}$ & $\begin{array}{l}\text { Measure } \\
\text { selection }\end{array}$ & $\begin{array}{l}\text { Measure } \\
\text { selection }\end{array}$ & $\begin{array}{l}\text { Measure } \\
\text { selection }\end{array}$ \\
\hline 4. & $\begin{array}{l}\text { Measure } \\
\text { implementation }\end{array}$ & $\begin{array}{l}\text { Measure } \\
\text { implementation }\end{array}$ & $\begin{array}{l}\text { Measure } \\
\text { implementation }\end{array}$ & $\begin{array}{l}\text { Measure } \\
\text { implementation }\end{array}$ & $\begin{array}{l}\text { Measure } \\
\text { implementation }\end{array}$ \\
\hline 5. & Measure monitoring & $\begin{array}{l}\text { Measure } \\
\text { monitoring }\end{array}$ & $\begin{array}{l}\text { Measure } \\
\text { monitoring }\end{array}$ & $\begin{array}{l}\text { Measure } \\
\text { monitoring }\end{array}$ & $\begin{array}{l}\text { Measure } \\
\text { monitoring }\end{array}$ \\
\hline
\end{tabular}

Figure 13 Linking R\&V-R tasks with the process of R\&V-R 
Hence, for each of the defined R\&V-R tasks of InaTEWS, options for task-specific measures are generated, assessed, selected, finally implemented and monitored. Thereby, some measures can support the implementation of only one or even more than one R\&V-R task. The order of measures to be decided upon and implemented must not follow the order of the response scheme and their associated R\&V-R tasks. For instance it might be advisable to first develop evacuation capacities and structures and thereafter socialize people to be ready to evacuate to designated safe areas. In the following, the InaTEWS specific R\&V-R tasks are detailed.

\section{VI.4.1 Developing a National Tsunami Warning Decision Support System}

Are authorities able to anticipate a tsunami threat and take decisions to warn and communicate them? For InaTEWS to be effective, investments in hazard detection infrastructure (GPS stations, ocean bottom units) and a decision support system are important to be able to issue timely warnings, which pose particularly a technical challenge.

\section{VI.4.2 Defining Areas of Intervention in Coastal Zones}

Where are the areas where $R \& V-R$ is required in terms of implementing local level peoplecentred warning and response structures? Where are the areas warnings have to be communicated to, and where are the areas where people have to find a safe place in due time?

In the face of the very limited time available for coastal communities to adequately respond to warnings, large parts of the exposed communities might get trapped and risk mortality if warning and response structures are not designed based on the anticipated tsunami characteristics, such as the Estimated Time of Arrival (ETA), and the inhabited area inundated by a tsunami. Local authorities have to know whom to warn in their community and where to deploy response structures. Hence, for InaTEWS to be effective, the knowledge of inhabited spatial entities potentially inundated by tsunamis is important (hazard knowledge). To do so, $R \& V-R$ practitioners need to define the spatial entities affected by different tsunami wave heights. The process of defining those inhabited areas that require adequate warning dissemination and warning response structures is built upon tsunami hazard information from which a set of "warning levels" are deduced. Each warning level represents a certain wave height at the coast that is linked with a specific inundation scenario for the area of concern. Hence, the overall goal is to identify spatial warning and response entities for different tsunami 
magnitudes, so that local authorities can decide to what degree they are willing to evacuate their territory for a given tsunami magnitude and invest in respective measures. For this purpose the following R\&V-R-measures are necessary:

- Defining warning levels: Warnings and guidance for action are to be disseminated for different types of tsunami magnitudes. Accordingly, so-called warning-levels are to be defined that represent a harmonized typology for different tsunami magnitudes and provide decision support for the type of tsunami that shall be warned for. InaTEWS differentiates between three different warning levels: "Advisory", "Warning" and "Major Warning" (BMKG 2008).

- Decision on warning level specific spatial entities requiring the establishment of effective warning and response structures at the local level: The warning levels defined at the national level have to be linked with the spatial entity that shall be evacuated. Identifying these spatial entities is the responsibility of local authorities with the support of scientific hazard and exposure assessment, including the assessment of the exposed critical facilities and lifelines (schools, hospitals etc.), to be able to define local "hotspots" for early warning and evacuation.

Table 5 shows the $R \& V-R$ process for defining those spatial entities that require the establishment of efficient warning and response structures.

Table 5 R\&V-R process to identify spatial entities for intervention

\begin{tabular}{|c|l|l|}
\hline \multicolumn{3}{|c|}{ Defining evacuation zones for legalizing spatial entities requiring warning and evacuation infrastructure } \\
\hline 1 & Measure generation & Elaboration of options for defining an evacuation zone \\
\hline 2 & Measure assessment & $\begin{array}{l}\text { Assessing different available options to identify the most acceptable / } \\
\text { manageable level of protection and evacuation zones }\end{array}$ \\
\hline 3 & Measure selection & Selection of the most appropriate evacuation zone \\
\hline 4 & Measure implementation & Legalizing the defined evacuation zone for different warning levels \\
\hline 5 & Measure monitoring & Monitoring of the evacuation zone performance \\
\hline
\end{tabular}

\section{VI.4.3 Establishing Warning Dissemination SOPs and Infrastructure for Enhancing Warning Reception}


In case in the course of a tsunami the corresponding warning is issued by the national warning centre, a fundamental question arises: Do tsunami exposed people receive the warning issued? Some might, some not, some too late. In the face of very limited evacuation time available and in case the local spatial conditions are unfavourable for ensuring timely evacuation, tsunami warnings have to reach hazard prone communities in due time. If not, large parts of the exposed communities might get trapped and risk mortality during a tsunami event. To ensure that warnings reach those prone communities, the warning issued needs to be communicated to the exposed populations in due time and in a manner understandable for a layperson. Especially where time is limited, full and timely access of the population to warnings is a prerequisite. The International Early Warning Programme (IEWP) stresses that warning dissemination mechanisms need to identify the most efficient way to reach tsunami-exposed populations in a very short time (UNISDR-PPEW). Thereby, some of the following challenges are subject to acknowledgment: How is the public media engaged in the process of warning? Are warnings communicated directly to the general public, or must they first pass through all levels of governance according to the institutional setup and power system? Who are the authorities that are engaged in the warning process; do they possess the capacities to provide 24-hour emergency services? Which devices are the most effective to warn citizens in due time?

Thus, for InaTEWS to be effective, investments in people-centred warning dissemination infrastructures and the design of respective SOPs for the establishment of an effective warning chain are required. The following $R \& V-R-M e a s u r e s$ complement people-centred warning dissemination:

- SOP for Warning Dissemination: They define modes of warning dissemination amongst authorities and to the general public across different administrative levels. At the national and local level quick communication mechanisms are needed that reach exposed communities once a warning is issued by the national warning centre. Due to the ability of the mobile phone technology to disseminate warnings quickly, flexibly and selectively to those exposed (e.g. for a given region), mobile phones are amongst the communication media considered suitable for use in Indonesia (German Technical Cooperation 2007), allowing to target individuals wherever they are and providing them with a clear guidance for action through text messages. However, other information dissemination tools such as TV and radio should be considered as well, due to their 
widespread accessibility even among the Indonesian rural population. (Salamun 1992) stated that radio is the primary mass medium for much of rural Indonesia, and TV is regarded in general as the most effective means of reaching mass audiences (Sen, Hill 2000).

To summarize, the development of SOPs for warning dissemination have to acknowledge the prevailing effective local warning channels to reach communities exposed and requirements related to the ETA of a tsunami. In doing so, three distinct effectiveness criteria to discern the adequacy of different warning dissemination tools play a role:

- The capacity of a warning dissemination tool to reach masses of population within a very short time and at any time;

- The reliability of a warning dissemination tool to also work under conditions of e.g. earthquakes;

○ The informative value different warning dissemination tools can provide.

- Local infrastructure for warning dissemination: After having decided upon SOPs for warning dissemination, a next step is to ensure physical full access of the population to warning dissemination tools. Setting up extensive local warning infrastructure has to consider the spatial and social settlement structure and requires complete spatial coverage to increase the likelihood that everybody exposed to a tsunami receives the warning directly.

Table 6 shows the steps of R\&V-R for the development of people-centred infrastructure for local warning dissemination. Thereby, a contextualization of each step with regard to the management topic is provided, from which step specific R\&V-A requirements are deduced. 
Table $6 \mathrm{R} \& V$-R process to enhance the effectiveness of warning dissemination

\begin{tabular}{|l|l|l|l|}
\hline \multicolumn{2}{|c|}{ R\&V-R process for people-centred warning SOP and Infrastructure development } \\
\hline 1 & Measure generation & $\begin{array}{l}\text { Elaboration on options for warning } \\
\text { dissemination from the national level to } \\
\text { recipient populations }\end{array}$ & $\begin{array}{l}\text { Elaboration on type of warning } \\
\text { dissemination infrastructure available } \\
\text { for the region }\end{array}$ \\
\hline 2 & Measure assessment & $\begin{array}{l}\text { Assess the different warning } \\
\text { communication options with regard to } \\
\text { their effectiveness to reach tsunami } \\
\text { exposed communities in due time }\end{array}$ & $\begin{array}{l}\text { Elaboration of the effectiveness of } \\
\text { the different warning dissemination } \\
\text { infrastructure (spatial distribution / } \\
\text { accessibility / reliability) from the } \\
\text { perspective of the population }\end{array}$ \\
\hline 3 & Measure selection & $\begin{array}{l}\text { Selection of the most effective warning } \\
\text { dissemination SOP }\end{array}$ & $\begin{array}{l}\text { Selection of the most efficient and } \\
\text { effective warning dissemination } \\
\text { infrastructure }\end{array}$ \\
\hline 4 & $\begin{array}{l}\text { Measure } \\
\text { implementation }\end{array}$ & $\begin{array}{l}\text { Institutionalize the most effective } \\
\text { warning dissemination SOP }\end{array}$ & $\begin{array}{l}\text { Placement and technical } \\
\text { prescriptions of warning } \\
\text { dissemination infrastructure }\end{array}$ \\
\hline 5 & Measure monitoring & $\begin{array}{l}\text { Monitoring institutional warning } \\
\text { dissemination performance }\end{array}$ & $\begin{array}{l}\text { Monitoring of warning infrastructure } \\
\text { performance }\end{array}$ \\
\hline
\end{tabular}

\section{VI.4.4 Developing and Implementing an Evacuation System}

\section{VI.4.4.1 Enhancing Evacuation Readiness Capacity of the Population to Increase their Evacuation Capacity}

In case in the course of a tsunami event people exposed have received a tsunami warning on time, the next question that arises is: "Are people prepared and ready to react to warnings?" (UN/ISDR Platform for the Promotion of Early Warning 2004): Some might do nothing, some may want to confirm the tsunami occurrence before they run, some hassle to find their children, and some run on their own to higher ground. In the face of the very limited evacuation time available as is the case in Indonesia, inappropriate reactions to warnings are a vulnerability factor that can increase the risk of mortality during a tsunami event. Thus, for a TEWS to be effective, appropriate investments to increase the effectiveness of evacuation readiness are a very important component of an effective TEWS in Indonesia and should not be underestimated compared to other R\&V-R-measures. The respective measures pose a general challenge for the way a TEWS has to be set up to become people-centred and effective. The following R\&V-R-measures play a crucial role for increasing the evacuation readiness of the population. 
- Warning message design: Especially for the case of Indonesia where the average Estimated Time of Tsunami Arrival (ETA) is 30 minutes only, populations exposed have to decide individually and to promptly evacuate, whereas in other regions such as Hawaii, authorities have enough time to persuade their inhabitants to leave their place. Thus, for the case of Indonesia, the tsunami warning system has to follow a unidirectional hierarchical communication process, in which a warning message needs to be directly understood by the recipient and provide clear guidance how to react in order to act themselves first-hand (Cf. Kunz-Plapp 2008; GIZ-IS 2009). To prevent misconceptions, a warning message shall be capable to translate a warning message from one social context (science community, authorities) into another social context (population exposed) by transforming the physical and scientific prediction of the hazard (e.g. information about location and extent of a potential tsunami impact, and its Estimated Time of Arrival, ETA) into a request for action by a layperson (John Handmer 2000): "Warnings are embedded within societal constituted frameworks that are determined by actions and perceptions of individuals" (Lars Clausen, Wolf R. Dombrowsky 1984, p. 299) Thus, warning messages need to fulfil certain criteria to ensure they are received and understood out of the context where people live so that they have a concrete meaning to them and bring about protective action.

- Education / Socialization for Evacuation and SOP: Often authorities perceive warning recipients as a passive general public, representing a single, monolithic and homogeneous entity just decoding and following instructions communicated in a warning (Ruhrmann, Kohring 1996). But in reality warning response behaviour is diverse and depends on a number of factors, such as social structure (age, health, and gender), experiences, subjective $R \& V$ perception, and attitudes that might lead to refusal of state authority and information. Thus, authorities face various uncertainties concerning the success of an issued warning: How many people will respond, how fast will they act, what will they do, and where will they go (John H. Sorensen 2000, p.121)? To increase the evacuation readiness of communities, households and individuals, R\&V-R practitioners need to ensure that they internalize, develop mechanisms and rules of procedures to ensure effective evacuation (e.g. knowledge of evacuation place and routes, family based rules on meeting points, plans for the usage of vehicles, and support for the elderly) by the means of socialization programmes, evacuation 
exercises and visualization of evacuation routes and shelters (signs, tables, maps, leaflets etc.).

Table 7 shows the steps of R\&V-R for increasing the evacuation readiness of the population. Thereby, a contextualization of each step with regard to the management topic is provided, from which step-specific $R \& V-A$ requirements are deduced.

Table 7 R\&V-R process to enhance the effectiveness of evacuation readiness

\begin{tabular}{|c|l|l|}
\hline \multicolumn{2}{|l|}{ R\&V-R process for enhancing evacuation readiness } \\
\hline 1 & $\begin{array}{l}\text { Measure } \\
\text { generation }\end{array}$ & $\begin{array}{l}\text { Elaboration of possible options how to increase evacuation readiness by the means of } \\
\text { raising awareness and warning message design }\end{array}$ \\
\hline 2 & $\begin{array}{l}\text { Measure } \\
\text { assessment }\end{array}$ & $\begin{array}{l}\text { Assessing options to increase evacuation readiness with respect to their degree of } \\
\text { effectiveness }\end{array}$ \\
\hline 3 & Measure selection & Selection of the most effective warning message and awareness strategy \\
\hline 4 & $\begin{array}{l}\text { Measure } \\
\text { implementation }\end{array}$ & Implementing warning messages and awareness campaigns \\
\hline 5 & $\begin{array}{l}\text { Measure } \\
\text { monitoring }\end{array}$ & Monitoring evacuation readiness perfromance \\
\hline
\end{tabular}

VI.4.4.2 Developing Evacuation Capabilities to Increase the Effectiveness of Timely Evacuation

When the people exposed have received a tsunami warning on time in the course of a tsunami event and are ready to immediately commence evacuation, the next question arises: Are people able to find a safe place in due time? Some might be able to, some live in areas where evacuation seems to be hopeless. In the face of very limited evacuation time available and when the local spatial conditions are unfavourable for ensuring timely evacuation, large parts of the exposed communities might get trapped and risk mortality when a tsunami strikes. Thus, for a TEWS to be effective, investments in evacuation and shelter infrastructure are required to increase the evacuation capacity of the population, posing a huge challenge for spatial planning, particularly within urban areas, such as the City of Padang, Cila cap and Kuta.

The process of evacuation planning describes activities and measures taken by local stakeholders to ensure short-term exposure of threatened locations is reduced by means of evacuation in due time before a tsunami strikes (Spahn et al. 2010). Such a plan includes a set of complementary R\&V-R-measures, listed as follows and drawn from (Spahn et al. 2010; Scheer et al. 2011) that might require changes of the urban landscape of a city. 
- Identifying existing shelters and designing and constructing new ones for horizontal and vertical evacuation (target points). Often shelter locations need to be integrated into the urban landscape, requiring changes of land use and settlement structures. Important evacuation target points and locations of emergency service providers can be located and characterised using clearly defined sets of criteria for vertical and horizontal evacuation.

- Identifying and constructing the fastest evacuation routes from each point of a defined area to the nearest evacuation target point. Thereby, the existing street network might require changes in width and orientation, implying also changes in the land use of cities and might also include resettlement. Where possible, adjustments of everyday traffic management systems are required in accordance with evacuation directions to ensure orientation if evacuation is required.

- Identifying high loss facilities that need special attention during evacuation (schools, hospitals, shopping malls, homes for the elderly, etc.).

- Socializing evacuation routes and shelters by the means of information materials, maps, signs, et al. developed to inform the general public about evacuation procedures.

Table 8 shows the steps of R\&V-R for the development of people-centred evacuation shelters. Thereby, a contextualization of each step with regard to the management topic is provided, from which step-specific $R \& V-A$ requirements are deduced.

Table 8 R\&V-R process and assessment requirements to enhance evacuation capability

\begin{tabular}{|c|l|l|}
\hline \multicolumn{2}{|l|}{ R\&V-R Tasks: Setting up effective evacuation infrastructure } \\
\hline 1 & Measure generation & Identification of spatial entities that require evacuation shelters \\
\hline 2 & Measure assessment & $\begin{array}{l}\text { Assessing identified spatial entities (options for placing shelters) urgently } \\
\text { needing evacuation shelters and their required capacities }\end{array}$ \\
\hline 3 & Measure selection & Selection of the size and location of evacuation shelters \\
\hline 4 & Measure implementation & Constructing evacuation infrastructure \\
\hline 5 & Measure monitoring & Monitoring evacuation infrastructure performance \\
\hline
\end{tabular}




\section{VI.5 Risk and Vulnerability Assessment in the Context of InaTEWS}

The conceptualization of R\&V-A in the context of InaTEWS is based on the provisions of the FARVAR framework (Cf. IV) that follows the notion that R\&V is a result of lack of capacity (Cf. IV.2). Translated into the R\&V-R context, this means that the causal structure of $R \& V$ has to be searched in the factors responsible for the lack of capacity to accomplish effective R\&V-R (Cf. IV.4). Hence, based on the description of InaTEWS' R\&V-R-tasks and measures for setting up an effective InaTEWS (Cf. VI.4), the conceptualization of R\&V-A can be conducted. This will be presented in chapter VI.5.1.

Thereafter, in adherence to the outlines portraying the role of R\&V-A in the process of R\&V-R (Cf. IV.5.3), chapter VI.5.2 briefly explores the R\&V-A concept in the context of InaTEWS. The utility of R\&V-A for the elaboration, assessment, selection, and implementation of InaTEWS task specific measures (Cf. Table 5, Table 6, Table 7, Table 8) is not outlined here. An own chapter has been dedicated to the evaluation of the utility of empirical results for the different steps of R\&V-R-decision-making in the context of InaTEWS (Cf. VI.4).

\section{VI.5.1 Defining Risk and Vulnerability in the Context of InaTEWS}

What are those prevailing spatial, technological, social, and institutional factors limiting the effectiveness of a TEWS that increase mortality risk during a tsunami event? In a global survey on capacities and gaps for early warning systems prepared by the UNISDR Secretariat, "warning dissemination and preparedness to act" (response capability) were identified as the weakest elements (UNISDR-PPEW). Also the InaTEWS lacks the capacity of strengthening local response capacities. The majority of investments have been allocated to the construction of the National Warning Centre. The findings of the survey reflect the need to develop People-Centred Early Warning Systems, which ensure that warnings reach hazard prone communities who know how to respond to these warnings :"\{...\} Warning systems by themselves are of little value unless communities understand how they work $\{\ldots\}$ ". (Raymond 2006). In the case of Indonesia as a large coastal country, the functioning of the different integrated components at different administrative levels, and in every geographic area exposed to tsunamis, is a particular challenge. If only one of the elements of the reaction scheme fails to be effective, the whole EWS does not function, failing to prevent fatalities when a tsunami occurs. 
Against this background, R\&V in the context of InaTEWS refers to those factors that constitute the causal structure of the (dis)functionality between the technological warning and the social response system. The following questions aim to point at the underlying factors of this disfunctionality to arrive at a comprehensive but disaggregated $R \& V$ definition:

- Who are the exposed populations and where are they living?

- What is their degree of capacity to receive warnings?

- What determines people's capacity to be ready to evacuate (evacuation readiness)?

- And why do they lack capacity to evacuate in due time?

Consequently, mortality risk in the context of early warning and evacuation is defined as

(...) the conditions that increase the likelihood of the population being exposed to tsunamis, lacking the capacity to access tsunami warnings, to be ready to evacuate after receiving a warning, to find a safe place in due time.

This definition indicates that the research on the single R\&V factors is guided by the specific R\&V-R tasks and measures that are important for the development of an effective TEWS. Moreover, it reflects the notion that R\&V-R has to be viewed as being embedded in societal conditions which is also true for setting up InaTEWS. Hence, rural or urban spatial and physical patterns as well as infrastructures, people's behaviour, perception, ethnicity, age and gender matter within processes of R\&V-R such as the establishment of InaTEWS. 
Figure 12 schematically summarizes how the FARVAR framework has been contextualized for InaTEWS and its defined R\&V-R tasks.

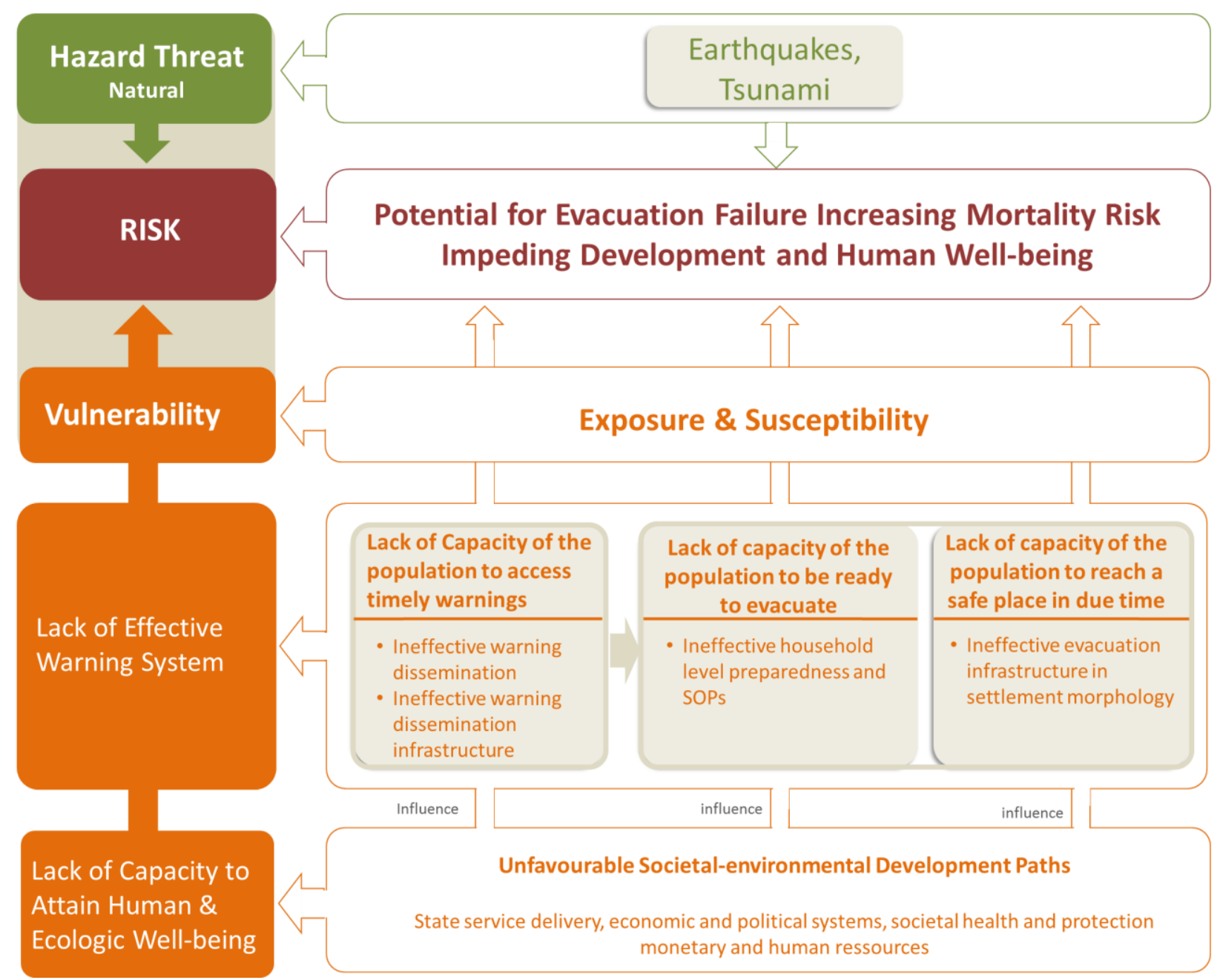

Figure 14: Components of R\&V in the context of TEWS in Indonesia

\section{VI.5.2 Defining Risk and Vulnerability Assessment and its Scope in the Context of InaTEWS}

Based on the definition of R\&V in the context of InaTEWS those factors and causalities are to be searched, measured, and mapped that are likely to create effectiveness problems for the different R\&V-R-tasks and measures of InaTEWS (Cf. Figure 12), and therefore increasing the likelihood of mortality during a tsunami event. More precise R\&V-A in the context of InaTEWS means identifying and assessing hazard and exposure parameters (e.g.; probabilities of occurrence, ETA and inundation) as well as vulnerabilities that are defined as lack of capacity of 
the tsunami exposed population to access timely warnings, lack of capacity to be ready to evacuate, and lack of capacity to find a safe place in due time.

Hence, R\&V-A in the context of InaTEWS is guided throughout by the questions: What are factors and conditions that hinder timely evacuation? Such information - based on the prescriptions of how R\&V-A shall be embedded in the processes of R\&V-R (Cf. IV.5.3), the different R\&V-R tasks and measures defined to accomplish an early warning system (Cf. VI.4), as well as the process defining how tasks and measures are to be decided upon and implemented (Cf. Table 5, Table 6, Table 7, Table 8) - is assumed to be useful for elaborating, assessing, selecting, and implementing the different tasks and measures defined for an early warning system. Hence, the $R \& V-A$ results are required to be delivered in disaggregated form, serving different requirements for each step of the $R \& V-R$ decision-making process.

For each R\&V-R-task of InaTEWS, the role of R\&V-A is depicted (Cf. Figure 15) and broadly scoped in the following.

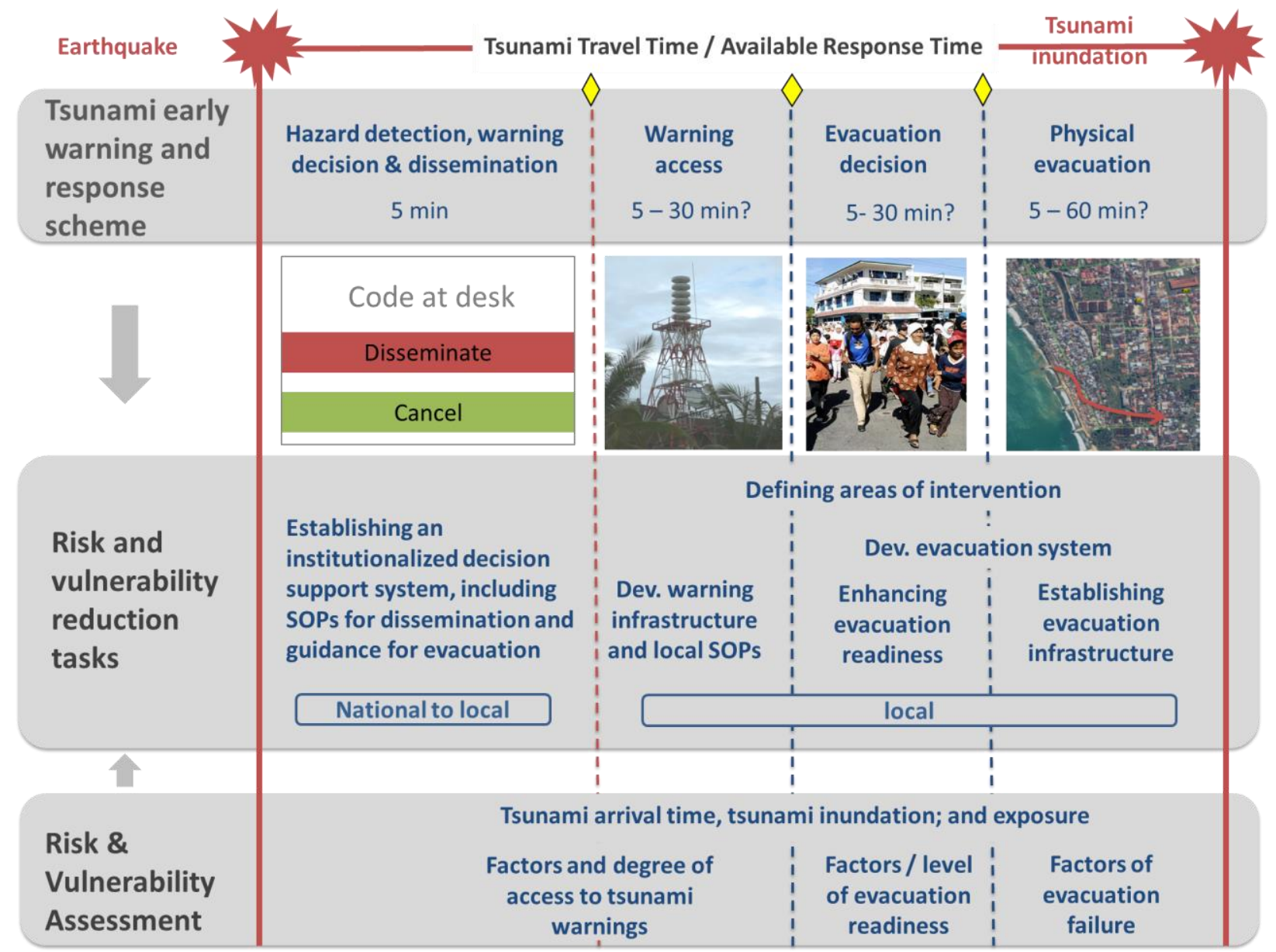


Figure 15 Topics of R\&V-A based on the definition of R\&V-R tasks in the context of InaTEWS

- R\&V-R-task 1: Defining an evacuation zone / area of intervention: Hazard inundation probabilities and exposure estimations ideally support decisions about identifying the spatial areas that require investments in warning and response structures.

- R\&V-R-task 2: Establishing warning dissemination SOPs and infrastructure: R\&V-A can provide the knowledge base by measuring the gaps and critical areas of the communities' access to tsunami warnings.

- R\&V-R-task 3: Ensuring evacuation readiness of the population: R\&V-A can provide the knowledge base by identifying and measuring the factors influencing evacuation readiness.

- R\&V-R-task 4: Ensuring safe evacuation: R\&V-A can provide the knowledge base by measuring the gaps and critical areas of evacuation.

The R\&V-A takes a people-centred perspective by redirecting attention from the technological component of InaTEWS to the often neglected socio-physical components (Cf. III.2), which also influence the effectiveness of InaTEWS in coastal communities and cities. Although technological issues are also subject to assessment, the focus of the R\&V-A in the context of InaTEWS concentrates on social and physical factors responsible for the incapacity of InaTEWS to be effective, thus increasing the likelihood of significant mortality risk. Hence, the assessment shall facilitate an R\&V-R-process by which the efficiency of the single components of the warning system can be achieved in a way to ensure safe evacuation on time. The different R\&V-A criteria are presented in more depth in the empirical chapter of this dissertation (Cf. VII) 


\section{Case Study Part 3 - Empirical Research; Methods and Results}

\section{VII.1 Introduction}

The research presented is structured based on how R\&V is defined in the context of InaTEWS (Cf. VI.5.1). For each assessment topic delineated for the different R\&V-R-tasks in the context of InaTEWS, an introduction is provided, and the assessment methods and results presented. To recall, an own chapter is dedicated to the evaluation of the utility of the R\&VA for setting up an effective InaTEWS (Cf. VIII), and is hence not included in this chapter.

\section{VII.2 Overview on the Research Process, Research Topics, Methods, and Data Sources}

\section{VII.2.1 The Research Process}

Applied R\&V-As not only aim at measuring the R\&V factors identified but also process, assemble, and transform them into products (aggregated and disaggregated, mapped and documented) that are tailored to the different end-users needs and their capacities (Cf. IV.5.3). In the following the generic steps are described to develop R\&V information of utility for establishing an effective InaTEWS:

- Pre-study - Elaboration of assessment criteria. Before collecting quantitative data, for each assessment topic - defined based on R\&V-R tasks and measures - criteria have to be brainstormed. E.g. what are the effectiveness criteria of a warning to timely reach exposed communities? The assessment criteria were elaborated based on scientific literature, and contextualized within a multi-stakeholder process (representing civil society organizations, the research community, and practitioners) and based on qualitative research in selected research areas at the household level. A set of preparatory meetings culminated in a workshop where by the means of participatory methods stakeholder's opinions were gathered and final decisions made.

- Data collection, assessment and processing. Based on the defined assessment topics and the elaborated criteria, quantitative data were collected, analysed, and processed by 
employing a range of topical assessment-specific methods including quantitative household surveys (descriptive and regression analysis); land use assessments using remote sensing and GIS; as well as existing socio economic statistics (e.g. Census data). For details please refer to Chapters VII.3.1, 0, and VII.6.1.

- $\quad R \& V-A$ information package development and refinement. The research results were processed to yield a preliminary set of "R\&V-A information packages" (e.g.; maps, tabular data, indexes). This step was subject to a wider discussion among members of the official GITEWS R\&V-A working group. The iterative process of the R\&V-A product development also included the validation of the assessment methods and products through multi-stakeholder dialogues and institutionalized feedback mechanisms on the basis on R\&V-R experiences (compare Figure 1) to generate products of utility for $R \& V-R$ practitioners.

\section{VII.2.2 Overview on Research Topics, Methods and Data}

Table 9 provides an overview on the research topics addresses and respective methods and data used. Moreover, for the purpose of transparency, the table indicates the division of work to cover the entire spectrum of R\&V-A in the context of GITEWS. Hence, the data collection conducted by the author only covers parts of the entire R\&V-A assessment. It is important to note again, that this case study serves the testing of the newly developed FARVAR, which means that all R\&V-A work conducted represents a comprehensive R\&V-A important to be used for developing a differentiated picture about how R\&V-A serves as support of R\&V-R decision-making. 
Table 9 Overview of empirical work - methods, data and division of work amongst GITEWS project partners

\begin{tabular}{|c|c|c|c|}
\hline Topic & Sub-topics, methods & Methods and data sources & Division of work \\
\hline $\begin{array}{l}\text { Tsunami hazard } \\
\text { mapping }\end{array}$ & $\begin{array}{l}\text { - Tsunami scenarios for area of interest } \\
\text { - Magnitude specific estimation of spatially distributed } \\
\text { - Sparthquake probabilities } \\
\text { - Continuous probabilities of inundation for different } \\
\text { - } \text { Marning levels }\end{array}$ & $\begin{array}{l}\text { - } \text { GITEWS Scenario data base: Numerical inundation modelling } \\
\text { (MIKE21 FM model) } \\
\text { - } \quad \text { Run-up modelling } \\
\text { - } \text { Consinami sources and moment earthquakes magnitudes } \\
\text { - Topography (Digital surface model, street and building data) } \\
\text { - Bathymetry (GEBCO) }\end{array}$ & $\begin{array}{l}\text { AWI, } \\
\text { GFZ, } \\
\text { DHI-Wasy, } \\
\text { GKSS, } \\
\text { DLR }\end{array}$ \\
\hline Exposure mapping & $\begin{array}{l}\text { - Land use specific disaggregated population distribution } \\
\text { modelling }\end{array}$ & $\begin{array}{l}\text { - } \quad \text { Land use data } \\
\text { - } \quad \text { Population data (BPS-CENSUS 2005) } \\
\text { - } \quad \text { Employment data (BPS-PODES) }\end{array}$ & DLR \\
\hline $\begin{array}{l}\text { Access to warning } \\
\text { assessment }\end{array}$ & $\begin{array}{l}\text { - Household survey, descriptive analysis and index } \\
\text { construction } \\
\text { - Calculation GIS mapping of warning infrastructure } \\
\text { coverage }\end{array}$ & $\begin{array}{l}\text { - } 2000 \text { households in exposed coastal areas } \\
\text { - Warning infrastructure GPS points (Mosques, Sirens) }\end{array}$ & $\begin{array}{l}\text { Baumert } \\
\text { Baumert }\end{array}$ \\
\hline $\begin{array}{l}\text { Evacuation readiness } \\
\text { assessment }\end{array}$ & $\begin{array}{l}\text { - Household survey, regression analysis \& index } \\
\text { construction }\end{array}$ & - 2000 households in exposed coastal areas & Baumert \\
\hline $\begin{array}{l}\text { Evacuation capacity } \\
\text { assessment } \\
\text { (evacuation time } \\
\text { people need mirrored } \\
\text { against available time } \\
\text { to evacuate, Tsunami } \\
\text { arrival time) }\end{array}$ & $\begin{array}{l}\text { - Median hazard arrival times and inundation at the coast } \\
\text { - Calculation of evacuation speed (cost surface) and time } \\
\text { using "Cost Distance Tool", ArcGIS }\end{array}$ & $\begin{array}{l}\text { - tsunami assessment (see above) } \\
\text { - Topography - Land use and slope (remote sensing) } \\
\text { - Population density \& demographic population (age / gender } \\
\text { distribution) } \\
\text { - Access points to safe areas and their capacity } \\
\text { - vertical: } \\
\text { - Building vulnerability. assessment } \\
\text { - Verizontal: topographic and land use criteria }\end{array}$ & $\begin{array}{l}\text { AWI } \\
\text { DLR } \\
\text { DLR / Baumert } \\
\text { DLR }\end{array}$ \\
\hline
\end{tabular}




\section{VII.3 Mapping Warning Level Specific Tsunami Inundation}

Hazard assessment in inhabited areas shall lay open the spatial distribution of hazard inundation probabilities. The assessment shall be able to identify areas that show higher probabilities of tsunami inundation than others. With such information optional measures can be generated enabling to decide which hazard inundation probability should be given priority for investment in warning dissemination and evacuation structures. The assessment shall be conducted for a predefined set of warning levels as a specific warning level, e.g. 4 metres (major warning) may lead to different inundations at different locations. The warning levels are specified by InaTEWS (Table 10)

Table 10: Defined Warning levels in Ina-TEWS (BMKG 2008)

\begin{tabular}{ccc}
\hline Tsunami Category & Warning Level & Wave Height (WH) range [m] \\
\hline$<$ none $>$ & $<$ none $>$ & $0,0=\mathrm{WH}<0,1$ \\
\hline Minor Tsunami & Advisory & $0,1=\mathrm{WH}<0,5$ \\
\hline Tsunami & Warning & $0,5=\mathrm{WH}<3,0$ \\
\hline Major Tsunami & Major Warning & $\mathrm{WH} \geq 3,0$ \\
\hline
\end{tabular}

To acknowledge this, the assessment and anticipation of differential tsunami inundation scenarios at the local level are important.

\section{VII.3.1 Methods}

The calculation of tsunami hazard inundation scenarios is derived from combining probabilistic with multi-scenario tsunami modelling ${ }^{17}$ linked to a set of pre-defined warning levels. The goal is to assess the likelihood of tsunamis of various sizes that can then be simplified into tsunami

\footnotetext{
${ }^{17}$ The tsunami modelling was performed by AWI (Alfred Wegener Institute) at epicentre locations (source grid) for tsunami scenarios provided by GFZ (German Research Centre for Geosciences, 2008). For the inundation modelling, the MIKE21 FM model from DHI-Wasy GmbH was used, and the run-up modelling was performed by GKSS and DHIWasy. The topography is based on digital surface model, street and building data provided by DLR, and differential GPS measurements performed by DHI-Wasy.
} 
hazard zones (tsunami probability and intensity distribution at the coast and the spatial distribution of the maximum inundation) linked with predefined warning levels by the Tsunami Warning Centre. The "Advisory Level" causes only a very small inundation area or no inundation at the coast. Hence, in the hazard mapping approach the "Advisory Level" and the "Warning Level" are used in combination. The assessment is based on an "event tree technique" with different steps to be accomplished to arrive at a warning level specific tsunami probability map. The method has been invented by the GITEWS consortium partner DLR; consequently, the following summary is based on the work of the DLR scientists (LIPI et al. 2011b; Post et al. 2009):

- Tsunami modelling: Along the Sunda Trench several thousands of realistic tsunami scenarios with different tsunami source locations and earthquake magnitudes $(7.5-9.0)$ has been calculated. All scenarios together cover the south coast of Sumatera, Java and Bali. These scenarios are used as input data for the hazard maps. Additional parameters include detailed local topography and bathymetry (elevation data on land and underwater, respectively). Modelling results shall include areas flooded as well as estimated water depths, current strengths, wave heights, and wave arrival times; with a spatial resolution between several hundreds of meters to ten meters, allowing for representation at a map scale of 1:25,000.

- Determine tsunami scenarios affecting the area of interest: All the scenarios which affect the area of interest are chosen from the GITEWS "Tsunami Scenario Database". This is realized by a spatial data query and selects all scenarios which at least inundate one point on land of the area of interest (e.g. a map sheet). The selected scenarios represent the basis for the further assessment.

- Classification of the scenarios depending on the warning levels: All chosen scenarios were grouped in the two warning level classes. By defining the outline of the consolidated inundation of these two classes a first map showing the maximum inundation areas for the different warning levels was developed.

- Estimation of the spatial distributed probability for earthquake occurrence: First, the Sunda Trench region is zoned into three smaller regions each representing different seismic activities (Latief Hamza et al. 2000). For each seismic zone the probability for an annually recurring earthquake magnitude is estimated using the historical earthquake data (NEIC). To improve the results, deterministic models are used to weight the 
occurrence probabilities between 1 (for determined hot spots with a high probability for an occurrence of a strong earthquake) and 0.1 (for determined more or less "inactive" spots) (Cf. Figure 12). Thus, every tsunami-genic source applied has an own occurrence probability.

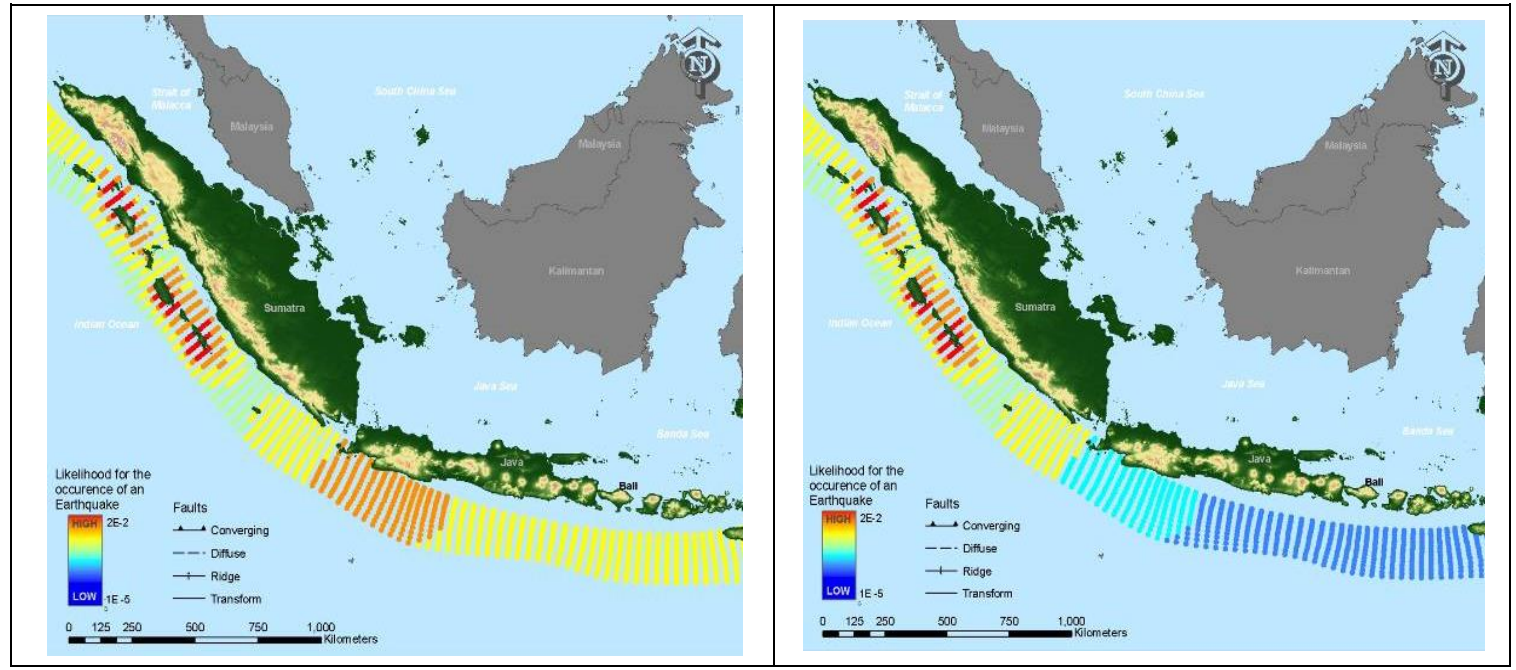

Figure 16: Assessment of the spatially differentiated likelihoods for the occurrence of an earthquake with a specific magnitude along the Sunda Trench; left: Mw 8.0, right: Mw 9.0 (Source: adapted from Babeyko et al. 2010)

- Determination of a spatially distributed inundation probability: In the next step a spatial differentiation for the possibility that a coastal area will be inundated was specified. The results of the modelled tsunami scenarios include impact on land, and the area on land which will be inundated by a tsunami with a specific magnitude. As the single impact areas from the different scenarios can overlap each other (because every point on land can be inundated several times by different scenarios), the spatially distributed inundation probability represents the probability that this point will be hit by a tsunami within a year. The yielded values are combined and quantified by a logical tree technique.

- Combination of the continuous probability with the "warning level" zone: In a final step the continuous tsunami impact probability is overlaid by the derived "warning level" zones. The threshold for the minimum Estimated Time of Arrival (ETA) is defined by the 1st percentile from the ETAs of all modelled tsunami scenarios at the displaced region. The median ETA describes the 50th percentile. For more information on this assessment step see (LIPI et al. 2011b; Post et al. 2009).

- Calculation of estimated times of tsunami arrival (ETA): Every modelled scenario comprises an Estimated Time of Arrival (ETA) of the first disastrous tsunami wave hitting 
the coast. The ETA can vary to a great extent for the various scenarios depending generally on the distance from the coast to the tsunami-genic source and the earthquake magnitude. The Median (50\%-value) of the minimum ETAs of all relevant scenarios have been used for the mapping and the calculation of the evacuation capacity (Cf. VII.7).

\section{VII.3.2 Results}

Map 2 is produced at a scale of 1:25 000. The High Tsunami Hazard Probability Zone (dark red) shows the areas with a high probability of being affected by every tsunami with a wave height at the coast greater than $3 \mathrm{~m}$ (warning level "major warning"). For this warning level continuous hazard probability visualization from moderate tsunami probability (light red) to low tsunami probability (yellow) is displayed. Only for the hazard zone linked to the level "major warning" hazard probabilities are shown (moderate to low probability). The area which will be inundated by the warning level "warning" is displayed as red zone summarizing quantified tsunami probabilities to high tsunami probability. The results show that the probability that a tsunami occurs decreases with an increasing distance from the coast and associated water bodies, such as rivers connected with the ocean. Thus, the probability of being inundated by a tsunami within a year ranges from about $0.03 \%$ (light yellow areas) to about $7 \%$ (red areas). Areas not affected by tsunamis are visualized in grey.

The map shows that the inundation probabilities at the coast are much higher in the eastern part of Cilacap bay than close to the city centre in the western part. This is due to the fact that the western part is protected by an island (Nusa Kambangan, not visible on the map). Nevertheless, high hazard probabilities occur along the inland reaching water bodies, due to the channelling effect of a tsunami wave. It has to be pointed out that the hazard information provided is based on modelling results which naturally hold some uncertainties. An additional important hazard assessment parameter is the Estimated Time of Arrival. For the case of Cilacap the calculated minimum ETA is less than 50 minutes, whereas the median ETA is less than 90 minutes. 


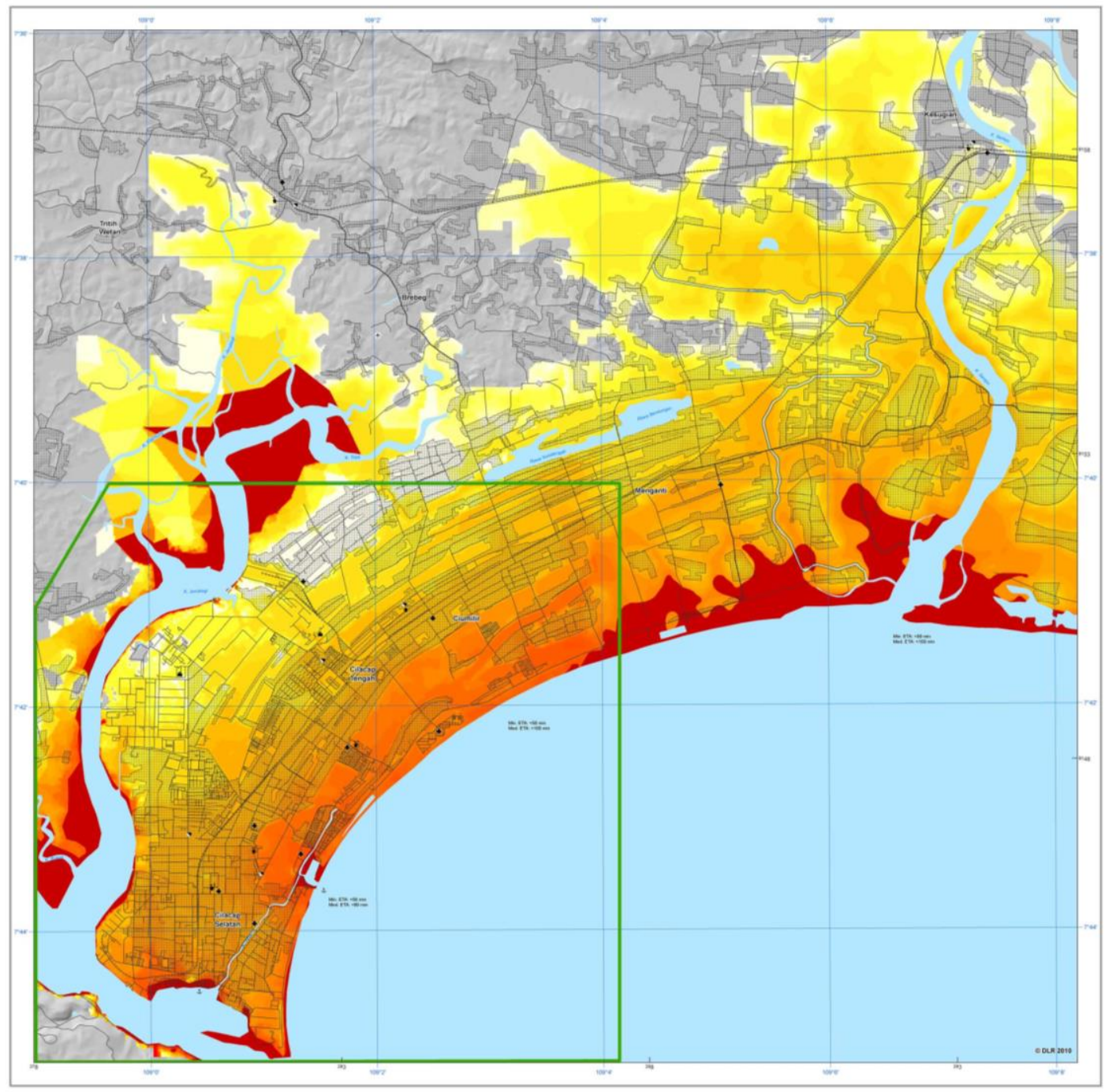

\section{Legend}

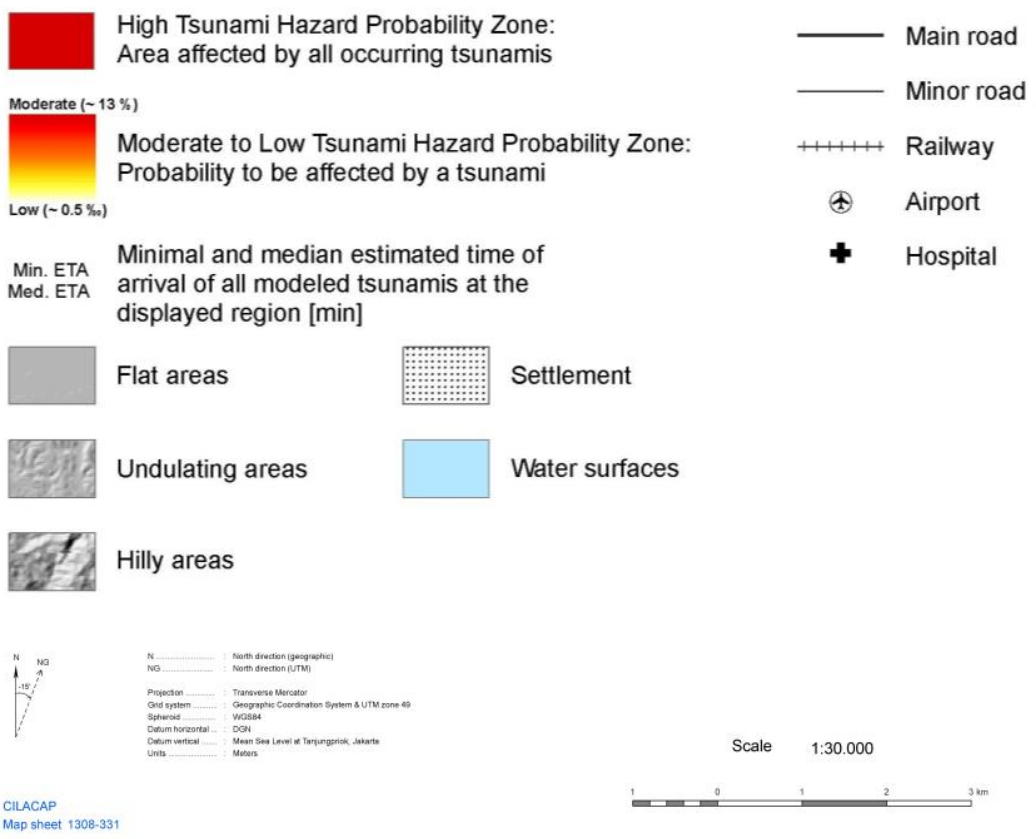

Map 2: Detailed tsunami hazard map of Cilacap 1:25 000 (Source: LIPI et al. 2011b) 
The hazard maps and the respective detailed and differentiated hazard parameters have only to be seen as best available reference information for the development of local specific disaster preparedness strategies, such as defining an evacuation zone, increasing evacuation preparedness and managing warning dissemination. The utility of the results for other R\&V-A information packages as well as for elaborating, assessing, selecting, and implementing R\&V-Rtask specific measures are discussed in the respective empirical sub-chapters as well as chapter VIII.

\section{VII.4 Assessing Exposure}

Exposure assessment in anticipated tsunami inundation zones shall lay open the spatial distribution of the population. The assessment shall be able to identify areas that require more attention when designing warning dissemination and evacuation structures. Moreover, the results can be used (e.g. number of exposed people for different hazard scenarios) for deciding much better about the desired level of protection. For instance, does it make sense to evacuate everybody within the exposed zone, irrespective of the assumed probability of tsunami inundation? Thus, both hazard and exposure information can support this decision. Also this assessment method has been invented by the GITEWS consortium partner DLR. The following summary of the methods to assess exposure is based on the provisions of the technical guideline for risk and vulnerability assessment (Cf. LIPI et al. 2011b).

\section{VII.4.1 Methods}

The available information on population - and that is also the case for Indonesia - is mostly based on statistical data and is related to administrative boundaries, like village, municipal, district, province, or national borders. Often in $R \& V$ research, population distribution is assessed at the level of different administrative boundaries of concern. But in reality population is not distributed homogeneously within an administrative unit of concern. Thus, to improve the spatial resolution of population data, a method is needed that allows the disaggregation of social statistics of the population for different spatial entities. Here, it is assumed that the population is differently distributed across different land use classes during day or night depending on people's activities and settlement areas. Thus, weighting factors for different land 
use types are required for the assessment based on statistical data that provide information about people's activities at village level ${ }^{18}$ :

- The PODES ("Village Potential Statistics") data (Statistics Indonesia, BPS ${ }^{19}$ ) contains information on the main income sources of the population in a community and the number of workers and non-workers.

- The CENSUS (Statistics Indonesia, BPS) data provide information on the percentage of employment in different sectors in each community. These parameters provide an indication of the type, volume, and locality of human activities, and can be used to calculate the potential number of people engaged in different land use activities at various times of the day.

Based on this information a more detailed and time-specific population distribution within a certain village can be stated based on the following workflow (Cf. LIPI et al. 2011a):

1. Modelling of population distribution (Literature, concept, generated formula)

2. Determination of the weighting factors (socio-economic data)

3. Questionnaire analysis (daily activity pattern of different income groups)

4. Accuracy assessment

5. Multi-scale disaggregation

\section{VII.4.2 Results}

Map 3 shows the population distribution and the degree of its tsunami exposure for a daytime situation as high (red), moderate (yellow) and low (green). The degree of exposure is based on the population density distribution during daytime, i.e., the higher the density the higher the exposure. The exposure class high is assigned to areas with population density greater than 2500 people per square kilometre, moderate to population density between 100 and 2500 people per square kilometre, and low to population density below 100 people per square

18 The original database for the population distribution modeling is provided by BPS Census 2000 data which contains the population density per desa/kelurahan. For assessing a precise population distribution, the land use information from BAKOSURTANAL and LAPAN were utilized.

${ }^{19}$ PODES data available at http://www.bps.go.id/ 
kilometre. This map shows a level of detail that is suitable to provide information on people exposure at sub-district level.

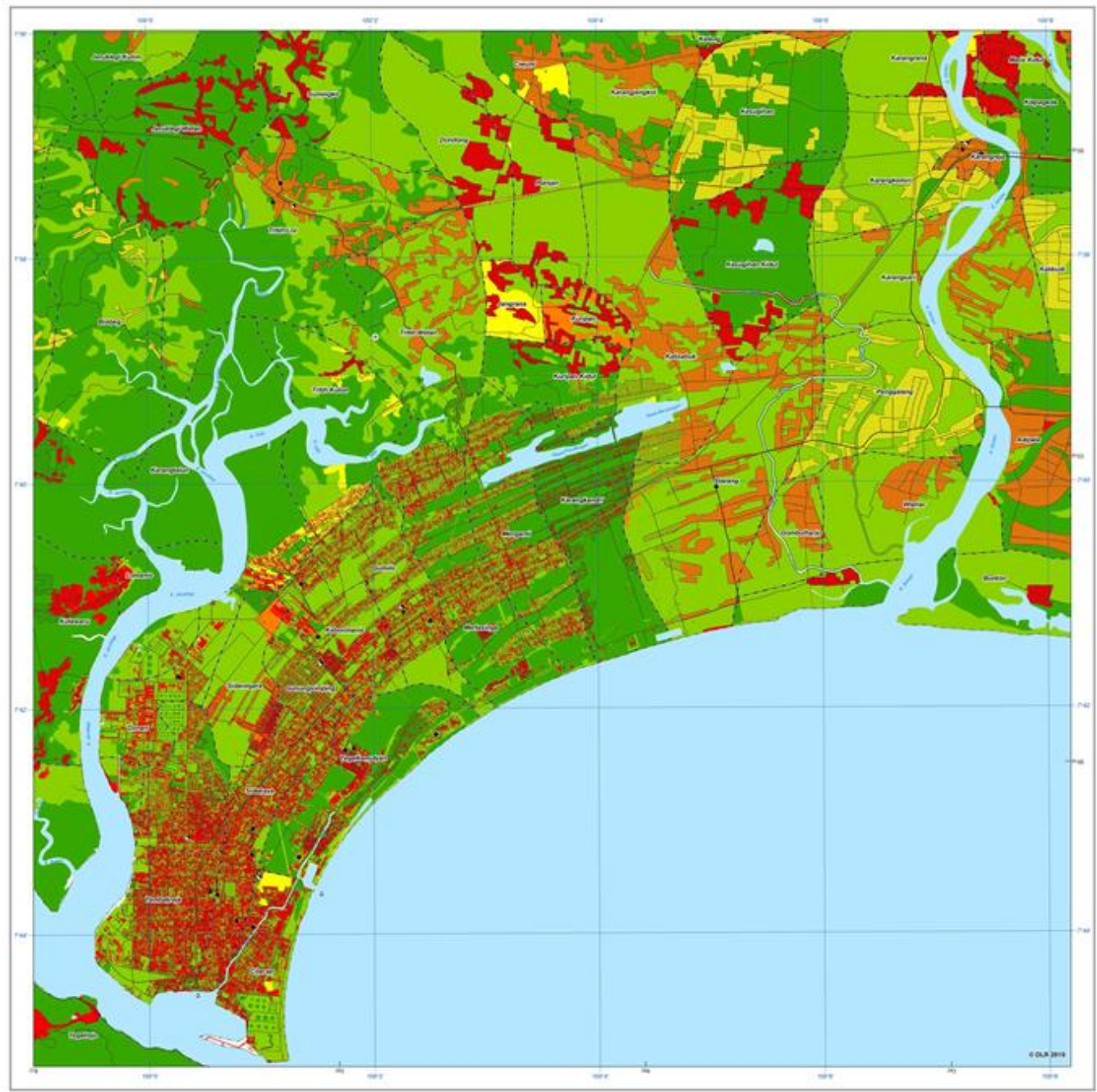

\section{Legend}
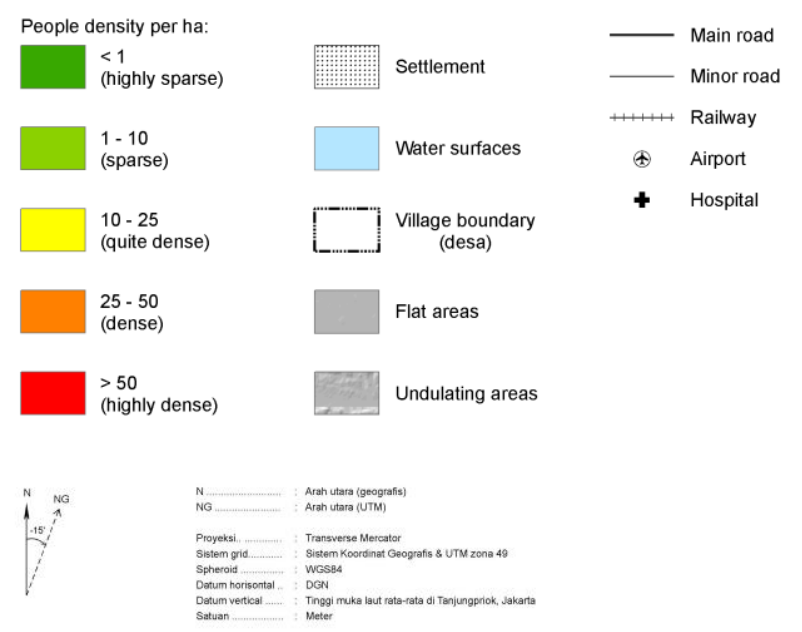

Skala $\quad 1: 30.000$

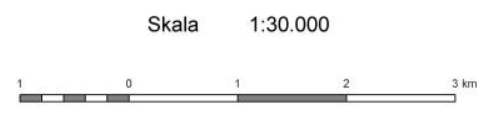


The results show that the population is not distributed homogen eously within an administrative unit, so that also uninhabited areas should not be neglected in terms of the required protection. The map clearly shows the high population densities in the urban areas of Cilacap and that the more coastal-rural areas show low densities. This situation might ease the establishment of warning and evacuation infrastructures in these coastal-rural areas. Linking the results with the hazard map it can be seen that in the inundation zone of waves up to 3 metres very few people live in the coastal-rural areas. In fact, they rather work in these areas, thus requiring specific mechanisms to be warned and the provision of solutions for evacuation.

The utility of the results for elaborating, assessing, selecting, and implementing R\&V-R-task specific measures are discussed in chapter VIII.

\section{VII.5 Assessing Lack of Capacity to Access Timely Warnings}

Once a tsunami warning has been issued by the national warning centre, a fundamental question arises, namely: Do tsunami exposed people receive the warning issued? Some might, some not, some too late. In the face of the very limited evacuation time available and in case the local spatial conditions are unfavourable for ensuring timely evacuation, tsunami warnings have to reach hazard prone communities in due time. If not, large parts of the exposed communities might get trapped and risk mortality in the course of a tsunami event. Hence, the lack of access of communities and social groups to warnings is a vulnerability factor increasing the risk of mortality during a tsunami. Although the best strategy is to channel warnings through all kinds of different devices available in a country, it is still necessary to look closer at capacity gaps in the communities' access to timely warnings in rural, urban as well as uninhabited areas, where people might work. 


\section{VII.5.1 Methods}

Figure 17 presents the key steps for mapping the access of exposed populations to tsunami warnings.

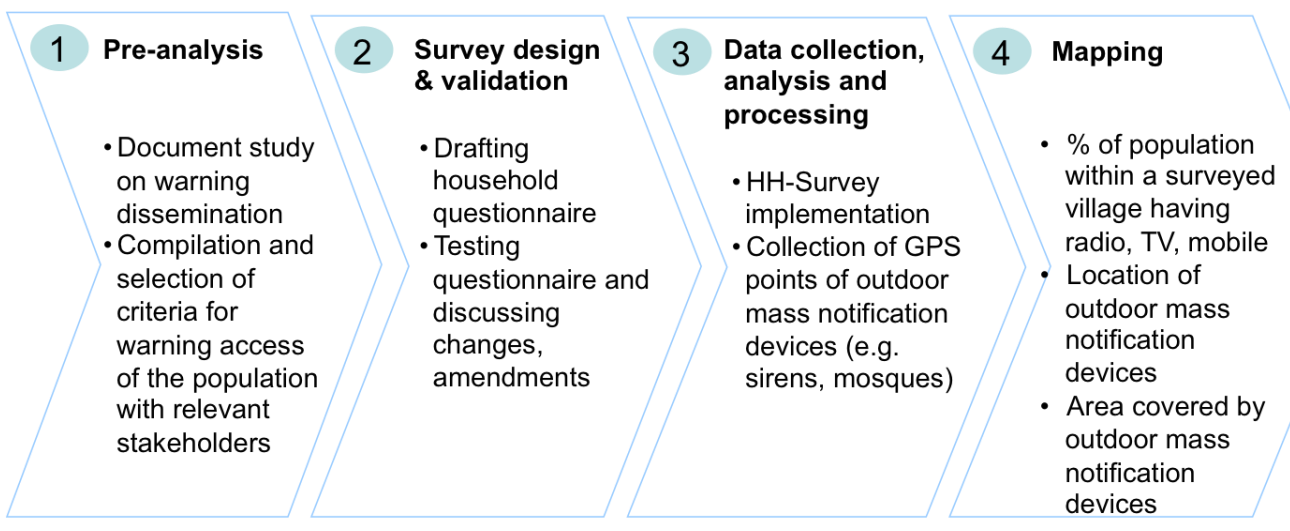

Figure 17: Process of mapping access to tsunami warnings by the population

\section{VII.5.1.1 Criteria Selection}

The access of communities to timely tsunami warnings at different places day and night is the function of the following criteria, which are evaluated in terms of their usefulness for assessment.

Table 11: Overview on the criteria selection process

\begin{tabular}{|c|c|c|}
\hline Criteria & $\begin{array}{l}\text { Assessment } \\
\text { Relevance }\end{array}$ & Explanation \\
\hline $\begin{array}{l}\text { Access to outdoor mass notification } \\
\text { tools: Outdoor warning infrastructure } \\
\text { relates to those warning dissemination } \\
\text { devices that cover greater areas, such } \\
\text { as sirens and any kind of } \\
\text { institutionalized loudspeaker facilities. }\end{array}$ & High & $\begin{array}{l}\text { Deploying outdoor mass notification infrastructure is the } \\
\text { responsibility of local governments. Investments can } \\
\text { quickly increase timely access to warnings. Thus, assessing } \\
\text { current conditions provides useful information to develop } \\
\text { a strategy for further investments. }\end{array}$ \\
\hline $\begin{array}{l}\text { Availability of indoor mass notification } \\
\text { tools: Indoor warning infrastructure } \\
\text { relates to those warning dissemination } \\
\text { devices that households have access to. } \\
\text { These are regular communication } \\
\text { devices: TV, mobile phone, and radio. }\end{array}$ & High & $\begin{array}{l}\text { R\&V-R practitioners can use social profiles of access to } \\
\text { indoor mass notification devices to understand better } \\
\text { which devices shall be given prioritized support and } \\
\text { where outdoor warning infrastructure is essential to be } \\
\text { deployed. Furthermore, assessing households' indoor } \\
\text { mass notification devices yields very reliable information. }\end{array}$ \\
\hline $\begin{array}{l}\text { Reliability of the tools (e.g. R\&V to } \\
\text { blackouts due to earthquake). }\end{array}$ & Low & $\begin{array}{l}\text { The reliability of different tools is well known, a spatial } \\
\text { assessment is not relevant. }\end{array}$ \\
\hline $\begin{array}{l}\text { Device usage patterns of households } \\
\text { and individuals during day and night } \\
\text { and at different places. }\end{array}$ & Low & $\begin{array}{l}\text { Device usage profiles are a very important factor for } \\
\text { having access to timely warnings. However, fluctuations in } \\
\text { usage patterns are high and for most devices usage } \\
\text { profiles are well known. }\end{array}$ \\
\hline
\end{tabular}




\begin{tabular}{lll}
\hline \multicolumn{1}{c}{ Criteria } & $\begin{array}{l}\text { Assessment } \\
\text { Relevance }\end{array}$ & \multicolumn{1}{c}{ Explanation } \\
\hline $\begin{array}{l}\text { Informal notification / warning } \\
\text { communication: community based } \\
\text { warning, word of mouth. }\end{array}$ & Low & $\begin{array}{l}\text { Informal notification is a very important factor increasing } \\
\text { the likelihood that people have access to warnings. But } \\
\text { for R\&V-R practitioners to increase the communities' } \\
\text { access to warnings, deploying infrastructure is relevant. }\end{array}$ \\
\hline
\end{tabular}

\section{VII.5.1.2 Assessing the distribution of indoor mass notification devices among households}

Household survey data ${ }^{20}$ were collected in 2008 in three districts (Padang, 1000 households; Cilacap, 500 households; Bali, 500 households). The survey included questions on whether the households / respondents possess a radio, a TV, and a mobile phone. Based on these data two indicators were calculated:

- Single device availability: The share of households in a village possessing a radio, or a TV or a mobile phone (in \%). This indicator shows how the distribution of different devices among households and villages is, and which are the most relevant to be used for timely warnings. The results of the descriptive analysis were aggregated at the village level (desa) as the reference unit for deriving relative values (\%).

- Device diversity: Share of households (\%) in a village having none, one, two, or all three devices. This indicator allows for receiving a spatially and socially differentiated picture of the likelihood that warnings reach tsunami exposed households disseminated through indoor mass notification.

\section{VII.5.1.2.1.1 Assessing the spatial coverage of outdoor warning infrastructures}

Depending on the cultural identities in the case study areas, different outdoor mass notification systems were selected for mapping. For example, in Cilacap and Padang the capacity of mosques to disseminate warnings was chosen for assessment, especially because in these areas religious leaders, NGOs and the local government had already started a process of coupling mosques with the local warning system. Also sirens play a role in these regions, as a few are installed and allow assessment (except for Cilacap).

Two steps need to be followed for calculating coverage areas of mass warning systems:

\footnotetext{
${ }^{20}$ The selection and surveying process of households was identical with those described in chapter VII.6.1
} 
(1) System's inventory: Compiling GPS information of all the locations where mass alert loudspeakers are placed including any kind of mass notification system existing within the tsunami exposed area.

(2) Estimation of the area where notifications are disseminated through a loudspeaker audible for the exposed populations. The geometry applied for calculating siren and mosque loudspeaker spatial coverage is circles. For mapping them in the urban and rural environment in the three pilot areas the buffer function in ArcGIS9.3 was applied. Thereby, two criteria determine conceptually the size of the area covered ${ }^{21}$ by mosque loudspeakers, sirens or other forms of outdoor mass notification:

i. Average city noise: Sound level (measured in $\mathrm{dB}$ ) at which a siren cannot be heard anymore: This is $80 \mathrm{~dB}$ (Federal Signal Corporation, 2005);

ii. Output level of the speaker: siren / mosque loudspeaker / any other system.

\section{Siren coverage calculation}

Estimations of the area where exposed populations can properly hear a specific siren are based on sound projection measurements published by the Federal Signal Corporation (2005). Figure 18 illustrates the maximum radius for sirens in an urban environment. The data reveals that sirens become ineffective at $80 \mathrm{~dB}$ (average surrounding noise level).

${ }^{21}$ The term "area covered" relates to the area where not only sound can be noticed, but where messages for guidance can still be understood. 

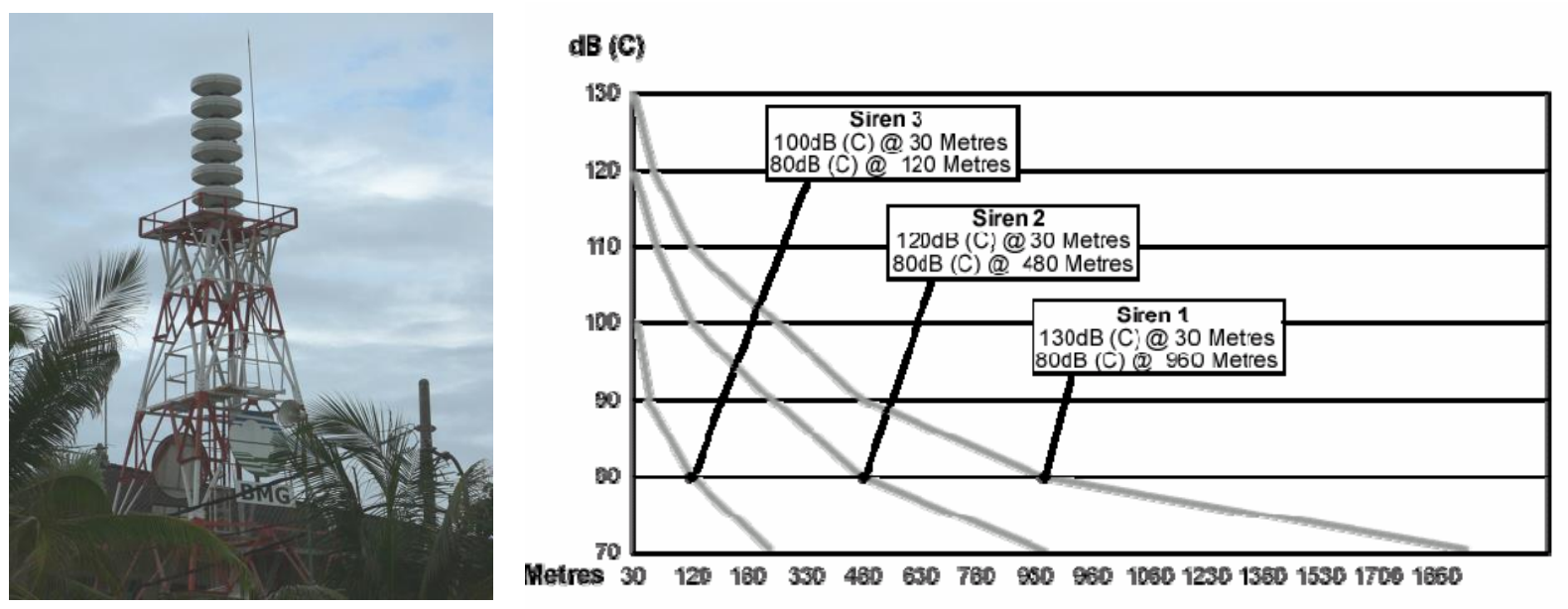

Figure 18: Sound projection for three sirens with different output power (Source: Federal Signal Corporation 2005)

Respectively, by using different siren output levels, three categories of siren coverage radius can be estimated and mapped:

- $100 \mathrm{~dB}$ siren output $=120 \mathrm{~m}$ coverage radius;

- $120 \mathrm{~dB}$ siren output $=480 \mathrm{~m}$ coverage radius;

- $130 \mathrm{~dB}$ siren output $=960 \mathrm{~m}$ coverage radius .

\section{$\underline{\text { Mosque coverage calculation }}$}

If authorities regard mosques as a suitable warning dissemination system, mapping their coverage area is needed. Inventories of mosques exist already in many statistics. Also data on GPS exists in some areas and need to be compiled where missing. This is also true for measuring mosque loudspeakers' output levels. Each mosque loudspeaker has different output levels, but these could not be assessed. Instead, a $150 \mathrm{~m}$ radius was used and mapped for each mosque surveyed using the Buffer technique in ArcGIS 9.3 explained above.

VII.5.1.2.1.2

Assessing Exposure: Merging night and day time population distribution

The method to calculate population densities at day and night time is based on land use and population data as described in chapter VII.4.1. For access to warning infrastructure maps, night and day population densities were merged. This was done by comparing the population density data values at day and night for each land use polygons and selecting only the higher value as the basis for the day and night exposure mapping. This step is important because decisions on warning dissemination infrastructure investments are not meant to take into account day and 
night exposure levels but the highest levels throughout 24 hours. In order to derive an exposure information layer, hazard inundation distribution information needs to be overlaid with the population distribution data to derive population distribution information for specific hazard areas. For methods of hazard inundation modelling, please compare chapter VII.3.1. For this map, the calculated maximum inundation area is used as an example.

\title{
VII.5.2 Results
}

\author{
The results have been processed as a map ( \\ Map 4) and tabular data (Table 12), taking the district of Cilacap as example.
}

Map 4 represents an image of the spatially distributed degree of access of the population to indoor and outdoor warning infrastructure. The map consists of three different information layers:

- Layer 1 - Hazard zone: This is the area of focus of the assessment, indicated by the colour boundaries of the exposure information.

- Layer 2 - Exposure information: people exposed per km2 at day- and night time) classified as high (red), moderate (yellow) and low (green).

- Layer 3 - Information on existing warning infrastructure: Provides an overview about the current status of warning infrastructure distribution and accessibility by the population.

a) Area covered with outdoor mass notification devices:

- Grey circle: Coverage area of the mosque loudspeaker

- Red circle: Coverage area of the sirens (only Padang, Bali)

b) Access of households to indoor mass notification devices in selected villages

- Bar chart (blue, yellow, grey): \% of households in a village possessing a radio, a TV and a HP (indoor mass notification devices).

- Pie chart (grey, white, red): \% of households in a village possessing all three, two, or only one of the indoor mass notification devices. 


\section{Case Study Part 3 - Empirical Research; Methods and Results}

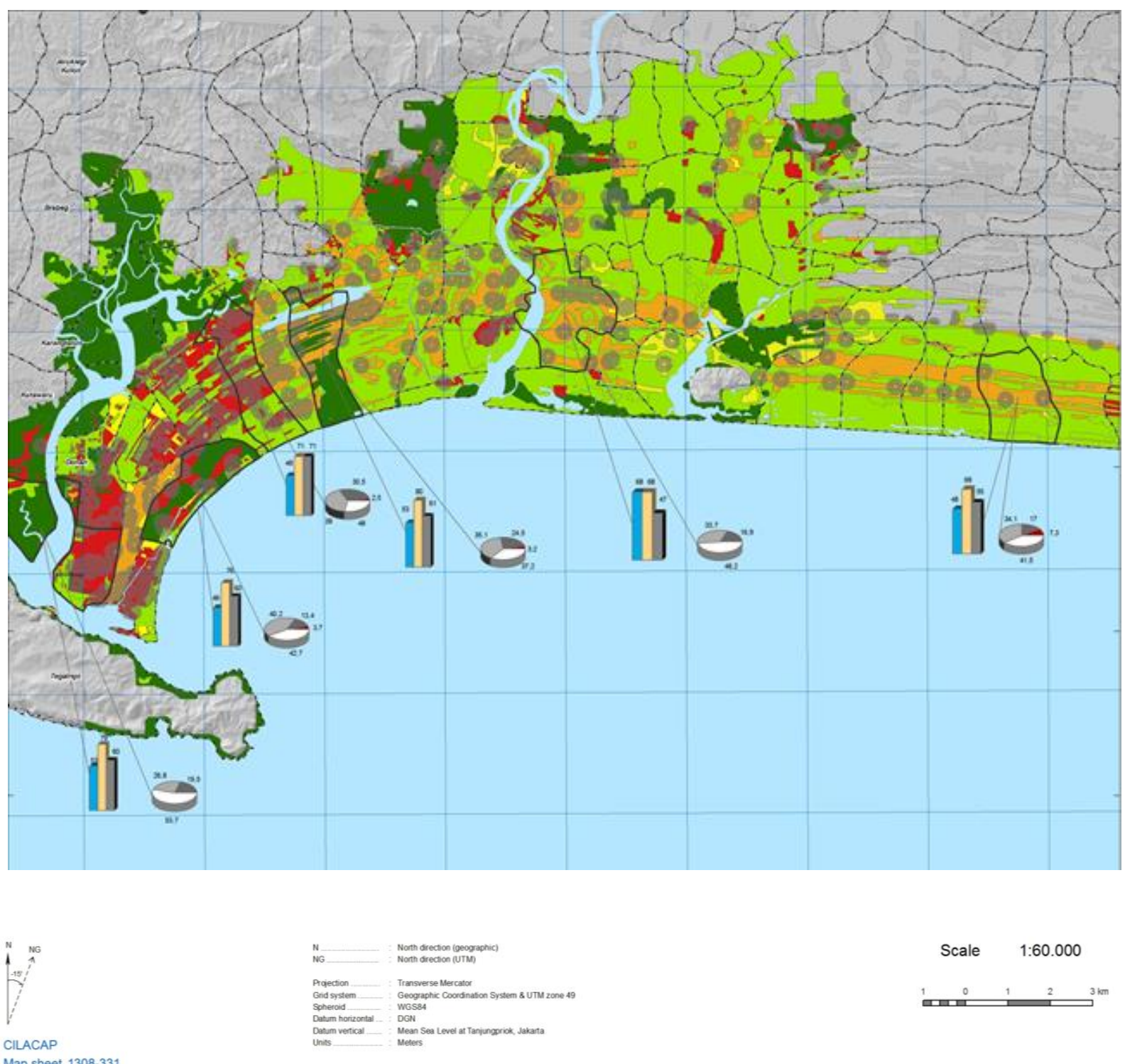

Map 4: Access to warning, of selected communities in the district of Cilacap, Java 


\section{Legend}

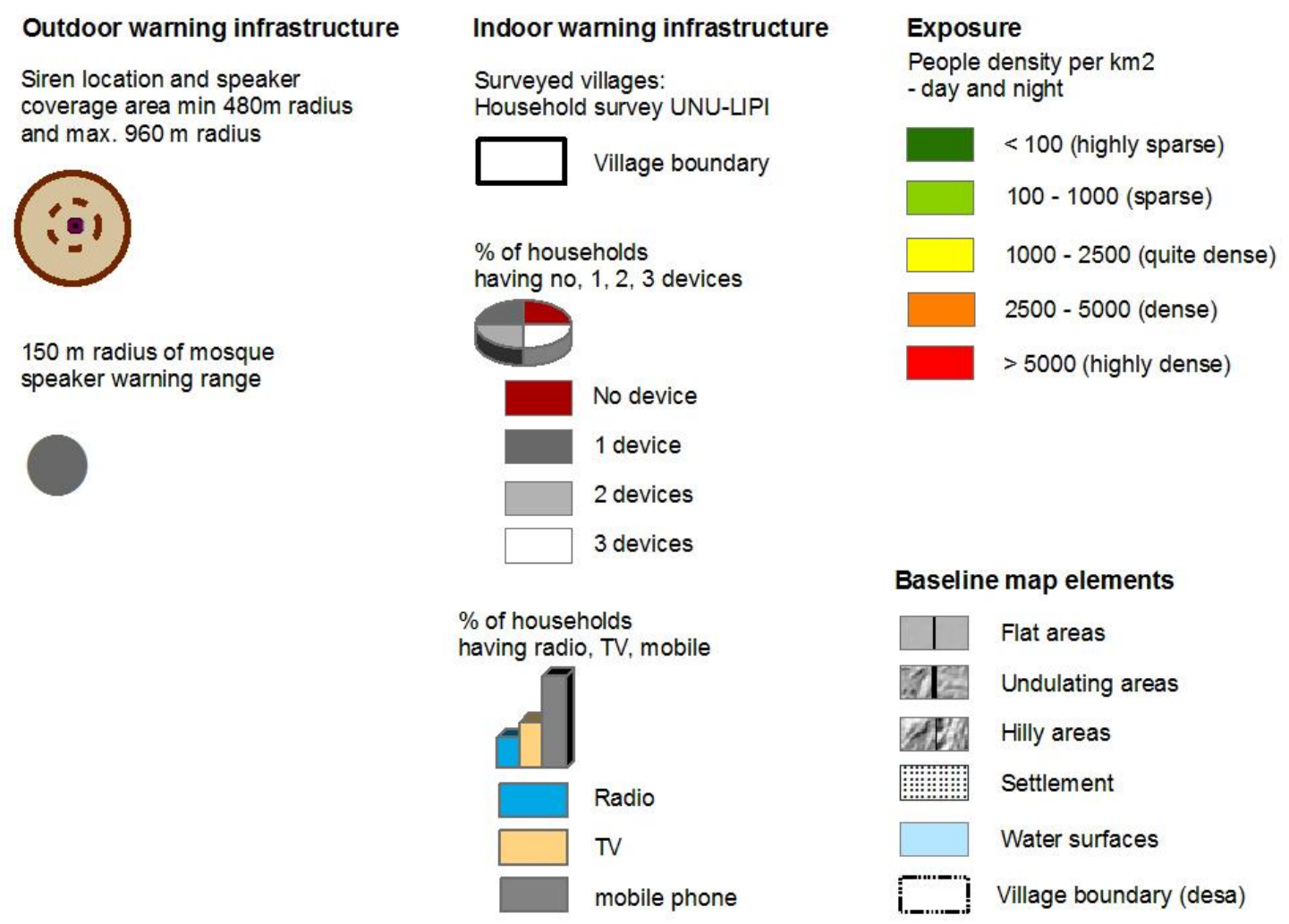

\section{VII.5.2.1 People's access to outdoor warning devices}

The map shows that since in Cilacap so far no sirens are installed and the majority of the population has a strong religious affiliation to Islam, mosques play a key role for outdoor mass warning. The results reveal that although mosques are in general quite well established in all populated areas, its current distribution pattern is not adequate to function as a hub for warning dissemination, considering the need for timely warnings to all population groups. Looking at both, population densities in the tsunami inundation zone (major warning) and the location of mosques and their spatial warning dissemination capacity, hotspots of outdoor mass notification deficiencies can be identified. With respect to this, three observations can be made that allow concluding that rural areas and non-inhabited areas seem to have the largest problems in accessing timely warnings:

- Urban areas show higher mosque densities than rural areas;

- But also in urban areas the spatial warning dissemination capacity of mosques is not sufficient;

- Especially in non-settlement areas, where a substantial amount of people work at daytime (such as in agriculture), warning dissemination infrastructure is barely existent. 


\section{VII.5.2.2 People's access to indoor warning devices}

Table 12 shows the results for the two types of information based on data collected from the household survey, measuring the populations' access to indoor mass notifications. Generally speaking for all villages, the share of households / individuals having TV at home is higher compared to radios and mobile phone, whereby the latter's availability is higher than that of radios. Very little households have no communication devices at all; to the contrary, the share of households possessing three devices is higher than of those having only two or even one device.

\begin{tabular}{lccccccc}
\hline & \multicolumn{2}{c}{ Access to devices in $\mathrm{HH}(\%)$} & \multicolumn{5}{c}{ Device diversity in HH (\%) } \\
Village & radio & TV & Mobile & No device & 1 device & 2 devices & 3 devices \\
Tambakreja & 53 & 79 & 60 & 0 & 19,5 & 26,8 & 53,7 \\
Tegalkatilayu & 46 & 76 & 60 & 3,7 & 13,4 & 40,2 & 42,7 \\
Mertasinga & 48 & 71 & 71 & 2,5 & 30,5 & 39 & 48 \\
Karangkandiri & 53 & 80 & 61 & 3,2 & 24,5 & 35,1 & 37,2 \\
Adipala & 68 & 68 & 47 & 0 & 16,9 & 33,7 & 48,2 \\
Widarapayung Wetan & 48 & 69 & 55 & 7,3 & 17 & 34,1 & 41,5 \\
\hline
\end{tabular}

Table 12: Calculation of village level access to indoor mass notification devices in Cilacap

This map allows for better location of the differences between different villages. For example, in the city centre of Cilacap, more than $50 \%$ of the population possess three devices in their households, whereas in the far eastern rural village Widarapayungwetan only $40 \%$ do so and a share of $7.3 \%$ of the population do not have any access to indoor mass warnings. The utility of the results for elaborating, assessing, selecting, and implementing R\&V-R-task specific measures is discussed in chapter VIII.3.3and VIII.3.1.

\section{VII.6 Assessing Lack of Evacuation Readiness Capacity}

In case people exposed have received a tsunami warning on time, the next question that arises is: "Are people prepared and ready to react to warnings"? (UNESCO-IOC et al. 2005) Some might do nothing, some may want to confirm the tsunami occurrence before they run, some hassle to find their children, and some run on their own to higher ground. In the face of the very limited evacuation time available, as is the case in Indonesia, inappropriate reactions to warnings are a vulnerability factor that can increase the risk of mortality during a tsunami event. 
Evacuation readiness is a social condition that varies geographically, over time and among different social groups. Identifying those factors that influence the degree of evacuation readiness as well as getting a spatial overview of different evacuation readiness levels are important to develop people-centred warning messages and socialization campaigns that aim at targeting specific population groups and increasing their evacuation readiness.

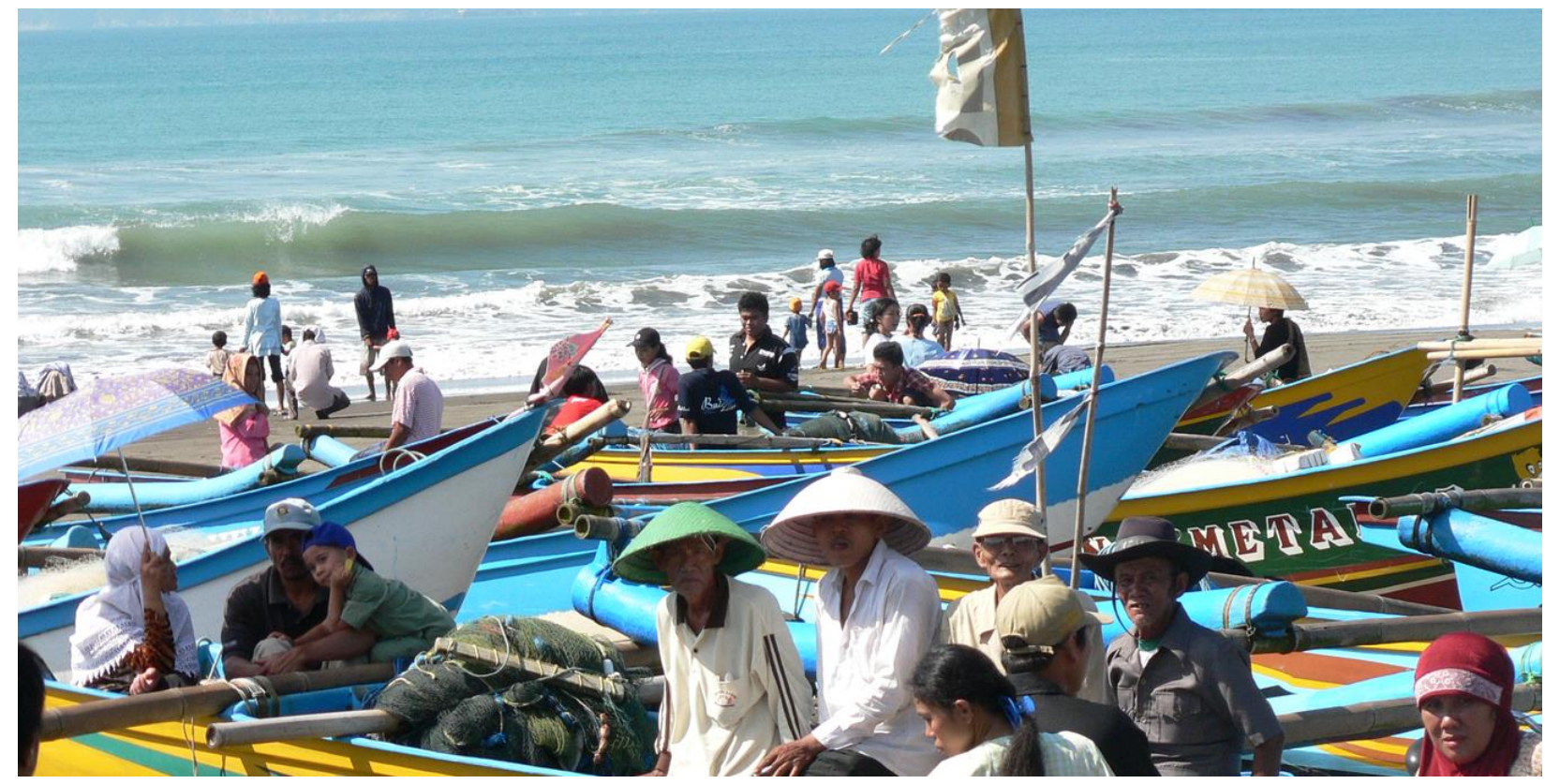

The understanding of warning response has been developed by social scientists (C.f. Lachman et al. 1961; Susan Cutter, Kent Barnes 1982; Mileti, Sorensen 1990), but has never been quantified and applied to tsunami evacuation. It is known that "evacuation is largely a function of people defining themselves as being in danger and believing that leaving the area in question is beneficial" (Fitzpatrick, Mileti 1990). The provisions of Rogers "Protection Motivation Theory" agree to this and add a few more cognitive processes that mediate behaviour such as the perceived probability of the occurrence of a hazard, or of vulnerability, the efficacy of the recommended preventive behaviour, and the perceived self-efficacy (Rogers 1975). These categories were adapted and contextualized for a tsunami related evacuation readiness assessment of exposed people in Indonesia, where evacuation readiness evolves from social spatial - technological and environmental interdependent drivers and conditions. An exploratory (qualitative) pre analysis to determine the key variables was important before testing their significance statistically and measuring levels of evacuation preparedness across different administrative boundaries and the community level. 


\section{VII.6.1 Methods}

Anticipating the actors warning response behaviour is challenging because it deals with identifying and estimating psychological and cognitive factors of individuals and groups. Conducting research in this field of vulnerability requires conducting integrated qualitative and quantitative research. Studying evacuation readiness requires research at the household level by means of questionnaire based data collection. Figure 19 shows the general methodological steps of the development of the Evacuation Readiness Index and its mapping. The overall methodological challenge was to identify the psychological (perception) and awareness (knowledge) factors that determine people's response to warnings and their evacuation readiness. The purpose of calculating an Index is to provide end users with an easy tool to communicate and discuss the factors of evacuation readiness.
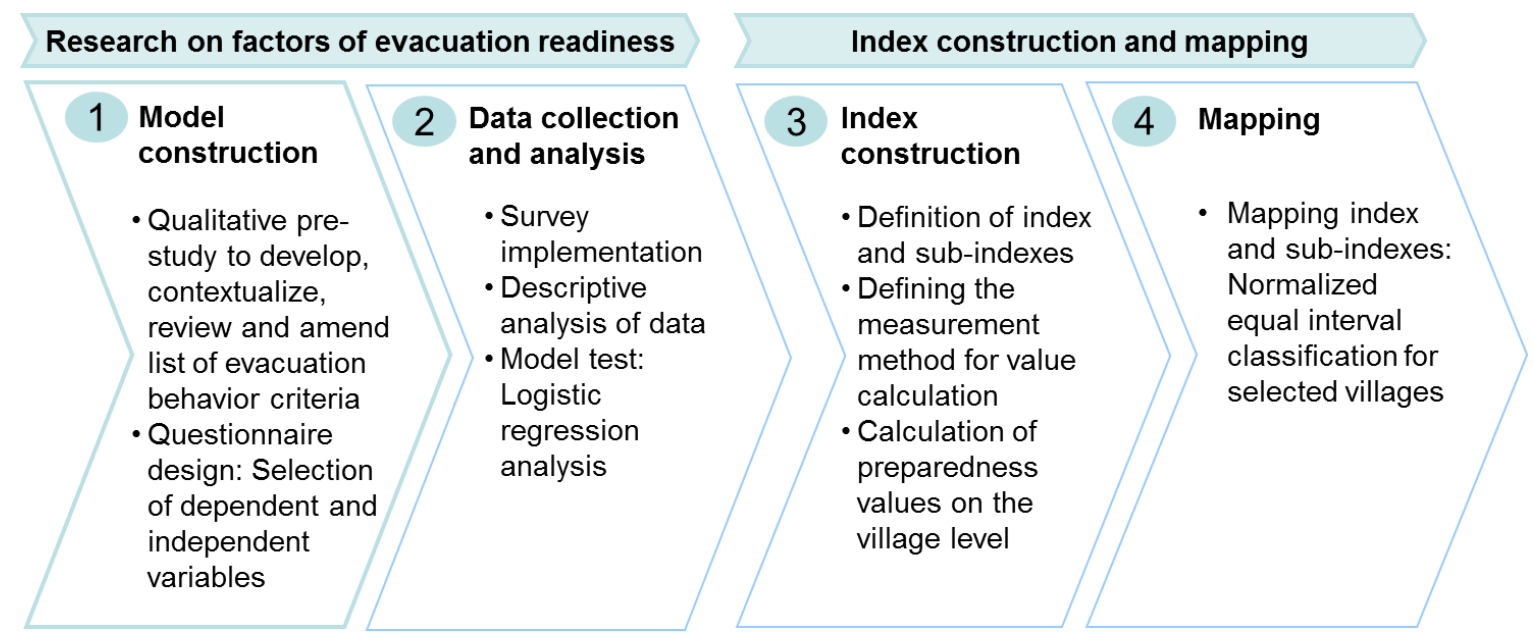

Figure 19: Methodological flowchart for constructing and mapping the Evacuation Readiness Index

This chapter explains the methods applied to identify those factors that shape individual evacuation readiness. Thus, the social science based assessment of evacuation readiness factors and levels of evacuation readiness across administrative units of concern includes the following steps:

- Household questionnaire design based on the requirements of a logistic regression model;

- Data collection;

- Data analysis using logistic regression to identify factors of evacuation readiness;

- Index construction and calculation;

- Mapping. 


\section{VII.6.1.1 Household questionnaire design}

To assess the factors of evacuation readiness, a household questionnaire ${ }^{22}$ based logistic regression analysis has been identified to be most appropriate method because it is designed to predict the probability of the occurrence of an event (anticipated evacuation yes, or no) by fitting data (set of variables influencing evacuation preparedness) to a logic curve. This means that the model aims at discovering those key factors (independent variables) that according to theory, qualitative analysis, and expert judgement are assumed to influence the individuals' decisions and speed to start evacuation after receiving a tsunami warning. The logistic regression is a generalized linear model applied for binominal regression (binominal dependent variables). Like many forms of regression analysis, it makes use of several predictor variables that may be either numerical and/or categorical (Bühl, Zöfel 2002). Constructing a social science based model for logistic regression included the definition of independent and dependent variables to be operationalised in a household survey. The variables included in the quantitative questionnaire were developed and selected based on the following analytical steps:

- Development of topics for variable selection based on theory: The Protective Motivation Theory (Rogers 1975) has acted as the theoretical background for the pre-selection of variables. The Theory assumes that cognitive processes are mediating individual and collective behaviour (Cf. VII.6);

- Qualitative pre-study; contextualization of the theory based variables:

- Defining evacuation behaviour requirements according to threat and EWS specifications in Indonesia;

- Semi-Structured Interviews (SSI) with exposed households and stakeholder consultations (workshops of the Indonesian - German Working Group on Tsunami R\&V-A ).

\section{Selection of dependent variables}

Eight response options were provided in the questionnaire to allow respondents to precisely reflect on, imagine, and judge on their hypothetical anticipated action after receipt of a tsunami

\footnotetext{
${ }^{22}$ The full questionnaire can be viewed in Annex XII.2
} 
warning alert. In order to use these variables as dependent variables in the logistic regression analysis, each variable was also defined as "quick" and "slow / no" warning alert response variable (Cf. Table 13).

Table 13: Dependent variables in the household questionnaire

$\begin{array}{ll}\begin{array}{l}\text { Question: Directly after having received a tsunami warning: What would you do immediately? } \\ \text { Quick }\end{array} & \text { I would immediately run to a safe place myself } \\ \text { Quick } & \text { I would gather my family members and then run to a safe place } \\ \text { Slow / no } & \text { I would listen to the radio or TV and wait for further instructions } \\ \text { Slow / no } & \text { I would go away from the beach } \\ \text { Slow / no } & \text { I would immediately run to the coast to observe and confirm } \\ \text { Slow / no } & \text { I would immediately inform and seek confirmation with my neighbours and friends around } \\ \text { Slow / no } & \text { I would follow what others do } \\ \text { Slow / no } & \end{array}$

This approach (asking close to reality hypothetical questions and then recoding into a dependent variable) yields a more robust database on people's anticipated response to tsunami warnings than confronting respondents with a quite technical binominal variable that does not represent people's world views with regard to their anticipated warning response behaviour.

\section{Selection of a set of independent / predictor variables to be used in a household survey}

What are the variables that are assumed to influence / predict people's response behaviour to tsunami alerts? Finally, 35 predictor variables (independent variables) were selected for the logistic regression assumed to represent those cognitive processes that shape the response of individuals to tsunami warnings in the case of Indonesia (Table 14)

Table 14: Overview of the survey parameters

Variables for the regression analysis

1 Correct tsunami definition

2 Correct knowledge of natural tsunami indications

3 Correct knowledge of estimated time of tsunami arrival (ETA)

4 Perception of the determinants of tsunami harm: Sins committed by society/politics

5 Perception of the determinants of tsunami harm: Many people live in the exposed area

6 Perception of the determinants of tsunami harm: People don't have enough preparedness

7 Generally I am very worried because tsunamis can strike anytime

8 I feel worried that my own home will be seriously damaged

9 I feel worried that myself or my loved ones will be hurt

10 I am not afraid of tsunamis

11 Your utmost concern: Income insecurity

12 Your utmost concern: Tsunamis 


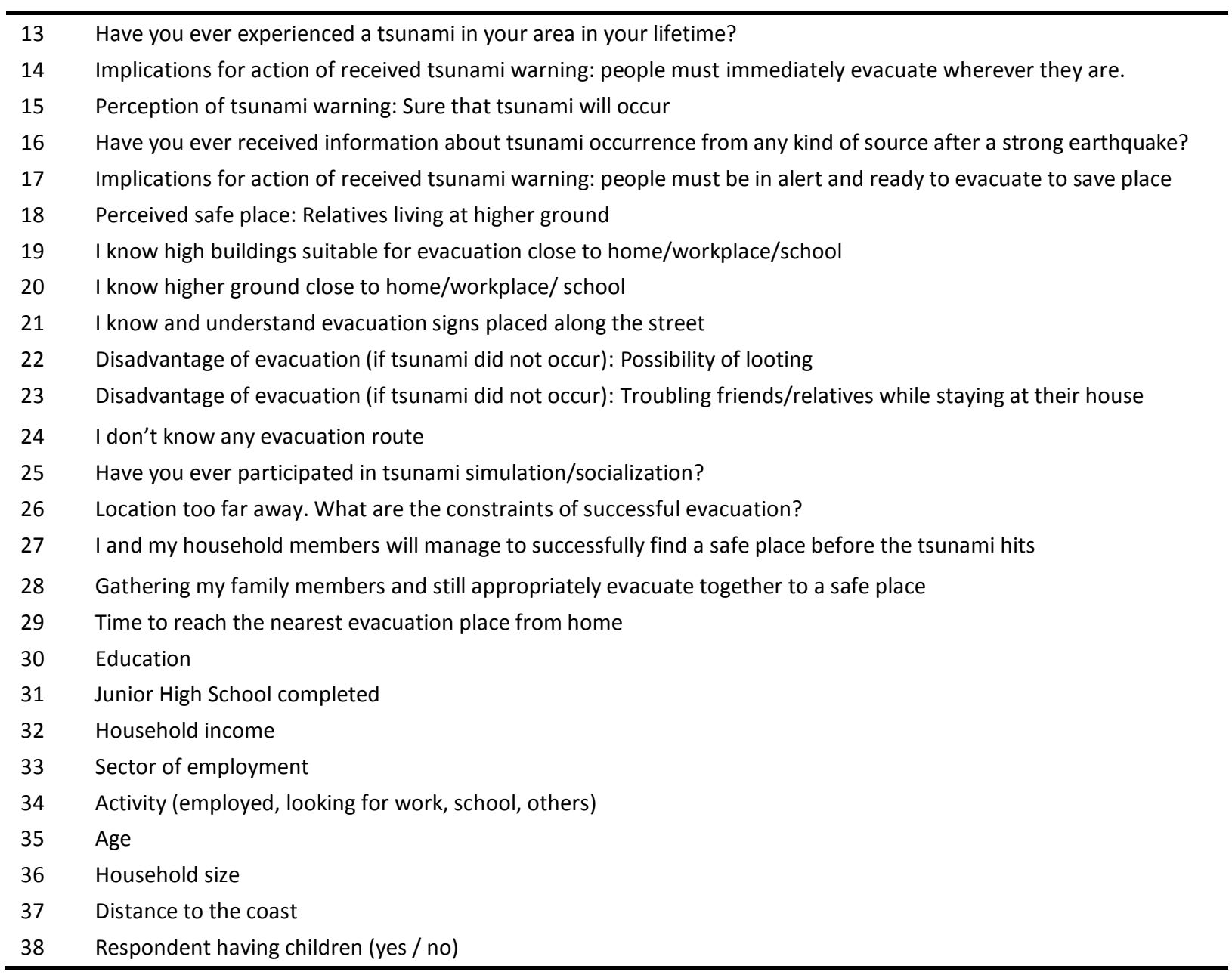

\section{VII.6.1.2 Data collection and survey sampling}

To define the number of survey samples and select sample locations it was necessary to define the product goal and desired output. Measuring evacuation readiness and developing decision support products for awareness rising and sensitization requires developing indicators whose values are representative for the decision makers' geographic territory of political power.

Thus, the survey sampling definition is based on the following steps:

1. Definition of the representative unit of analysis

2. Sample size selection

3. Sample location selection

4. Household selection

The household survey data were collected in 2008 in the three pilot areas of InaTEWS (Padang, Cilacap, Badung) with a total of 2000 households in 20 villages. The data were collected jointly with Andalas University (Padang) and Ghajah Mada University (Yogyakarta). The sampling 
method, sample size and the selection of villages to survey were defined according to the survey's goals. Since it was intended to develop an Evacuation Readiness Index, the following choices were made:

\section{Definition of the representative unit of analysis}

The evacuation readiness assessment results were defined to be representative at the village level. This scale has been chosen because it allows for a spatial analysis of evacuation readiness at different exposure levels. In addition, it allows for prioritizing and designing village specific socialization campaigns, depending on the level of evacuation readiness within a village.

\section{Sample size}

For the assessment to be representative at the village level, the sample size needs to be selected according to the social structure and its heterogeneity within a village. Generally speaking, the higher the heterogeneity is, the higher the sample size. In this case the sample size for each village ranges from 60 - 90 households. In total, 2000 households were surveyed in 24 villages.

\section{Household selection: Stratified sampling}

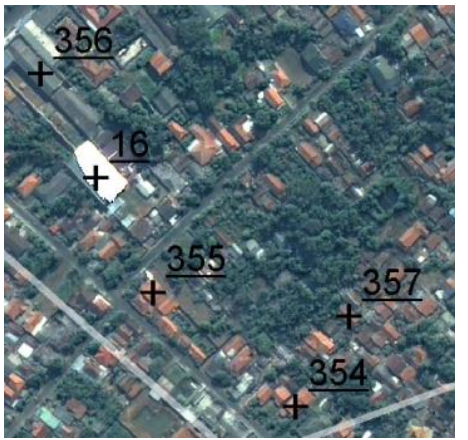

Due to the lack of precise socio-economic sampling data for different villages / city wards, the household samples were selected based on remote sensing analysis of the physical urban structure of residential areas (building type, density and size, rural/urban area). Thereby, it is assumed that the physical structure corresponds with the socio-economic structure of the household entities residing in the respective building. Thus, in order to include all sub-groups of the population, an equal share of the different residential building types that exist within a village was selected randomly. The precise remote-sensing based pre-selection of single households was only possible in urban Padang and Cilacap due to the availability of highResolution Ikonos satellite imagery. For the more rural areas and for Badung (Bali) simple random sampling has been conducted.

\section{Village Selection}




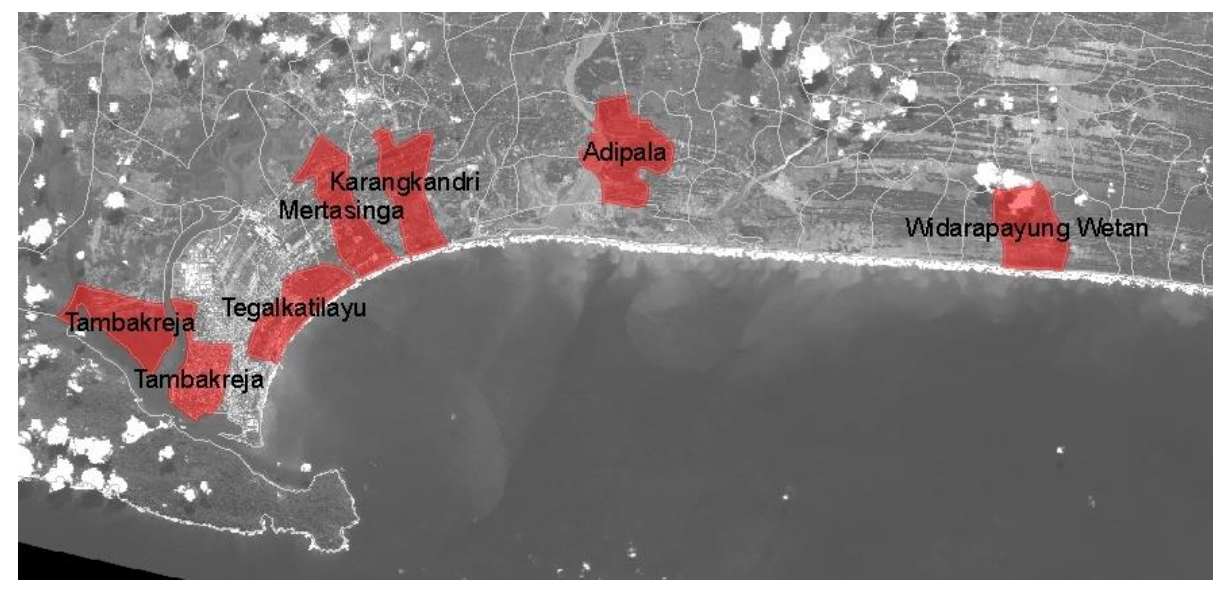

Map 5: Selected city wards / villages in Kabupaten Cilacap

The criteria 'coastal / hazard exposed' and 'regional / developmental difference' were the two main criteria applied for selecting the villages of interest for the study. In the case of Cilacap (Map 5), all villages selected are coastal, whereby two are urban (Tambakreja, Tegalkatilayu), two semi-urban (Mertasinga, Karangkandiri) and two rural (Adipala, Widarapayung Wetan).

Also in the study area of South Bali, the villages selected are all coastal representing the most touristic area on the island, except for Tibubeneng, whose structures are still in transition from rural / agricultural to solely tourism-based ones (compare map om Annex XII.1.2.1). In Padang, due to available resources twelve city wards could be surveyed (compare map in Annex XII.1.2.2). Thereby, a comparison of the household survey results according to the different hazard zones was possible

\section{VII.6.1.3 Data analysis: Logistic Regression}

The data analysis has been conducted using SPSS (Statistical Package for Social Science). Before conducting the multivariate analysis, descriptive analysis of the data was important to judge whether the data were good enough to be utilized for further analysis. The regression models were performed separately for each pilot area (Cilacap, Bali and Padang) considering the fact that those variables showing strong influence do not have to be identical for all those areas because of location specific differences.

\section{VII.6.1.4 Index Calculation and Mapping}

The single evacuation readiness factors identified in the logistic regression were aggregated into understandable and logic clusters, here termed sub-indexes. To derive aggregated information about the degree of evacuation readiness of the population that can be used by decision 
makers, the factors identified in the regression analysis were grouped into sub-indexes and labelled according to their logic association. Finally, an aggregated Evacuation Readiness Index was created (Figure 20).

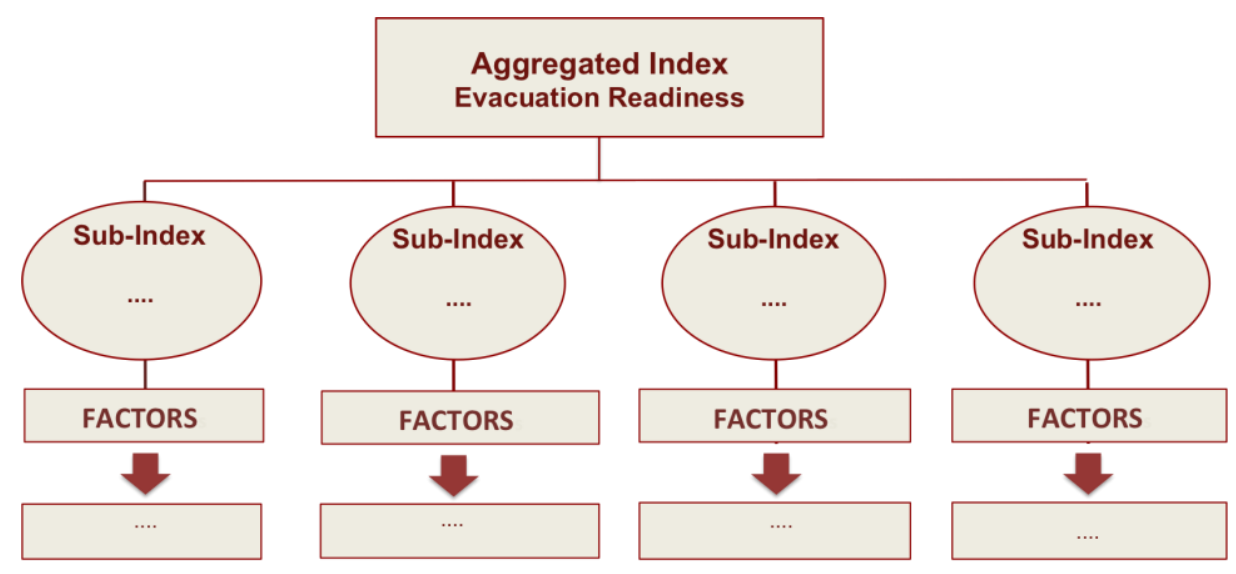

Figure 20: Evacuation readiness sub-indexes and aggregated index

Figure 20 shows the set up and clustering of the evacuation readiness factors into a number of sub-indexes. Finally, an overall Evacuation Readiness Index was developed. To measure the degree of evacuation readiness and its sub-indexes at the village level the following calculation steps were conducted (Cf. Figure 21).

1. Developing a scoring system: Recoding the case values of each variable into " 0 ", " 0.5 ", " 1 ". The higher the value the more likely the specific factor contributes to overall evacuation readiness.

2. Aggregation by calculating mean values: All case values of variables belonging to the same village were aggregated.

3. Sub-(index) calculation: To derive sub-index values, village level mean values of the variables belonging to a sub-index were calculated. The same procedure was applied to derive evacuation readiness index values.

4. Grouping of the index values: The index values were grouped into four levels of evacuation readiness using the equal interval method: very low, low, high, very high. 


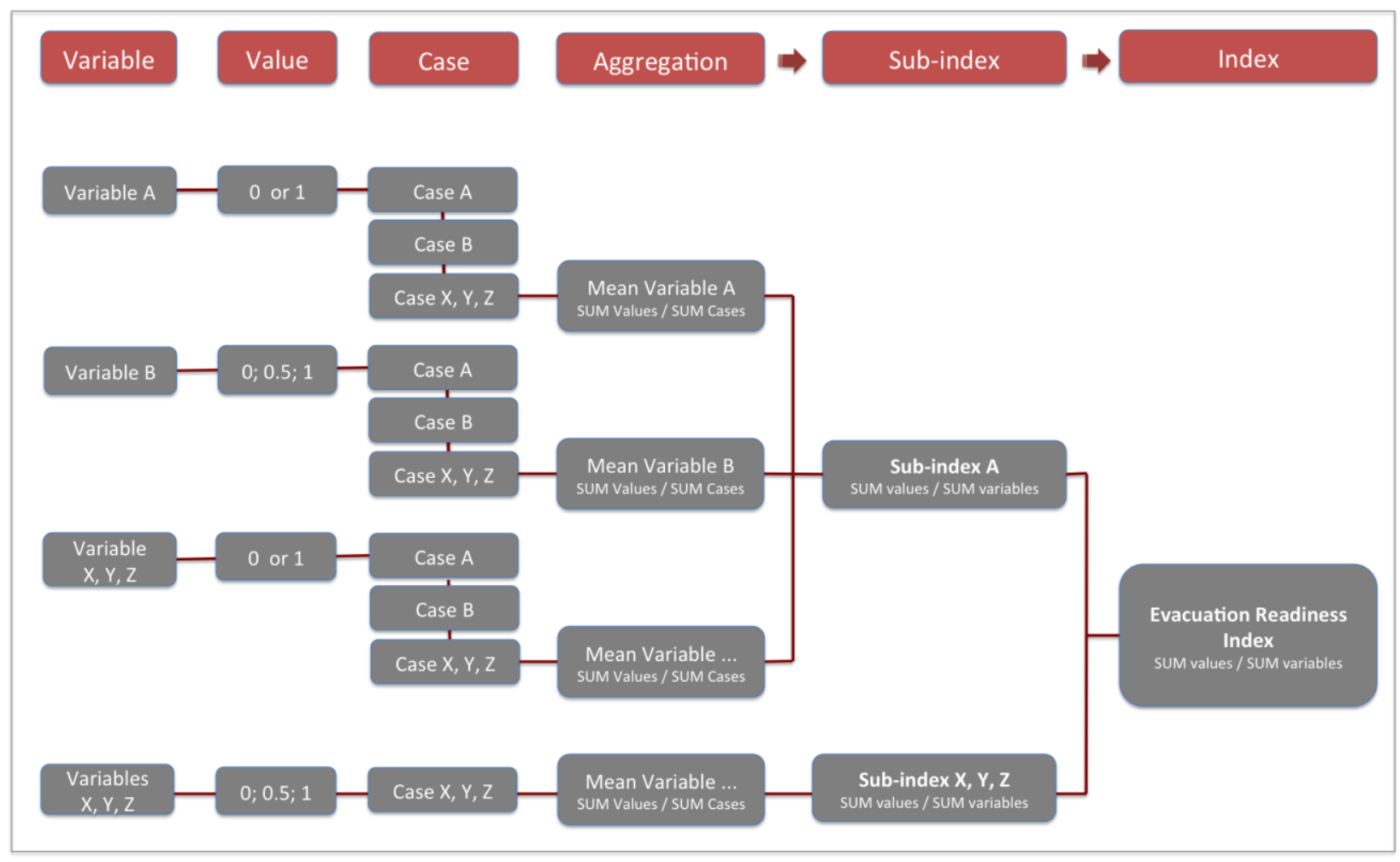

Figure 21: Evacuation Readiness Index construction

Finally, the index and sub-index results were mapped for each surveyed village in the three pilot areas. Here an equal intervals classification scheme was employed.

\section{VII.6.2 Results}

In the following two different types of evacuation readiness information packages are presented. End users can choose themselves which are most helpful to manage programmes that increase the evacuation readiness of their citizens. Two products are described in detail as follows as well as their area of application:

1. Factors of evacuation readiness: Awareness creation amongst stakeholders involved in EWS governance and design of the content of awareness material.

2. Measured and mapped index and sub-indexes of evacuation readiness: Understanding the degree and spatial distribution of individuals' evacuation readiness.

VII.6.2.1 Descriptive Analysis of the Dependent Variables: Anticipated Response Behaviour The descriptive data analysis of the dependent variables of Cilacap and Bali shows that there is a diversity of anticipated responses to tsunami warnings amongst the test group (Figure 22). 


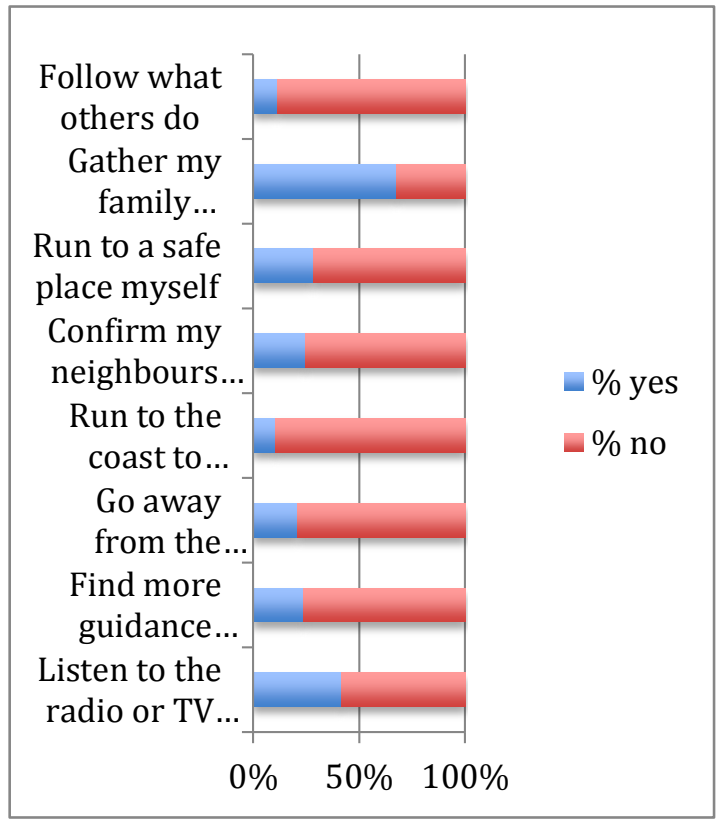

Cilacap

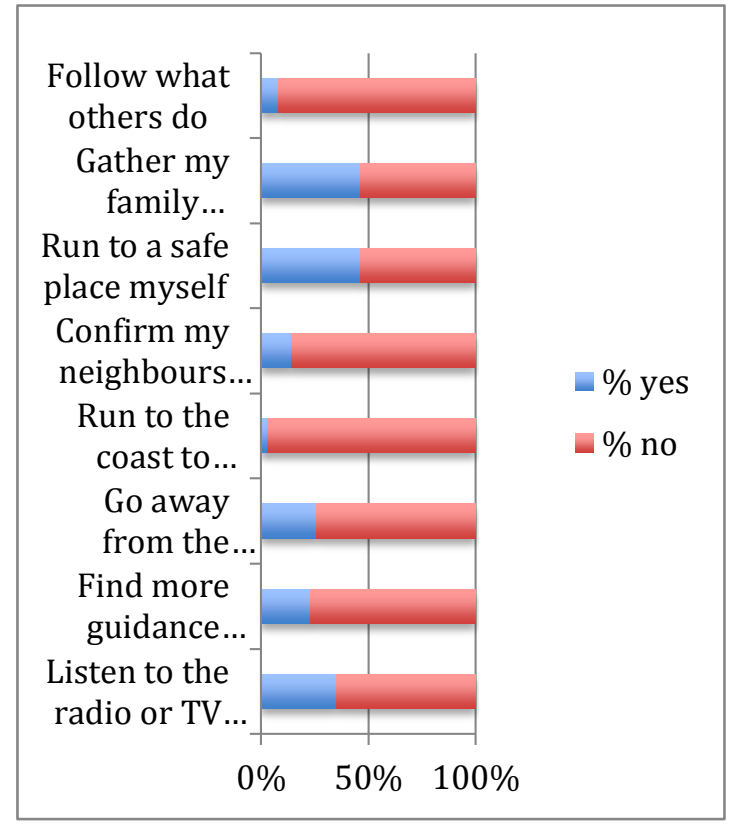

Bali

Figure 22: Respondents anticipated response to tsunami warning in Cilacap and Bali

Although a large proportion of the respondents indicate that they would either run to a safe place themselves or gather their family members first and then run to a safe place (quick response), there is a significant amount of respondents preferring to conduct other activities prior to evacuation. Amongst them are to wait for further instructions or confirmation of tsunami occurrence from the radio, TV, the mosques or even friends and neighbours. Even $10 \%$ of the respondents in Cilacap chose to get direct confirmation by observing changes in sea water levels. Obviously, the respondents have subjective reasons for not responding to tsunami warnings and its associated threat. The results show clearly that the social response to technological systems is non-linear. This is an expected result that is less useful for the development of contextual socialization measures and preparedness strategies when the underlying factors that shape a specific behaviour pattern during an alarming event are not known.

\section{VII.6.2.2 Logistic Regression Results: Factors Influencing Individuals` Evacuation Readiness}

Table 15 shows for all pilot areas those variables that were identified in the "full model" (all case study areas) as being significant $(P>|z|=$ close to 0 , values can be between 0 and 1$)$. Thereby, out of 38 variables 22 were identified to possess a statistically significant impact on the individuals' response to tsunami warnings. 
Table 15: Significant variables for all three pilot areas

\begin{tabular}{|c|c|c|c|}
\hline Variables significant in the "full model" & Padang & Cilacap & Bali \\
\hline Correct definition of tsunami & $\mathbf{x}$ & & \\
\hline Correct knowledge of natural signs of tsunami occurrence & $\mathbf{x}$ & & \\
\hline Correct knowledge of Estimated Time of Tsunami Arrival (ETA) & & $\mathbf{x}$ & \\
\hline Hazard occurrence perception: Tsunami can strike anytime & $\mathbf{x}$ & & \\
\hline $\begin{array}{l}\text { Perception of the determinants of tsunami harm: People don't have } \\
\text { enough protection and preparedness }\end{array}$ & $\mathbf{x}$ & & \\
\hline $\begin{array}{l}\text { Perception on the determinants of tsunami harm: Sins committed by } \\
\text { society/politics }\end{array}$ & & & $\mathbf{x}$ \\
\hline $\begin{array}{l}\text { Implications of tsunami occurrence: Home will be destroyed (exposure } \\
\text { perception) }\end{array}$ & $\mathbf{x}$ & & \\
\hline $\begin{array}{l}\text { Implications of tsunami occurrence: Myself or loved ones will be hurt/ } \\
\text { killed (exposure perception) }\end{array}$ & & & $\mathbf{x}$ \\
\hline Fear of tsunami: Yes & & $\mathbf{x}$ & \\
\hline Perceived upmost concern in everyday life: Priority is the tsunami & & $\mathbf{x}$ & $\mathbf{x}$ \\
\hline $\begin{array}{l}\text { What to do in case of warning: Residents must be aware and wait for } \\
\text { further instructions }\end{array}$ & & $\mathbf{x}$ & \\
\hline Implications of warnings: Sure that the tsunami will happen & $\mathbf{x}$ & & $\mathbf{x}$ \\
\hline What to do in case of warning: People must evacuate immediately & & $\mathbf{x}$ & $\mathbf{x}$ \\
\hline Perceived safe place: Relatives living at higher ground & & $\mathbf{x}$ & $\mathbf{x}$ \\
\hline Evacuation buildings knowledge: Yes & & $\mathbf{x}$ & \\
\hline Evacuation signs knowledge: Yes & $\mathbf{x}$ & & $\mathbf{x}$ \\
\hline Evacuation routes knowledge: No knowledge & $\mathbf{x}$ & $\mathbf{x}$ & \\
\hline $\begin{array}{l}\text { Evacuation manageability: Gathering my family members and still } \\
\text { appropriately evacuate together to a safe place }\end{array}$ & $\mathbf{x}$ & & \\
\hline Household's distance to the coast & $\mathbf{x}$ & & \\
\hline High Income & & $\mathrm{x}$ & \\
\hline Age & $\mathbf{x}$ & & \\
\hline Household size & & & $\mathbf{x}$ \\
\hline
\end{tabular}

But before getting an understanding of how to interpret the variables' statistical behaviour in the model, its validity and accuracy need to be proven.

\section{VII.6.2.3 Accuracy and Validity of the Model: Model Fit Measures}

The interpretation of the logistic regression results is based on two steps:

1. A set of model fit measures explains the accuracy of the "top model": LR chi2 test, Pseudo-R square, Hosmer-Lemeshow test, classification table.

2. A set of measures provides information on how to interpret each of the variables in the model. 
For an overview the key model fit measures for all pilot areas are shown in Table 16.

Table 16: Model fit measures for Cilacap, Bali, and Padang

\begin{tabular}{lccc}
\hline & $\mathrm{p}$-value for LR chi ${ }^{2}$ test & $\begin{array}{c}\mathrm{p} \text {-value for Hosmer- } \\
\text { Lemeshow test }\end{array}$ & Pseudo-R squared \\
\hline Padang (N=933) & 0.000 & 0.430 & 0.110 \\
\hline Cilacap ( $\mathbf{N = 5 0 5 )}$ & 0.000 & 0.685 & 0.142 \\
\hline Bali $(\mathbf{N}=\mathbf{5 0 1})$ & 0.000 & 0.981 & 0.145 \\
\hline
\end{tabular}

The following detailed presentation and explanation of the model results is based on the example of Cilacap:

a) LR chi2 (Likelihood ratio chi ${ }^{2}$ ) test: Prob $>$ chi2 $=0.000$

The LR chi2 tests the 0-hypotheses that the independent variables do not contribute to the explanation of the variance of the dependent variables.

If the $p$-value (=Prob > chi2) is close to zero, it can be assumed that at least one of the variables contributes to the explanation of the variance of the dependent variables. The results show that the variables selected in the "top model" are to be acknowledged as important factors that influence a household's reaction pattern to tsunami warnings.

\section{b) Pseudo-R square: 0.19}

This measure explains how much of the variance of the observed dependent variables can be explained through the predicted variance. The values of the Pseudo-R square measure are always fluctuating between 0 and 1 , the higher the value the more of the variance is explained. In the case of Cilacap $19 \%$ of the variance of the observed dependent variables can be explained. The rest of the variance is assumed to be a non-linear relationship between the dependent and independent variables which cannot be captured through this measure. Thus, although this measure seems to be important, it has been developed for engineering science and not for social science. The complexity of interrelationships between variables in social science and cognitive models cannot be revealed by the Pseudo-R square measure alone.

c) Hosmer-Lemeshow test: $p$-value: 0,68 
This measure explains the probability that the predicted and observed frequencies of the dependent variables (fast and slow response group) match. The higher the value the better the model fit. A p-value of 0.5 is regarded as the starting point for accepting a certain accuracy of the model, but values at around 0.5 are needed to be treated carefully. A value of 0.7 is considered as good. Judging the values for Cilacap $(0,685)$ and Bali $(0.981)$ against these scientifically accepted benchmarks, the model can be considered as quite good, whereas the model for Padang is not as good (0.43).

\section{d) Classification table as model fit measure: Correctly classified $80.00 \%$}

In the classification process one of the two predicted dependent variable values will be classified into each empirically observed case, 0 or 1 (slow and quick response group). Normally, a value of 1 will be classified into an observed value if the model predicts a probability of above 0.5 , whereas if the probability is below 0.5 , a value of 0 will be attributed to the observed value. The classified values of the dependent variable are typically displayed in a classification table. The table is a simple cross tabulation of the classified values with the empirically observed values (See Table 17). 
Table 17: Observed and classified sample cases for Cilacap

\begin{tabular}{l|lll}
\hline & \multicolumn{3}{|c}{ True / observed cases } \\
\hline $\begin{array}{l}\text { Classified / } \\
\text { predicted }\end{array}$ & Quick resp. & Slow resp. & Total \\
Quick resp. & 371 & 93 & 464 \\
Slow resp. & 13 & 28 & 41 \\
\hline Total & 384 & 121 & 505 \\
\hline
\end{tabular}

As can be seen from Table 8, in the case of Cilacap, 464 cases were predicted and classified in the quick response group, but only 371 of those were classified correctly and 93 were wrong. On behalf of the slow response group, 41 were predicted and classified in the slow response group of which 28 were correctly classified and 13 were not.

Thus the percentage of correctly predicted / classified overall values is calculated as follows:

$$
r \text { count }=(371+28) / 505 * 100=79,00 \%
$$

The value is quite good showing that the prediction of a household to belong to a quick response group can be roughly approximated through assessing household or individual hazard knowledge, vulnerability perception, warning perception, evacuation perception, social indicators, and the average distance of a household to the sea.

VII.6.2.4 Interpretation of the Results for Single Variables

A standard coefficient for single variable interpretation is the odds ratio: It determines the direction of the influence of the variable: The higher the value is above 1 the more likely the respondent belongs to a fast response group and vice versa. 
Table 18: Model fit measures for top model variables in Cilacap

\begin{tabular}{|c|c|c|c|c|c|c|}
\hline $\begin{array}{l}\text { Variables that influence the probability to belong } \\
\text { to the quick response group }\end{array}$ & Odds ratio & $\begin{array}{l}\text { Std. } \\
\text { Err }\end{array}$ & z & $P>|z|$ & \multicolumn{2}{|c|}{$\begin{array}{l}95 \% \text { Conf. } \\
\text { Interval }\end{array}$} \\
\hline $\begin{array}{l}\text { Correct knowledge of "Estimated Time of Tsunami } \\
\text { Arrival" (ETA) }\end{array}$ & 1.67 & 0.10 & -3.45 & 0.001 & 0.29 & 0.71 \\
\hline Fear of tsunamis: Yes & 1.45 & 0.21 & 2.52 & 0.012 & 1.09 & 1.93 \\
\hline $\begin{array}{l}\text { Perceived upmost concern in everyday life: } \\
\text { Priority is tsunami }\end{array}$ & 1.23 & 0.17 & 1.51 & 0.132 & 0.94 & 1.60 \\
\hline $\begin{array}{l}\text { In case of tsunami warning residents must be } \\
\text { aware and wait for further instructions }\end{array}$ & 0.58 & 0.11 & -2.85 & 0.004 & 0.39 & 0.84 \\
\hline $\begin{array}{l}\text { In case of a tsunami warning residents must } \\
\text { evacuate immediately }\end{array}$ & 1.24 & 0.21 & 1.29 & 0.198 & 0.89 & 1.72 \\
\hline $\begin{array}{l}\text { Perceived safe place: Relatives living at higher } \\
\text { ground }\end{array}$ & 8.53 & 6.49 & 2.82 & 0.005 & 1.92 & 37.90 \\
\hline Evacuation buildings knowledge: Yes & 2.13 & 0.66 & 2.45 & 0.014 & 1.16 & 3.90 \\
\hline No knowledge of evacuation routes & 0.22 & 0.08 & -4.02 & 0.000 & 0.10 & 0.46 \\
\hline High income & 1.89 & 0.67 & 1.80 & 0.072 & 0.94 & 3.78 \\
\hline
\end{tabular}

The results for Cilacap are taken as an example for interpreting the Odds ratio for each of the significant variables $(P>|z|)$, here. They are discussed according to the categories associated with the variables (, first column):

- Hazard knowledge: E.g. respondents possessing the correct knowledge of the Estimated Time of Tsunami Arrival (ETA $<=30 \mathrm{~min}$ ) rather tend to respond quickly to a given warning.

- Vulnerability perception: Those respondents, who generally fear a tsunami impact and those who even consider and perceive a tsunami as a major threat unlike other threats such as car accidents or the struggle for daily livelihoods, rather tend to quickly respond to tsunami warnings.

- Perception of the implications for action of tsunami warnings: Respondents, who rather expect guidance for action and not just a tsunami warning alert, tend to hesitate before they start evacuation. Vice versa, those who understand tsunami warning alerts as an indirect call for evacuation, also tend to quickly respond to warnings and evacuate immediately.

- Evacuation perception: The knowledge of evacuation routes and safe areas (higher ground or vertical shelters) is of utmost importance for quick reactions to tsunami warning alerts. 
Especially those who are familiar with the shelters accessible to them (relatives living at higher ground) tend to quickly respond to warnings.

- Socio-economic features of the respondents: In general, the analysis does not provide information of a specific social group that tends to respond slowly or quickly to tsunami warnings. In this model, income plays the sole role. It assumes that the higher the incomeclass the higher the probability of quick response. Also a qualitative assessment of the triggers for warning response revealed that low income groups rather fear not being able to maintain their livelihoods if they evacuate as a consequence of its time consuming nature.

A summary of the identified factors in the logistic regression analysis that influence individuals' evacuation readiness is provided in Table 19. The knowledge of these factors is of utmost importance for designing effective socialization and awareness strategies and thus to enhance overall evacuation readiness.

Table 19: Factors of Evacuation Readiness

1. Knowledge of tsunami definition

2. Knowledge of tsunami indications

3. Knowledge of tsunami ETA

4. Tsunami seen as permanent danger

5. Knowledge about own exposure

6. Cause of harm: Not enough protection \& preparedness

7. Tsunami regarded as major concern

8. Fear of tsunamis

9. Warnings relate to call for Immediate evacuation

10. EWS precisely predicts tsunami occurrence

11. Knowledge of safe area

12. Knowledge of safe building

13. Knowledge of routes and signs

14. Perceived manageability of evacuation
E.g. respondents possessing the correct knowledge of the Estimated Time of (Tsunami Arrival) (ETA $<=30 \mathrm{~min}$ ) rather tend to respond quickly to a given warning.

Those respondents, who generally fear a tsunami impact and those who even consider and perceive a tsunami as a major threat unlike other threats such as car accidents or the struggle for daily livelihoods, rather tend to quickly respond to tsunami warnings.

Respondents, who rather expect guidance for action and not just a tsunami warning alert, tend to hesitate before they start evacuation. Vice versa, those who understand warning alerts as an indirect call for evacuation, also tend to quickly respond to warnings and evacuate immediately.

The knowledge of evacuation routes and safe areas (higher ground or vertical shelters) is of utmost importance for quick reactions to tsunami warning alerts. Especially those who are familiar with the shelters accessible to them (relatives living at higher ground) tend to quickly respond to warnings. 
The results show that in the absence of warning guidance information and evacuation infrastructure it is very unlikely that the population will start timely evacuation. Also when the population has no knowledge of tsunami threats (and their specific characteristics) as well as their degree of exposure, proceeding to evacuation is highly unlikely.

\section{VII.6.2.4.1.1 Evacuation Readiness Index}

The set of sub-indexes and the final Evacuation Readiness Index are designed to measure the degree of evacuation readiness of the population in a way that it is of use for decision makers. Based on this indexing system, evacuation readiness is measured, allowing disaggregating or getting an overall picture of evacuation readiness. Measuring evacuation readiness allows for comparing the degree of evacuation readiness of individuals, villages or districts. The example given here is the aggregation of the survey and analysis results at the village level The Evacuation Readiness Index is composed of the following sub-indexes representing the contributing factors to overall evacuation readiness: hazard knowledge, vulnerability perception, warning perception, and evacuation perception.

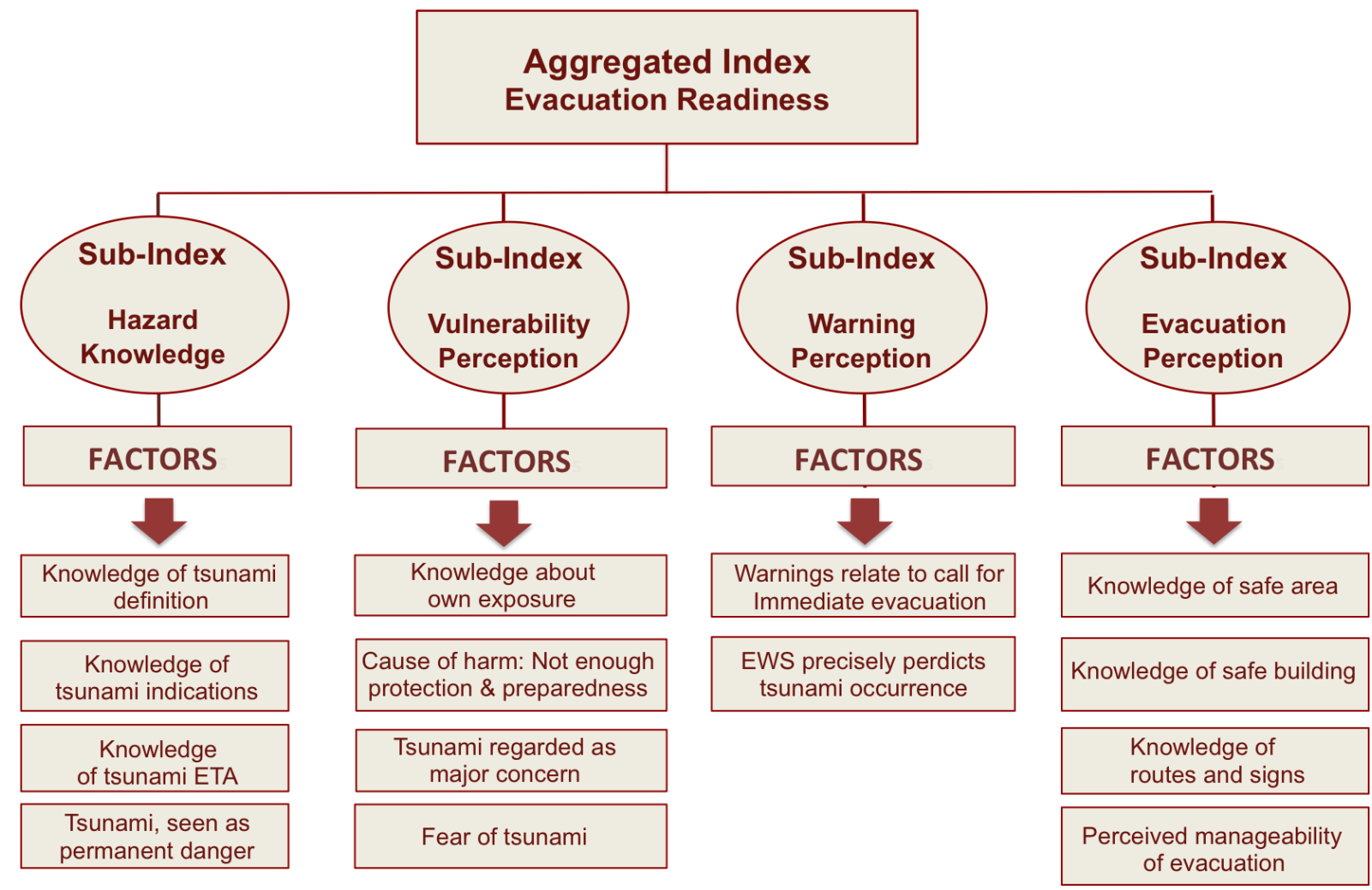

Figure 23: Evacuation readiness sub-indexes and aggregated index 
The index generated can be displayed in various ways. The example presented here shows the visualization of the index results in the form of tabular data, bar charts (Figure 24, Figure 25) and maps (Cf. Map 6). Overall the index results are presented as the percentage of individuals within a village having "very low", "low", "high", and "very high" levels of aggregated evacuation readiness capacity, as well as its contributing components: hazard knowledge, evacuation, warning, and vulnerability perception. They indicate how the different averaged readiness levels of households are distributed across surveyed villages.

One added value of mapping is to receive an overview of the spatial distribution of evacuation readiness and its factors. Mapping the results is also interesting, and provides a spatial dimension in the distribution of the results. 


\section{Case Study Part 3 - Empirical Research; Methods and Results}
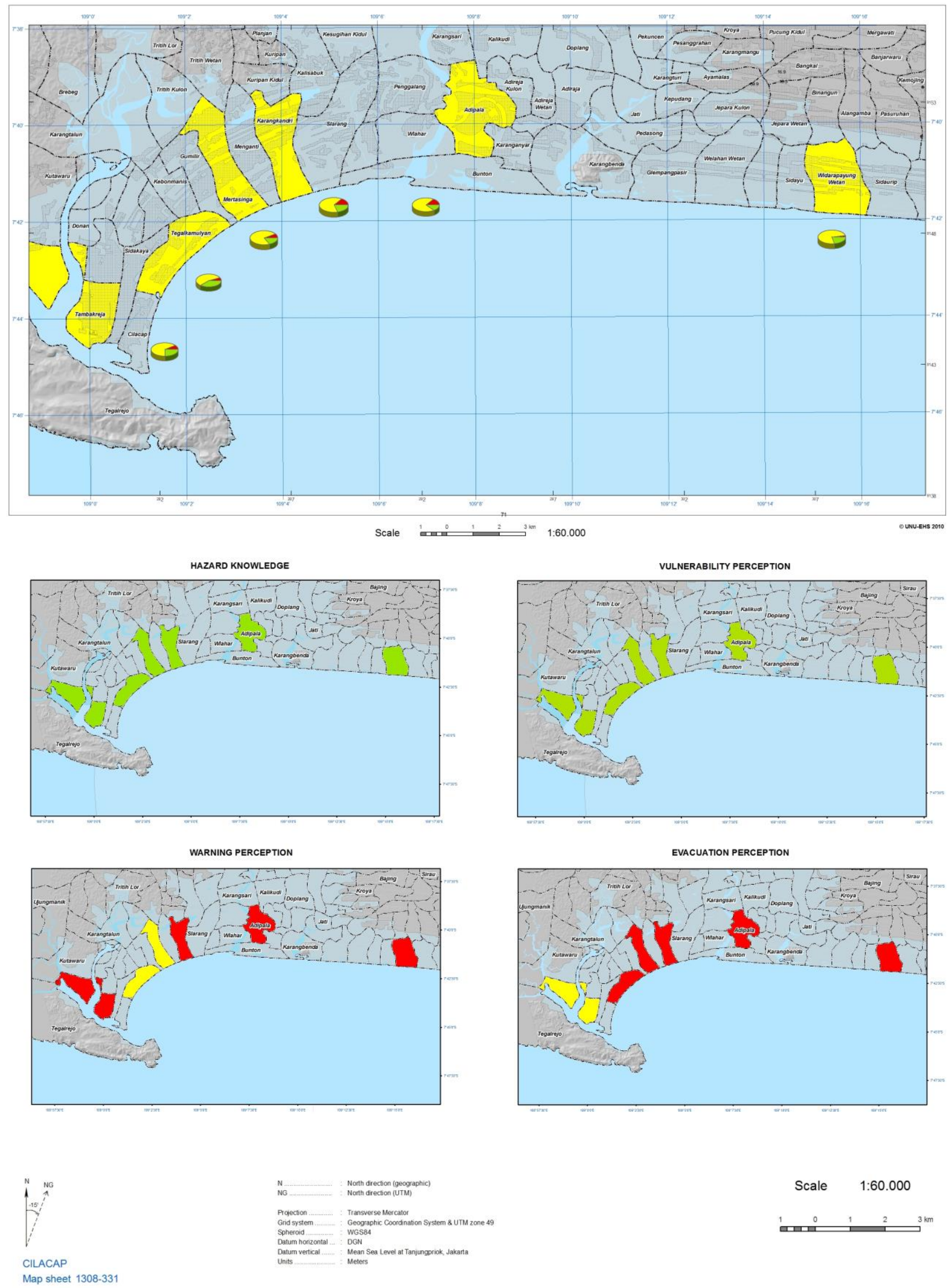

Scale $\quad 1: 60.000$

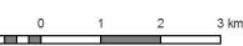

Map 6: Evacuation readiness map of selected villages in the district of Cilacap (Java) 


\section{Legend}

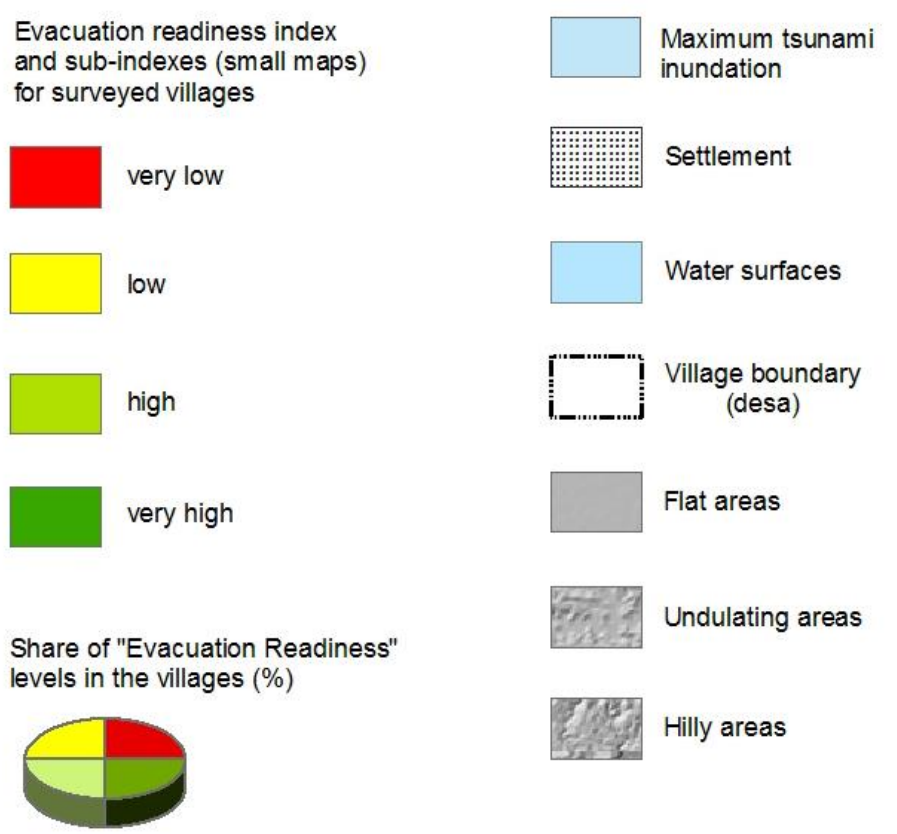

The map represents an equal intervals classification of the four (sub) index values at the village level (0-0.25; $0.26-0.5 ; 0.51-0.75 ; 0.76-1)$ indicating "very low", "low", "high", and "very high" levels of evacuation readiness. Index levels with the highest share of cases within each class are displayed. Whereas, the pie charts show the distribution of evacuation readiness levels amongst households within the surveyed villages.

The overall map is sub-divided into different maps representing an aggregation of all evacuation readiness indicators (large map) as well the single sub-indexes each (small maps: upper left: Hazard Knowledge; upper right: Vulnerability Perception; lower left: Warning Perception; lower right: Evacuation Perception). The aggregation, as well as the sub-indexes reveals only little spatial differences of the degree of evacuation readiness between the communities, although a warning and evacuation perception is lightly better developed in the urban areas of Cilacap city. Much more differences can be discovered when comparing the values of the different subindexes, which will be detailed in the following sections. 


\section{Descriptive analysis of evacuation readiness in the Cilacap district}

Taking the district of Cilacap as an example, the calculated overall "Evacuation Readiness Index" shows that there is a significant lack of evacuation readiness capacity amongst the population in the different communities in the Cilacap district (the majority of cases falls in the yellow class) and generally no large differences between the villages can be discovered. But looking at the four sub-indexes, differences across and within communities are noticeable (C.f. Figure 24, Figure 25). For example, in the village of Tegalkatilayu, the share of households having high readiness level is significantly higher (light green) than in others (also compare pie charts in the map). This is due to the fact that on average more households in this village trust warnings and take appropriate action accordingly than households in others. When looking at the overall mean values of the sub-indexes one clear trend in Cilacap can be discovered: Since Cilacap experienced a fatal tsunami in 2005; it seems that the hazard and vulnerability knowledge amongst citizens is high. But in the absence of a functioning early warning system and no (even presumable) evacuation infrastructure, people's knowledge and perception of early warning systems and evacuation infrastructure is very low thus leading to an overall low degree of evacuation readiness increasing the likelihood that people are not ready to evacuate when a warning is issued and received. The results presented here show that a warning system alone is of little value when place-specific spatial configurations related to evacuation infrastructure are not developed and the spatiality of threats is not effectively communicated to the tsunamiexposed populations. In their absence, warning systems are not effective and warning response behaviour is left to coincidence and individuals. 


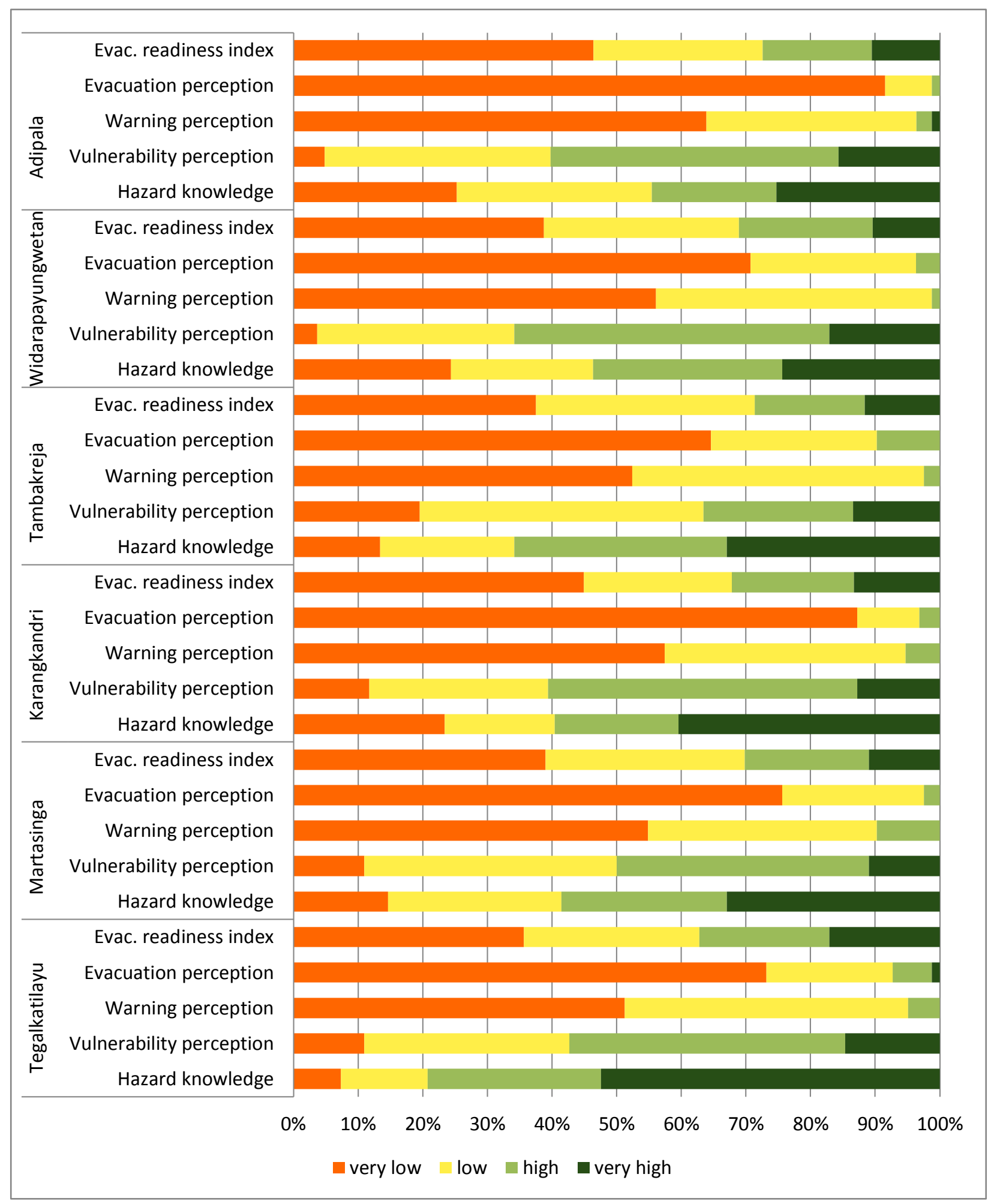

Figure 24: Evacuation readiness assessment results for communities in Cilacap 
Descriptive analysis of evacuation readiness variables compared across all three research areas. Especially comparing the three research areas is interesting and allows drawing important conclusions about how the current performance of the different R\&V-R-tasks affects the degree of evacuation readiness of the population.

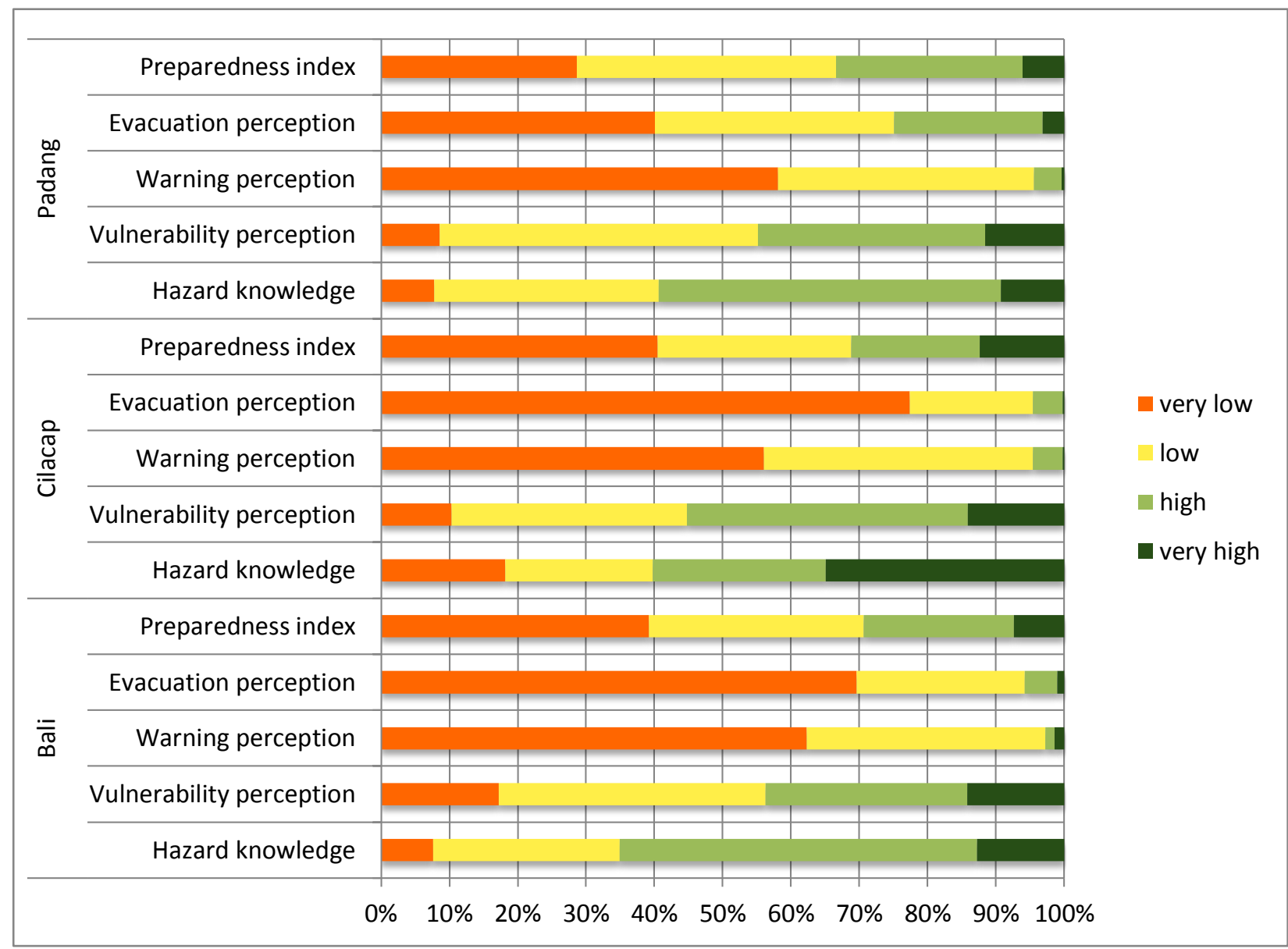

Figure 25: Evacuation readiness assessment results for all research areas

In all three research areas the value for good (high, very high) hazard knowledge is relatively on the same level, adequately high compared to the other factors influencing evacuation readiness capacity. The tsunami events experienced and the resulting vast and long-term media coverage might have shaped hazard knowledge simultaneously across the country. Also vulnerability perceptions are relatively well developed, but less than hazard knowledge. It is far more difficult to understand one`s own exposure conditions and perceived safety.

The values of all other sub-indexes are significantly lower, but show interesting differences when comparing the three research sites:

- The majority of all households in all research areas show a very low degree of adequate warning perception. During the time of the survey, InaTEWS was still in the construction 
process, without SOPs and infrastructure for warning dissemination. People considerably lacked trust in the state authority's ability to precisely predict tsunamis.

- The levels of evacuation perception in Bali and Cilacap are very low; up to $95 \%$ of the population have low or very low evacuation perception, which means they thought they were unable to manage evacuation in the course of a tsunami event. In Padang the values shown are a bit better but not much. Here, $75 \%$ perceived they would not manage evacuation. The results reflect the spatial and physical landscape of the three research areas. Whereas in Padang higher ground is available as well as different evacuation simulations have been conducted, Cilacap and Padang are flat areas, where horizontal evacuation is much more difficult.

The results show that without establishing local infrastructures for warning dissemination and developing effective evacuation systems and socializing them by familiarizing relevant components (warning messages, evacuation routes, shelters etc.), a warning system remains ineffective because exposed populations are lacking the capacity to be ready to evacuate.

The utility of the results for elaborating, assessing, selecting, and implementing R\&V-R-task specific measures are discussed in chapter VIII. 


\section{VII.7 Assessing Lack of Evacuation Capacity}

Evacuation failure modelling shall lay open the spatially differentiated deficiencies of existing evacuation infrastructures with respect to their role in providing sufficient facilities to safe citizens in due time in the course of a tsunami event. The assessment shall be able to locate evacuation bottlenecks and difficult-to-evacuate areas by taking into account the available evacuation time, shelter capacities, population density, and main evacuation routes. From such modelling time-dependent expected casualties can be calculated. A comprehensive evacuation failure modelling approach includes the following steps:

- Hazard assessment to define evacuation zones and assign potential safe areas.

- Assessing areas with deficiencies in timely evacuation (difficult-to-evacuate areas).

- Calculating amount of people having difficulties to timely evacuate thus representing the number of potential casualties.

\section{VII.7.1 Methods}

In case people have more - or as much - available time to evacuate than they currently need $(\mathrm{aET}>=\mathrm{cET})$, they are able to reach a safe place and rescue themselves. High risk areas are those where people do not have sufficient time to find a safe place. Thus, the lack of evacuation capacity is a crucial factor of mortality $R \& V$ during the occurrence of a tsunami event. In the following the methods for assessing and mapping spatially distributed evacuation failure risks will be shown. The method builds upon the logic that people's evacuation capacity is a function of the relationship between "current Evacuation Time" (cET, time people need to find a safe place) and "available Evacuation Time" (aET, time people have to evacuate in due time). The methods represent a complex aggregation of the following calculation steps presented as follows.

- Calculation of Available Evacuation Time at each point within the evacuation zone

- Evacuation speed calculation.

- Assessing distances to safe areas.

- Calculation of Current Evacuation Time at each point within the evacuation zone.

- Calculation of Aggregated Risk of Evacuation Failure at each point within the evacuation zone. 


\section{VII.7.1.1 Calculation of Available Evacuation Time}

The available Evacuation Time (aET) is the function of the Estimated Time of Arrival (ETA) - from which by concept the Tsunami warning dissemination Time (TwdT) and the Reaction Time (RT) of the population is subtracted. Since it is not possible to quantify TwdT and RT the only parameter calculated is the estimated minimum time of arrival of the tsunami (ETA) per scenario and for predefined coastal locations. For each tsunami scenario the median value for a rasta cell (50th percentile of ETA distribution at the respective location) is calculated (LIPI et al. 2011b).

\section{VII.7.1.2 Calculation of Current Evacuation Time}

The quantification of location specific current evacuation time is based on an ArcGIS costdistance algorithm (ESRI, 2001). The evacuation time provides information on the time someone needs from a certain location within the warning level specific evacuation zone to reach the area where people are able to evacuate to the nearest shelter in a certain time following the fastest path. Hence, the current evacuation time is calculated based on the identification of the distance (via best evacuation route) between a given point within a defined evacuation zone to the next safe area as well as the calculation of evacuation speed.

Thus, methods include identifying safe areas and calculating evacuation speeds. On the basis of the calculated evacuation speed and starting from each of the placed access points, the current evacuation time can be calculated for any spatial area of interest (defined cells in ArcGIS). The value of each cell represents the cost (in terms of time) necessary to go from there to the "costless" shelter following the fastest available evacuation path (Figure 27). In the following the single assessment steps are presented.

\section{Evacuation speed calculation}

The evacuation speed is measured by introducing a cost surface model. It assumes that land cover, population density, slope, critical facility density, age and gender distribution determine the evacuation speed of people. The cost surface model consists of a regular two-dimensional grid where each cell value of an area of interest represents the cost to travel calculated and transformed into an evacuation speed value. The evacuation speed is calculated with the formula presented in the following. The result is an inverse speed value, expressing the walking time in sec/m. 


$$
\frac{1}{\frac{\cos t s_{\text {_landuse }}}{100} * \frac{\cos t s_{\text {_ }} \text { slope }}{100} * \frac{\cos t s_{-} \text {criticalfa cilities }}{100} *\left(\frac{\text { speed }_{\text {populationensity }}+\text { speed }_{\text {populatioindex }}}{2}\right)}
$$

- $\quad$ Land use and topography (slope) alters the evacuee's movement and speed (ADPC, 2007). For each land use and slope class a new speed value for a walking person has been calculated.

- Density of critical facilities distribution such as schools and hospitals result in reduced response capabilities due to the presence of people needing special attention during an evacuation. Obviously physical and mental disabilities are limiting factors for individuals to cope with during a disaster. Within a buffer of 100 meter around these facilities a speed reduction of $50 \%$ is assumed to meet the situation during an evacuation.

- Population density distribution. In evacuation modelling studies, different group sizes on evacuation speed properties are accounted for. It is assumed that the larger the population density the larger the group size will slower the evacuation process (Klüpfel 2012). Studies about average evacuation walking speed show values in the range of 0.7 to $1.5 \mathrm{~m} / \mathrm{s}$ (Klüpfel 2003). For the calculation of the evacuation speed an average speed of $1.2 \mathrm{~m} / \mathrm{s}$ is used for a medium population density area.

- $\quad$ Age and gender distribution (demographic population index). In several studies it has been found that age and gender are factors contributing to different mortality due to differences in evacuation speed. This is because average walking and maximum running speeds are age and gender specific in the productive age, whereby gender does not make a difference for children and the elderly. A respective index has been calculated (LIPI et al. 2011b).

\section{Assessing distances to safe areas}

The distance an evacuee located in an evacuation zone has to overcome during evacuation depends on the location and carrying capacity of safe areas. Safe areas include options for vertical and horizontal evacuation. To calculate the distance from each "grid cell" in the evacuation area (both "warning" and "major warning") to a respective safe area, two major 
variables are relevant: (1) The location of suitable shelter access points ${ }^{23}$ to safe areas (horizontal and vertical); and (2) their carrying capacity (vertical evacuation).

- To locate and determine suitable shelter access points, potential sites have to be assessed by applying a bunch of criteria such as favourable land use/cover and topography (slope) conditions as well as a minimum space of $10000 \mathrm{~m}^{2}$ ensuring the temporary gathering of evacuees. For horizontal evacuation areas, the access points are identified along the border of the hazard zone (maximum inundation line) accessible through the street network; for vertical evacuation shelters (existing buildings) on the top of buildings. To identify buildings suitable for vertical evacuation, their vulnerability has been assessed. Only buildings fulfilling criteria such as structural stability, accessibility, and non-liquefaction were selected as suitable for evacuation.

- Whether a shelter for vertical evacuation is accessible for people within an evacuation zone also depends on the carrying capacity of vertical shelters. Existing and available buildings suitable for vertical evacuation can have different primary functions (hotels, governmental facilities, schools, etc.) and therefore available space for evacuation is varying. As illustrated in Figure 28 below, during an evacuation the area surrounding a tsunami evacuation building is defined by either Evacuation time (L1) or Capacity range (L2) constraints.

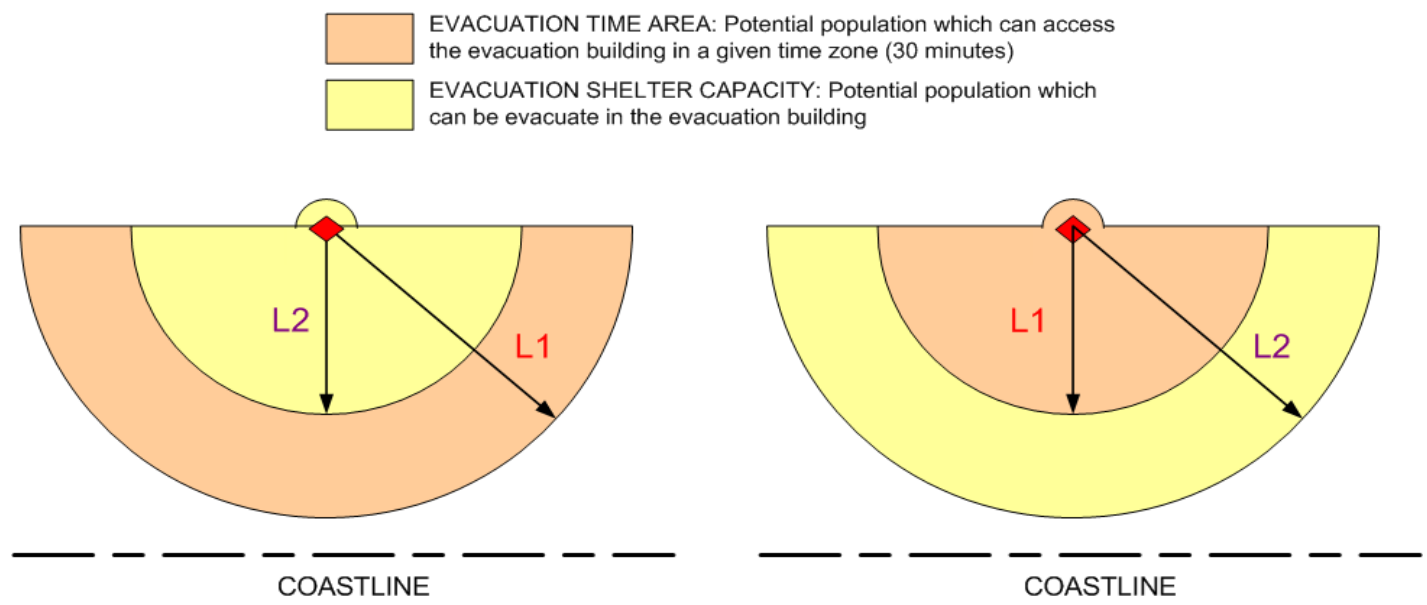

Figure 26: Evacuation time and building capacity as decisive evacuation constraints (Source: LIPI et al 2011)

\footnotetext{
${ }^{23}$ Access points are defined as spatial entities that allow for accessing an evacuation target point.
} 


\section{VII.7.1.3 Calculation of Aggregated Evacuation Failure}

The aggregated risk calculation for both warning levels is composed of three information layers. The spatially distributed evacuation failure as outlined above has been overlaid by location specific hazard probabilities and intensities, as well as population density distributions. The yielded large number of 14 risk classes were aggregated to six classes ranging from very low (dark green) to very high (red).

\section{VII.7.2 Results}

Map 7 represents the spatial distribution of "risk of evacuation failure" at a scale of 1: 25000. The map is a result of the calculation of people's evacuation capabilities and considers both, horizontal and vertical evacuation opportunities. Areas where evacuation is likely to be successful, i.e. an evacuation building or area can be reached within the available time, are indicated as low risk areas (green). Areas where evacuation is likely to be impossible are indicated as high risk areas (dark red). All currently existing buildings suitable for evacuation and their capacities are shown on the map. The following criteria were applied to determine a location where additional shelters are required:

- The time people need from each point to find a safe place

- The hazard zone and the Estimated Time of Arrival (Median ETA)

- The degree of exposure

The red and orange areas indicate where shelter areas are lacking. Additionally, the amount of people per village requiring additional shelter is shown on the map (circles). The circle size depicts the amount of people exposed per village, while the colours in the circles show the proportion of exposed people who are able to evacuate within 50 minutes (light grey), the proportion of people who are able to evacuate within 90 minutes (striped), and the proportion of people who are not able to evacuate (dark grey). 
Case Study Part 3 - Empirical Research; Methods and Results
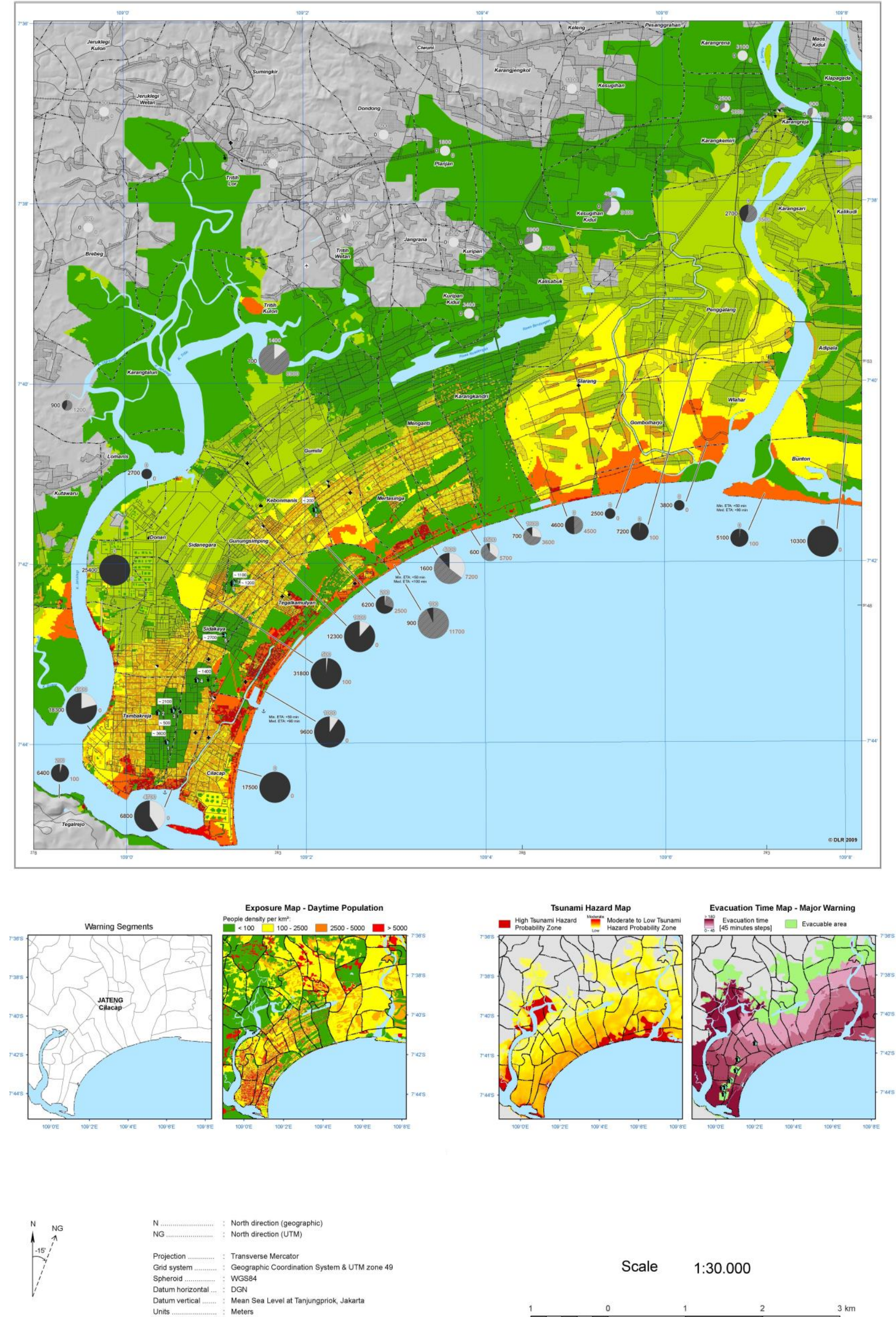

Scale $\quad 1: 30.000$

$\begin{array}{l:l}\text { Datum vertical ...... } & \text { Mean Sea Level at Tanjungpriok, Jakarta } \\ \text { Uniuts }\end{array}$

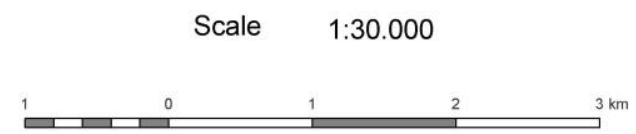




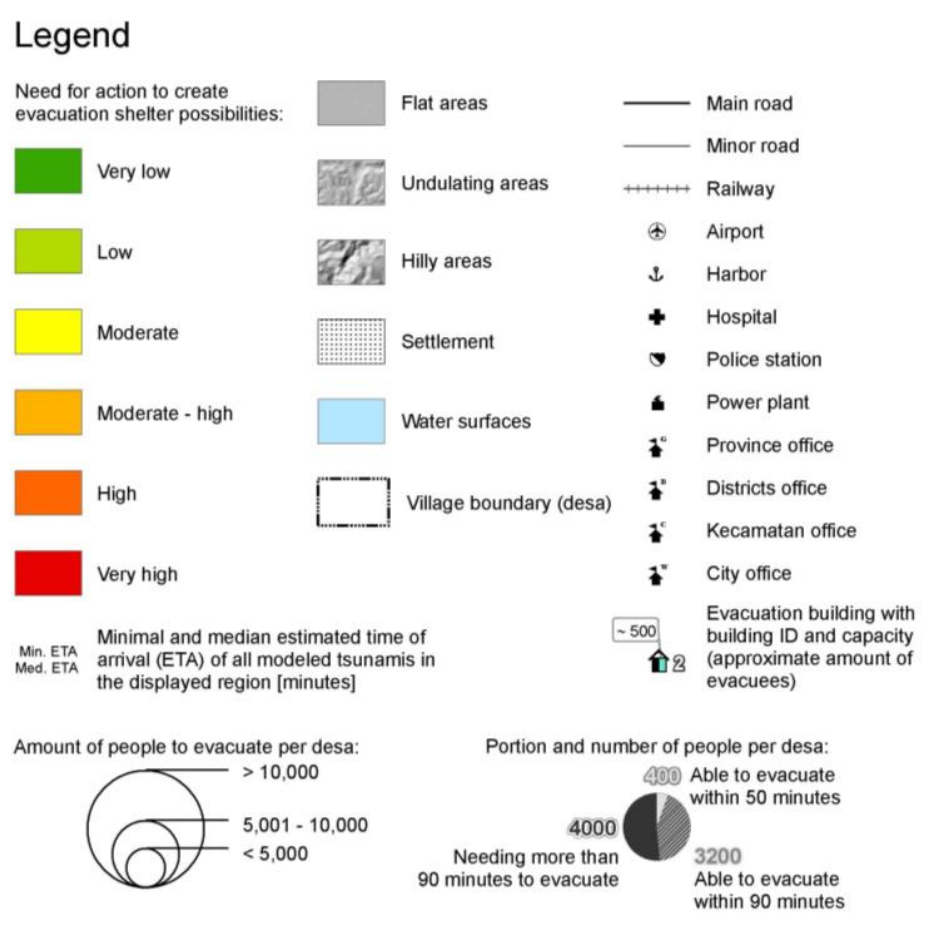

Map 8: Risk of Evacuation Failure Map, Cilacap (Source: LIPI et al. 2011)

The map shows that especially the coastal zone has the greatest problem to be evacuated in due time, whereby the largest share of the number of people requiring more than 90 minutes to evacuate lives in the coastal city centre and far off in rural Cilacap. A more detailed evacuation capacity related assessment has been conducted by the "Last Mile" project (H. Taubenböck et al. 2009), supported a dissertation of Neysa Setiadi with the title "Assessing People's Early Warning Response Capability to Inform Urban Planning Interventions to Reduce Vulnerability to Tsunamis" (Setiadi 2014). The utility of the results for elaborating, assessing, selecting, and implementing R\&V-R-task specific measures are discussed in chapter VIII.3.5 


\section{VIII. $\quad$ Case Study Part 4 - The Utility of Risk and Vulnerability Assessment Results for InaTEWS}

\section{VIII.1 Introduction}

The final step of the case study is to discuss how and to what extent the R\&V-A -information packages developed can provide decision support to increase the effectiveness of $R \& V-R$ ( $R Q$ 2.2). The R\&V-A results (VII.3.2, VII.4.2, VII.5.2, VII.6.2, VII.7.2) will be subject to a respective evaluation in this chapter. What is the interpretative value of the R\&V-A -products to support the establishment of an effective and people-centred end-to-end early warning system? In other words, what would have happened if the TEWS had been established without R\&V-A? The evaluation of the assessment results and products is guided by these fundamental questions.

\section{VIII.2 Utility Evaluation Method}

The evaluation of the utility of the R\&V-A results (Cf. Chapter VIII.3) shall allow judging to what extent and how the quantitative and spatial $R \& V-A s$ and respective products developed can contribute to the establishment of an effective TEWS. To guide the evaluation, an "R\&V-A Utility Evaluation Framework" is being developed. It is built upon the combination of framing applied $R \& V$ science (Cf. IV), defining the R\&V-R nomenclature (Cf. III.3), the procedural steps of R\&V-R (Cf. III.4), and finally the framing of R\&V-R and R\&V-A in the context of InaTEWS (Cf. VI).

The readings of the respective chapters suggest that for each defined R\&V-R task within InaTEWS a R\&V-R process needs to be ideally initiated and accomplished for which R\&V-A is necessary. Hence, the goal of the utility evaluation is to examine how and at which stage of the $R \& V-R$ process $R \& V-A$ can valuably support decisions related to implementing the defined R\&V$\mathrm{R}$ tasks. Based on this, the framework developed (Cf. Table 20) builds upon the integral components of the described R\&V-R process (Cf.III.4) including the definition of the generic process of R\&V-R (Cf. III.4), composed of the steps "option generation", "option assessment", "option selection", "option implementation", and "option performance monitoring" (first column), and the definition of the different steps to navigate through the hierarchically ordered R\&V-R nomenclature. The utility evaluation focusses on the decision-making process to arrive at 
appropriate measures contextualized based on the tsunami warning reaction scheme in Indonesia (Cf. VI.4), as well as their implementation and monitoring.

Table 20 Overview of the utility evaluation approach

\begin{tabular}{|c|c|c|c|c|c|c|}
\hline \multicolumn{2}{|c|}{$R \& V-R$ tasks } & \multirow[t]{2}{*}{$\begin{array}{l}\text { National to local } \\
\text { level Warning } \\
\text { Dissemination } \\
\text { Chain }\end{array}$} & \multirow[t]{2}{*}{$\begin{array}{l}\text { Defining areas } \\
\text { of intervention }\end{array}$} & \multirow[t]{2}{*}{$\begin{array}{l}\text { Warning } \\
\text { dissemination \& } \\
\text { SOPs and } \\
\text { infrastructure }\end{array}$} & \multirow[t]{2}{*}{$\begin{array}{l}\text { Evacuation } \\
\text { readiness }\end{array}$} & \multirow[t]{2}{*}{$\begin{array}{l}\text { Evacuation } \\
\text { infrastructure }\end{array}$} \\
\hline \multirow[t]{4}{*}{1} & Option generation & & & & & \\
\hline & 1. Step description & & & & & \\
\hline & 2. $R \& V$ information required & & & & & \\
\hline & 3. Utility of results & & & & & \\
\hline \multirow[t]{4}{*}{2} & Option assessment & & & & & \\
\hline & 1. Step description & & & & & \\
\hline & 2. $R \& V$ information required & & & & & \\
\hline & 3. Utility of results & & & & & \\
\hline \multirow[t]{4}{*}{3} & Option selection & & & & & \\
\hline & 1. Step description & & & & & \\
\hline & 2. $R \& V$ information required & & & & & \\
\hline & 3. Utility of results & & & & & \\
\hline \multirow[t]{4}{*}{4} & Option implementation & & & & & \\
\hline & 1. Step description & & & & & \\
\hline & 2. $R \& V$ information required & & & & & \\
\hline & 3. Utility of results & & & & & \\
\hline \multirow[t]{4}{*}{5} & $\begin{array}{l}\text { Option performance } \\
\text { monitoring }\end{array}$ & & & & & \\
\hline & 1. Step description & & & & & \\
\hline & 2. $R \& V$ information required & & & & & \\
\hline & 3. Utility of results & & & & & \\
\hline
\end{tabular}

The evaluation has been conducted based on (1) a clear description of what is subject to option generation, assessment, selection, implementation, and monitoring for each of the different R\&V-R tasks. (2) Based on this, the R\&V information required had to be defined that is supposed to support the accomplishment of each of the specific R\&V-R task and steps. Such provision acts as the reference for (3) finally evaluating how and to what extent the R\&V-A results are of utility for each of the steps of the R\&V-R process but also for drawing more general conclusions about the role of $R \& V-A$ for $R \& V-R$. 


\section{VIII.3 Results}

\section{VIII.3.1 Utility of the Results to Establish Effective Warning Dissemination Chains}

How shall warnings issued at the national level be communicated to the local level and the recipient population? How shall authorities pass on warning messages? Who needs to be involved in the dissemination of warnings developing early warning chains and infrastructures? These questions need to be addressed when developing SOPs for warning dissemination to ensure the dissemination of timely warning to the coastal population (Cf. VI.4.3, VII.5).

Table 21 shows how the R\&V-A results contribute to the single steps of the R\&V-R-process for the development of an effective warning dissemination system from the national to the local level.

Table 21: Utility of R\&V-A to establish effective warning dissemination chains from the national to the local level

\begin{tabular}{|c|c|c|}
\hline \multirow[t]{4}{*}{1} & $\begin{array}{l}\text { Option } \\
\text { generation }\end{array}$ & ation of options for warning dissemination from the national to the local level \\
\hline & Step description & $\begin{array}{l}\text { This step requires the elaboration on different options how warnings should be } \\
\text { communicated across different administrative levels, from the warning centre to the } \\
\text { authorities responsible at the local level and recipient population. }\end{array}$ \\
\hline & $\begin{array}{l}\mathrm{R} \& \mathrm{~V} \text { information } \\
\text { required }\end{array}$ & $\begin{array}{l}\text { No } R \& V-A \text { information required: } R \& V \text { information cannot contribute to this since the } \\
\text { different communication pathways are subject to a general brainstorming. }\end{array}$ \\
\hline & Utility of results & There is no utility. \\
\hline \multirow[t]{4}{*}{2} & $\begin{array}{l}\text { Option } \\
\text { assessment }\end{array}$ & $\begin{array}{l}\text { Assess the effectiveness of different warning communication options from the } \\
\text { national to the local level }\end{array}$ \\
\hline & Step description & $\begin{array}{l}\text { Many administrative bodies claim to be responsible and legitimate institutions to } \\
\text { decide upon warning message dissemination. But not all warning communication } \\
\text { pathways are effective. This step aims at assessing the different existing warning chain } \\
\text { options with regard to how fast and reliably they can reach hazard prone communities. }\end{array}$ \\
\hline & $\begin{array}{l}\mathrm{R} \& \mathrm{~V} \text { information } \\
\text { required }\end{array}$ & $\begin{array}{l}\text { Lack of evacuation capacity (Cf. VII.3) composed of the components: } \\
\text { - Evacuation time that is available (hazard information on Estimated Time of } \\
\text { Tsunami Arrival (Cf. VII.3), mirrored against the time that the population needs } \\
\text { to reach a safe place (Cf. VII.7). }\end{array}$ \\
\hline & Utility of results & $\begin{array}{l}\text { The R\&V-A reveals an approximated value for a benchmark defining at which point in } \\
\text { time after a warning has been issued the number of casualties will increase dramatically } \\
\text { if warnings do not reach the exposed people. The value allows judging how fast an } \\
\text { elaborated warning dissemination chain should be in order to save as many lives as } \\
\text { possible. With this benchmark value all the elaborated warning dissemination options } \\
\text { can be assessed in terms of their effectiveness. The results show that the warning time } \\
\text { must be as short as possible as the majority of the population requires far more time } \\
\text { for evacuation than they have left (ETA). }\end{array}$ \\
\hline 3 & Option selection & Selection of the most effective warning dissemination option from the national to the \\
\hline
\end{tabular}




\begin{tabular}{|c|c|c|}
\hline & & local level \\
\hline & Step description & $\begin{array}{l}\text { This step requires selecting the most effective warning dissemination chain to reach } \\
\text { hazard prone communities. Thereby, also questions arise such as which of the warning } \\
\text { dissemination tools shall be selected first for implementation, how to arrange SOPs for } \\
\text { warning communication between different interfaces? }\end{array}$ \\
\hline & $\begin{array}{l}\mathrm{R} \& \mathrm{~V} \text { information } \\
\text { required }\end{array}$ & $\begin{array}{l}\text { No R\&V-A information required: The decision is based on the results of the option } \\
\text { assessment }\end{array}$ \\
\hline & Utility of results & $\begin{array}{l}\text { The assessment results facilitates } \mathrm{R} \& \mathrm{~V} \text { communication to harmonize and resolve } \\
\text { conflicting positions and perceptions about the conditions under which available } \\
\text { warning dissemination options are effective and provide argumentation lines for } \\
\text { selecting the most effective warning dissemination option. For example, during a } \\
\text { workshop with staff from the national warning centre, warning chains had been } \\
\text { discussed, where some participants raised the issue of communicating warnings } \\
\text { through all administrative levels to account for the decentralization process. But once } \\
\text { they were confronted with the R\&V-A (available evacuation time of the population) } \\
\text { quick consensus could be reached that warnings are required to be communicated } \\
\text { directly to the population exposed, not including different authorities at different } \\
\text { administrative levels into the warning chain. The decision was made to communicate } \\
\text { warnings via public media as well as directly to the district authorities. }\end{array}$ \\
\hline 4 & $\begin{array}{l}\text { Option } \\
\text { implementation }\end{array}$ & $\begin{array}{l}\text { Institutionalization of the most effective warning dissemination option from the } \\
\text { national to the local level }\end{array}$ \\
\hline & Step description & $\begin{array}{l}\text { The development of SOPs for warning dissemination is a political process in which } \\
\text { standards and actors for warning dissemination are approved. }\end{array}$ \\
\hline & $\begin{array}{l}\mathrm{R} \& \mathrm{~V} \text { information } \\
\text { required }\end{array}$ & No R\&V-A information required. \\
\hline & Utility of results & There is no utility. \\
\hline & $\begin{array}{l}\text { Option } \\
\text { performance } \\
\text { monitoring }\end{array}$ & $\begin{array}{l}\text { Monitoring the effectiveness of warning dissemination from the national to the local } \\
\text { level }\end{array}$ \\
\hline & Step description & $\begin{array}{l}\text { This step requires the regular observance whether warning dissemination is accurately } \\
\text { institutionalized; and whether institutions and responsible individuals understand their } \\
\text { mandate and serve the quick dissemination of warning messages. }\end{array}$ \\
\hline & $\begin{array}{l}\mathrm{R} \& \mathrm{~V} \text { information } \\
\text { required }\end{array}$ & $\begin{array}{l}\text { Potentially assessing changing patterns of R\&V, e.g. Estimated Times of Tsunami Arrival } \\
\text { (ETA) and changes of people's time needed to reach safe places. }\end{array}$ \\
\hline & Utility of results & $\begin{array}{l}\text { Rather no utility. Most probably there will be little changes in R\&V patterns on how to } \\
\text { adjust warning dissemination chains. }\end{array}$ \\
\hline
\end{tabular}




\section{VIII.3.2 Utility of the Results to Identify Spatial Entities Requiring Intervention at the Local Level}

Where and what are the areas where local level people-centred warning and response structures are required? And hence, where are the areas warnings have to be communicated to and where are the areas where people have to find a safe place in due time? These questions need to be addressed by defining the most appropriate level of protection and therefore the evacuation zone (Cf. VI.4.2). Here R\&V information can support the decision-making process.

Table 22 shows how the R\&V-A results contribute to the single steps of the R\&V-R process for identifying spatial entities for intervention.

Table 22 Utility of R\&V-A for identifying an effective and manageable evacuation zone

\begin{tabular}{|c|c|c|}
\hline \multirow[t]{4}{*}{1} & Option generation & Generation of options for defining a warning and evacuation zone \\
\hline & Step description & $\begin{array}{l}\text { This step requires the generation of a number of possible options to define an } \\
\text { evacuation zone and an acceptable level of protection. }\end{array}$ \\
\hline & $\begin{array}{l}\mathrm{R} \& \mathrm{~V} \text { information } \\
\text { required }\end{array}$ & $\begin{array}{l}\text { Hazard inundation probability assessment (Cf. VII.3) and exposure (Cf. VII.4) } \\
\text { Lack of evacuation capacity assessment for different hazard inundation probabilities } \\
\text { (Cf. VII.6) }\end{array}$ \\
\hline & Utility of results & $\begin{array}{l}\text { The assessment results generate a number of possible options for defining an } \\
\text { evacuation zone and an manageable and acceptable level of protection (e.g. amount } \\
\text { of people requiring evacuation for a defined hazard inundation probability) for the } \\
\text { warning levels defined in InaTEWS (Cf. VII.3, Table 10). Hence, they serve as an option } \\
\text { generating tool. } \\
\text { They allow R\&V-R practitioners to understand that for each warning level (wave height } \\
\text { at the coast) different inundation probabilities with different spatial coverage within an } \\
\text { exposed area exist and that for each of the different spatialized probabilities different } \\
\text { exposure patterns can be derived. Hence, hazard probability and exposure analysis are } \\
\text { crucial for generating scientific based options for defining a warning and evacuation } \\
\text { zone and a desired level of protection }{ }^{24} \text {. }\end{array}$ \\
\hline \multirow[t]{2}{*}{2} & Option assessment & $\begin{array}{l}\text { Assessing options to identify the most acceptable / manageable level of protection } \\
\text { and evacuation zone }\end{array}$ \\
\hline & Step description & $\begin{array}{l}\text { This step relates to assessing the different available options to define an effective, } \\
\text { manageable, and acceptable level of protection: } \\
\text { - For example; does it make sense and is it feasible to invest in evacuation } \\
\text { infrastructure, where the probability of tsunami occurrence is low although } \\
\text { many people are living in these areas (high level of exposure)? }\end{array}$ \\
\hline
\end{tabular}

\footnotetext{
${ }^{24}$ Absence of assessment of the level of exposure for a set of different inundation probabilities reduces the capacity of elaborating different options related to assessing and selecting the appropriate level of protection. Conversely, the available data of the assessment allows calculating probability specific exposure levels.
} 


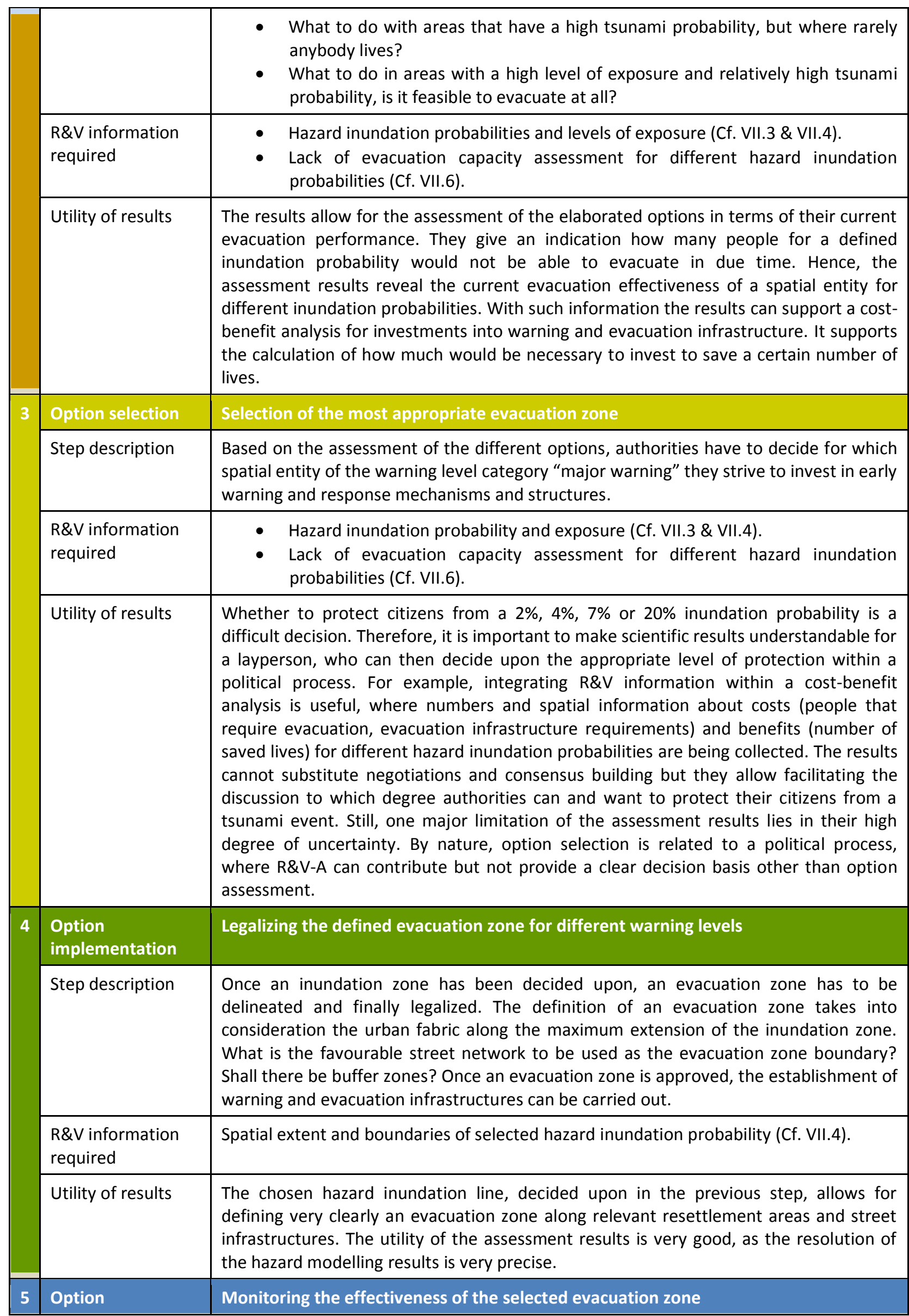


performance

monitoring

Step description

This step deals with regularly reassessing the effectiveness of the selected evacuation zone. Population shifts, land use alterations, and even improvements in tsunami modelling can imply changing the spatial conditions of an evacuation zone.

$R \& V$ information

Continuous tsunami inundation modelling, exposure estimations and evacuation required capacity assessment.

Utility of results

According to new findings of the reassessment of the defined evacuation zones, they can be readjusted following the $R \& V-R$ process outlined.

In addition to the utility of the results for defining areas of intervention, they can be used for many purposes, as hazard and exposure assessments lay the foundation for all subsequent $R \& V-R$ tasks and measures of the tsunami early warning reaction scheme. Besides the utility of exposure assessment to better estimate the emergency potential, it acts as intermediate assessment for other subsequent assessments and $R \& V-R$ processes. Both, the access to warning assessment (Cf. VII.5) as well as the evacuation capability assessment (Cf.VII.6), are strongly dependent on population data. For example, a high population density influences the demand for tsunami warning and evacuation infrastructure.

\section{VIII.3.3 Utility of the Results to Establish Effective Warning Dissemination Infrastructure at the Local Level}

How shall exposed populations access warnings, what are the most effective warning dissemination infrastructures at the local level and where shall they be located to reflect population distribution, cultural and social conditions? Who needs to be involved in the dissemination of warnings and the development of early warning infrastructures? These questions need to be addressed when elaborating, assessing, selecting, and implementing warning dissemination infrastructures in communities to ensure the dissemination of timely warnings to the coastal population (Cf. VI.4.3, VII.5).

Table 23 shows how the R\&V-A results contribute to the single steps of the R\&V-R-process for the development of an effective warning dissemination system from the national to the local level.

Table 23 Utility of R\&V-A for developing people-centred warning infrastructures at the local level

1 Option generation
Elaborating on types of warning infrastructures to be accessed by the recipient population 


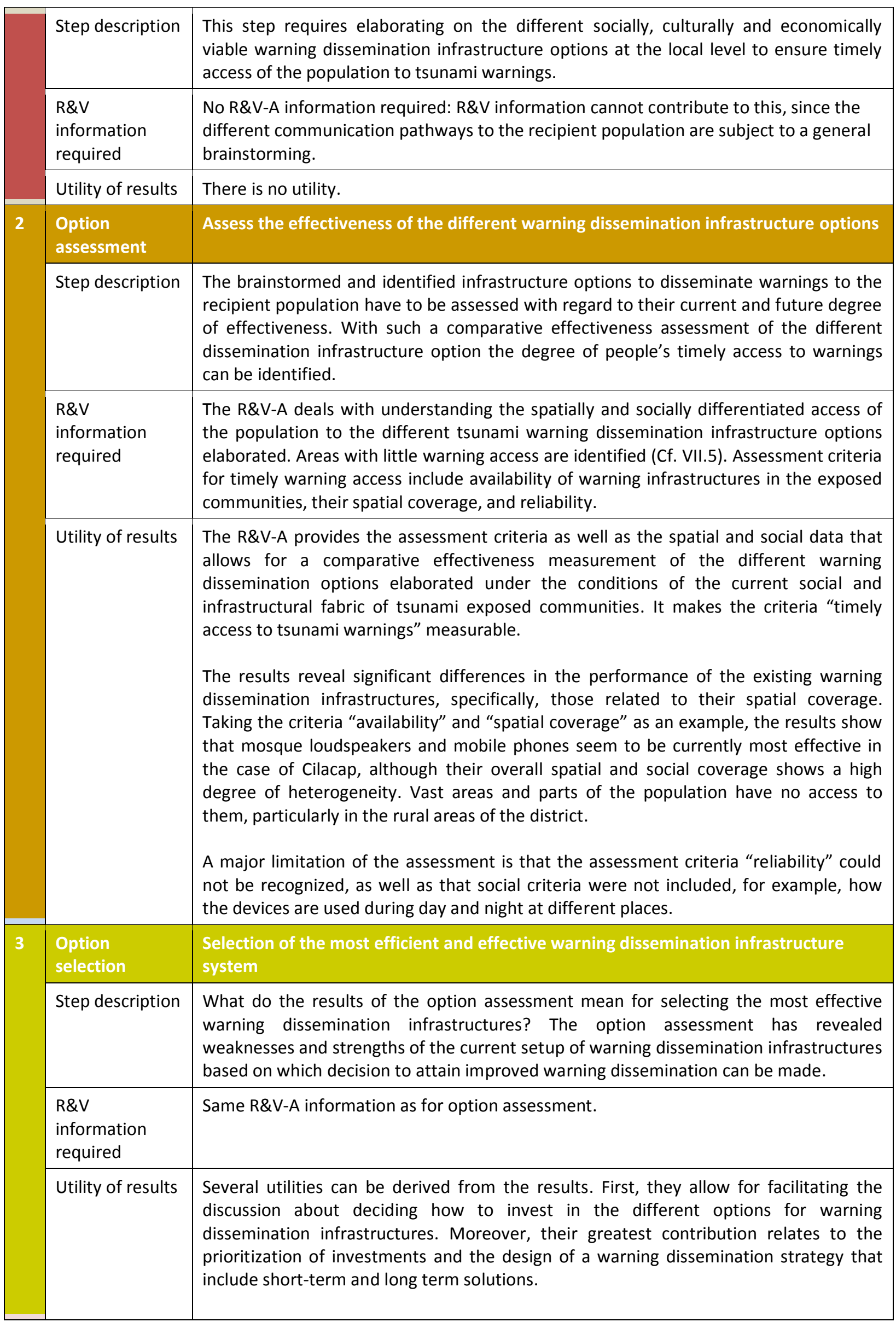




\begin{tabular}{|c|c|c|}
\hline & & 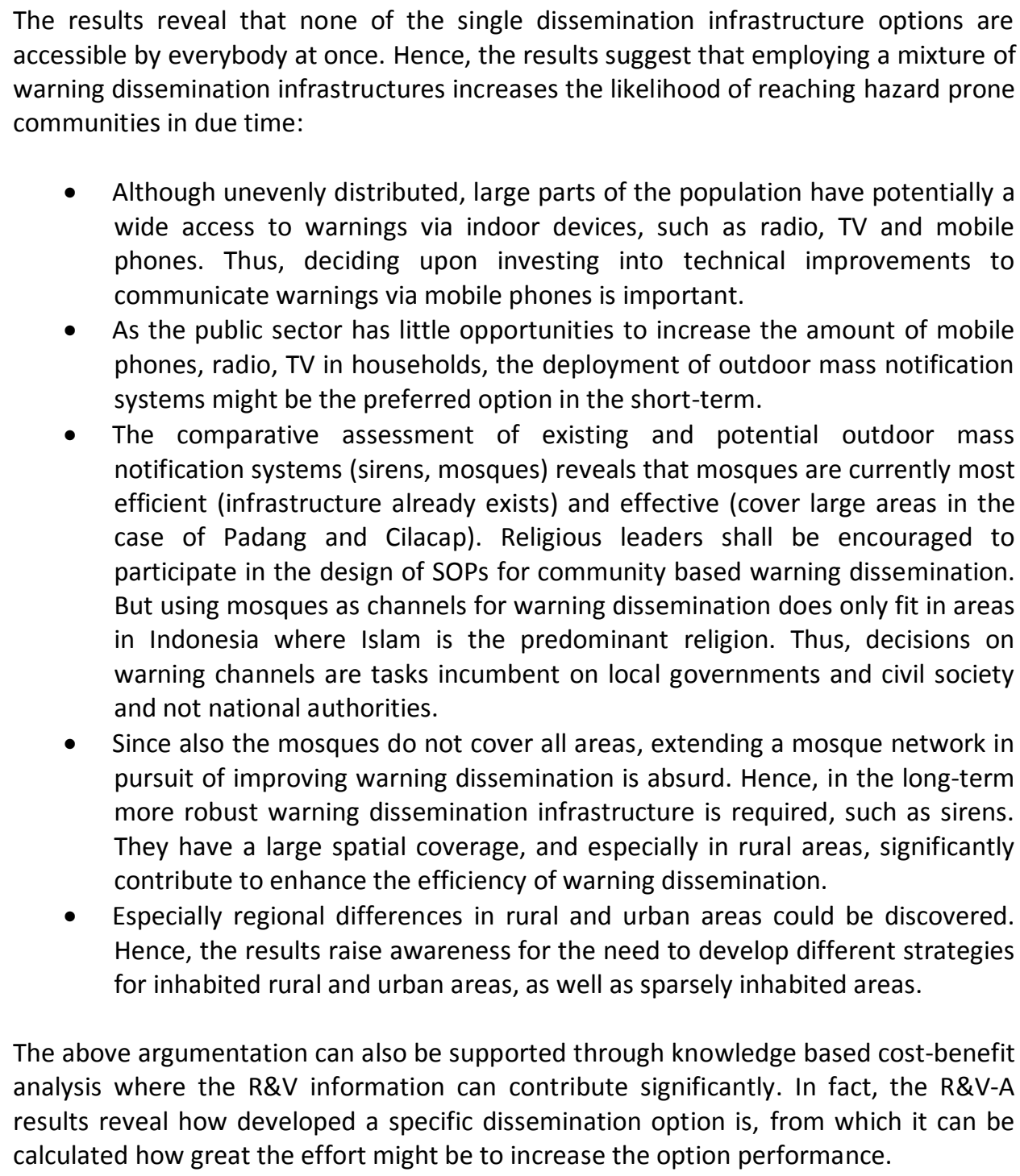 \\
\hline \multirow[t]{4}{*}{4} & $\begin{array}{l}\text { Option } \\
\text { implementatio } \\
\text { n }\end{array}$ & Placement and technical prescriptions of warning dissemination infrastructure \\
\hline & Step description & $\begin{array}{l}\text { Once decisions are taken on which dissemination options to use, the deployment of } \\
\text { warning dissemination infrastructure at the local level and developing the SOPs for } \\
\text { communicating warnings to the population is necessary. }\end{array}$ \\
\hline & $\begin{array}{l}\mathrm{R} \& \mathrm{~V} \\
\text { information } \\
\text { required }\end{array}$ & $\begin{array}{l}\text { - Hazard / Evacuation zones. } \\
\text { - } \quad \text { Exposure data / population distribution in the hazard zone. } \\
\text { mechanisms, particularly outdoor notification infrastructures, such as sirens, } \\
\text { mosques. }\end{array}$ \\
\hline & Utility of results & $\begin{array}{l}\text { The results can facilitate the discussion about where, what type and with which } \\
\text { specifications warning dissemination infrastructures shall be deployed. Although the } \\
\text { results show the spatial and social deficiencies of people's access to tsunami warnings, } \\
\text { the deployment of outdoor mass notification infrastructure cannot solely be made on } \\
\text { the basis of the assessment results. A major constraint of the assessments was that no } \\
\text { data could be collected about the location specific outreach area of mosque or siren } \\
\text { speakers indicating precisely the boundaries of warning dissemination gaps in order to } \\
\text { define the locations and configuration of the warning infrastructure. Here it would be } \\
\text { necessary to measure the clearness and sound of warning messages under real-life }\end{array}$ \\
\hline
\end{tabular}




\begin{tabular}{|c|c|c|}
\hline & & $\begin{array}{l}\text { conditions as a function of the speaker capacity, and acoustic noise absorbing features } \\
\text { such as time and location specific background noise and buildings depending on their } \\
\text { distance from the source. }\end{array}$ \\
\hline \multirow[t]{4}{*}{5} & $\begin{array}{l}\text { Option } \\
\text { performance } \\
\text { monitoring }\end{array}$ & $\begin{array}{l}\text { Monitoring the effectiveness of installed and institutionalized warning dissemination } \\
\text { infrastructures at the local level }\end{array}$ \\
\hline & Step description & $\begin{array}{l}\text { This step requires the regular observance whether warning dissemination } \\
\text { infrastructures are adequately placed, and suitable for the given societal and spatial } \\
\text { conditions. E.g. population shifts, exposure intensification, policy shifts can require } \\
\text { adjustments in warning dissemination infrastructure planning. }\end{array}$ \\
\hline & $\begin{array}{l}\mathrm{R} \& \mathrm{~V} \\
\text { information } \\
\text { required }\end{array}$ & $\begin{array}{l}\text { - Hazard assessment (Cf. VII.3) } \\
\text { - } \quad \text { Exposure assessment (Cf. VII.4) } \\
\text { - Warning coverage assessment of warning dissemination infrastructure } \\
\text { currently in place (Cf. VII.5) }\end{array}$ \\
\hline & Utility of results & $\begin{array}{l}\text { The disaggregated R\&V-A results can be used for setting up a monitoring system. } \\
\text { Assessment methods and indicators have to be adjusted to the options assessed, } \\
\text { selected, and implemented. }\end{array}$ \\
\hline
\end{tabular}

\section{VIII.3.4 Utility of the Results to Increase the Evacuation Readiness of the Population}

What is the best strategy to increase the evacuation readiness of the population to ensure timely evacuation? On which topics and how to sensitize the population about what to do in case of a tsunami alert issued by the government? These questions need to be addressed when setting up an early warning system. Without appropriate social response to warnings, any sophisticated warning system is useless (Cf. VI.4.4.10).

Table 24 shows how the R\&V-A results contribute to guide the single steps of the R\&V-R process to strengthen the evacuation readiness of the population.

Table 24 Utility of R\&V-A to enhance warning response and the effectiveness of evacuation readiness

\begin{tabular}{|l|l|l|}
\hline 1 & Option generation & Generation of options how to increase evacuation readiness \\
\hline Step description & $\begin{array}{l}\text { This phase of R\&V-R relates to the elaboration of possible options how to increase } \\
\text { the evacuation readiness of the population. }\end{array}$ \\
\hline $\begin{array}{l}\text { R\&V information } \\
\text { required }\end{array}$ & \begin{tabular}{l} 
Identifying those factors that influence the evacuation readiness (Cf.VII.6, VII.6.2). \\
\hline Utility of results
\end{tabular} & $\begin{array}{l}\text { Based on such analysis, options can be elaborated to increase the general } \\
\text { performance of the tsunami warning and response system. More specifically, the } \\
\text { results help to add social criteria to the different R\&V-R tasks within an early } \\
\text { warning system. } \\
\text { The following options for increasing the evacuation readiness can be deduced, } \\
\text { demonstrating that scientific and contextualized assessments even support the }\end{array}$ \\
\hline
\end{tabular}




\begin{tabular}{|c|c|c|}
\hline & & 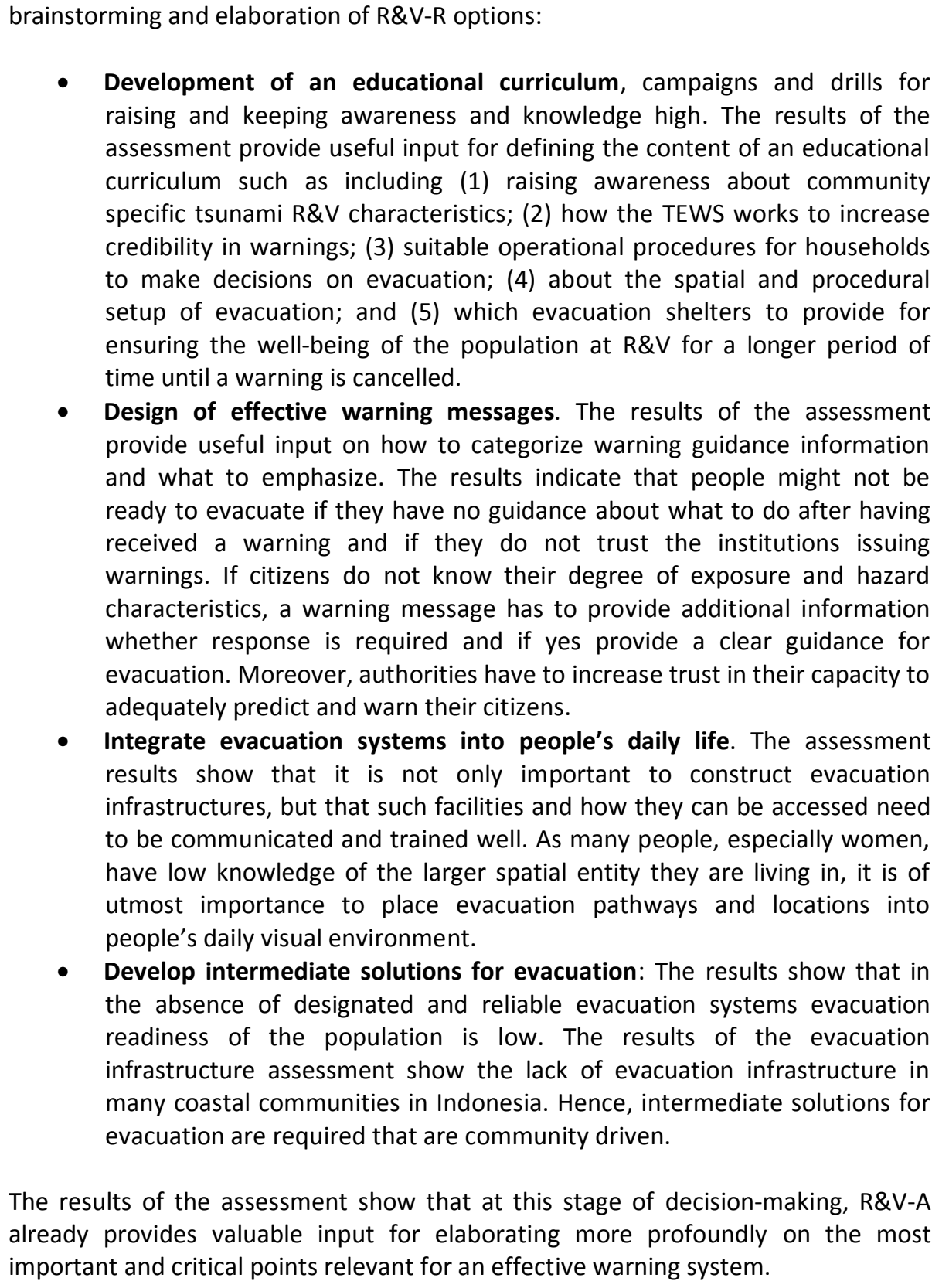 \\
\hline \multirow[t]{4}{*}{2} & Option assessment & Assessing current performance of evacuation readiness in the communities \\
\hline & Step description & $\begin{array}{l}\text { This step is not required since the options identified are complementary, and all of } \\
\text { them relevant. }\end{array}$ \\
\hline & $\begin{array}{l}\mathrm{R} \& \mathrm{~V} \text { information } \\
\text { required }\end{array}$ & No R\&V information required. \\
\hline & Utility of results & No utility. \\
\hline \multirow[t]{4}{*}{3} & Option selection & $\begin{array}{l}\text { Selection of the most effective options to increase evacuation readiness in the } \\
\text { communities }\end{array}$ \\
\hline & Step description & $\begin{array}{l}\text { This step is not required since the options identified are complementary, and all of } \\
\text { them relevant. }\end{array}$ \\
\hline & $\begin{array}{l}R \& V \text { information } \\
\text { required }\end{array}$ & No R\&V information required. \\
\hline & Utility of the results & No utility. \\
\hline
\end{tabular}




\begin{tabular}{|c|c|c|}
\hline \multirow[t]{4}{*}{4} & $\begin{array}{l}\text { Option } \\
\text { implementation }\end{array}$ & Implementing options to increase the evacuation readiness of the population \\
\hline & Step description & $\begin{array}{l}\text { As can be deduced from the first stage, the implementation of options to increase } \\
\text { evacuation readiness relates to all the other components of the early warning } \\
\text { system. Hence, it is the task of R\&V-R practitioners to mainstream the elaborated } \\
\text { options into the other components, there where the warning communication } \\
\text { system is elaborated and warning messages are designed, awareness campaigns are } \\
\text { programmed, and evacuation infrastructures and procedures are established. }\end{array}$ \\
\hline & $\begin{array}{l}\mathrm{R} \& \mathrm{~V} \text { information } \\
\text { required }\end{array}$ & $\begin{array}{l}\text { Factors influencing evacuation readiness (Cf.VII.6). } \\
\text { Degree of evacuation readiness (Cf.VII.6). }\end{array}$ \\
\hline & Utility of results & $\begin{array}{l}\text { Therefore, the assessment results offer a critical opportunity to setting a frame for } \\
\text { action with strong reference points to ensure the establishment of a "people- } \\
\text { centred" warning and response system. This is specifically helpful where many } \\
\text { different specialized actors and institutions at different administrative levels are } \\
\text { involved in the construction of a tsunami early warning system and might risk } \\
\text { detaching their work from the needs of the population in the communities. Hence, } \\
\text { the results help the harmonization and integration of the different components of } \\
\text { the warning system. Again, the assessment results lay emphasis on the "people- } \\
\text { centred" feature as a starting point for all major decisions related to the integral } \\
\text { components of an early warning system. } \\
\text { Moreover, the assessment of the degree of evacuation readiness and the degree } \\
\text { of how each of its contributing factors performs in the different communities } \\
\text { exposed is highly utilizable for the proper targeting of exposed communities: The } \\
\text { assessment results show a high spatial and social variation of evacuation readiness } \\
\text { across different communities. For example, in some areas R\&V knowledge is } \\
\text { adequate, but evacuation knowledge is lacking. For the case of Cilacap the results } \\
\text { show that communicating and building trust into the EWS and the participatory } \\
\text { identification of evacuation routes and shelters (as they do not exist yet) is urgently } \\
\text { needed and a matter of priority. Hence, the results allow for better targeting and } \\
\text { tailoring measures to increase the evacuation readiness customized to meet the } \\
\text { needs of communities. Here, responsible actors are urged to facilitate the } \\
\text { communication process of societal change with respect to the acceptance of the } \\
\text { EWS as a new technology of Disaster R\&V-R. }\end{array}$ \\
\hline \multirow[t]{4}{*}{5} & $\begin{array}{l}\text { Option performance } \\
\text { monitoring }\end{array}$ & Monitoring of evacuation readiness performance \\
\hline & Step description & $\begin{array}{l}\text { Regular monitoring of the evacuation readiness is important as societal as well as } \\
\text { warning and evacuation conditions change over time; for example due to migration } \\
\text { and population shifts patterns of R\&V perception change. Or, established } \\
\text { evacuation shelters and routes lose their effectiveness because of changes of land } \\
\text { uses, which in turn changes perceptions on the manageability of evacuation. Hence, } \\
\text { assessing the degree to which the population feels comfortable with the existing } \\
\text { warning and response system is important in order to adjust it to emerging and new } \\
\text { conditions. }\end{array}$ \\
\hline & $\begin{array}{l}\mathrm{R} \& \mathrm{~V} \text { Information } \\
\text { required }\end{array}$ & $\begin{array}{l}\text { Factors influencing evacuation readiness (Cf.VII.6). } \\
\text { Degree of evacuation readiness (Cf.VII.6). }\end{array}$ \\
\hline & Utility of results & $\begin{array}{l}\text { Both assessment results are relevant. The first can be used to develop the } \\
\text { monitoring indicators; the latter can be used to develop a metric for measuring } \\
\text { option performance. }\end{array}$ \\
\hline
\end{tabular}


The results show a strong utility for elaborating and further contextualizing options for R\&V-R. The findings are highly relevant for understanding the conditions of human response and behaviour to tsunami warnings and how to develop people-centred warning and response structures that are efficient: Early warning messages need to include a clear guidance for action with spatial reference, the spatial setup of evacuation related infrastructures (hazard and evacuation zoning signs, defining and labelling routes and identifying shelters with basic service provisions). In addition, and not less importantly, socialization of the population exposed is a precondition for efficient evacuation readiness.

Moreover, the results demonstrate that they can facilitate coherence whilst implementing the different components of an warning system as well as target more differentiated people's capacities to increase their readiness to evacuate in due time.

\section{VIII.3.5 Utility of the Assessment Results to Establish Evacuation Infrastructure}

How shall evacuation happen, what is the most effective strategy for localities to evacuate their population within a short time? These questions need to be addressed when planning for and deciding upon setting up effective evacuation infrastructures to ensure timely evacuation (Cf. VI.4.4.2, VII.7). Here R\&V-A can support such decisions. This chapter discusses the R\&V-A results in terms of their utility for the process of planning for evacuation systems and infrastructures at the community level - from the generation of the respective options to their assessment, selection, and implementation.

Although, the establishment of an evacuation system includes a number of tasks and measures, such as selecting the appropriate evacuation zone, adjusting the urban street network conducive for evacuation, and setting up shelter systems (Cf. VI.4.4.2), the utility evaluation done here only refers to the R\&V-R process regarding the establishment of effective evacuation shelters. Table 25 summarizes how the R\&V-A results contribute to the single steps of the R\&V$\mathrm{R}$ process for setting up people-centred evacuation shelters. 
Table 25 Utility of R\&V-A for the establishment of effective evacuation infrastructure

\begin{tabular}{|c|c|c|}
\hline \multirow[t]{4}{*}{1} & Option generation & Generation of options for establishing an evacuation infrastructure system \\
\hline & Step description & $\begin{array}{l}\text { This step requires the identification of options how to set up at best evacuation } \\
\text { infrastructures, including types of infrastructures as well as the location of } \\
\text { infrastructures. }\end{array}$ \\
\hline & $\begin{array}{l}\mathrm{R} \& \mathrm{~V}-\mathrm{A} \text { information } \\
\text { required }\end{array}$ & $\begin{array}{l}\text { Estimated Time of Tsunami Arrival (ETA) and Evacuation Time Map (Cf. VII.7.2, small } \\
\text { maps) }\end{array}$ \\
\hline & $\begin{array}{l}\text { Utility of the R\&V-A } \\
\text { results }\end{array}$ & $\begin{array}{l}\text { When contrasting the ETA with the time people need to find a safe place outside the } \\
\text { evacuation zone (Evacuation Time Map), it becomes obvious that especially vertical } \\
\text { shelters as well as the construction of more effective evacuation routes would help } \\
\text { tremendously to guaranteeing safe evacuation. This is not always the case. E.g.; in } \\
\text { cases where the ETA is very long (e.g. } 2 \text { hours), vertical shelters are not necessarily } \\
\text { required and do not have the desired impact. Hence, the assessment results' utility is } \\
\text { to emphasize the need of investment into evacuation infrastructures that allow for } \\
\text { quick and safe evacuation. Therefore, the results confirm that all evacuation } \\
\text { infrastructure options elaborated are badly needed in the case of Indonesia, and in } \\
\text { particular the district of Cilacap. }\end{array}$ \\
\hline \multirow[t]{4}{*}{2} & Option assessment & $\begin{array}{l}\text { Assessing existing evacuation infrastructure performance within a spatial entity of } \\
\text { concern }\end{array}$ \\
\hline & Step description & $\begin{array}{l}\text { Often, although not authorized, a certain level of evacuation capacity of a spatial } \\
\text { entity already exists. Hence, the evaluation and selection of generated and assessed } \\
\text { options relates to the assessment of the current degree of performance capacity of a } \\
\text { spatial entity to effectively perform evacuation, which depends upon the current land } \\
\text { use setting, as well as the structure of the built environment. }\end{array}$ \\
\hline & $\begin{array}{l}\mathrm{R} \& \mathrm{~V}-\mathrm{A} \text { information } \\
\text { required }\end{array}$ & $\begin{array}{l}\text { "Evacuation failure R\&V map" and its disaggregated information (Cf. VII.7.2) } \\
\text { The R\&V information reveals the spatial entities and the spatially distributed number } \\
\text { / proportion of people that might not be able to evacuate in due time during the day } \\
\text { and hence most probable suffer death when a tsunami event strikes (Cf. VII.7.2). } \\
\text { With its disaggregation it informs about the evacuation bottlenecks and fastest } \\
\text { evacuation routes and distribution, and the capacity of existing buildings suitable to } \\
\text { potentially function as shelters, and the identification of areas having difficulties to } \\
\text { evacuate in due time. }\end{array}$ \\
\hline & $\begin{array}{l}\text { Utility of the R\&V-A } \\
\text { results }\end{array}$ & $\begin{array}{l}\text { A range of utilities of assessing evacuation performance (or risk of evacuation failure) } \\
\text { exist that provide decision support for selecting the appropriate evacuation } \\
\text { infrastructure system. The evacuation performance assessment allows for conducting } \\
\text { the following actions: }\end{array}$ \\
\hline
\end{tabular}

- Determining the demand for investments into evacuation infrastructure: R\&V information provides the knowledge base for judging on the current capacity / lack of capacity of the current setup of (potentially suitable) evacuation infrastructures (buildings, open space for meeting points along the evacuation zone boundary) to save as many lives as possible. Hence, the assessment unfolds the demand for investments into evacuation infrastructure, or in other words, what still has to be done in order to accomplish full evacuation capacity of a spatial entity of concern. This can be done for each of the options identified. E.g.; the calculated amounts of people that cannot manage safe evacuation indicate the needs for vertical shelters with adequate capacity.

- Calculating costs of investments into evacuation infrastructure: Knowing the gap between the demand for evacuation infrastructure and the existing provisions of evacuation infrastructure within a community or urban area, the assessment of the costs of investments into this type of infrastructure can be conducted. It can 


\begin{tabular}{|c|c|c|}
\hline & & $\begin{array}{l}\text { also be used to decide upon a certain desired protection level for different hazard } \\
\text { scenarios. } \\
\text { - Providing guidance for disaster resilient urban planning: The results can inform } \\
\text { about the need for modifications in the current land use system in favour of quick } \\
\text { and safe evacuation, including the acknowledgement of evacuation route } \\
\text { systems and the integration of evacuation shelters in the urban / rural setups. }\end{array}$ \\
\hline \multirow[t]{4}{*}{3} & Option selection & $\begin{array}{l}\text { Selection of investment requirements to improve evacuation infrastructure based } \\
\text { on the tsunami threat }\end{array}$ \\
\hline & Step description & $\begin{array}{l}\text { A decision need to be done how, when, and where to invest in evacuation } \\
\text { infrastructure. The assessment of evacuation performance has laid the foundation for } \\
\text { conducting the selection process for deciding upon the demand for investment, } \\
\text { calculating costs and prioritizing investments. Especially selecting the different } \\
\text { options assessed need. }\end{array}$ \\
\hline & $\begin{array}{l}\mathrm{R} \& \mathrm{~V}-\mathrm{A} \text { information } \\
\text { required }\end{array}$ & $\begin{array}{l}\text { "Evacuation failure R\&V map" and its disaggregated information (Cf. VII.7), such as } \\
\text { hazard, exposure, evacuation capacity information. }\end{array}$ \\
\hline & $\begin{array}{l}\text { Utility of the R\&V-A } \\
\text { results }\end{array}$ & $\begin{array}{l}\text { The results can be used for a cost-benefit analysis to } \\
\text { - Spatially prioritize investments into evacuation infrastructure: Knowing for } \\
\text { different spatial entities those spatial entities having relatively higher } \\
\text { tsunami probability, being highly exposed and owning comparably little } \\
\text { evacuation capacity (hot spots of mortality) then others, a prioritization can } \\
\text { be conducted. } \\
\text { - Prioritization of investments into specific types of evacuation infrastructure } \\
\text { (roads, shelters, etc.): Putting into relation the calculated option specific } \\
\text { demand for investment and their contribution to increase the effectiveness } \\
\text { of the evacuation system, the most effective evacuation infrastructure can } \\
\text { be prioritized. }\end{array}$ \\
\hline \multirow[t]{4}{*}{4} & $\begin{array}{l}\text { Option } \\
\text { implementation }\end{array}$ & Designing and locating selected evacuation infrastructure options \\
\hline & Step description & $\begin{array}{l}\text { Setting up evacuation infrastructure includes many tasks and steps, such as } \\
\text { designating precisely the space for constructing evacuation shelters, identifying and } \\
\text { constructing fastest evacuation routes from each point of a defined area to the } \\
\text { nearest evacuation target point, as well as developing respective SOPs. }\end{array}$ \\
\hline & $\begin{array}{l}\mathrm{R} \& \mathrm{~V}-\mathrm{A} \text { information } \\
\text { required }\end{array}$ & “Evacuation failure R\&V map” and its disaggregated information (Cf. VII.7). \\
\hline & $\begin{array}{l}\text { Utility of the R\&V-A } \\
\text { results }\end{array}$ & $\begin{array}{l}\text { For the adequate design and construction of evacuation infrastructure the map is of } \\
\text { rather little value. Serving the purpose of option implementation, the assessment } \\
\text { results would need to be of high spatial resolution. The manner the map has been } \\
\text { developed, it helps to broadly suggest spatial areas where evacuation infrastructure } \\
\text { is needed but does not allow defining precisely their location within the urban } \\
\text { morphology of a city. Other than R\&V information is necessary here, such as the } \\
\text { fabric of neighbourhood, space availability, trade-offs of specific identified spaces in } \\
\text { terms of design, accessibility of the facility. The same accounts for implementing } \\
\text { appropriate evacuation routes. Are new roads needed requiring resettlement as well } \\
\text { as major alterations of the land use pattern, are fly-overs more appropriate than } \\
\text { broadening existing roads? These questions and tasks cannot be answered by R\&V } \\
\text { information but are a crucial to deal with in the implementation phase of R\&V-R }\end{array}$ \\
\hline
\end{tabular}




\begin{tabular}{|l|l|l|}
\hline 5 & measures. \\
\hline $\begin{array}{l}\text { Option } \\
\text { merformance } \\
\text { monitoring }\end{array}$ & Monitoring the effectiveness of implemented options and measures \\
\hline Step description & $\begin{array}{l}\text { In this step R\&V-R specialists need to regularly monitor the progress and } \\
\text { effectiveness of the implemented measures. }\end{array}$ \\
\hline $\begin{array}{l}\text { R\&V-A information } \\
\text { required }\end{array}$ & $\begin{array}{l}\text { "Evacuation failure R\&V map" and its disaggregated information (Cf. VII.7). } \\
\text { results }\end{array}$ & $\begin{array}{l}\text { The utility of the Evacuation Failure R\&V Map and its disaggregated information is } \\
\text { limited. But with the same data structure and the calculation methods, newly } \\
\text { acquired data (such as the new evacuation infrastructure implemented, modified } \\
\text { population distribution, land use patterns) the map can be reproduced to evaluate } \\
\text { the effectiveness of the evacuation infrastructure in a dynamically changing urban } \\
\text { environment, also requiring adjustments of the setup of evacuation infrastructures. } \\
\text { Hence, the regular update of the Evacuation Failure R\&V Map can be used for } \\
\text { assessing the degree of protection level attained for specifically conducted } \\
\text { investments in evacuation infrastructure (e.g. residual mortality rates for a specific } \\
\text { investment). }\end{array}$ \\
\hline
\end{tabular}

\section{VIII.4 Conclusion}

The utility assessment has clearly shown the important value of R\&V-A for establishing a people-centred early warning system but also the limitations. Four concluding sub-chapters are presented that address the utility of the R\&V-A for R\&V-R from different perspectives.

\section{VIII.4.1 Overview on the Utility of R\&V-A to Establish a Tsunami Warning System in Indonesia}

The results indicate that $R \& V-A$ can contribute to the $R \& V$ - $R$-task specific $R \& V-R$ process, from the elaboration, assessment, selection, and implementation of R\&V-R options as well as the monitoring of R\&V-R performance, including all R\&V-R tasks as they previously defined (Cf. VI.4) to establish an effective people-centred early warning system. Moreover, a number of generic utilities could emerge such as R\&V communication, spatial planning, education, resource planning, process-planning as well as cost-benefit analysis.

On the other side, the results have also shown that R\&V-A information is not necessarily always relevant to accomplish a specific $R \& V-R$ step. The very nature of specific $R \& V-R$ tasks decides upon at which stage of the R\&V-R process, $R \& V$ information is required. For example, in the case of establishing warning dissemination chains and infrastructure, no R\&V-A is needed for 
elaborating options. Whereas, in the case of elaborating options to increase the evacuation readiness of the population the scientific knowledge of $R \& V$ factors contributes significantly.

The results also show that not only one type of R\&V-A information is of utility for only one R\&V$\mathrm{R}$ task, but is at the same time of utility for others even though requiring other types of visualization. For example, for assessing options to define areas of intervention and select an evacuation zone a set of hazard scenarios are required, whereas for implementing a selected evacuation zone, only the spatial entity affected by one hazard scenario is important. Or, exposure data related to population distribution are included in calculations of R\&V factors, such as evacuation capacity, whereas for planning warning dissemination infrastructure, exposure mapping is combined with mapping warning infrastructure distribution. Hence, the results have clearly shown that the utility of $R \& V-A$ for $R \& V-R$ increases if the way how $R \& V$ information is assembled, processed, and visualized is tailored to the needs of specific R\&V-R tasks and suits the steps of the R\&V-R process.

Table 26 provides a summary of the utility of disaggregated R\&V-A information for each step of the R\&V-R process to devise a complementary set of R\&V-R tasks for establishing a tsunami early warning system. 


\begin{tabular}{|c|c|c|c|c|c|}
\hline \multirow[b]{2}{*}{ Process steps } & \multicolumn{5}{|c|}{ EWS-R\&V-R tasks } \\
\hline & $\begin{array}{l}\text { National to local level Warning } \\
\text { Dissemination Chain }\end{array}$ & Defining areas of intervention & $\begin{array}{l}\text { Warning dissemination \& SOPs and } \\
\text { infrastructure }\end{array}$ & Evacuation readiness & Evacuation infrastructure \\
\hline $\begin{array}{ll}1 & \text { Option } \\
& \text { generation }\end{array}$ & No utility of R\&V-A Results & $\begin{array}{l}\text { Scientifically based delivery of } \\
\text { options for defining an evacuation } \\
\text { zone. }\end{array}$ & No utility of R\&V-A Results & $\begin{array}{l}\text { R\&V-A results support the } \\
\text { development of } R \& V-\mathbf{R} \text { options } \\
\text { for increasing the evacuation } \\
\text { readiness of the population. }\end{array}$ & No utility of R\&V-A Results \\
\hline $\begin{array}{ll}2 & \text { Option } \\
\text { assessment }\end{array}$ & $\begin{array}{l}\text { R\&V-A Results (Estimated Time } \\
\text { of (Tsunami Arrival, evacuation } \\
\text { capacity) delivers effectiveness } \\
\text { assessment criteria and } \\
\text { benchmark value to support } \\
\text { comparative effectiveness } \\
\text { measurement of different } \\
\text { warning dissemination pathways } \\
\text { from national to local levels. }\end{array}$ & $\begin{array}{l}\text { R\&V-A Results (hazard probability, } \\
\text { exposure, evacuation capacity) } \\
\text { delivers criteria and data for: } \\
\text { - Comparative effectiveness } \\
\text { measurement of different } \\
\text { possible evacuation zones. } \\
\text { - Input data for cost-benefit } \\
\text { analysis of different evacuation } \\
\text { zone options. }\end{array}$ & $\begin{array}{l}\text { R\&V-A Results (access of population to } \\
\text { warning via different devices) delivers } \\
\text { criteria and data for: } \\
\text { - Comparative effectiveness } \\
\text { measurement of different warning } \\
\text { dissemination options. } \\
\text { - Determination of demands for } \\
\text { investment into warning } \\
\text { dissemination infrastructure. } \\
\text { - Infrastructure specific comparative } \\
\text { calculation of costs of investments. } \\
\text { - Prioritization of investments. }\end{array}$ & No utility of R\&V-A Results & $\begin{array}{l}\text { R\&V-A Results (evacuation capacity of } \\
\text { specific spatial entities) delivers criteria } \\
\text { and data for: } \\
\text { - Assessing current evacuation } \\
\text { effectiveness of spatial entities } \\
\text { within a defined evacuation zone. } \\
\text { - Determining demands for } \\
\text { investment into evacuation } \\
\text { infrastructure. } \\
\text { - Calculating costs of investments } \\
\text { into evacuation infrastructure. } \\
\text { - Prioritizing investments. }\end{array}$ \\
\hline $\begin{array}{ll}3 & \text { Option } \\
\text { selection }\end{array}$ & $\begin{array}{l}\text { The integration of R\&V-A Results } \\
\text { into the option assessment } \\
\text { facilitates risk communication } \\
\text { and resolving conflicting } \\
\text { positions to harmonize opinions }\end{array}$ & $\begin{array}{l}\text { The integration of R\&V-A Results into } \\
\text { the option assessment and the cost- } \\
\text { benefit results allows for knowledge } \\
\text { based discussion for selecting } \\
\text { appropriate evacuation zones. }\end{array}$ & $\begin{array}{l}\text { The integration of R\&V-A Results into the } \\
\text { option assessment facilitates knowledge } \\
\text { based discussion and delivering } \\
\text { argumentation lines for selecting a people } \\
\text { centred warning dissemination strategy. }\end{array}$ & No utility of R\&V-A Results & $\begin{array}{l}\text { The integration of R\&V-A Results into a } \\
\text { cost-benefit analysis allows for } \\
\text { prioritizing investments into evac. } \\
\text { infrastructure for different spatial } \\
\text { entities and types of infrastructure. }\end{array}$ \\
\hline $\begin{array}{ll}4 & \text { Option } \\
\text { implement-A } \\
\text { tion }\end{array}$ & No utility of R\&V-A Results & $\begin{array}{l}\text { R\&V-A Results (selected hazard } \\
\text { inundation line) provide basis for } \\
\text { defining spatial boundaries of an } \\
\text { selected evacuation zone }\end{array}$ & $\begin{array}{l}\text { R\&V-A Results (gaps of warning coverage) } \\
\text { support } \\
\text { The identification of spatial entities } \\
\text { requiring the warning infrastructures } \\
\text { selected. }\end{array}$ & $\begin{array}{l}\text { R\&V-A Results (determinants of } \\
\text { evacuation readiness, degree of } \\
\text { evacuation readiness) provide } \\
\text { - A general reference frame / } \\
\text { frame for action for setting up } \\
\text { an effective TEWS. } \\
\text { - The sequential order of } \\
\text { implementing R\&V-R tasks } \\
\text { and measures. }\end{array}$ & $\begin{array}{l}\text { R\&V-A Results (evacuation capacity of } \\
\text { specific spatial entities) provide } \\
\text { knowledge base for selecting spatial } \\
\text { areas where evacuation infrastructure } \\
\text { (location, capacity, size) is needed. } \\
\text { Hence, RA-Results support spatial } \\
\text { planning. }\end{array}$ \\
\hline $\begin{array}{ll}5 & \text { Option } \\
& \text { performance } \\
& \text { monitoring }\end{array}$ & Little utility & $\begin{array}{l}\text { The R\&V-A Results provide criteria, } \\
\text { indicators and methods for } \\
\text { developing a monitoring system to } \\
\text { continuously adjust the evacuation } \\
\text { zones selected. }\end{array}$ & $\begin{array}{l}\text { The R\&V-A Results provide criteria, } \\
\text { indicators and methods for developing a } \\
\text { monitoring system for ensuring the } \\
\text { effectiveness of warning infrastructures. }\end{array}$ & $\begin{array}{l}\text { R\&V-A Results provide criteria, } \\
\text { indicators and methods for } \\
\text { developing a monitoring system } \\
\text { for ensuring the evacuation } \\
\text { readiness of the people. }\end{array}$ & $\begin{array}{l}\text { R\&V-A Results provide criteria, } \\
\text { indicators and methods for developing } \\
\text { a monitoring system for measuring } \\
\text { evacuation performance. }\end{array}$ \\
\hline
\end{tabular}


In the following a set of major conclusions regarding the utility of R\&V-A for establishing a tsunami early warning system is presented.

\section{VIII.4.2 The Utility of R\&V-A for Each Step of the R\&V-R Process to Establish a Tsunami Early Warning System}

In the following the utility of R\&V-A for each of the different process steps to accomplish the defined R\&V-R tasks in the context of the Tsunami Early Warning System in Indonesia is summarized.

Option generation: When options are on hand, R\&V-A is not necessarily inevitable. Only, when there is too much uncertainty and there is very little information on possible options, scientific based R\&V-A can support the identification of options. For example, the definition options to decide on a reliable and manageable evacuation zone can be supported by scientific hazard assessments. Also, options to increase the evacuation readiness become much more apparent if the R\&V factors that limit the evacuation readiness of the population are assessed based on scientific evidence.

Option assessment: In this stage of the R\&V-R process R\&V-A plays a significant role. It provides assessment criteria, benchmark values for judging the effectiveness and performance of the different options available; hence, it also allows estimating demands for investments into R\&VR. In cases where the generated options are complementary no R\&V-A is required.

Option selection: As options assessment is a preparatory step towards selecting options, the role of R\&V-A can be shortly summarized as facilitating knowledge based discussion and providing more profound argumentation lines for selecting one or the other options related to a specific R\&V-R task. In some cases where the assessment results cannot provide sufficient information for taking sound decisions, a cost-benefit analysis is appropriate (for example to prioritize investments) for which R\&V-A can also play a significant role.

Option implementation: Depending on the accuracy, precision and reliability of the R\&V information available, the results (specifically those providing spatial information) can be used for instance for defining and legalizing spatial entities of $R \& V-R$ intervention, spatial planning related investments into warning and evacuation infrastructure. 
Option performance monitoring: Monitoring of $R \& V-R$ options is a crucial element for enhancing adaptive capacity. Here, the R\&V-A provides the reference frame for a monitoring system, provides criteria and benchmark values to continuously assess to which degree selected and implemented options perform effectively.

\section{VIII.4.3 The Utility of the R\&V-A for the Entire Process of Establishing a Tsunami Early Warning System}

It can be observed that some of the R\&V-A results have an overarching utility, and do not relate to single R\&V-R tasks. For example the assessment of the evacuation readiness reveals the most critical elements of an early warning system and defines the reference frame for setting up a people-centred effective tsunami warning system. The results have brought the evidence that if only one element of a EWS does not perform the entire system does not work. The lack of evacuation infrastructure within communities, for example, significantly reduces the evacuation readiness of the population. Without education and socializing private evacuation plans, effective evacuation infrastructure and evacuation proofed land use and spatial planning, a warning system does not function. Hence, the utility of R\&V-A can redirect attention to R\&V-R practitioners by urging them to reflect on the capabilities of local conditions, communities, individuals, land use settings when establishing an early warning system. Hence, the assessment results show that investments into so-called "last-mile" infrastructures have to be prioritized. Especially for Indonesia with a vast exposed coastline this poses a huge challenge, both in organizational and financial terms.

A very generic and important utility of R\&V-A is its contributing role to facilitate communication amongst R\&V-R practitioners working at different corners of an early warning system. R\&V-As and their information have the utility to provide an evidence based knowledge base and platform for the convergence and harmonization of opinions and perceptions with the aim to increase the coherence and gearing of different $R \& V-R$ tasks of an early warning system. For example, by knowing the evacuation capacity and tsunami threat (ETA) of a community, national authorities can reflect such results when it comes to defining the appropriate warning dissemination strategy. Hence, $R \& V-A$ can redirect the attention of $R \& V-R$ practitioners at different administrative levels to the requirements of a people-centred early warning system. 


\section{VIII.4.4 Limitations of the Utility of Risk and Vulnerability Assessment}

In the following a number of shortcomings of the R\&V-A conducted are outlined. They have emerged as a result of the macro-methodological approach of the thesis (Cf. I.4): The elaboration of the FARVAR framework, including the conceptualization of an iterative process of R\&V-A and R\&V-R (Cf.III.4, IV.5.3), has been based on the experiences with the R\&V-A conducted within the framework of the GITEWS implementation process. Hence, the key shortcomings of the R\&V-A conduced are highly valuable for increasing the potential of R\&V-As for providing decision support for different processes of R\&V-R.

- The research results include a high degree of uncertainty. Have hazard inundation assessment been realistic, are other factors influencing the capacity of individuals and households to commence evacuation in due time? Have the spatial entities that were identified as lacking capacity to evacuate in due time reflect the reality conditions on the ground? So far, no reality check could be done. Hence, planning based on research results might lead to mal-planning. Consequently, careful observation and monitoring while implementing the selected measures is necessary to continuously improve the R\&V-A methods and information packages.

- The assessment results presented have been produced at an enormous expense and high complexity, such as conducting large scale household surveys or using high resolution satellite images. It is doubtful that authorities are capable to reproduce such assessments.

- The results presented do not go very much beyond addressing unsafe conditions, which means they do not address the different root causes and societal conditions for InaTEWS being less effective. Although, for example, the factors that determine evacuation readiness have been identified, no assessment has been conducted that reveals why people have no trust in warnings, why they do not understand their vulnerability.

- The utility of results for assessing identified options, such as providing R\&V data for costbenefit analysis could not be entirely proved. The processing and integration process of data for such an analysis has not been done within the context of the GITEWS project; hence, the utilities described are lacking empirical evidence within the frame of this PhD. Nevertheless, the results presented could provide an argument for the feasibility of integrating R\&V data into cost-benefit analysis. 
- Overall, the results are limited to be used for implementing selected R\&V-R measures, since other considerations have to be taken into account for the implementation process. For example, setting up evacuation infrastructures requires more detailed information about the feasibility of widening roads, or about constructing shelters in proposed areas based on the R\&V-A results. Also, the implementation of a warning message is subject to technical prescriptions, and the design of awareness materials and exercises to enhance evacuation readiness needs to be tailored to the local social conditions.

- The results reveal a lack of utility due to lack of iteration of the R\&V-A information package development and the actual requirements for R\&V-R. The R\&V-A has not been conducted according to the proposed iterative process of R\&V-A and R\&V-R outlined in chapter IV.5.3. The research project commenced with a traditional perspective of R\&V-A and R\&V-R, which is assessing first $R \& V$ and thereafter entering the $R \& V-R$ process. Hence, the $R \& V-A$ packages that have been developed were based on the assumption that the scientific based selection of assessment criteria and input parameters were also representing the choices of authorities, for example defining the existing evacuation infrastructures for developing the "lack of capacity to evacuate" information package. Hence, the map produced is of limited use for generating options for investments in additional evacuation infrastructures.

- Although the results already represent a high degree of disaggregation, more disaggregation would enhance their utility for R\&V-R. For example, the Lack of Evacuation Capacity Assessment presented (Cf. VII.7.1) only indicates the current spatially distributed R\&Vs of mortality, but fails to provide the base to construct an optimal evacuation route scenario, as evacuation bottlenecks are not indicated for identifying options on how to alter the land use system in favour of increasing the effectiveness of evacuation, e.g. through widening and constructing new evacuation routes to reduce the time needed for evacuation. But the input data used for the presented map (Cf. VII.7.1) could be utilized for such purpose by identifying major evacuation bottlenecks, develop solutions, and identify more accurately spatial entities requiring a specific density and size of evacuation shelters. 


\section{Summary and Discussion}

\section{IX.1 Introduction}

Based on the title of the dissertation - Advancing Scientific R\&V-A for R\&V-R Decision-Making and Research - this chapter summarizes and discusses the findings and achievements of this dissertation. As the scientific evolution of the New Framework for Applied Risk and Vulnerability Assessment and Research (FARVAR) has been embedded within the provisions of contemporary $R \& V$ science and $R \& V-A$, this chapter summarises and discusses, based on the research questions posed, what has been achieved, but does not feedback the findings into the general scientific debate on R\&V or R\&V.A, as this has been already done while developing the FARVAR. Instead, the conceptualizations done in this dissertation, such as the development of the FARVAR, the definition of a process of $R \& V-R$, and how $R \& V-A$ is integrated within such a process, are reflected against the empirical findings of the R\&V-A conducted in the context of the Tsunami Early Warning System in Indonesia. Chapter IX.2 reflects on the FARVA development process and its provisions for R\&V-Assessments and R\&V-Research and hence addresses RQ 1.1 and RQ 2.1; chapter IX.3 discusses the revealed utilities of R\&V-A for processes of R\&V-R and hence addresses RQ 1.2 and RQ 2.2.

\section{IX.2 Development of a Framework Shared by R\&V-Scholars and R\&V-R Practitioners to Facilitate Applied R\&V-A and Research}

It could be found that despite the proliferation of scientific R\&V-As, using them as a basis for R\&V-R decision-making is still lacking. Some explanation for this could be the fact that the perceived vague meaning and definition of the determinants of R\&V (notably; exposure, susceptibility, and adaptive capacity), the fuzziness and at times incomplete clarity of how they relate to each other, and the diversity of $R \& V$ framings in science (different disciplinary roots and histories) (Cf. III.4.1) have led to a general detachment of scientific R\&V-A from the requirements of $R \& V-R$ practitioners to advance in overall R\&V-R (Cf. I.2, IV.3.1, IV.5.1). This circumstance has called forth the necessity to resolve this observed mismatch (Cf. I.2) and to promote more profound liaising between R\&V-A scholars and R\&V-R practitioners allowing 
them to derive greater benefit from each other's work in progress. Based on the summarized problem setting, the following research questions are addressed in this chapter.

RQ 1.1 What could a R\&V framework look like applicable for both R\&V-A scholars as well as $R \& V-R$ practitioners, acting as a reference frame for action, and facilitating a mutual understanding and exchange?

RQ 2.1 What could a contextualized framework of applied R\&V-As look like that facilitates the establishment of a tsunami early warning system in Indonesia?

Especially in view of the fact that a societally inclusive perspective on $R \& V-R$ is emerging in which societal conditions and processes become important and influence R\&V-R performance, particularly the role of vulnerability assessment for taking R\&V-R decisions is increasing. To acknowledge this circumstance, the purpose and vision of the dissertation was that R\&V-A scholars and R\&V-R practitioners would be able to share the same work-guiding framework without losing academic relevance and justification. The benefits of such a framework are that it speaks a language understandable to both communities, therefore fostering mutual understanding and fluid exchange of information; that it better addresses $R \& V-R$ requirements and enhances the applicability of R\&V-A for R\&V-R; and finally, that it provides normative guidance for applied R\&V research and R\&V-A (Cf. I.2, I.3).

\section{IX.2.1 Evolution and Key Provisions of the FARVAR for Enhancing Applied R\&V- Assessment}

The challenges outlined above have been addressed to finally arrive at the scientifically grounded Framework for Applied Risk and Vulnerability Assessment and Research (FARVAR) (Cf. IV). Of key importance has been the translation of the provisions of the scientific debate about $R \& V$ into a R\&V-R perspective, where the initial point of departure of the FARVAR development process is the widely acknowledged notion that R\&V (respectively, exposure and susceptibility) can be viewed as a result of lack of capacity, where capacity is the depending variable that decides upon vulnerability outcomes (Cf. IV.2). By substituting the common definitions of different types of capacity (coping-, adaptive-, response capacity) in exchange for the scientifically derived hierarchically structured R\&V-R nomenclature (Cf. IV.3), the FARVAR defines $R \& V$ as not well implemented or absent R\&V-R that renders weak performance in the 
$\mathrm{R} \& \mathrm{~V}$ anticipation, prevention, and preparedness (including subsequent components, tasks and measures), due to shortcomings rooted in wider societal development paths (Cf. IV.4) - A R\&Vcausality frame that provides the basis for applied R\&V-Assessment and -Research (detailed summary of the scientifically grounded evolution of the FARVAR is presented in Box 2). For example, the case study has demonstrated that the current performance of the Indonesian Tsunami Early Warning System is not effective enough to save lives in the course of a tsunami event, revealing vulnerability and risk. Neither have the people access to timely tsunami warnings, nor are they ready and capable to evacuate in due time.

\section{Summary of the scientifically grounded evolution of the FARVAR}

A core provision of FARVAR is an R\&V causality frame that is based on the argumentatively evidenced notion that processes of capacity obstruction reveal exposure and susceptibility to a well-defined threat. Such an argumentation line contradicts the widely followed notion that $R \& V s$ are the opposite of capacity, or that vulnerability and capacity within a specific reference system can coexist (Cf. IV.2) In contrast, the FARVAR is based on the conception that the compound configuration of capacity influencing factors and processes within a predefined system of analysis is the dependent "set of variables (or causality) that decide upon whether risky and vulnerable conditions are generated, prevail or are successfully reduced. Such explicit causality framing is the core component of the FARVAR and signifies a major difference compared to other R\&V-A frameworks, where the terms suceptibility, exposure, and capacity are treated as independent determinants of $R \& V$ without putting them into a logical order, thus revealing a lack of clarity on how they relate to each other (Cf. IV.3.1). The case study has operationalized this causality by defining and assessing R\&V as the lack of people's capacity to access tsunami warnings, to adequately respond to tsunami warnings, and to manage physical evacuation in due time, hence showing their susceptibility to loss of life in the course of a tsunami event (Cf. II.3, 0).

A next fundamental step towards the FARVAR was to provide a more structured frame for capacity causality analysis, a common frame that shall guide $R \& V$ scholars as well as R\&V-R practitioners. A very important sequence of the FARVAR development process was the design of an applied R\&V causality frame (Cf. IV.4) that evolved from rethinking the dialectics and inter-relationships between the conceptualizations of capacity and vulnerability (exposure / susceptibility) (Cf. IV.2), and how different types of capacity (such as response, coping and adaptive capacity) can be compared with the set of R\&V-R options (such as prevention, preparedness) defined by the traditional risk management community (Cf.IV.2). The initial point of departure was to evaluate in more depth how the very broad definition of the term capacity - defined as "the combination of all strengths [...] and resources [...] to achieve agreed goals" - is used by R\&V scholars and how it provides guidance for R\&V-R practitioners. Based on the notion that improving capacity means increasing the capacity to reduce R\&V (Cf. IV.3.2), the analysis has come to the conclusion that the term capacity has to be explicitly related to 
options and processes of $R \& V-R$, a link which is missing in contemporary $R \& V$ science. Although it is well acknowledged in scientific literature that improving capacity means increasing the capacity to reduce $R \& V$, no reference is made to the variety of well distinguished "capacities to reduce $R \& V$ " in the risk management literature, such as capacity to anticipate, prevent, and prepare (Cf. IV.2). Instead, the scientific discourse around different types of capacity is related to how to distinguish between expressions such as response-, coping-, and adaptive capacity, showing its very weak link with R\&V-R in practice.

By comparing the definition of types of capacity by R\&V scholars with those types and options of R\&V-R used by practitioners the weaknesses of the scientific differentiation of types of capacity became evident, demonstrating conceptual overlaps and fuzziness owed to their different disciplinary roots and their historical evolution (Cf. II.4.1). As a consequence, the capacity discourse and terminology used by R\&V scholars has never been taken up by R\&V-R practitioners, revealing little exchange between the two communities at the disadvantage of lack of diffusion of scientific R\&V-As in processes of R\&V-R (Cf. I.2).

Hence, based on a careful comparison, it has been decided to replace the different types of capacity defined by the $R \& V$ science community with an elaborated R\&V-R nomenclature. As both the definitions of different types of capacity home to $R \& V$ science and the different options described in the risk management literature represent approaches to reduce $R \& V$, this thesis has developed a hierarchically integrated R\&V-R nomenclature, in which each of the independent $R \& V-R$ domains (anticipation, prevention, preparedness) are composed of $R \& V-R$ components (hazard threat reduction, accommodation, retreat, exposure prevention, early warning, relief, recovery), which again include different R\&V-R tasks and R\&V-R measures (Cf. III.3). Such classification reflects very well the different types of capacity described in different vulnerability concepts, but also offers the additional advantage of being more coherent, differentiated and clear. An exception is the term "adaptive capacity" that has been defined as the capacity to navigate through a defined process of R\&V-R including taking cyclical decisions to select the most favourable or a set of favourable R\&V-R-components, and carrying out the corresponding tasks and measures by means of elaborating, assessing, selecting, implementing, and evaluating R\&V-R options (Cf. III.4). The case study has shown the advantage of using the R\&V-R nomenclature as a point of departure for R\&V-A. Instead of having developed susceptibility, capacity to cope, or capacity to adapt indicators and indices, a set of types of capacity (corresponding with the R\&V-R tasks) has been defined to accomplish the R\&V-R component "Early Warning System" (capacity to access warnings, to be ready to evacuate, and to evacuate), using it as the reference system for the R\&V-A (Cf. VI.5.1).

By incorporating the R\&V-R nomenclature into a R\&V causality frame the statement already made in the 70ies that "disasters signify unmanaged risks" (Westgate, O'Keefe 1976) acquires a new meaning and is operationalized in the FARVAR framework. Accordingly, R\&V can be defined as the outcome of lack of $R \& V-R$, an expression that represents the ultimate common denominator in the process of terminology harmonization. Hence, the R\&V-R-nomenclature provides guiding and structuring categories for delineating causal pathways of R\&V. Given that the development and outcomes of $R \& V-R$ performance are embedded within socio-political, socio-economic and socio-environmental conditions and processes (Cf. III.2), the point of departure for $R \& V$ research and $R \& V-R$ is to understand those $R \& V$ causalities within societal, economic, and environmental structures and processes that may lead to a lack of or a mal- 
developed R\&V-R pathway of a given society or subject of concern, hence increasing a society`s exposure and susceptibility to harm (Cf. IV.4). The case study aimed at figuring out what are the factors that leave an early warning system mal functioning. It was discovered that the lack of integration of societal, technological, and governmental elements relevant for the function of an early warning system has led to the lack of capacity of the TEWES to perform effectively, causing R\&V to tsunami hazards. For example, the unfavourable urban fabric in pursuit of evacuation in the surveyed cities in Indonesia, the lack of trust of the population in the reliability of state services such as tsunami warnings, and the low knowledge of exposure, as well as the lack of warning dissemination infrastructure development, has altogether led to a high risk of evacuation failure in the course of a tsunami event risking high numbers of fatalities (Cf. VII.6.2).

A causal analysis of $R \& V$ structured on the basis of the hierarchical $R \& V-R$ nomenclature focuses on disaggregated R\&Vs structured according to this nomenclature. This means assessing those factors and processes related to specific societal and environmental conditions that reveal a lack of effective R\&V-R performance, whether in the context of anticipation, preparedness, or prevention and their subsequent components, tasks and measures. Thereby, for any defined system of interest within the R\&V-R nomenclature, the focus of $R \& V-A$ can be placed on understanding R\&V causalities - using the analytical provisions of existing R\&V schools - or on purely measuring the gap between intended or required and accomplished risk and vulnerability reduction, revealing a specific degree of susceptibility, exposure, vulnerability, and risk. The context within the R\&V-A to be conducted - such as the R\&V-R domain "Preparedness" and the component focussing on "Early Warning System" - can be decided either through a specific research programme, but also, on the other hand, through the chosen $R \& V-R$ path and the requirements of $R \& V-R$ practitioners. Hence, when engaging into an iterative $R \& V-A$ and $R \& V-R$ process, the generic FARVAR framework requires contextualization depending on the system of interest at the R\&V-R path in focus.

The case study has proven the usefulness of the R\&V-R nomenclature as a structuring frame for defining R\&V-A topics and methods as they directly relate language and content-wise, to the different requirements of $R \& V-R$ practitioners who use the $R \& V-R$ nomenclature as their framework for R\&V-R. In the case of the Tsunami Early Warning System in Indonesia, R\&V-R practitioners intuitively understood the rationale and purpose of the $R \& V-A$, as the labelling of the respective assessments corresponded with the labelling $R \& V-R$ components and tasks they had been dealing with for developing their tsunami early warning system. Respectively, the 
assessment focused on the (lack of) capacity to receive warnings, respond to warning, and evacuate exposed populations that in their sum determine the susceptibility to mortality in the course of a tsunami event. To better understand R\&V causalities as a basis for decision-making, applied R\&V-As can also benefit from the diverse existing R\&V causal analysis frameworks provided by R\&V scholars. The FARVAR explicitly promotes this. Especially, the role of vulnerability assessment for taking R\&V-R decisions is significant. Identifying - by employing a chosen theoretical lens - the weaknesses in societal and environmental conditions (e.g., the conditions of environmental service performance, spatial configurations, entitlements, access to land, the formation of social or human capital, development paths, economic systems, urban development, social justice and sustainable livelihoods) hindering and undermining the development of capacities to accomplish individual or collective $R \& V-R$, can provide useful information upon which $R \& V-R$ practitioners can build their decisions. For example, the analysis of the evacuation readiness of the population in Cilacap, Padang and Bali has demonstrated that structural framework conditions, such as evacuation capacity provisions of the spatial set up in these coastal cities, have a strong influence on people's agency, here defined as their response behaviour to tsunami warnings (Cf. VII.6.2). Hence, the definition of the research topic has been guided by the specific R\&V-R component and task of interest for R\&V-R (such as increasing the evacuation readiness of the population), and its operationalization has been tied to vulnerability schools that had focussed in the case study on the interrelation of structure and agency (Cf. II.3) to reveal and understand the emergence of vulnerability.

\section{IX.2.2 The FARVAR Providing a Normative Research Frame}

The FARVAR provides normative orientation for $R \& V$ research and the respective scientific $R \& V$ As, as the $R \& V$ causality frame with its $R \& V-R$ nomenclature includes a coherent and comprehensive classification of R\&V-research entry points. There R\&V-A research can derive great value from using the $R \& V-R$ nomenclature as a normative entry point for the definition of research topics, leaving at the same time sufficient academic freedom to choose how to operationalize the respective research, and how to apply different theoretical conceptions and methods. Within applied research, normative orientation is important, a point which is only superficially outlined in the current research agendas, such as "providing evidence in pursuit of 
disaster R\&V-R". But normative orientation can be much more detailed and deconstructed as the diversity of entry points for R\&V-R is high as demonstrated by the FARVAR.

Therefore, the FARVAR offers the opportunity to conduct more in-depth applied research by linking R\&V-A challenges derived from the R\&V-R nomenclature with different theoretical approaches for understanding R\&V causalities. Instead of selecting and calculating common indicators of R\&V based on the contemporary definition of determinants of vulnerability, such as susceptibility, exposure, capacity, the focus of research has been shifted towards a causality analysis within a specific R\&V-R context that allows for more analytical, topic focussed research as demonstrated by the case study. For example, understanding causalities related to evacuation readiness is a research topic of its own, such as assessing weaknesses and their causes related to the spatial setup of an urban system to accommodate an evacuation system, requiring the unique integration of different research methods (household surveys, national statistics, GIS, remote sensing, numerical modelling) and data sources (structural and social household data, land use data-specific hazard characteristics). For example, the analysis of the evacuation readiness of the population in Cilacap, Padang and Bali has demonstrated the interrelation of structure and agency (Cf. II.3). Structural framework conditions, such as the evacuation capacity provisions of the spatial setup in these coastal cities, have a strong influence on people's agency, here defined as their response behaviour to tsunami warnings (Cf. VII.6.2).

Hence, by using the FARVAR as a basic framework for research, R\&V research becomes more applied and topic-specific, and if utilized by a large amount of research projects in various disciplines, allows for a better comparison of research approaches and results and fosters the discussion of their applicability for R\&V-R, as well as determining how to set research priorities and define new topics. Such normative orientation is missing to-date, i.e., an orientation in which research is dedicated to enhancing its usefulness to the benefit of overall $R \& V-R$, a link of concern apparently unnoticed so far by international policy makers. 


\section{IX.3 Widening the Scope and Utility of R\&V-A for R\&V-R in Processes of R\&V-R}

Based on applying and testing the FARVA, this chapter resumes the achievements made with respect to increasing the applicability of $R \& V-A$ for processes of $R \& V-R$ decision-making and hence demonstrates how to put an end to the very superficial and piecemeal descriptions of the utility of R\&V-A (Cf. I.2, IV.5.1). Consequently, this chapter addresses the following research questions RQ 1.2 and RQ 2.2:

RQ 1.2 How to conceptualize the role of applied R\&V-A for R\&V-R decision-making that promotes and guides the integration of R\&V-As into the different process steps of $\mathrm{R} \& \mathrm{~V}-\mathrm{R}$ ?

RQ 2.2 What are the areas of application of R\&V-A for different processes for establishing a tsunami early warning system in Indonesia and in general?

This thesis has elaborated conceptually on how R\&V-A can provide useful support for and can be integrated into $R \& V-R$ decision-making, hence dismissing a linear process in which $R \& V$ are assessed first, before engaging into R\&V-R decision-making. The conceptualization of applied $R \& V-A$ promotes an iterative process of $R \& V-R$ decision-making and R\&V-A: Defining R\&V-R as a process - representing a cyclical procedure consisting of generic steps of R\&V-R decisionmaking ("elaborating", "assessing", "selecting" R\&V-R options for each level within the hierarchy of the R\&V-R nomenclature) and steps that refer to the implementation, monitoring and evaluation of the most appropriate R\&V-R measures identified (Cf. III.4) - implies an opportunity to integrate R\&V-A within such a R\&V-R process iteratively (Cf. IV.5.3). In order to arrive at the next level in the hierarchy of the R\&V-R nomenclature and to support each process step within the entire $R \& V-R$ process, process step specific $R \& V$ information packages are required, where $R \& V$ information is collected, assembled, processed, and visualized according to the specific requirements of R\&V-R practitioners.

The case study operationalized a specific section of the entire iterative $R \& V-R$ and $R \& V-A$ process. It focussed on the contribution of differential R\&V-A information packages to the elaboration, assessment, selection, implementation and monitoring of R\&V-R tasks and measures for the R\&V-R component "Early Warning System". Hence, the case study elaborated 
upon the role R\&V-A information packages can play in pursuit of increasing the effectiveness of the R\&V-R component "Early Warning System". The results have clearly shown that R\&V-A significantly improves $R \& V-R$ decision-making and outcomes if $R \& V$ information is assembled, processed, and visualized to deliver disaggregated R\&V-A information packages tailored according to the needs of specific R\&V-R tasks and steps of the R\&V-R process. It was interesting to discover that the provision of more disaggregated information packages resulted in an increase of the R\&V-A utility. In the context of InaTEWS, disaggregated R\&V-A information packages had been produced serving as decision support for accomplishing singular early warning system related $R \& V-R$ challenges. For example, the separate assessment of different hazard characteristics - such as tsunami arrival times, tsunami inundation scenarios, and wave heights at the coast, did serve different R\&V-R purposes, such as defining evacuation times, defining an evacuation zone, defining warning levels. This also accounted for exposure and evacuation readiness assessment.

Utility of $R \& V$-A for the different steps within the process of $R \& V-R$

The integration of $R \& V-A$ into processes of $R \& V-R$ serving the step-specific elaboration, assessment, selection and implementation and monitoring of $R \& V-R$ options represents a first order description of the utility of R\&V-A for R\&V-R. Process step-specific utilities could be discovered. $R \& V-A$ for the generation of $R \& V-R$ options is especially useful where for example a huge knowledge gap or uncertainty regarding possible options prevail. For example, assessing those factors determining people's readiness to evacuate provided the baseline for identifying options how to increase the awareness of people to adequately respond to warnings and develop their personal evacuation plans (Cf. VII.6). Another example is the need to understand tsunami hazard characteristics, such as tsunami inundation to elaborate options how to define an evacuation zone.

The case study has demonstrated that R\&V-A plays a very important and outstanding role for assessing the options elaborated, requiring context-specific R\&V-A information packages. For example, R\&V-A information used for assessing politically driven elaborated warning dissemination options from the national to the community level turned out to be very useful: The assessment of tsunami arrival times and the estimation of the evacuation time people need to find a safe place within different spatial entities were used as criteria and benchmark values 
to rationalize the debate and focus decision-makers on deciding upon the quickest warning dissemination chain instead of acknowledging the different institutional bodies' demands for being the legitimate authority in passing on warning messages (Cf. VIII.3.1). Or, the identification of tsunami inundation scenario-specific spatial entities, and numbers of people that need to evacuate, as well as the current evacuation performance act as input data for costbenefit and comparative effectiveness analysis to select the best options for manageable, acceptable, and effective evacuation zones (Cf. VIII.3.2).

The role of R\&V-A for selecting and implementing the options assessed is rather facilitating, providing more profound argumentation lines for selecting one or the other options. The utility of R\&V-A information for implementing the selected options is often limited due to lack of measurement accuracy, precision, and reliability. But if processed well with adequate spatial resolution, accurate and precise R\&V-A can be used for disaster preventive land use planning, for example by spatially defining and legalizing a precise evacuation zone, and localizing investments in warning and evacuation infrastructures.

\section{Summary of differential utilities within the process of $R \& V-R$}

Next to and within the different R\&V-R process phases and steps, R\&V-A offers a number of specialized utilities which include supporting the development of quality criteria for successful $R \& V-R$, spatial planning, defining the sequential order for the implementation of R\&V-R options, developing education curricula, conducting cost-benefit and comparative effectiveness analysis, comparative calculation of costs of investments, prioritizing R\&V-R options, specifying spatial intervention areas, increasing the transparency of $R \& V-R$ decisions, contributing to $R \& V-R$ specific $R \& V$ communication, rationalizing public and expert debates through knowledge based opinion, broadening the perspective of $R \& V-R$ from technical fields of action to social ones, thereby acknowledging the role of people, actors and their interests in processes of R\&V-R (Cf. III.2).

The utility of $R \& V-A$ to redirect attention to people as agency in $R \& V-R$

A very specific utility, especially regarding vulnerability information, is redirecting the focus from traditional R\&V-R - as a matter of investments in infrastructure provided by authorities towards also the unavoidable consideration of societal factors in which people, their 
perceptions, livelihoods, and capacities must be part of R\&V-R solutions (the success of a tsunami early warning system is a matter of individual preparedness to respond adequately to warnings). Many R\&V-A and vulnerability frameworks before have demonstrated the need to focus on people (Birkmann et al. 2013a; Wisner et al. 2004; Ashley, Carney 1999) (Bogardi, Birkmann 2004), but none could make an explicit reference and provide guidance to the role of social and individual responsibilities within processes of R\&V-R as they have not attached their $R \& V-A$ schemes and indicators to specific $R \& V-R$ topics and requirements, such as the FARVAR does. For example, the factors that influence people's readiness to respond to warnings are different from those influencing people's participation in insurance schemes in pursuit of sustainable recovery. Hence, people-centred R\&V-A is only valued by practitioners if the vulnerabilities addressed and assessed are linked to a specific R\&V-R challenge. Hence, by using the R\&V-nomenclature as a structuring frame for R\&V-A and at the same time focussing on the role of societal conditions in R\&V-R through the lens of vulnerability, people-centred R\&V-As gain significant policy relevance and recognition among R\&V-R practitioners. For example, having assessed the cultural dimension of warning dissemination has created the awareness that building warning infrastructure has to take into account culturally evolved communication networks such as mosques. Also the notion that not all people react to warnings in the same way has created awareness amongst authorities about the need to invest in household level preparedness.

Hence, in this way, the case study has demonstrated that the development of R\&V-A information packages is highly contextual and requires a clear definition of how R\&V information is intended to be used. Compared to the differential utilities of the R\&V-A revealed by the FARVAR-guided R\&V-A, the utility of generic and aggregated R\&V indicators representing relative vulnerabilities for a specific spatial entity of concern (Cf. IV.5.1) proves to be rather limited to broader R\&V communication. To overcome the stated lack of R\&V-R decisions taken based on R\&V-A, the need has become evident to embed R\&V-A within processes of R\&V-R and to focus on "how to make each element of the system less vulnerable" (Patt et al. 2009a).

The results have demonstrated that applied $R \& V-A$ cannot be separated from real or simulated processes of R\&V-R. The research conducted within the context of InaTEWS represents such an 
example, where the definition of the R\&V-A topics had been based on the requirements to design and implement InaTEWS, with all its R\&V-R tasks and measures.

The demonstrated wide spectrum of the utility of disaggregated R\&V-A information to provide support for processes of $R \& V-R$ is unique and requires further elaboration in future research projects. The adoption of internationally well accepted R\&V-A utility standards including a methodological description of how to design R\&V-As of utility for R\&V-R decision-making, would help countries in their efforts to engage in knowledge based processes of R\&V-R. The findings of the thesis could be a starting point. 


\section{Conclusion}

\section{X.1 Advancing Applied R\&V-A for Decision Making}

According to the overall objective of this dissertation, this dissertation has demonstrated that the developed Framework for Applied Risk and Vulnerability Assessment and Research (FARVAR) and the attached conceptualization of how R\&V-A is integrated into processes of $R \& V-R$, improved the integration of R\&V-Research, R\&V-Assessment and R\&V-Reduction.

Such integration opened the door for exploring the vast potential and variety of possible applications of R\&V-A, in particular of vulnerability assessment, in processes of R\&V-R decisionmaking. It could be proved that the applicability of R\&V-A increases when respective information is collected and processed according to practitioners needs to accomplish the different steps of R\&V-R, such as their integration into cost-benefit analysis for assessing and selecting options. Consequently, it could be shown that instead of defining R\&V-A and R\&V-R as a linear rather process, $R \& V-A$ and $R \& V-R$ rather refers to an iterative process, where particularly vulnerability assessment can support decisions in different contexts and steps in the processes of R\&V-R. Hence, the weaknesses of contemporary R\&V-As in terms of their applicability for R\&V-R decision making have become evident, when contrasting them with the evidence brought how applied R\&V-A can be integrated into processes of R\&V-R. Instead of operationalizing scientific framings of $R \& V$, applied $R \& V-A$ shall be guided by the specific requirements of $R \& V-R$ practitioners to navigate through the different steps of $R \& V-R$ decision making, by making use of R\&V theory. This dissertation has shown how this can work. It represents an initial point of departure to spark off the debate about how to improve the role of R\&V-A for R\&V-R decision making and therefore aims to redirect the focus away from the tiring and endless debates about how to classify determinants of risk and vulnerability. R\&V scholars and R\&V-R practitioners might jointly instigate the need to invest into more research and dialogue on how $R \& V-R$ can make more use of $R \& V-A$, and in particular of vulnerability assessment. This does not mean, that $R \& V$ research shall entirely submit itself to the requirements of $R \& V$ practitioners. It can, but $R \& V$-research projects also can solely use the overarching coordinate system of the FARVAR - which represents a R\&V causality frame built 
upon the R\&V-R nomenclature - to justify, facilitate and conduct more in-depth, analytical and theory driven inter-disciplinary research.

\section{X.2 The Role of Geography in Applied Risk and Vulnerability Research}

The dissertation has strengthened the role of geography as an interdisciplinary research discipline working at the interface of humanity and the environment as well as focussing on actors and agency to understand spatial configurations revealing R\&Vs. Geography, as a discipline, has historically a strong focus on applied science. The dissertation has demonstrated how the highly respected previous and ongoing theoretical work to understand R\&V causalities can be translated into a practical tool for decision-making, and hence has contributed to enhance the role of Geography in applied $R \& V$ research, also because it has demonstrated a new spatial perspective within the domain of quantitative R\&V-A. The R\&V-A conducted based on the FARVAR has revealed pictures of real spatial configurations of the area of interest. In contrast to R\&V-As conducted here-to-fore, where social data and indexes have been mapped based on defined political entities, the R\&V-A in this dissertation has demonstrated that processing R\&V-A information based on the integration of social, topographical, land use, and environmental data sources yields assessment results aiming to depict spatial and non-spatial human-environmental conditions and their processes behind that go beyond artificially defined boundaries of representation. Hence, the results show that quantitative R\&V-A shall not be reduced to developing indicators representing administrative spatial units, but that spatially created R\&Vs can be visualized based on the real spatial configuration of an area.

\section{X.3 Strengths and Weaknesses of the Dissertation}

In the following, the strengths and the weaknesses of the work are elaborated and discussed, that also lead to the formulation of future research challenges.

- Integration of the conceptual provisions and the case study work. The dissertation has emerged from an applied research project, in which the development of the conceptual foundation of the dissertation is a result of the empirical work conducted within the frame of the German Tsunami Early Warning System Project. Hence, the research followed an inductive process of concept development - based on an empirical case 
study. A distinct advantage of this approach is that the R\&V-A was guided by the equation that risk is the function of hazard and vulnerability, hence having put much emphasis on vulnerability; but that the definition of the assessment topics followed the broader framework of an early warning system. This advantageous circumstance has brought up the opportunity to raise the issue of how R\&V-A can become of increased utility for R\&V-R and to develop an R\&V-A framework that facilitates the integration of $R \& V-A$ into processes of R\&V-R. An observable disadvantage of this approach is that the empirical work conducted did not exactly follow the conceptual provisions delineated, especially with regard to the integration of $R \& V-A$ into processes of $R \& V-R$. The $R \& V-A$ information packages developed were guided only by defining the assessment topic in relation to the defined $R \& V-R$ tasks ( $R \& V$ as lack of capacity to disseminate warnings effectively, to be ready to respond to warnings, and to physically evacuate in due time), but were not based on what R\&V-R practitioners require with regard to accomplishing the sequential steps of a R\&V-R process, such as elaborating, assessing, selecting, and implementing optional R\&V-R tasks. Hence, the utility discussion conducted in this thesis (Cf. VIII.4) was done a bit on a hypothetical basis, and the finalized R\&V-A results were discussed with regard to their utility for a hypothetical R\&V-R process that has not been realized in the context of the Tsunami Early Warning System in Indonesia yet. Here, it would have become interesting to empirically invest in how R\&V-A can support such a decision-making process within a real iterative R\&V-A and R\&V-R systems.

- Focussing on one R\&V-R component acting as a test bed for the FARVAR. Deducing a conceptual Framework for Applied Risk and Vulnerability Assessment Research and generalizing differential utilities of R\&V-A for R\&V-R from a case study focussed on one hazard-specific R\&V-R component (Tsunami Early Warning System) only, might have been very ambitious. Still it was a decision taken with the explicit intention to only focus on an early warning system, and not make a comparative analysis of different case studies representing different R\&V-R components, such as those within the domain of "preparedness" or related to the domain of "prevention". With the focus on only one $R \& V-R$ component, more in-depth empirical research could be conducted covering the 
entire spectrum of component specific R\&V-R tasks and measures, enabling to discuss the utility of the R\&V-A results for each of the different process steps allowing, in turn, to derive effective task specific R\&V-R measures.

- Methodological innovation and challenges. The delineation of the R\&V-A topics based on the different R\&V-R tasks in the context of the Tsunami Early Warning System have demanded the development of tailored R\&V-A information packages. A major challenge was how to integrate different assessment procedures, data sources, and different analytical tools (e.g. remote sensing, GIS, regression analysis of household data) to arrive at a specific R\&V-A information package. By far the most multidisciplinary information package developed was the assessment of evacuation capacity, where spatially distributed walking speeds of different age groups were integrated along with land use pattern assessment and topographical information. The case study has demonstrated that the application of methods and the collection and processing of data in pursuit of applied R\&V-A is highly contextual. With regard to this, a disadvantage of the case study is that it has failed to engage into a process that adapts the assessment methods according to the skills of the local authorities and universities in developing countries. If the methods applied are too sophisticated, R\&V-A will never be updated in its pursuit of providing added value for a cyclical R\&V-R process in which evaluation and monitoring of $R \& V-R$ performance require the adaptation of $R \& V-A$ information packages since R\&V-R challenges might alter.

\section{X.4 Future Research Challenges and Requirements}

Based on the contributions of this dissertation, this chapter lays down the future research challenges and requirements in pursuit of further enhancing the applicability of R\&V-A for processes of $R \& V-R$. The dissertation and the findings revealed represent only a starting point to advance applied R\&V-A in such a way that its usefulness for processes of R\&V-R is more acknowledged and further elaborated. Some of the most important issues are raised as follows:

- The definition of an applicable iterative process of R\&V-A and R\&V-R is not yet mature. Although the dissertation has defined a relevant methodology, it has to be proven in real life how R\&V-A can effectively contribute a) to the single steps of R\&V-R decision- 
making within each level of the hierarchically structured R\&V-R nomenclature; and b) to existing and traditional decision and assessment tools, such as cost-benefit and multicriteria analysis.

- The utilities of $R \& V-A$ for the accomplishment of the various process steps of $R \& V-R$ have been brought to light based on only one R\&V-R component - a Tsunami Early Warning System. Hence, more research is needed to widen the spectrum of utilities of R\&V-A even further by conducting similar research within the other domains and components of the R\&V-R nomenclature, as well as the other process levels, such as the utility of R\&V-A for the anticipation of future R\&V as well as the selection of the most favourable R\&V-R component. A similar assessment - but less in-depth - has been conducted by the author within the framework of the CLICO project, where R\&Vs had been assessed in the context of resettlement - a R\&V-R scenario for the case of the Nile Delta (Kloos et al. 2013, (Kloos, Baumert 2015).

- The more case studies are conducted using the FARVAR and operationalizing the iterative $R \& V-A$ and $R \& V-R$ process, the more scientific validation and opportunities for adjustments are possible. More research revealing assessment requirements, procedures and methods for different geographic and administrative levels as well as different types of threats and development contexts would be essential.

- The integration of theory driven $R \& V$ research into applied R\&V-A of such kind as demonstrated in this thesis is still a great challenge. Comparative disciplinary research using the $R \& V-R$ nomenclature as the defined comparative interfaces would be important to understand the form and type of utility of different theoretical approaches in pursuit of enhancing knowledge based R\&V-R decisions.

- The dissertation has mainly focussed on elaborating on the role of R\&V-A for R\&V-R to provide decision support for increasing the effectiveness of $R \& V-R$ performance when elaborating, assessing, and selecting R\&V-R options. But also other criteria exist such as the minimization of side effects, efficiency, sustainability, fairness, ethical acceptability, and public acceptance (Renn 2008, p. 177), all fields where R\&V-R could play an important role. 


\section{Publication bibliography}

Abarquez, I.; Murshed, Z.: Community-based disaster risk management field practitioners' handbook. Asian Disaster Preparedness Center. Bangkok.

Adger, W. Neil; Vincent, Katharine (2005): Uncertainty in adaptive capacity. In Comptes Rendus Geoscience 337 (4), pp. 399-410. DOI: 10.1016/j.crte.2004.11.004.

Adger, W.N; Brooks, N.; Bentham; Agnew, M.; Eriksen, S.: New indicators of vulnerability and adaptive capacity. Tyndall Centre (Technical Report, 7).

ANDERSON, MARY B.; WOODROW, PETER J. (1998): Rising from the ashes. Development strategies in times of disaster. London: IT Publications.

Angela Queste; Peter Lauwe (2006): User needs: Why we need indicators. 4. In Jörn Birkmann (Ed.): Measuring Vulnerability to Natural Hazards: Towards Disaster Resilient Societies: United Nations University Press.

Ashley, Caroline; Carney, Diana (1999): Sustainable livelihoods. Lessons from early experience. London: Dept. for International Development (Issues).

Babeyko, A. Y.; Hoechner, A.; Sobolev, S. V. (2010): Source modeling and inversion with near real-time GPS: a GITEWS perspective for Indonesia. In Nat. Hazards Earth Syst. Sci. 10 (7), pp. 1617-1627. DOI: 10.5194/nhess-10-1617-2010.

Bankoff, Greg; Frerks, Georg; Hilhorst, Dorothea (Eds.) (2004): Mapping vulnerability. Disasters, development, and people. London, Sterling, VA: Earthscan Publications.

Barry Smit; Johanna Wandel (2006): Adaptation, adaptive capacity and vulnerability. In Global Environmental Change 16, pp. 282-292.

Beck, Ulrich (1992): Risk society. Towards a new modernity. London, Newbury Park, Calif: Sage Publications (Theory, culture $\&$ society). 
Benioff, Ron; Guill, Sandra; Lee, Jeffrey (Eds.) (1996): Vulnerability and Adaptation Assessments. Dordrecht: Springer Netherlands (7).

Berkes, F. (2007): Understanding uncertainty and reducing vulnerability: lessons from resilience thinking. In Natural Hazards 41, pp. 283-295.

Birkmann, J.; Cardona, O.D.; Carreño, M.L; Barbat, A.H; Pelling, M.; Schneiderbauer, S. et al. (2013a): Framing vulnerability, risk and societal responses: the MOVE framework. In Natural Hazards 67 (2), pp. 193-211. DOI: 10.1007/s11069-013-0558-5.

Birkmann, Jörn (2006a): Conceptual frameworks and definitions. In Jörn Birkmann (Ed.): Measuring Vulnerability to Natural Hazards: Towards Disaster Resilient Societies: United Nations University Press.

Birkmann, Jörn (2006b): Indicators and criteria for measuring vulnerability: Theoretical bases and requirements. 2. In Jörn Birkmann (Ed.): Measuring Vulnerability to Natural Hazards: Towards Disaster Resilient Societies: United Nations University Press.

Birkmann, Jörn (Ed.) (2006c): Measuring Vulnerability to Natural Hazards: Towards Disaster Resilient Societies: United Nations University Press.

Birkmann, Jörn (2011): Regulation and Coupling of Society and Nature in the Context of Natural Hazards. In Hans Günter Brauch, Úrsula Oswald Spring, Czeslaw Mesjasz, John Grin, Patricia KameriMbote, Béchir Chourou et al. (Eds.): Coping with Global Environmental Change, Disasters and Security, vol. 5: Springer Berlin Heidelberg (Hexagon series on human and environmental security and peace), pp. 1103-1127. Available online at http://dx.doi.org/10.1007/978-3-64217776-7_68.

Birkmann, Jörn; Cutter, Susan L.; Rothman, Dale S.; Welle, Torsten; Garschagen, Matthias; van Ruijven, Bas et al. (2013b): Scenarios for vulnerability: opportunities and constraints in the context of climate change and disaster risk. In Climatic Change. DOI: 10.1007/s10584-013-0913-2.

Blaikie, Piers (1995): Changing Environments or Changing Views? A Political Ecology for Developing Countries. In Geography 80 (3), pp. p 203-214. Available online at http://www.jstor.org/stable/40572665. 
Boebel, O.; Busack, M.; Flueh, E. R.; Gouretski, V.; Rohr, H.; Macrander, A. et al. (2010): The GITEWS ocean bottom sensor packages. In Natural Hazards and Earth System Science 10 (8), pp. 17591780. DOI: 10.5194/nhess-10-1759-2010.

Bogardi, Janos; Birkmann, Jörn (2004): Vulnerability Assessment: The First Step Towards Disaster Risk Reduction. In Dörthe Malzahn, Tina Plapp: Disasters and Society, From Hazard Assessment to Risk Reduction. Proceedings of the international conference, Universität Karlsruhe (TH), Germany, July 26-27, 2004. Berlin: Logos.

Bohle, H.-G.; Etzold, B.; Keck, M. (2009): Resilience as Agency. Available online at http://www.ihdp.unu.edu/file/IHDP+Updates/Update+2.2009+GECHS/Bohle_Etzold_Keck_Upd ate_2009.2.pdf.

Bohle, Hans Georg (2001): Vulnerability and Criticality: Perspectives from social geography. IHDP (Newsletter of the International Human Dimensions Programme on Global, 2).

Bohle, Hans Georg (2008): Krisen, Katastrophen, Kollaps. Geographien von Verwundbarkeit in der Risikogesellschaft. In Elmar Kulke, Herbert Popp (Eds.): Umgang mit Risiken. Katastrophen Destabilisierung - Sicherheit. Deutscher Geographentag Bayreuth - Kongress für Wissenschaft, Schule und Praxis. Berlin, pp. 69-82.

Bohle, Hans Georg; Glade, Thomas (2008): Vulnerabilitätskonzepte in Sozial- und Naturwissenschaften. In Carsten Felgentreff, Thomas Glade (Eds.): Naturrisiken und Sozialkatastrophen. Berlin: Spektrum Akademischer Verlag, pp. 99-119.

Borrero, J. C.; Sieh, K.; Chlieh, M.; Synolakis, C. E. (2006): Tsunami inundation modelling for western Sumatra. In Proceedings of the National Academy of Sciences 103 (52), pp. 19673-19677. DOI: 10.1073/pnas.0604069103.

Brooks, Nick; Neil Adger, W.; Mick Kelly, P. (2005): The determinants of vulnerability and adaptive capacity at the national level and the implications for adaptation. In Global Environmental Change 15 (2), pp. 151-163. DOI: 10.1016/j.gloenvcha.2004.12.006.

Bühl, Achim; Zöfel, Peter (2002): SPSS 11: Eine Einführung in die moderne Datenanalyse unter Windows. $8^{\text {th }}$ ed.: Addison Wesley. 
Burns, T. R.; Dietz, T. (1992): Cultural Evolution: Social Rule Systems, Selection and Human Agency. In International Sociology 7 (3), pp. 259-283. DOI: 10.1177/026858092007003001.

Cannon, Terry (2006): Vulnerability analysis, livelihoods and disasters. In Walter J. Ammann, Stefanie Dannenmann, Laurent Vulliet (Eds.): Coping with Risks Due to Natural Hazards in the 21st Century. RISK 21. Monte Verità, Ascona, Switzerland, 28 November-3 December 2006. London: Taylor \& Francis.

Cardona, O. D. (2004): The need for rethinking the concepts of vulnerability and risk from a holistic perspective. A necessary review and criticism for effective risk management. In Greg Bankoff, Georg Frerks, Dorothea Hilhorst (Eds.): Mapping vulnerability. Disasters, development, and people. London, Sterling, VA: Earthscan Publications.

Cardona, O. D. (2006a): A system of indicators for disaster risk management in the Americas. In Jörn Birkmann (Ed.): Measuring Vulnerability to Natural Hazards: Towards Disaster Resilient Societies: United Nations University Press, pp. 189-209.

Cardona, O. D. (2006b): A system of indicators for disaster risk management in the Americas. 10. In Jörn Birkmann (Ed.): Measuring Vulnerability to Natural Hazards: Towards Disaster Resilient Societies: United Nations University Press.

Cardona, O. D. (2011): Disaster Risk and Vulnerability: Notions and Measurement of Human and Environmental Insecurity. In : Coping with global environmental change, disasters and security. Threats, challenges, vulnerabilities and risks. Berlin, [S.I.]: Springer; Berghof Foundation (Hexagon series on human and environmental security and peace, 5), pp. 107-122.

Cardona, O. D.; Huarto, J.E; Duque, G.; Moreno, A.; Chardon, A.C; Velàsquez, L.S; Prieto, S.D (2003): The Notion of Disaster Risk. Conceptual Framework for Integrated Management. National University of Colombia / Inter-American Development Bank. Washington, DC, updated on 4/9/2004, checked on 4/10/2013.

Cardona, O. D.; van Aalst, M.; Birkmann, J.; Fordham, M.; McGregor, G.; Perez, R. et al. (2012): Determinants of Risk - Exposure and Vulnerability. In C. B. Field, V. Barros, T. F. Stocker, D. Quin, D. J. Dokken, K. L. Ebi et al. (Eds.): Managing the Risks of Extreme Events and Disasters to 
Advance Climate Change Adaptation. A Special Report of Working Groups I and II of the Intergovernmental Panel on Climate Change. Cambridge, UK, New York.

Carreño, M. L.; Cardona, O. D.; Barbat, A. H. (2007): A disaster risk management performance index. In Natural Hazards 41 (1), pp. 1-20. DOI: 10.1007/s11069-006-9008-y.

Carter, T. R.; Parry, M. L.; Harasawa, H.; Nishioka, S. (1994): IPCC Technical Guidelines for Assessing Climate Change Impacts and Adaptations. Center for Global Environmental Research, National Institute for Environmental Studies. London, UK, checked on 3/18/2015.

Cash, D. W. (2006): Countering the Loading-Dock Approach to Linking Science and Decision Making: Comparative Analysis of El Nino/Southern Oscillation (ENSO) Forecasting Systems. In Science, Technology \& Human Values 31 (4), pp. 465-494. DOI: 10.1177/0162243906287547.

Chambers, Robert (1989): Editorial Introduction: Vulnerability, Coping and Policy. In IDS Bulletin 20 (2), pp. 1-7. DOI: 10.1111/j.1759-5436.1989.mp20002001.x.

Cousins, W. J.; Power, W. L.; Palmer, N. G.; Reese, S.; Tejakusuma, I. G.; Nugrahadi, S. (2007): Damage and Casualties in the South Java tsunami of 17th July 2006. In : Proceedings. 2007 Conference of the New Yealand Society for Earthquake Engineering. Palmerston North, 30 March - 1 April 2007. New Zealand Society for Enthquake Engineering.

Cuny, F. C. (1983): Disaster and Development. New York, NY: Oxford University Press.

Cutter, S. L.; Finch, C. (2008): Temporal and spatial changes in social vulnerability to natural hazards. In Proceedings of the National Academy of Sciences 105 (7), pp. 2301-2306. DOI: 10.1073/pnas.0710375105.

Cutter, Susan L.; Boruff, Bryan J.; Shirley, W. Lynn (2003): Social Vulnerability to Environmental Hazards*. In Social Science Q 84 (2), pp. 242-261. DOI: 10.1111/1540-6237.8402002.

Damm, Marion (2010): Mapping Social-Ecological Vulnerability to Flooding - A sub-national approach for Germany. Dissertation. Rheinischen Friedrich-Wilhelms-Universität zu Bonn, Bonn. Hohe Landwirtschaftliche Fakultät, checked on 7/1/2015.

Davies, Susanna (1996): Adaptable livelihoods. Coping with food insecurity in the Malian Sahel. Houndmills, Basingstoke [England], New York: Macmillan Press; St. Martin's Press. 
Davis, Ian; Haghebaert, B.; Peppiatt, D. (2004): Social Vulnerability and Capacity Analysis Workshop. ProVention Consortium. Geneva, Switzerland, updated on 8/22/2006, checked on 5/6/2013.

Denis Chang Seng (2010): Disaster Risk Preparedness. The Role of Risk Governance, Multi-Institutional Arrangements and Polycentric Frameworks for a Resilient Tsunami Early Warning System in Indonesia. Dissertation. Rheinischen Friedrich-Wilhelms-Universität Bonn. Department of Geography.

Dilley, Maxx (2006): Disaster risk hotspots: A project summary. In Jörn Birkmann (Ed.): Measuring Vulnerability to Natural Hazards: Towards Disaster Resilient Societies: United Nations University Press.

Downing, T. E.; Patwandhan, A. (2004): Assessing vulnerability for climate adaptation, Technical Paper 3. In B. Lim, E. Spanger-Siegfrid (Eds.): Adaptation Policy Frameworks for Climate Change: Developing Strategies, Policies and Measures. New York, NY.

Dulal, Hari B.; Shah, Kalim U.; Ahmad, Nilufar (2009): Social Equity Considerations in the Implementation of Caribbean Climate Change Adaptation Policies. In Sustainability 1 (3), pp. 363-383. DOI: $10.3390 /$ su1030363.

Farrell, Alex; Van Deveer, Stacy D.; Jäger, Jill (2001): Environmental assessments: four under-appreciated elements of design. In Global Environmental Change 11 (4), pp. 311-333. DOI: 10.1016/S09593780(01)00009-7.

Farrell, Alexander E.; Jäger, Jill (Eds.) (2005): Assessments of regional and global environmental risks. Designing process for the effective use of science in decisionmaking. Washington, D.C: Resources for the Future.

Federal Signal Corporation (2005): Modular Series Speaker Arrays. Illinois.

Fekete, Alexander (2010): Assessment of Social Vulnerability for River-Floods in Germany. Dissertation. Rheinischen Friedrich-Wilhelms-Universität zu Bonn, Bonn. Hohe Landwirtschaftliche Fakultät, checked on $7 / 1 / 2015$.

Felgentreff, Carsten; Glade, Thomas (Eds.) (2008): Naturrisiken und Sozialkatastrophen. Berlin: Spektrum Akademischer Verlag. 
Fitzpatrick, C.; Mileti, D. S. (1990): Perception and Response to Aftershock Warnings During the Emergency Period. In R Bolin (Ed.): The Loma Prieta Earthquake - Studies of Short-Term Impacts: Natural Hazards Research and Applications Information Center, Institute of Behavioral Science, University of Colorado (Monograph, 50), pp. 75-83.

Fritzsche, Kerstin; Schneiderbauer, Stefan; Bubeck, Philipp; Kienberger, Stefan; Buth, Mareike; Zebisch, Marc; Kahlenborn, Walter (2015): The Vulnerability Sourcebook. Concept and guidelines for standardised vulnerability assessments. Edited by Gesellschaft fuer Internationale Entwicklung (GIZ), checked on 3/31/2015.

Füssel, Hans-Martin (2007): Vulnerability: A generally applicable conceptual framework for climate change research. In Global Environmental Change 17 (2), pp. 155-167. DOI: 10.1016/j.gloenvcha.2006.05.002.

Füssel, Hans-Martin; Klein, Richard (2006): Climate Change Vulnerability Assessments: An Evolution of Conceptual Thinking. In Climatic Change 75 (3), pp. 301-329. DOI: 10.1007/s10584-006-0329-3.

Gaillard, J.C (2010): Vulnerability, capacity and resilience: Perspectives for climate and development policy. In J. Int. Dev. 22 (2), pp. 218-232. DOI: 10.1002/jid.1675.

Garschagen, Matthias (2014): Risky Change? Vulnerability and Adaptation Between Climate Change and Transformation Dynamics in Can Tho City, Vietnam: Franz Steiner Verlag Wiesbaden gmbh (Geographie, Band 15).

Gayer, G.; Leschka, S.; Nöhren, I.; Larsen, O.; Günther, H. (2010): Tsunami inundation modelling based on detailed roughness maps of densely populated areas. In Natural Hazards and Earth System Science 10 (8), pp. 1679-1687. DOI: 10.5194/nhess-10-1679-2010.

German Technical Cooperation (2007): Tsunami Early Warning Technologies and Methods in Indonesia.

Giddens, Anthony (1986): The constitution of society. Outline of the theory of structuration. Berkeley, Los Angeles: University of California Press.

GIZ-IS (2009): Concepts \& Recommendations for the Implementation of Tsunami Early Warning in Bali. Goodwin, Paul; Wright, George (2009): Decision analysis for management judgment. 4th ed. Chichester, West Sussex: Wiley. 
H. Spahn; M. Hoppe; H. D. Vidiarina; B. Usdianto (2010): Experience from three years of local capacity development for tsunami early warning in Indonesia: challenges, lessons and the way ahead. In Natural Hazards and Earth System Sciences 10, pp. 1411-1429.

H. Taubenböck; N. Goseberg; N. Setiadi; G. Lämmel; F. Moder; M. Oczipka et al. (2009): “Last-Mile” preparation for a potential disaster - Interdisciplinary approach towards tsunami early warning and an evacuation information system for the coastal city of Padang, Indonesia. In Natural Hazards and Earth System Sciences 9, pp. 1509-1528.

Hanka, W.; Saul, J.; Weber, B.; Becker, J.; Harjadi, P.; Fauzi; GITEWS Seismology Group (2010): Real-time earthquake monitoring for tsunami warning in the Indian Ocean and beyond. In Natural Hazards and Earth System Science 10 (12), pp. 2611-2622. DOI: 10.5194/nhess-10-2611-2010.

Hidayati, Deny (2012): Striving to Reduce Disaster Risk. Vulnerable Communities with Low Levels of Preparedness in Indonesia. In Journal of Disaster Research 7 (1), pp. 75-82, checked on $8 / 17 / 2013$.

Hinkel, Jochen (2008): Transdisciplinary knowledge integration. Cases from integrated assessment and vulnerability assessment. Ph.D. thesis. Wageningen University, [Wageningen], checked on $3 / 18 / 2015$.

Hinkel, Jochen (2011): "Indicators of vulnerability and adaptive capacity": Towards a clarification of the science-policy interface. In Global Environmental Change 21 (1), pp. 198-208. DOI:

10.1016/j.gloenvcha.2010.08.002.

ICSU-LAC (2010): Science for a better life. Developing regional scientific programs in priority areas for Latin America and the Caribbean. Understanding and Managing Risk Associated with Natural Hazards: An Integrated Scientific Approach in Latin America and the Caribbean. With assistance of O.D Cardona, J.C Bertoni, A. Gibbs, M. Hermelin, A. Lawell. Rio de Janeiro, Brazil (2), checked on $4 / 15 / 2013$.

IFRC (1999): Vulnerability and capacity assessment.

IPCC (2007): Climate Change 2007. Impacts, Adaptation and Vulnerability. Contribution of Working Group II to the Fourth Assessment Report of the IPCC. Edited by Martin Parry, Oswaldo 
Canziani, Jean Palutikof, Paul Van der Linden, Clair Hanson. Cambridge, UK: Cambridge University Press, checked on 4/10/2013.

IPCC (2012): Managing the Risks of Extreme Events and Disasters to Advance Climate Change Adaptation. A Special Report of Working Groups I and II of the Intergovernmental Panel on Climate Change. Edited by C. B. Field, V. Barros, T. F. Stocker, D. Quin, D. J. Dokken, K. L. Ebi et al. Cambridge, UK, New York.

Janssen, M. A.; Ostrom, E. (2006): Resilience, vulnerability, and adaptation: A cross-cutting theme of the International Human Dimensions Programme on Global Environmental Change. In Global Environmental Change 16 (3), pp. 237-239. DOI: 10.1016/j.gloenvcha.2006.04.003.

Janssen, M.A; Ostrom, E. (2007): Chapter 30 Governing Social-Ecological Systems. In : Words Into Action. A guide to implementing the Hyogo Framework. Hyogo Framework for Action 2005-2015: Building the resilience of nations and communities to disasters, vol. 2. United Nations International Strategy for Disaster Reduction (UNISDR), pp. 1465-1509. Available online at http://www.scopus.com/inward/record.url?eid=2-s2.034848925365\&partnerID=40\&md5=194f0c924b891e8d20b26c8ecf516010.

John H. Sorensen (2000): Hazard Warning Systems: Review of 20 years of progress. In Natural Hazards Review 1 (2), pp. 119-125.

John Handmer (2000): Are Flood Warnings Futile? Risk communication in emergencies. In Australasian Journal of Disaster and Trauma Studies 2. Available online at http://www.massey.ac.nz/ trauma/issues/2000-2/handmer.htm.

Kasperson, Jeanne X.; Kasperson, Roger E. (Eds.) (2005): The social contours of risk. Publics, risk communication and the social amplification of risk. London, Sterling, Va: Earthscan (Risk, society, and policy series).

Kates, R. W. (1985): The interaction of Climate and Society. In R. W. Kates, J. H. Ausubel, M. Berberian (Eds.): Climate Impact Assessment: Studies of the Interaction of Climate and Society. Wiley, Chichester, UK (SCOPE, 27), checked on 3/18/2015. 
Kloos, Julia; Baumert, Niklas (2015): Preventive resettlement in anticipation of sea level rise: a choice experiment from Alexandria, Egypt. In Natural Hazards 76 (1), pp. 99-121. DOI: 10.1007/s11069-014-1475-y.

Kloos, Julia; Gebert, Niklas; Rosenfeld, Therese; Renaud, Fabrice (2013): Climate Change, Water Conflicts and Human Security. Regional Assessment and Policy Guidelines for the Mediterranean, Middle East and Sahel. CLICO final report. UNited Nations University - Institute for Environment and Human Security (Report, 10), updated on 8/27/2013, checked on 12/10/2013.

Klüpfel, Hubert (2012): A Cellular Automaton Model for Crowd Movement and Egress Simulation. München: GRIN Verlag GmbH.

Kuban, R.; MacKenzie-Carey, H. (2001): Community-Wide Vulnerability and Capacity Assessment (CVCA). Turning Point Group Inc. Canada.

Kunz-Plapp, Tina (2008): Vorwarnung, Vorhersage und Frühwarnung. In Carsten Felgentreff, Thomas Glade (Eds.): Naturrisiken und Sozialkatastrophen. Berlin: Spektrum Akademischer Verlag, pp. 214-223.

Lachman, R.; Tatsuoka, M.; Bonk, W. J. (1961): Human Behavior during the Tsunami of May 1960: Research on the Hawaiian disaster explores the consequences of an ambiguous warning system (3462).

Lars Clausen; Wolf R. Dombrowsky (1984): Warnpraxis und Warnlogik. In Zeitschrift für Soziologie: ZfS 13 (4), pp. 293-307.

Latief Hamza; Nanang T. Puspito; Fumihiko Imamura (2000): Tsunami Catalog and Zones in Indonesia. In Journal of Natural Disaster Science 22 (1), pp. 25-43.

Lauterjung, J.; Koltermann, P.; Wolf, U.; Sopaheluwakan, J. (2010a): The UNESCO-IOC framework â?] establishing an international early warning infrastructure in the Indian Ocean region. In Natural Hazards and Earth System Science 10 (12), pp. 2623-2629. DOI: 10.5194/nhess-10-2623-2010.

Lauterjung, J.; Münch, U.; Rudloff, A. (2010b): The challenge of installing a tsunami early warning system in the vicinity of the Sunda Arc, Indonesia. In Natural Hazards and Earth System Science 10 (4), pp. 641-646. DOI: 10.5194/nhess-10-641-2010. 
Lavell, Allan (1999): Environmental degradation, risks and urban disasters. Issues and concepts: Towards the definition of a research agenda. In M.A Fernández (Ed.): Cities at Risk. Environmental Degradation, Urban Risks, and Disaster in Latin America: AH/editorial.

Lavell, Allan (2003): Regional Programme for Risk Management in Central America. Ideas and Notions Relating to Concept and Practice. CEPREDENAC and UNDP.

Lavell, Allan (2010): Unpacking Climate Change Adaptation and Disaster Risk Management: Searching for the Links and the Differences: A Conceptual and Epistemological Critique and Proposal. IUCNFLACSO, International Union for Conservation of Nature - Latin American School of Social Sciences, checked on $1 / 15 / 2014$.

Lavell, Allan; Oppenheimer, Michael; Diop, Cherif; Hess, Jeremy; Lempert, Robert; Li, Jianping et al. (2012): Climate Change: New Dimensions in Disaster Risk, Exposure, Vulnerability, and Resilience. In C. B. Field, V. Barros, T. F. Stocker, D. Quin, D. J. Dokken, K. L. Ebi et al. (Eds.): Managing the Risks of Extreme Events and Disasters to Advance Climate Change Adaptation. A Special Report of Working Groups I and II of the Intergovernmental Panel on Climate Change. Cambridge, UK, New York, pp. 25-64.

Lazarus, Richard S.; Alfert, Elizabeth (1964): Short-circuiting of threat by experimentally altering cognitive appraisal. In The Journal of Abnormal and Social Psychology 69 (2), pp. 195-205. DOI: 10.1037/h0044635.

LIPI; DLR; UNU-EHS (2011a): Guideline for Tsunami Risk Assessment in Indonesia. Scientific Proposal for Practitioners and End Users. Provided by the Indonesian - German Working Group on Tsunami Risk Assessment, checked on 8/15/2013.

LIPI; DLR; UNU-EHS (2011b): Technical Guideline for Tsunami Risk Assessment in Indonesia. Scientific Proposal for Practioners and End Users. Provided by the Indonesian - German Working Group on Tsunami Risk Assessment, checked on 8/15/2013.

Liverman, Diana M. (1990): Vulnerability to Global Environmental Change. In Roger E. Kasperson (Ed.): Understanding Global Environmental Change. The Contributions of Risk Analysis and Management. Clark University. 
Luers, Amy L.; Lobell, David B.; Sklar, Leonard S.; Addams, Lee C.; Matson, Pamela A. (2003): A method for quantifying vulnerability, applied to the agricultural system of the Yaqui Valley, Mexico. In Global Environmental Change 13 (4), pp. 255-267. DOI: 10.1016/S0959-3780(03)00054-2.

Marion Damm (2008): Mapping Social-Ecological Vulnerability to Flooding - A sub-national approach for Germany. In S. P. Simonovic, P. G. Bourget, S. F. Blanchard (Eds.): Managing Flood Risk, Reliability \& Vulnerability. 4th International Symposium on Flood Defence. Toronto, Ontario, 6-8 May 2008. Institute for Catastrophic Loss Reduction, Toronto.

McCloskey, John; Antonioli, Andrea; Piatanesi, Alessio; Sieh, Kerry; Steacy, Sandy; Nalbant, Suleyman et al. (2008): Tsunami threat in the Indian Ocean from a future megathrust earthquake west of Sumatra. In Earth and Planetary Science Letters 265 (1-2), pp. 61-81. DOI: 10.1016/j.epsl.2007.09.034.

McCloskey, John; Antonioli, Andrea; Piatanesi, Alessio; Sieh, Kerry; Steacy, Sandy; Nalbant, Suleyman S. et al. (2007): Near-field propagation of tsunamis from megathrust earthquakes. In Geophys. Res. Lett. 34 (14). DOI: 10.1029/2007GL030494.

Metzger, Marc J.; Schröter, Dagmar (2006): Towards a spatially explicit and quantitative vulnerability assessment of environmental change in Europe. In Regional Environmental Change 6 (4), pp. 201-216. DOI: 10.1007/s10113-006-0020-2.

Mileti, D. S.; Sorensen, J. H. (1990): Communication of emergency public warnings: A social science perspective and state-of-the-art assessment. Oak Ridge National Lab. TN, USA.

Miller, F.; Osbahr, H.; Boyd, E.; Thomalla, F.; Bharwani, S.; Ziervogel, G. et al. (2010): Resilience and Vulnerability. Complementary or Conflicting Concepts? In Ecology and Society 15 (3), checked on $4 / 10 / 2013$.

Mitchell, Ronald B.; Clark, William C.; Cash, David W.; Dickson, Nancy M. (2006): Global environmental assessments: Information, institutions, and influence: MIT Press. Available online at http://www.ksg.harvard.edu/gea/pubs/geavol\info.htm.

Moss, R. H.; Brenkert, A. L.; Malone, E. L. (2001): Vulnerability to Climate Change: A Quantitative Approach. Pacific Northwest National Laboraties. Richland, WA (Technical Report, PNNL-SA33642), checked on $1 / 15 / 2014$. 
MOVE (2010): Generic Conceptual Framework for Vulnerability Measurement. Seven Framework Programme, Methods for the Improvement of Vulnerability Assessment in Europe. European Commission. Brussels, Belgium, updated on 10/24/2010, checked on 4/10/2013.

Munich Re (2012): Natural catastrophes 2011. Analysis, assessments, positions. In Topics GEO, checked on $3 / 18 / 2015$.

Murphy, Lois Barclay; Moriarty, Alice E. (1976): Vulnerability, coping, and growth. From infancy to adolescence. New Haven: Yale University Press.

Nelson, Donald R.; Adger, W. Neil; Brown, Katrina (2007): Adaptation to Environmental Change: Contributions of a Resilience Framework. In Annu. Rev. Environ. Resourc. 32 (1), pp. 395-419. DOI: 10.1146/annurev.energy.32.051807.090348.

O'Brien, K.L; R.M. Leichenko (2000): Double exposure: assessing the impacts of climate change within the context of economic globalization. In Global Environmental Change 10 (3), pp. 221-232. DOI: 10.1016/S0959-3780(00)00021-2.

O’Neill, Brian C.; Kriegler, Elmar; Ebi, Kristie L.; Kemp-Benedict, Eric; Riahi, Keywan; Rothman, Dale S. et al. (2015): The roads ahead: Narratives for shared socioeconomic pathways describing world futures in the 21st century. In Global Environmental Change. DOI:

10.1016/j.gloenvcha.2015.01.004.

O'Brien, Karen; ERIKSEN, SIRI; NYGAARD, LYNN P.; SCHJOLDEN, A. N.E. (2007): Why different interpretations of vulnerability matter in climate change discourses. In Climate Policy 7 (1), pp. 73-88. DOI: 10.1080/14693062.2007.9685639.

OECD (2009): Integrating Climate change Adaptation into Development Co-operation. Policy Guidance, 2009 , checked on 2/25/2015.

Patt, Anthony; Schröter, Dagmar; de la Vega-Leinert, Anne Christina; Klein, Richard (2009a): Vulnerability Research and Assessment to Support Adaptation and Mitigation. Common Themes from the Diversity of Approaches. In Anthony Patt, Dagmar Schröter, Richard Klein, Anne Christina de la Vega-Leinert (Eds.): Assessing vulnerability to global environmental change. Making research useful for adaptation decision making and policy. London, Sterling, VA: Earthscan. 
Patt, Anthony; Schröter, Dagmar; Klein, Richard; de la Vega-Leinert, Anne Christina (Eds.) (2009b):

Assessing vulnerability to global environmental change. Making research useful for adaptation decision making and policy. London, Sterling, VA: Earthscan.

Patt, Anthony G. (2009): Assessing vulnerability to global environmental change. Making research useful for adaptation decision making and policy. London, Sterling, VA: Earthscan.

Patt, Anthony G. (2011): Assessing vulnerability to global environmental change. Making research useful for adaptation decision making and policy. Paperback ed. London [u.a.]: Earthscan.

Paul McLaughlin; Thomas Dietz (2008): Structure, agency and environment: Toward an integrated perspective on vulnerability. In Global Environmental Change 18, pp. 99-111.

Pelling, M. (1997): What determines vulnerability to floods; a case study in Georgetown, Guyana. In Environment and Urbanization 9 (1), pp. 203-226. DOI: 10.1177/095624789700900116.

Pelling, Mark (2003): The Vulnerability of Cities. Natural Disasters and Social Resilience: Earthscan.

Pelling, Mark (2010): Adaptation to climate change. A progressive vision of human security. London, New York: Routledge.

Pelling, Mark (2011): Adaptation to climate change. From resilience to transformation. London, New York: Routledge.

Permana (2005): Lessons Learnt from Aceh: Understanding Geological Disaster. Paper presented at BAPPENAS Meeting, Jakarta.

Post, J.; Wegscheider, S.; Mück, M.; Zosseder, K.; Kiefl, R.; Steinmetz, T.; Strunz, G. (2009): Assessment of human immediate response capability related to tsunami threats in Indonesia at a sub-national scale. In Nat. Hazards Earth Syst. Sci. 9 (4), pp. 1075-1086. DOI: 10.5194/nhess-9-1075-2009.

PROVIA (2013a): PROVIA Guidance on Assessing Vulnerability, Impacts and Adaptation to Climate Change. Consultation document, United NAtions Environment Programme. Nairobi, Kenya, checked on $3 / 20 / 2015$. 
PROVIA (2013b): Research Priorities on Vulnerability, Impacts and Adaptation. Responding to the Climate Change Challenge, United Nations Environment Programme. Nairobi, Kenya, checked on $3 / 20 / 2015$.

Rauch, T. (2003): Bessere Rahmenbedingungen allein beseitigen Armut nicht! Eine theoriegeleitete Vier Ebenen-Strategie für entwicklungspolitische Interventionen. In Geogr. Helv. 58 (1), pp. 35-46. DOI: $10.5194 /$ gh-58-35-2003.

Raymond, Forde (2006): Effective early warning. International Federation of Red Cross and Red Crescent Societies. Geneva, Switzerland.

Reilly, John; Schimmelpfennig, David (2000): Irreversibility, Uncertainty, and Learning: Portraits of Adaptation to Long-Term Climate Change. In Climatic Change 45 (1), pp. 253-278. DOI: 10.1023/A:1005669807945.

Renn, Ortwin (2008): Risk Governance: Coping with Uncertainty in a Complex World. Edited by Ortwin Renn: Earthscan.

Ribot, Jesse C. (1995): The causal structure of vulnerability: Its application to climate impact analysis. In GeoJournal 35 (2), pp. 119-122. DOI: 10.1007/BF00814058.

Risbey, James; Kandlikar, Milind; Dowlatabadi, Hadi; Graetz, Dean (1999): Scale, context, and decision making in agricultural adaptation to climate variability and change. In Mitigation and Adaptation Strategies for Global Change 4 (2), pp. 137-165. DOI: 10.1023/A:1009636607038.

Roessler, D.; Krueger, F.; Ohrnberger, M.; Ehlert, L. (2010): Rapid characterisation of large earthquakes by multiple seismic broadband arrays. In Natural Hazards and Earth System Science 10 (4), pp. 923-932. DOI: 10.5194/nhess-10-923-2010.

Rogers, Ronald W. (1975): A Protection Motivation Theory of Fear Appeals and Attitude Change. In The Journal of Psychology 91 (1), pp. 93-114. DOI: 10.1080/00223980.1975.9915803.

Rudloff, A.; Lauterjung, J.; Münch, U.; Tinti, S. (2009): Preface "The GITEWS Project (German-Indonesian Tsunami Early Warning System). In Natural Hazards and Earth System Science 9 (4), pp. 13811382. DOI: 10.5194/nhess-9-1381-2009. 
Ruhrmann, Georg; Kohring, Matthias (1996): Staatliche Risikokommunikation bei Katastrophen. Informationspolitik und Akzeptanz. Bonn (Zivilschutzforschung, 27). Available online at http://www.bbk.bund.de/SharedDocs/Downloads/BBK/DE/Publikationen/PublikationenForschu ng/Band27.pdf;jsessionid=68354A580FE69D172013BF9FE2B811AE.1_cid345?_blob=publicatio nFile, updated on $11 / 17 / 2003$, checked on $7 / 19 / 2013$.

Salamun (Ed.) (1992): Dampak masuknya media komunikasi terhadap kehidupan sosial budaya masyarakat pedesaan. (Impact of mass media and broadcasting programs on socio-cultural changes in Indonesian rural communities). Departemen Pendidikan dan Kebudayaan. Jakarta.

Scheer, S.; Gardi, A.; Guillande, R.; Eftichidis, G.; Varela, V.; de Vanssay, B.; Colbeau-Justin, L. (2011): Handbook of Tsunami Evacuation Planning. With assistance of IPSC JRC, updated on 2/25/2011, checked on $7 / 17 / 2013$.

Schellnhuber, Hans Joachim (2009): Foreward. In Anthony Patt, Dagmar Schröter, Richard Klein, Anne Christina de la Vega-Leinert (Eds.): Assessing vulnerability to global environmental change. Making research useful for adaptation decision making and policy. London, Sterling, VA: Earthscan.

Schröter, D.; Polsky, C.; Patt, A. G. (2005): Assessing vulnerabilities to the effects of global change: an eight step approach. In Mitigation and Adaptation Strategies for Global Change 10 (4), pp. 573595. DOI: 10.1007/s11027-005-6135-9.

Sen, Amartya (1983): Poverty and Famines: Oxford University Press.

Sen, Krishna; Hill, David T. (2000): Media, Culture and Politics in Indonesia: Oxford University Press.

Setiadi, Neysa Jaqueline (2014): Assessing People's Early Warning Response Capability to Inform Urban Planning Interventions to Reduce Vulnerability to Tsunamis. Case Study of Padang City, Indonesia. Dissertation. Rheinischen Friedrich-Wilhelms-Universität zu Bonn, Bonn. Institut für Geodäsie und Geoinformation.

Smith, B.; Burton, I.; Klein, R.; Wandel, J. (2000): An Anatomy of Adaptation to Climate Change and Variability. In Climatic Change 45 (1), pp. 223-251. DOI: 10.1023/A:1005661622966. 
Smith, Joel B.; Lenhart, Stefanie S. (1996): Climate change adaptation policy options. In Climate Research (6), pp. 193-201, checked on 2/25/2015.

Snow, David A.; Rochford, E. Burke, JR.; Worden, Steven K.; Benford, Robert D. (1986): Frame Alignment Processes, Micromobilization, and Movement Participation. In American Sociological Review 51 (4), pp. p 464-481. Available online at http://www.jstor.org/stable/2095581.

Spahn, Harald; Hoppe, Michael; Usdianto, Benny; Vidiarina, Henny (2010): Guidebook. Planning for Tsunami Evacuations. GITEWS, GTZ-International Services. Jakarta, updated on 10/6/2010, checked on $7 / 17 / 2013$.

Strübing, Jörg (2008): Grounded Theory. Zur sozialtheoretischen und epistemologischen Fundierung des Verfahrens der empirisch begründeten Theoriebildung. 2., überarbeitete und erweiterte Auflage. Wiesbaden: VS Verlag für Sozialwissenschaften / GWV Fachverlage GmbH, Wiesbaden (Bd. 15).

Susan Cutter; Kent Barnes (1982): Evacuation behavior and Three Mile Island. In Disasters 6 (2), pp. 116124.

Thomalla, Frank; Downing, Tom; Spanger-Siegfried, Erika; Han, Guoyi; Rockstrom, Johan (2006): Reducing hazard vulnerability: towards a common approach between disaster risk reduction and climate adaptation. In Disasters 30 (1), pp. 39-48. DOI: 10.1111/j.1467-9523.2006.00305.x.

Thywissen, Katharina (2006): Core terminology of disaster reduction: A comparative glossary. 24. In Jörn Birkmann (Ed.): Measuring Vulnerability to Natural Hazards: Towards Disaster Resilient Societies: United Nations University Press.

Timmerman, P. (1981): Vulnerability, Resilience and the Collapse of Society: A Review of Models and Possible Climatic Applications: Institute for Environmental Studies, University of Toronto (Environmental monograph series). Available online at http://books.google.co.mz/books?id=XOAJAQAAMAAJ.

Tröger, S. (2003): Akteure in ihrer Lebensgestaltung (livelihood) zu Zeiten sozialer Transformation. Theoretische Überlegungen und ihre Anwendung auf das Beispiel von Landnutzungskonflikten in Tansania. In Geogr. Helv. 58 (1), pp. 24-34. DOI: 10.5194/gh-58-24-2003. 
Turner, B. L.; Kasperson, R. E.; Matson, P. A.; McCarthy, J. J.; Corell, R. W.; Christensen, L. et al. (2003): A framework for vulnerability analysis in sustainability science. In Proceedings of the National Academy of Sciences 100 (14), pp. 8074-8079. DOI: 10.1073/pnas.1231335100.

Twigg, John (2007): Characteristics of a Disaster-resilient Community. A Guidance Note. DFID, updated on 9/21/2007, checked on 4/10/2013.

UNDHA (1992): Internationally Agreed Glossary of Basic Terms Related to Disaster Management. United Nations. Geneva, Switzerland.

UNDP (2004): Reducing Disaster Risk - A Challenge for Development. A Global Report. United Nations. New York, NY, updated on 4/8/2004, checked on 4/10/2013.

UNDRO (1980): Natural Disasters and Vulnerability Analysis. Report of Experts Group Meeting of 9-12 July 1997. United Nations. Geneva, Swizerland.

UNESCO-IOC (2009): Hazard Awareness and Risk Mitigation in Integrated Coastal Area Management. United Nations. Paris, France (Manuals and Guides, 50), updated on 6/14/2009, checked on 8/23/2013.

UNESCO-IOC; UNISDR-PPEW; WMO (2005): Assessment of Capacity Building Requirements for an Effective and Durable Tsunami Warning and Mitigation System in the Indian Ocean. Consolidated Report for Countries Affected by the 26 December 2004 Tsunami. United Nations. Paris, France.

UNFCCC (2011): Assessment of the Costs and Benefits of Adaptation Options - An Overview of Approaches. The Nairobi Work Programme on Impacts, Vulnerability and Adaptation to Climate Change, updated on 11/9/2011, checked on 11/26/2013.

UNISDR (2004): Living with Risk. A global review of disaster reduction initiatives. United Nations. Geneva, Switzerland.

UNISDR (2005): Hyogo Framework for Action 2005 - 2015 - Building Resilience of Nations and Communities to Disasters. United Nations. Geneva, Switzerland, updated on 3/22/2005, checked on 9/6/2013. 
UNISDR (2008): Indicators of Progress. Guidance on Measuring the Reduction of Disaster Risks and the Implementation of the Hyogo Framework for Action. Geneva, Switzerland.

UNISDR (2009a): 2009 UNISDR Terminology on Disaster Risk Reduction. Geneva, Switzerland.

UNISDR (2009b): Global Assessment Report on Disaster Risk Reduction, Risk and poverty in a changing climate. Invest today for a safer tomorrow. United Nations. Geneva, Switzerland.

UNISDR (2011a): Global Assessment Report on Disaster Risk Reduction: Revealing Risk, Redefining Development. United Nations. Geneva, Switzerland, checked on 4/10/2013.

UNISDR (2011b): Hyogo Framework For Action 2005-2015. Building the Resilience of Nations and Communities to Disasters - Mid-Term Review 2010-2011. United Nations. Geneva, Switzerland, checked on $9 / 6 / 2013$.

UNISDR-PPEW: Global Survey of Early Warnings Systems: An assessment of capacities, gaps and opportunities towards building a comprehensive global early warning system for all natural hazards. Geneva, Switzerland.

Villagrán De León, Juan Carlos (2006): Vulnerability. A Conceptual and Methodological Review. Bonn (Source Publication Series of the United Nations University, Institute for Environment and Human Security (UNU-EHS), 4), updated on 8/21/2006, checked on 4/10/2013.

Viscusi, W.Kip (1994): Risk-risk analysis. In Journal of Risk and Uncertainty 8 (1), pp. 5-17. DOI: 10.1007/BF01064083.

Vogel, Coleen; O'Brien, Karen (2004): Vulnerability and Global Change: Rhetoric and Reality (AVISO, Bulletin on Global Environmental Change and Human Security, 13).

W. Neil Adger (2006): Vulnerability. In Global Environmental Change 16 (3), pp. 268-281. DOI: 10.1016/j.gloenvcha.2006.02.006.

Watts, M. J.; Bohle, H. G. (1993): The space of vulnerability: the causal structure of hunger and famine. In Progress in Human Geography 17 (1), pp. 43-67. DOI: 10.1177/030913259301700103.

Weichselgartner, Juergen (2001): Disaster mitigation: the concept of vulnerability revisited. In Disaster Prevention and Management 10 (2), pp. 85-95. DOI: 10.1108/09653560110388609. 
Welle, Torsten; Birkmann, Jörn; Rhyner, Jakob; Witting, Maximilian; Wolfertz, Jan (2012):

WorldRiskIndex 2012. Concept, updating and results. In Alliance Development Works (Ed.): World Risk Report 2012, pp. 11-25.

Werlen, Benno (1993): Society action and space. An alternative human geography. London, New York: Routledge.

Westgate, Kenneth N.; O'Keefe, Philip (1976): Some definitions of disaster. Bradford: University of Bradford.

Wisner, B.; Walter, J. (2005): Data or dialogue? The role of information in disasters. In International Federation of Red Cross and Red Crescent Societies (Ed.): World Disaster Report. Geneva.

Wisner, Ben; Blaikie, Piers; Cannon, Terry; Davis, lan (2004): At Risk: Natural hazards, people's vulnerability and disasters Second edition. Edited by Ben Wisner, Piers Blaikie, Terry Cannon, Ian Davis: Routledge.

Wisner, Ben; Gaillard, J. C.; Kelman, lian (Eds.) (2012): Handbook of Hazarfds and Disaster Risk Reduction: Routledge.

Wolf, Sarah; Hinkel, Jochen; Hallier, Mareen; Bisaro, Alexander; Lincke, Daniel; Ionescu, Cezar; Klein, Richard J.T. (2013): Clarifying vulnerability definitions and assessments using formalisation. In Int J of Cl Chan Strat and Man 5 (1), pp. 54-70. DOI: 10.1108/17568691311299363.

Wood, Nathan J.; Burton, Christopher G.; Cutter, Susan L. (2010): Community variations in social vulnerability to Cascadia-related tsunamis in the U.S. Pacific Northwest. In Nat Hazards 52 (2), pp. 369-389. DOI: 10.1007/s11069-009-9376-1.

Yodmani, S. (Ed.) (2001): Disaster risk management and vulnerability reduction: Protecting the poor. Reforming policies and institutions for povety reduction. Manila, Philippines, 5-9 February. Asia and Pacific Forum on Poverty, checked on 1/15/2014. 


\section{Appendix}

\section{XII.1 Local Assessment Results}

\section{XII.1.1 Access to warning}

XII.1.1.1 Bali

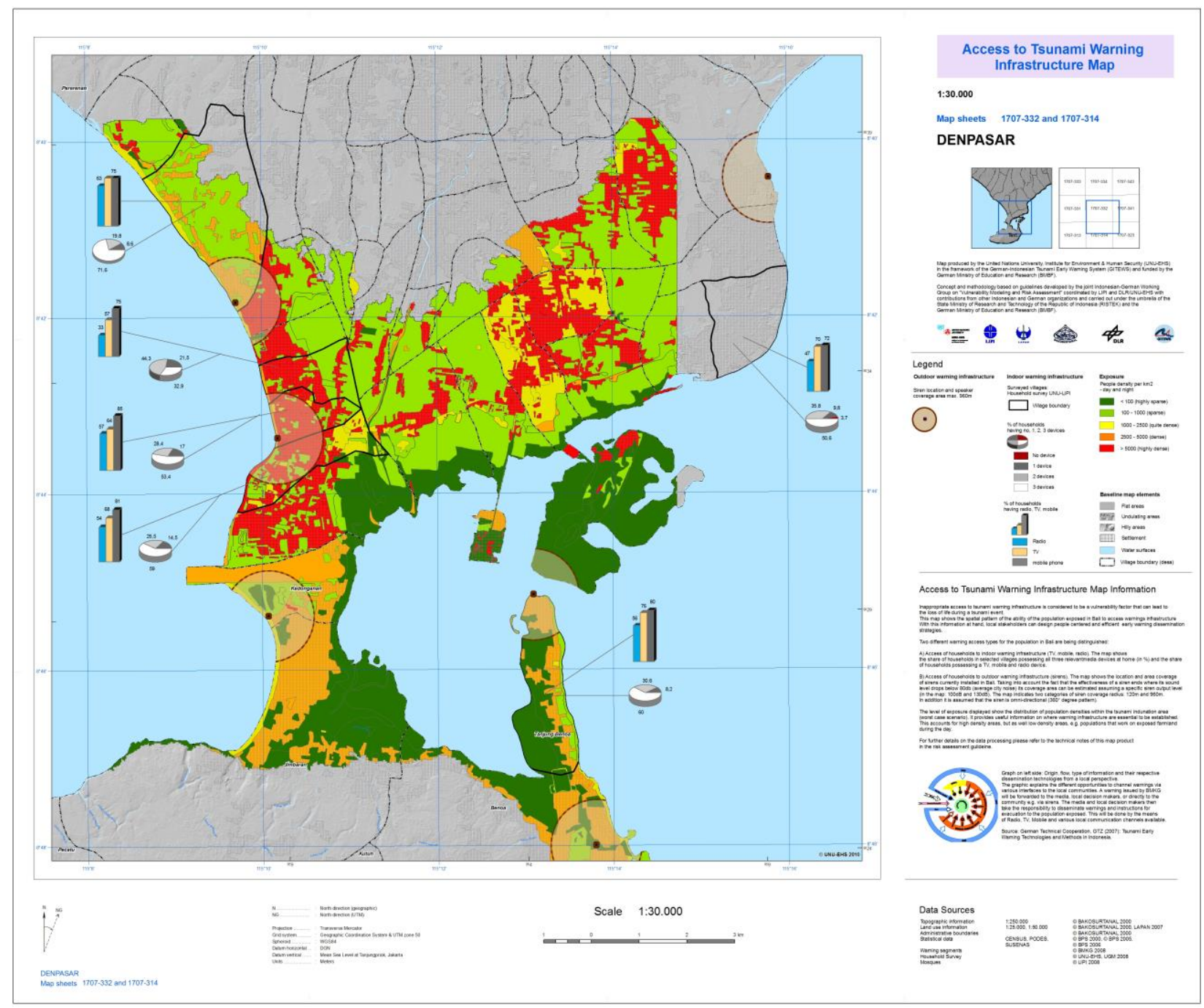

Map 9: Access to tsunami warning in exposed areas in Bali 


\section{XII.1.1.2 Padang}

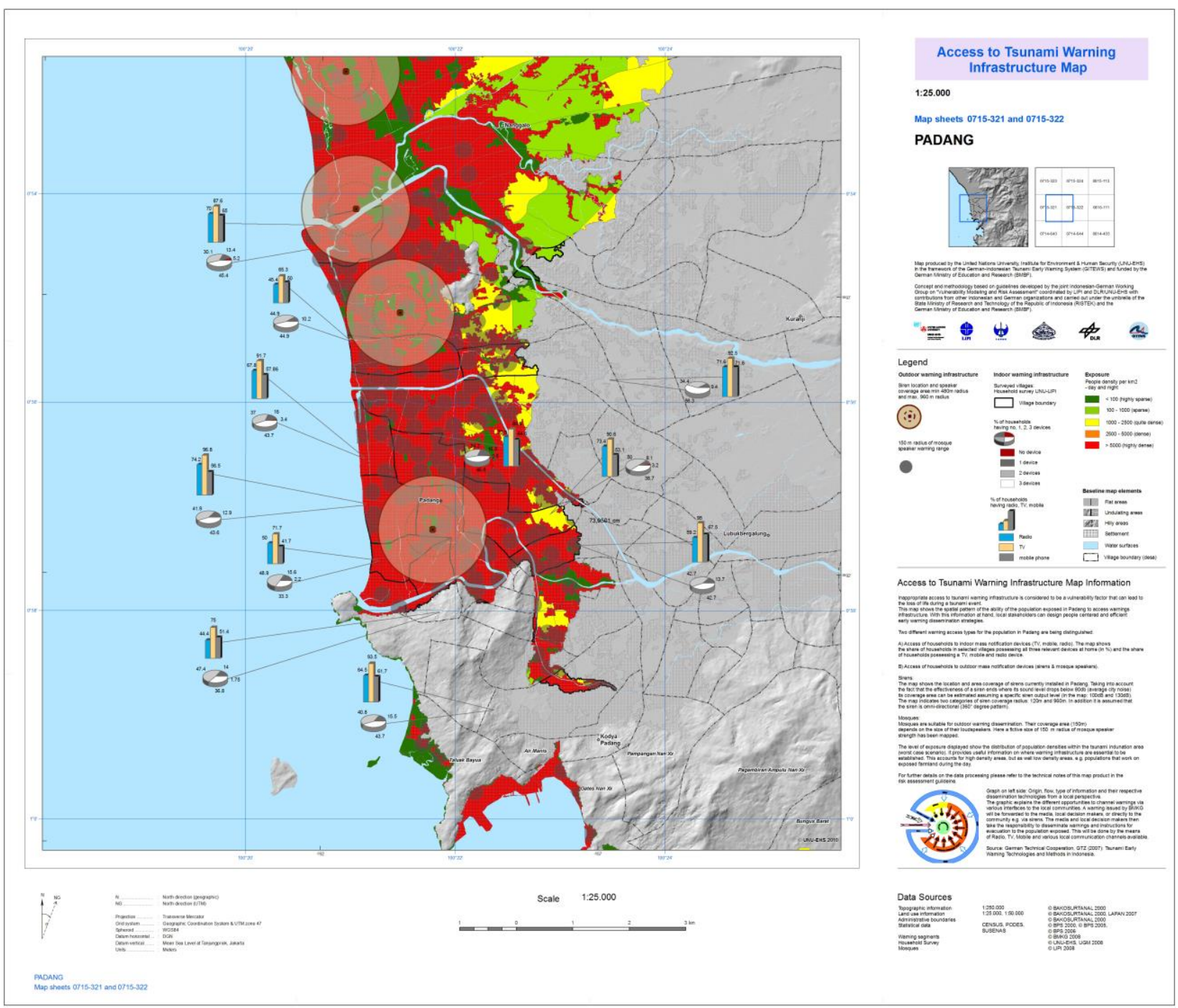

Map 10: Access to tsunami warning in exposed areas in Padang 


\section{XII.1.2 Evacuation Readiness}

\section{XII.1.2.1 Bali}

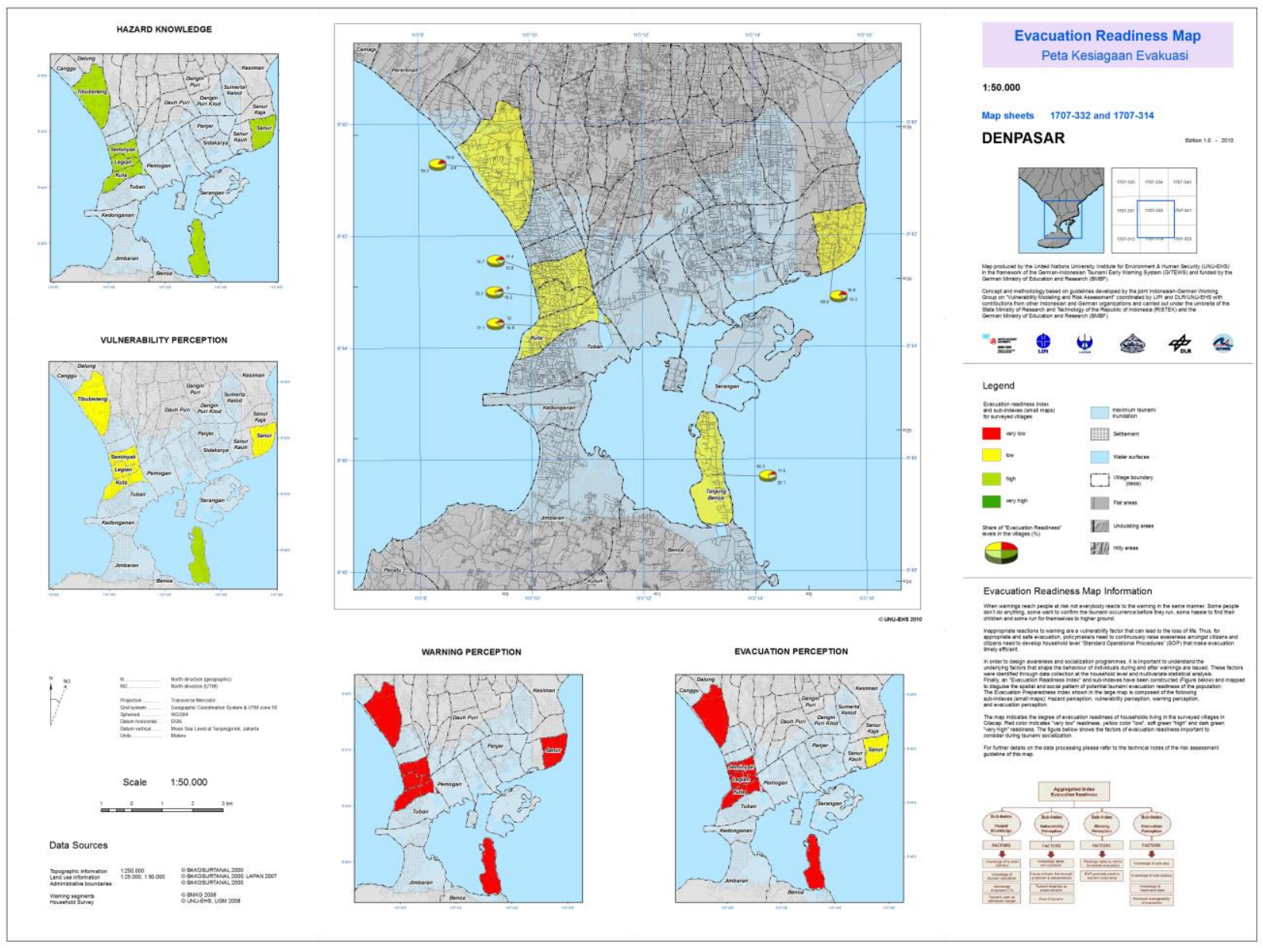

Map 11: Degree of evacuation readiness of the populaiton in exposed communities in the district of Badung 


\section{XII.1.2.2 Padang}

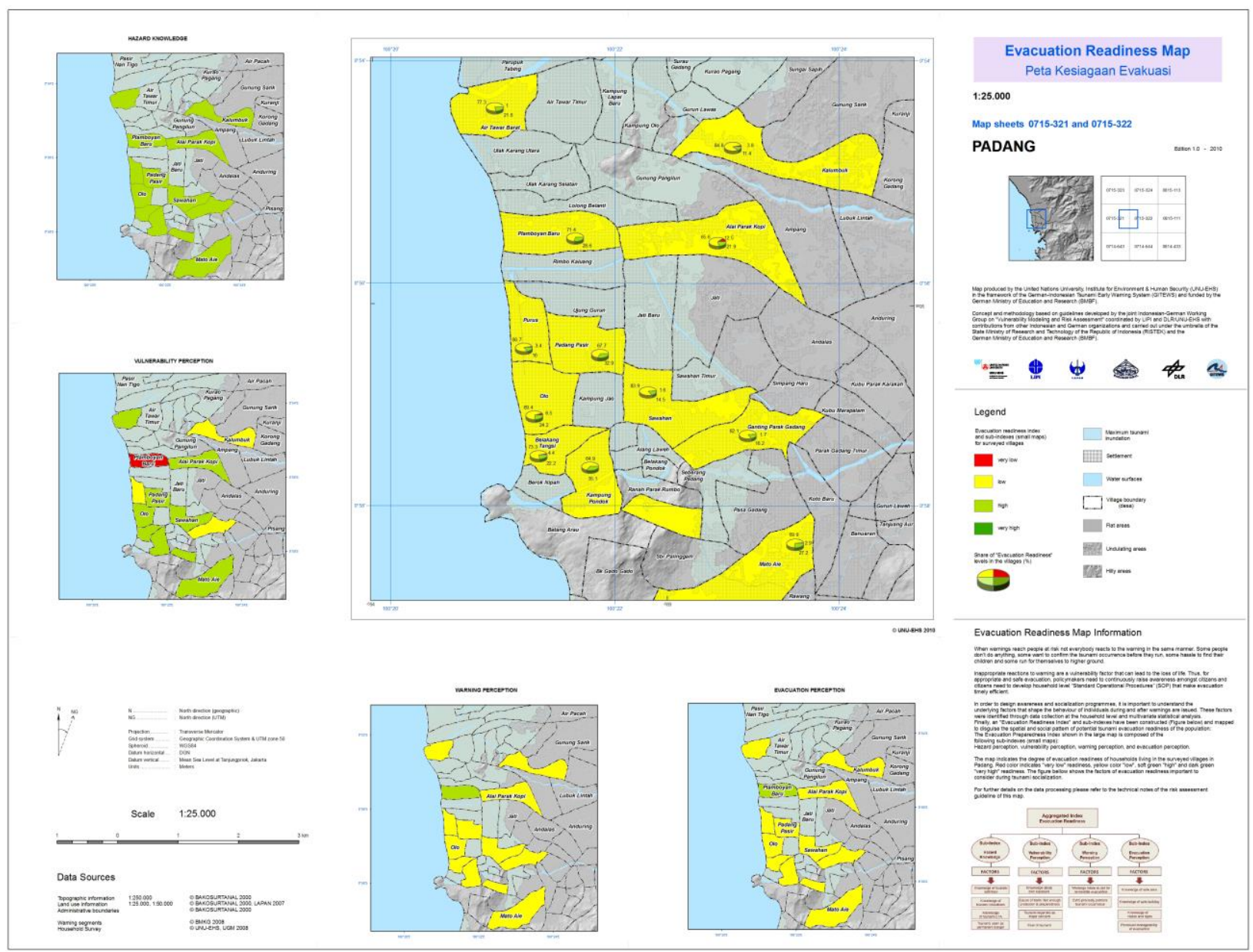

Map 12: Degree of evacuation readiness of the populaiton in exposed communities in the district of Padang 
XII.2 Household Questionnaire

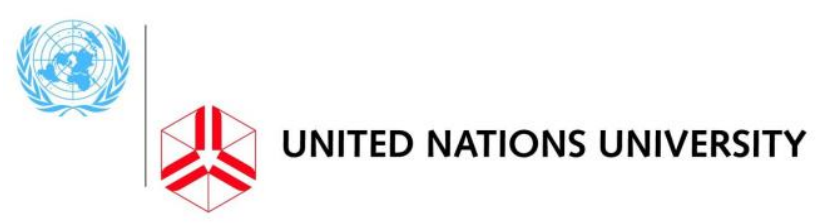

Household Questionnaire

Socio-economic Vulnerability Assessment in Padang (Sumatra), Cilacap (Java) and Badung (Bali) in the Context of the Indonesian Tsuami Early Warning System 


\section{General information of the interview}

\begin{tabular}{|c|c|}
\hline Date of interview & \\
\hline \multicolumn{2}{|l|}{ Time of interview } \\
\hline \multicolumn{2}{|l|}{ Interviewer ID } \\
\hline \multicolumn{2}{|l|}{ Name of Editor } \\
\hline \multicolumn{2}{|l|}{ ID Household (in the map) } \\
\hline \multicolumn{2}{|l|}{$\begin{array}{l}\text { If this building is not dwelled house, what is the } \\
\text { function? }\end{array}$} \\
\hline \multicolumn{2}{|l|}{ Kecamatan / Kelurahan } \\
\hline \multicolumn{2}{|l|}{ RT /RW } \\
\hline ID respondent (ART 01) & 01 \\
\hline \multicolumn{2}{|l|}{ Name of the respondent } \\
\hline Type of household & $\begin{array}{l}\text { - If dwelled by family } \\
\text { - If dwelled by people without family } \\
\text { relationship but eat from the same kitchen }\end{array}$ \\
\hline
\end{tabular}




\section{Socio-Demographic Household Characteristics}

\begin{tabular}{|c|c|c|c|c|c|c|c|c|c|c|}
\hline & $\begin{array}{l}\text { Name of } \\
\text { the } \\
\text { househol } \\
\text { d member }\end{array}$ & $\begin{array}{l}\text { Relationship to the } \\
\text { HH head } \\
\text { 1. Head } \\
\text { 2. Spouse of head } \\
\text { 3. Birth/Step children } \\
\text { 4. Birth/Step siblings } \\
\text { 5. Siblings in law } \\
\text { 6. Children in law } \\
\text { 7. Birth/Step grandchildren } \\
\text { 8. Parents/in law } \\
\text { 9. Other family } \\
\text { 10. House maid } \\
\end{array}$ & $\begin{array}{l}\begin{array}{l}\text { Age } \\
\text { (years) } \\
\text { Baby }=0\end{array} \\
\end{array}$ & $\begin{array}{l}\text { 5ex } \\
\text { 1. male } \\
\text { 2. female }\end{array}$ & $\begin{array}{l}\text { Religion } \\
\text { 1. Islam } \\
\text { 2. Catholic } \\
\text { 3. Kristen } \\
\text { 4. Hindu } \\
\text { 5. Buda } \\
\text { 6. Others__- }\end{array}$ & \begin{tabular}{|l} 
Ethnicity \\
1. Minang \\
2. Jawa \\
3. Batak \\
4. Cina \\
5. Nias \\
6. Others__
\end{tabular} & $\begin{array}{l}\text { How long } \\
\text { has the } \\
\text { HH } \\
\text { member } \\
\text { stayed in } \\
\text { the } \\
\text { Kelurahan } \\
\text { (years) } \\
\text { Baby=0 }\end{array}$ & $\begin{array}{l}\text { How long } \\
\text { has the HH } \\
\text { member } \\
\text { stayed in } \\
\text { Padang } \\
\text { (years) } \\
\text { Baby=0 }\end{array}$ & $\begin{array}{l}\text { Attained education } \\
\\
\text { 0. Never went to school } \\
\text { 1. Not attained SD } \\
\text { 2. Attained SD } \\
\text { 3. Attained SMP } \\
\text { 4. Attained SMA/SMK } \\
\text { 5. Diploma and Bachelor } \\
\text { 6. Graduate/PhD } \\
\text { 77. }<5 \text { years old }\end{array}$ & $\begin{array}{l}\text { Physical/mental } \\
\text { limitation } \\
\text { 1. mentally disabled } \\
\text { 2. blind } \\
\text { 3. deaf/mute } \\
\text { 4. physically diasbled } \\
\text { 5. in bed due to sickness } \\
\text { 6. others } \\
\mathbf{0 .} \text { normal } \\
\text { 77. }<5 \text { years old }\end{array}$ \\
\hline $\begin{array}{l}\text { ART } 01 \\
\text { respond } \\
\text { en }\end{array}$ & & $\square \square$ & $\square \square$ & $\square$ & $\square$ & $\square$ & $\square \square, \square$ & $\square \square, \square$ & $\square$ & $\square$ \\
\hline ART 02 & & $\square \square$ & $\square \square$ & $\square$ & $\square$ & $\square$ & $\square \square, \square$ & $\square \square, \square$ & $\square$ & $\square$ \\
\hline ART 03 & & $\square \square$ & $\square \square$ & $\square$ & $\square$ & $\square$ & $\square \square, \square$ & $\square \square, \square$ & $\square$ & $\square$ \\
\hline ART 04 & & $\square \square$ & $\square \square$ & $\square$ & $\square$ & $\square$ & $\square \square, \square$ & $\square \square, \square$ & $\square$ & $\square$ \\
\hline ART .... & & $\square \square$ & $\square \square$ & $\square$ & $\square$ & $\square$ & $\square \square, \square$ & $\square \square, \square$ & $\square$ & $\square$ \\
\hline ART .... & & $\square \square$ & $\square \square$ & $\square$ & $\square$ & $\square$ & $\square \square, \square$ & $\square \square, \square$ & $\square$ & $\square$ \\
\hline
\end{tabular}


Can the HH-members communicate well in Bahasa Indonesia?

1 yes

0 no

77 not applicable (e.g. $<5$ years old, mute)

\begin{tabular}{|c|c|c|c|c|c|c|c|}
\hline ART 01 & ART 02 & ART 03 & ART 04 & ART 05 & ART 06 & ART 07 ... \\
\hline$\square$ & $\square$ & $\square$ & $\square$ & $\square$ \\
\hline
\end{tabular}

IS THE RESPONDENT ABLE TO READ AND UNDERSTAND THE TEXT IN BAHASA INDONESIA? (PLS GIVE THE RESPONDENT THE TEXT TO READ AND ASK HIM/HER THE MEANING OF THE TEXT

4 very good -3 good -2 not so good -1 bad

If (2) or (1) why? (Except if never went to school);

\section{We would like to ask you to read the given text (in a separate sheet):}

"Wawancara ini berisi tema mengenai kerentanan (atau kesiagaan) masyarakat terhadap bencana tsunami dalam rangka perbaikan sistem peringatan dini tsunami dan pengurangan risiko tsunami di kota Padang. Hasil akhir dari penelitian ini akan kami manfaatkan sebesar-besarnya untuk menunjang sistem peringatan dini tsunami dan upaya peningkatan kesiagaan bencana di kota Padang" 


\section{Labour force assessment in the household}

\begin{tabular}{|c|c|c|c|c|c|c|c|c|c|}
\hline \multicolumn{10}{|c|}{ ART > 10 THN Employment Profile of the HH members during the last week } \\
\hline ART 01 & ART 02 & ART 03 & \multicolumn{2}{|l|}{ ART 04} & ART 05 & ART 06 & \multicolumn{2}{|c|}{ ART 07} & ART 08 \\
\hline$\square$ & $\square$ & $\square$ & $\square$ & \multicolumn{2}{|c|}{$\square$} & $\square$ & \multicolumn{2}{|c|}{$\square$} & $\square$ \\
\hline ART 09 & ART 10 & ART 11 & ART 12 & \multicolumn{2}{|c|}{ ART 13} & ART 14 & \multicolumn{2}{|c|}{ ART 15} & ART 16 \\
\hline$\square$ & $\square$ & $\square$ & $\square$ & \multicolumn{2}{|c|}{$\square$} & $\square$ & \multicolumn{2}{|c|}{$\square$} & $\square$ \\
\hline $\begin{array}{l}\text { 1. Earning } \\
\text { 2. Earning } \\
\text { 3. Unemp } \\
\text { 4. Mengar } \\
\text { 5. Workin } \\
\text { 6. School } \\
\text { 7. Househ } \\
\text { 8. Retired } \\
\text { 66. Others }\end{array}$ & $\begin{array}{l}\text { nanently ( } \\
\text { porarily (e } \\
\text { g time (< } \\
\text { ployed for } \\
\text { regularly }\end{array}$ & $\begin{array}{l}\text { ear) } \\
\text { oney, bu }\end{array}$ & iving othe & terial & & & & & \\
\hline \multicolumn{10}{|c|}{ The following questions are for the WORKING HH members ( $\rightarrow$ Question 1.24 , code $1,2,5$ ) } \\
\hline \multicolumn{10}{|c|}{ IF WORKING, where is the location of the main job? (CODE of HH members filled by enumerators) } \\
\hline & & ART .... & ART .... & ART ..... & ART ..... & ART ..... & ART .... & ART ... & ART .... \\
\hline \multicolumn{10}{|c|}{$\begin{array}{l}\text { IF INSIDE PADANG, please mention } \\
\text { the closed main road or name of } \\
\text { area/building/monument known by } \\
\text { the people }\end{array}$} \\
\hline $\begin{array}{l}\text { IF OUTSIDE PA } \\
\text { Please mentio } \\
\text { Kabupaten/cit }\end{array}$ & & & & & & & & & \\
\hline
\end{tabular}




\begin{tabular}{|c|c|c|c|c|c|c|c|c|c|c|c|c|c|c|c|c|c|}
\hline \multicolumn{18}{|c|}{ IF WORKING during the last week, in which sector is the main and secondary job (CODE of HH members filled by enumerators) } \\
\hline \multicolumn{2}{|c|}{ ART ..... } & \multicolumn{2}{|c|}{ ART ..... } & \multicolumn{2}{|c|}{ ART ..... } & \multicolumn{2}{|c|}{ ART $\ldots . .}$. & \multicolumn{2}{|c|}{ ART ..... } & \multicolumn{2}{|c|}{ ART ..... } & \multicolumn{2}{|c|}{ ART ..... } & \multicolumn{2}{|c|}{ ART ..... } & \multicolumn{2}{|c|}{ ART ..... } \\
\hline $1^{\text {st }}$ & $2^{\text {nd }}$ & $1^{\text {st }}$ & $2^{\text {nd }}$ & $1^{\text {st }}$ & $2^{\text {nd }}$ & $1^{\text {st }}$ & $2^{\text {nd }}$ & $1^{\text {st }}$ & $2^{\text {nd }}$ & $1^{\text {st }}$ & $2^{\text {nd }}$ & $1^{\text {st }}$ & $2^{\text {nd }}$ & $1^{\text {st }}$ & $2^{\text {nd }}$ & $1^{\text {st }}$ & $2^{\text {nd }}$ \\
\hline$\square$ & $\square$ & $\square$ & $\square$ & $\square$ & $\square$ & $\square$ & $\square$ & $\square$ & $\square$ & $\square$ & $\square$ & $\square$ & $\square$ & $\square$ & $\square$ & $\square$ & $\square$ \\
\hline \multicolumn{18}{|c|}{$\begin{array}{l}\text { 1. Agriculture, hunting, forestry } \\
\text { 2. Fishery } \\
\text { 3. Mining } \\
\text { 4. Manufacture } \\
\text { 5. Whole and Retail Trading } \\
\text { 6. Government employee } \\
\text { 7. Bank, insurance, Real Estate, and Service Firm } \\
\text { 8. Educational Service, Health, Social Activity, Society, Home Service, Transportation, Accomodation, etc } \\
\text { 66. Others..... }\end{array}$} \\
\hline \multicolumn{18}{|c|}{ What type of job in that Sector? } \\
\hline \multicolumn{2}{|c|}{ ART ..... } & \multicolumn{2}{|c|}{ ART ..... } & \multicolumn{2}{|c|}{ ART ..... } & \multicolumn{2}{|c|}{ ART ...... } & \multicolumn{2}{|c|}{ ART ..... } & \multicolumn{2}{|c|}{ ART ..... } & \multicolumn{2}{|c|}{ ART ..... } & \multicolumn{2}{|c|}{ ART ..... } & \multicolumn{2}{|c|}{ ART ..... } \\
\hline $1^{\text {st }}$ & $2^{\text {nd }}$ & $1^{\text {st }}$ & $2^{\text {nd }}$ & $1^{\text {st }}$ & $2^{\text {nd }}$ & $1^{\text {st }}$ & $2^{\text {nd }}$ & $1^{\text {st }}$ & $2^{\text {nd }}$ & $1^{\text {st }}$ & $2^{\text {nd }}$ & $1^{\text {st }}$ & $2^{\text {nd }}$ & $1^{\text {st }}$ & $2^{\text {nd }}$ & $1^{\text {st }}$ & $2^{\text {nd }}$ \\
\hline$\square$ & $\square$ & $\square$ & $\square$ & $\square$ & $\square$ & $\square$ & $\square$ & $\square$ & $\square$ & $\square$ & $\square$ & $\square$ & $\square$ & $\square$ & $\square$ & $\square$ & $\square$ \\
\hline $\begin{array}{ll}\text { 1. } & \mathrm{Pr} \\
\text { 2. } & \mathrm{st} \\
\text { 3. } & \mathrm{Sr} \\
\text { 4. } & \mathrm{Sr} \\
\text { 66. } & \mathrm{W}\end{array}$ & $\begin{array}{l}\text { ssiona } \\
\text { opera } \\
\text { and } n \\
\text { Servic } \\
\text { the } \mathrm{t} \\
\ldots: 1 \mathrm{st} \\
\ldots: \text { 1st } \\
\ldots: \text { 1st } \\
\ldots: \text { 1st } \\
\ldots: \text { 1st }\end{array}$ & $\begin{array}{l}\text { g. res } \\
\text { adm } \\
\text { le sta } \\
\text { d lab } \\
\text { of ea }\end{array}$ & $\begin{array}{l}\text { cher, } \\
\text { tratior } \\
\text { g. Wo } \\
\text { er, e.g } \\
\text { RT pl }\end{array}$ & $\begin{array}{l}\text { sling } \\
\text { ss, Cr } \\
\text { uli", la }\end{array}$ & $\begin{array}{l}\ldots \text { 2nd } \\
\ldots .2 \text { nd } \\
\ldots .2 \text { nd } \\
\ldots .2 \text { nd } \\
\ldots .2 \text { nd }\end{array}$ & $\begin{array}{l}\text { ager, } \\
\text { mech } \\
\text { rker, }\end{array}$ & $\begin{array}{l}\text { tary } \\
\text { sale } \\
\text { gan s }\end{array}$ & $\begin{array}{l}\text { ket } \\
\text { ", se } \\
\text { "tuk }\end{array}$ & $\begin{array}{l}y \\
\text { besi" }\end{array}$ & & & & & & & & \\
\hline
\end{tabular}




\section{Income}

In the following questions, we are going to ask some information on your household income. We know they are very personal and private. However, as with all the other questions, all your responses will be kept confidential

\begin{tabular}{|c|c|c|c|c|c|c|c|c|c|c|}
\hline \multicolumn{11}{|c|}{$\begin{array}{l}\text { Approximately how much your household's before-tax income from all sources last year? (If you are self-employed or own your own business, please report your } \\
\text { net income after business deductions.) }\end{array}$} \\
\hline & & ART ..... & ART ..... & ART .... & ART .... & ART .... & ART .... & ART .... & ART .... & ART .... \\
\hline \multirow[t]{2}{*}{1} & $\begin{array}{l}\text { Estimated average } \\
\text { monthly income for }\end{array}$ & $\mathrm{Rp}$ & $\mathrm{Rp}$ & $\mathrm{Rp}$ & $\mathrm{Rp}$ & $\mathrm{Rp}$ & $\mathrm{Rp}$ & $\mathrm{Rp}$ & Rp & $\mathrm{Rp}$ \\
\hline & $\begin{array}{l}\text { 1. Rp } \\
\text { 88. Don't know } \\
99 \text { Refused answering }\end{array}$ & $\square$ & $\square$ & $\square$ & $\square$ & $\square$ & $\square$ & $\square$ & $\square$ & $\square$ \\
\hline \multicolumn{9}{|c|}{$\begin{array}{l}2 \text { How much transfer did the household get from family/relative in last } 12 \text { months } \\
\text { 1. Rp } \\
0 \text { No one } \\
99 \text { Refused answering } \\
\text { If it is goods, give the estimated value in RP }\end{array}$} & \multicolumn{2}{|c|}{ Rp............................... } \\
\hline 3 & $\begin{array}{l}\text { How much the avera } \\
\text { 3. Average sum inc } \\
\text { If you don't know the } \\
\text { 1. < Rp. } 800.000 \\
\text { 2. Rp. } 800.001-1.600 \text {. } \\
\text { 3. Rp. } 1.600 .001-4.00 \\
\text { 4. > Rp. } 4.000 .000 \\
\text { 88. Don't know } \\
\text { 99 Refused answering }\end{array}$ & $\begin{array}{l}\text { e sum incom } \\
\text { exact numbe househo } \\
00 \\
.000\end{array}$ & $\begin{array}{l}\text { ast year per } \\
+ \text { delivery } m \\
\text { please give }\end{array}$ & $\begin{array}{l}\text { lonth } \\
\text { a guess acco }\end{array}$ & g to the follo & categories & & & \multicolumn{2}{|c|}{ Rp............................... } \\
\hline
\end{tabular}




\section{Tsunami Experience in Padang}

Maybe you have experienced some earthquake in the past time and even there was a tsunami warning. We would like to know about that experience.

\begin{tabular}{|l|c|}
\hline Have you heard the word tsunami before? & Answer \\
\hline 1 Yes & Code: $\square$ \\
\hline If yes, what is "tsunami" ? & Answer \\
\hline 1. Big flood due to rain & Code: $\square$ \\
2. High sea waves due to storm occurring regularly & \\
3. High sea waves caused by earthquake in sea. & \\
4. Earthquake & \\
66. Others & \\
88. Don't know & \\
\hline
\end{tabular}

If no / never, which word is used to call a big destructive wave that happened because strong earthquake in sea

Open question

\begin{tabular}{|l|c|}
\hline Have you ever experienced a tsunami in your area in your lifetime? & Answer \\
\hline $\begin{array}{l}1 \text { Yes } \\
0 \text { No }\end{array}$ & Code: $\square$ \\
\hline $\begin{array}{l}\text { Have you ever received information about a tsunami occurrence from any kind of } \\
\text { source (e.g. radio, TV, friends calling) immediately an after strong earthquake } \\
\text { event in your region? }\end{array}$ & Answer \\
\hline $\begin{array}{l}1 \text { Yes } \\
0 \text { No } \rightarrow \text { Go to Chapter } 4 \text { (Receiving warning) }\end{array}$ & Code: $\square$ \\
\hline
\end{tabular}

If yes, please answer the following questions based on your latest experience

\begin{tabular}{|l|c|}
\hline Through which devices/person did you receive the warning information? & Multiple answer \\
\hline A. RADIO & \\
B. TV & \\
C. SMS & \\
D. RT/RW STAFFS & \\
E. FRIEND/NEIGHBOURS/RELATIVES & \\
F. BMG SIREN & \\
G. MOSQUE SPEAKER & \\
66. OTHERS & \\
\hline Could you understand the received warning information easily? & Answer \\
\hline $\begin{array}{l}1 \text { Yes } \\
0 \text { No }\end{array}$ & Code: \\
\hline Did you evacuate? & Answer \\
\hline $\begin{array}{l}1 \text { Yes } \rightarrow \text { Go to } 3.11 \\
0 \text { No } \rightarrow \text { Go to } 3.9 \text { and then skip the other until chapter 4, site } 15\end{array}$ & Code: \\
\hline
\end{tabular}




\begin{tabular}{|l|c|}
\hline Why didn't you evacuate? & Maximal 3 answers \\
\hline A. I wanted to wait and be sure about the tsunami occurrence \\
B. I didn't trust the warning \\
C. I didn't know what to do \\
D. There was no clear evacuation guidance \\
E. The other people also stayed \\
F. I followed the instruction of religious/cultural leaders \\
G. I thought it was only allert warning \\
66. Others
\end{tabular}

Blank, omitted

Question 3.11 until 3.14. are for the respondents who evacuated

\begin{tabular}{|c|c|}
\hline $\begin{array}{l}\text { If you didn't evacuate immediately after the warning, what did you do first before } \\
\text { you tried to evacuate to a safe place? }\end{array}$ & Maximal 3 answers \\
\hline $\begin{array}{l}\text { I. NOTHING, I EVACUATED IMMEDIATELY } \\
\text { A. FINDING MORE INFORMATION FROM TV/RADIO } \\
\text { B. FINDING MORE INFORMATION FROM RT/RW OR OTHER GOVERNMENT } \\
\text { AUTHORITIES } \\
\text { C. GOING TO THE COAST AND OBSERVED THE SEAWATER TO CONFIRM } \\
\text { D. GATHERING THE HOUSEHOLD MEMBERS AT HOME / AT A PARTICULAR } \\
\text { PLACE } \\
\text { E. COLLECING AND PACKING ALL IMPORTANT ITEMS AT HOME: IMPORTANT } \\
\text { DOCUMENTS, MONEY, MEDICINES, ETC.... } \\
\text { F. TAKING A FIRST AID BOX OR EMERGENCY BAG WITH ME } \\
\text { G. SECURING THE HOUSE: E.G. TURN OFF ELECTRICITY, STOVE, LOCK THE DOOR } \\
\text { H. INFORMING THE FAMILY, FRIENDS AND NEIGHBORS ABOUT POTENTIAL } \\
\text { TSUNAMI G } \\
\text { 66. OTHERS }\end{array}$ & $\begin{array}{l}\text { Code: } \\
\qquad \begin{array}{l}\square \\
\square \\
\square\end{array}\end{array}$ \\
\hline With whom did you evacuate? & Answer \\
\hline $\begin{array}{l}\text { 1. By myself } \\
\text { 2. Together with my household members } \\
\text { 3. Together with my friends and neighbors } \\
\text { 4. Together with hh members, as well as friends and neighbours } \\
\text { 66. Others : }\end{array}$ & $\begin{array}{l}\text { Code: } \\
\square\end{array}$ \\
\hline Where did you evacuate to? & Answer \\
\hline $\begin{array}{l}\text { 1. HIGH BUILDING CLOSE-BY } \\
\text { 2. HIGH BUILDING FURTHER INLAND } \\
\text { 3. HIGHER GROUND } \\
\text { 4. FRIENDS / RELATIVES LIVING IN THE HIGHER GROUND } \\
\text { 5. MOSQUE } \\
\text { 66. OTHERS }\end{array}$ & $\begin{array}{l}\text { Code: } \\
\square\end{array}$ \\
\hline \multicolumn{2}{|c|}{$\begin{array}{l}\text { LOCATION'S NAME: NAME OF THE NEAREST BIG STREET OR THE NAME OF THE PLACE / BUILDING/ } \\
\text { MONUMENT THAT IS KNOWN) ENUMERATOR IS ASKED TO CATEGORIZE DUE TO THE ANSWER BEYOND; IF } \\
\text { POSSIBLE }\end{array}$} \\
\hline
\end{tabular}




\begin{tabular}{|l|c|}
\hline $\begin{array}{l}\text { During evacuation / in the evacuation place, who were the first person / institution } \\
\text { that helped youß }\end{array}$ & Multiple Answer \\
\hline A. Police & Code: \\
B. Fire Brigade & $\square \square \square$ \\
C. Army & $\square \square$ \\
D. Friend / Neighbour / Relative & \\
E. NGO & \\
66. Others & \\
0. No one & \\
\hline
\end{tabular}

\section{Warning dissemination / Receiving the warning}

We would like to ask you about receiving the warning and how is the best way for you to get that warning.

\begin{tabular}{|c|c|c|}
\hline \multirow{2}{*}{$\begin{array}{l}\text { Do you have access to the following media devices at home or at } \\
\text { workplace? }\end{array}$} & \multicolumn{2}{|c|}{ Multiple answer } \\
\hline & At home & $\begin{array}{l}\text { At place of work / } \\
\text { school }\end{array}$ \\
\hline $\begin{array}{l}\text { A. Radio } \\
\text { B. TV } \\
\text { C. HP } \\
\text { D. Fixed Phone } \\
\text { E. Amateur Radio / HT } \\
\text { 66. Others } \\
\text { 0. No }\end{array}$ & $\square \square \square \square \square \square$ & $\begin{array}{l}\square \square \square \\
\square \square \square\end{array}$ \\
\hline \multicolumn{3}{|l|}{ How many mobile phone is used and working in this household? } \\
\hline $\begin{array}{l}\text { Is there any communication device in your neighborhood, which is } \\
\text { used to disseminate information to the people? }\end{array}$ & \multicolumn{2}{|c|}{ Multiple Answer } \\
\hline $\begin{array}{l}\text { A. Mosque Megaphone } \\
\text { B. Siren } \\
\text { C. Kentongan } \\
\text { D. Community Radio } \\
\text { 66. Others }\end{array}$ & \multicolumn{2}{|c|}{$\begin{array}{l}\square \square \square \\
\square \square\end{array}$} \\
\hline $\begin{array}{l}\text { In case of a tsunami warning whom would you contact first about } \\
\text { the warning }\end{array}$ & \multicolumn{2}{|c|}{ Please rank from 1 - 5} \\
\hline $\begin{array}{l}\text { 1. Government } \\
\text { 2. Police / Military } \\
\text { 3. BMG } \\
\text { 4. Mosque } \\
\text { 66. Others }\end{array}$ & $\begin{array}{l}\text { Pri } \\
\text { Pri } \\
\text { Pri } \\
\text { Pri } \\
\text { Pri }\end{array}$ & $\begin{array}{l}\text { ty } 1 \square \\
\text { ty } 2 \square \\
\text { ty } 3 \square \\
\text { ty } 4 \square \\
\text { ty } 5\end{array}$ \\
\hline
\end{tabular}




\section{General knowledge about Tsunami (Answer it according to your opinion)}

We would like to know nature disaster aspects based on your knowledge.

\begin{tabular}{|l|c|}
\hline What are the natural signs that tsunami might arrive in a short time & Multiple Answer \\
\hline A. BIRDS AND UNUSUAL ANIMAL'S HABIT & $\square$ \\
B. BIG EARTHQUAKE IN A SEA & \\
C. EARTHQUAKE & \\
D. SUBSIDED WATER FROM SEA & Answer \\
66. OTHERS, NAME IT & \\
88. HAVE NO IDEA & $\square$ \\
\hline How long will tsunami occur after those natural signs & \\
\hline 1. < 10 min & \\
2. $11-20$ min & \\
3. 21-30 min & \\
4. 31-60 min & \\
5. > 61 min & \\
88. Have no idea & Multiple answer \\
\hline What determines the harm of a tsunami? & $\square$ \\
\hline A. God's will/Anger of the south sea spirits & $\square \square$ \\
B. Sins by the society / politics & \\
C. Physical and natural mechanisms & \\
D. Many people live in exposed areas & \\
E. People don't have enough protection and preparedness & \\
66. Others & \\
88. Have no idea & \\
\hline
\end{tabular}

\begin{tabular}{|c|c|}
\hline What is the things that $\mathrm{hh}$ and you most concern or worry? & Choose 3 answer \\
\hline $\begin{array}{l}\text { A. Storm wave } \\
\text { B. Earthquake } \\
\text { C. Neighborhood security } \\
\text { D. Traffic accident } \\
\text { E. Income insecurity } \\
\text { F. The possibiltiy of tsunamy occurance } \\
\text { G. Seawater level rise } \\
\text { H. Climate changing } \\
\text { I. Flood } \\
\text { J. Environmental threat to health such as water and air pollution } \\
\text { K. Other social problem (e.g. social isolation, etc) }\end{array}$ & $\begin{array}{l}\square \\
\square \\
\square\end{array}$ \\
\hline Which has happened to you? & 1. Yes 0 . No \\
\hline $\begin{array}{l}\text { A. Storm wave } \\
\text { B. Earthquake } \\
\text { C. Criminality (robbery, crime, etc.) } \\
\text { D. Traffic accident } \\
\text { E. Income insecurity } \\
\text { F. Tsunami } \\
\text { G. Seawater level rise } \\
\text { H. Climate changing } \\
\text { I. Flood } \\
\text { J. Health problem because water and air pollution } \\
\text { K. Other social problem (e.g. social isolation, etc.) }\end{array}$ & $\begin{array}{l}\square \\
\square \\
\square \\
\square \\
\square \\
\square \\
\square \\
\square \\
\square \\
\square\end{array}$ \\
\hline
\end{tabular}




\section{Evacuation behaviour / Decision to evacuate}

A. Perception of the tsunami's impact

\begin{tabular}{|c|c|c|c|c|c|c|}
\hline \multicolumn{2}{|r|}{$\begin{array}{l}\text { We would like to know, what would come into your mind, if you get tsunami } \\
\text { warning after big earthquake. What is your opinion about the following } \\
\text { statements } \\
\text { 4 Strongly agree - } 3 \text { Agree - } 2 \text { Disagree - } 1 \text { Strongly disagree }\end{array}$} & 4 & 3 & 2 & 1 & $\begin{array}{l}88 \\
\text { Don't } \\
\text { know }\end{array}$ \\
\hline 1 & Not sure whether tsunami will happen & & & & & \\
\hline 2 & Not sure where the tsunami will happen. & & & & & \\
\hline 3 & Resident must be aware and wait for further instruction from the government & & & & & \\
\hline 4 & Resident must be aware dan ready to evacuate to save place & & & & & \\
\hline 5 & Resident evacuate immediately whenever they are & & & & & \\
\hline \multicolumn{2}{|r|}{$\begin{array}{c}\text { How do you judge on the follwing statements? } \\
4 \text { very probable }-1 \text { not probable at all }\end{array}$} & 4 & 3 & 2 & 1 & $\begin{array}{l}88 \text { Dont } \\
\text { know }\end{array}$ \\
\hline 1 & It is probable that a small tsunami can happen in my life time & & & & & \\
\hline 2 & It is probable that a medium size tsunami can happen in my life time & & & & & \\
\hline 3 & It is probable that a huge tsunami can happen in my lifetime & & & & & \\
\hline 4 & It is probable that several tsunami can happen in my lifetime & & & & & \\
\hline \multicolumn{2}{|r|}{$\begin{array}{l}\text { Please read and judge on the following statements about your personal worries } \\
\text { with regard to possible tsunami impacts in your region? } \\
4 \text { strongly agree }-1 \text { strongly disagree }\end{array}$} & 8. & 9. & 10 & 11 & $\begin{array}{l}\text { 12. } 88 \\
\text { Don't } \\
\text { know }\end{array}$ \\
\hline 1 & $\begin{array}{l}\text { Generally, I am very worried, because a tsunami can strike anytime of the day } \\
\text { and time of the year }\end{array}$ & & & & & \\
\hline 2 & $\begin{array}{l}\text { Generally, I very often think about the probability that a tsunami can destroy the } \\
\text { life of my family. }\end{array}$ & & & & & \\
\hline 3 & $\begin{array}{l}\text { I am afraid that in case of a tsunami, supplies (electricity, telephone, water, etc.) } \\
\text { will be interrupted so that our daily activities will be disrupted }\end{array}$ & & & & & \\
\hline 4 & $\begin{array}{l}\text { It worries me that some of my assets (e.g. car, cattle, crops), except for my } \\
\text { home, will be seriously damaged or destroyed by a tsunami. }\end{array}$ & & & & & \\
\hline 5 & I feel worried that my own home will be seriously damaged or destroyed & & & & & \\
\hline 6 & $\begin{array}{l}\text { I feel worried that myself or some of my loved ones will be hurt (wounded or } \\
\text { killed) }\end{array}$ & & & & & \\
\hline 7 & I am not really worried, since I know how to behave if a tsunami would occur & & & & & \\
\hline 8 & I am not afraid of tsunami & & & & & \\
\hline \multicolumn{2}{|r|}{$\begin{array}{l}\text { What are your concerns, if you had to move from your area of living because of } \\
\text { tsunami risk? } \\
\text { 13. } 4 \text { strongly agree }-1 \text { strongly disagree }\end{array}$} & 4 & 3 & 2 & 1 & $\begin{array}{l}88 \\
\text { Don't } \\
\text { know }\end{array}$ \\
\hline 1 & I can easily move and find a job & & & & & \\
\hline 2 & $\begin{array}{l}\text { I got so familiar with the place and with the neighborhood so that I cannot } \\
\text { imagine to leave the place }\end{array}$ & & & & & \\
\hline 3 & I can easily move and find nice new friends & & & & & \\
\hline 4 & I cannot move easily but I will get help from my friends/family & & & & & \\
\hline 5 & I have enough money/will be able to borrow money to move & & & & & \\
\hline 6 & $\begin{array}{l}\text { I would never leave because here I have the facilities that I need (transport, } \\
\text { market, shopping centre, school) }\end{array}$ & & & & & \\
\hline
\end{tabular}




\section{B. Trust in the Tsunami Warning}

\begin{tabular}{|c|c|c|c|c|c|c|}
\hline \multicolumn{2}{|r|}{ Do you know that there is a TEWS in this city? } & \multicolumn{5}{|c|}{ Answer } \\
\hline \multicolumn{2}{|c|}{$\begin{array}{l}1 \text { Yes } \\
0 \text { No } \rightarrow \text { Go to question } 6.9\end{array}$} & \multicolumn{5}{|c|}{$\square$} \\
\hline \multicolumn{2}{|r|}{$\begin{array}{l}\text { If yes: do you think that a tsunami early warning system TEWS is an appropriate } \\
\text { tool to predict a tsunami? } \\
4 \text { strongly agree }-1 \text { strongly disagree }\end{array}$} & 4 & 3 & 2 & 1 & $\begin{array}{c}88 \\
\text { Don't } \\
\text { know }\end{array}$ \\
\hline 1 & TEWS has been set up completely in this city/Kabupaten & & & & & \\
\hline 2 & TEWS can predict very accurately the tsunami occurrence & & & & & \\
\hline \multicolumn{2}{|r|}{ Who is most trustworthy in issuing and disseminating a warning? } & 4 & 3 & 2 & 1 & $\begin{array}{c}88 \\
\text { Don't } \\
\text { know }\end{array}$ \\
\hline 1 & Walikota is a very reliable source of tsunami warning & & & & & \\
\hline 2 & RT / RW is a very reliable source of tsunami warning & & & & & \\
\hline 3 & National Early Warning Centre (BMG) is a very reliable source of tsunami warning & & & & & \\
\hline 4 & Neighbour / family member is a very reliable source of tsunami warning & & & & & \\
\hline 5 & $\begin{array}{l}\text { In case of tsunami, I would definitely receive a tsunami warning from the most } \\
\text { reliable source }\end{array}$ & & & & & \\
\hline & What are other reliable sources of tsunami warning? & & & & & \\
\hline
\end{tabular}

C. Predicted / intended and planned response measures (Response efficacy)

\begin{tabular}{|c|c|c|}
\hline Immediately after a big earthquake, what would you do? & $\begin{array}{c}\text { Max } \\
\text { 4 answers }\end{array}$ & $\begin{array}{c}\text { socialized } \\
\text { behavior }\end{array}$ \\
\hline A. I will wait at open space until the earthquake is over and just continue & $\square$ \\
my activity casually & $\square$ \\
B. I will try to find information / Turn on a radio or television and wait for & $\square$ \\
C. I news & $\square$ \\
D. I staff try to find more information about what is going on from RW / RT & $\square$ \\
E. I will run to the coast to observe the sea & \\
F. I will immediately evacuate to a safe place myself & $\square$ \\
G. I will immediately gather my family members and evacuate to a safe & \\
place & \\
66. Others & \\
\hline
\end{tabular}




\begin{tabular}{|c|c|c|}
\hline $\begin{array}{c}\text { Directly after having received a tsunami warning: What would you do } \\
\text { immediately? (Prioritize: only five most appreciated actions }\end{array}$ & $\begin{array}{c}\text { Max } \\
4 \\
\text { answers }\end{array}$ & $\begin{array}{l}\text { socialized } \\
\text { behavior }\end{array}$ \\
\hline $\begin{array}{l}\text { A. I will carefully listen to the radio or television and wait where I am for } \\
\text { further instruction from the government } \\
\text { B. I will directly try to find more guidance from RW / RT staff / Mosque } \\
\text { C. I will go away from the beach there } \\
\text { D. I will immediately run to the coast to observe the sea to confirm } \\
\text { E. I will immediately inform my neighbours and friends around (e.g using } \\
\text { Kentongan) } \\
\text { F. I will immediately run to a safe place myself } \\
\text { G. I will collect my family members first then and run to a safe p lace } \\
\text { H. I will follow what others do (neighbours, friends, family members) } \\
\text { I. I would not know what to do } \\
\text { 66. Others }\end{array}$ & $\begin{array}{l}\square \\
\square \\
\square \\
\square\end{array}$ & $\begin{array}{l}\square \\
\square \\
\square \\
\square \\
1 \text { yes } \\
0 \text { no }\end{array}$ \\
\hline
\end{tabular}

\begin{tabular}{|c|l|l|}
\hline Which is the save place, you think, if tsunami occurs. & $\begin{array}{l}\text { Maximal } 4 \\
\text { answers }\end{array}$ & $\begin{array}{l}\text { Socialized } \\
\text { behaviour }\end{array}$ \\
\hline A. HIGH BUILDING CLOSE-BY & $\square$ & $\square$ \\
B. HIGH BUILDING AWAY FROM THE COAST (HINTERLAND) & $\square$ \\
C. HIGHER GROUND, E.G. LIMAU MANIS, INDARUNG, LUBUK & $\square$ & $\square$ \\
DEGALUNG, GN. PANGILUN & $\square$ & 1 yes \\
E. NELATIVES HOUSE LIVING AT HIGHER GROUND & & 0 no \\
F. AT HOMEST MOSQUE & & \\
66. OTHERS & & $\square$ \\
\hline
\end{tabular}

ii) Direct intentional behaviour after realizing tsunami occurrence (Evacuation): According to your opinion, what kind of activities are effective to reduce the amount of victims during a tsunami occurrence?

\begin{tabular}{|c|c|c|c|c|c|c|}
\hline \multicolumn{2}{|r|}{$\begin{array}{l}\text { Do you think the following actions are appropriate in case of a tsunami early } \\
\text { warning? } \\
4 \text { very appropriate - } 1 \text { very inappropriate }\end{array}$} & 4 & 3 & 2 & 1 & $\begin{array}{l}\text { Agreed } \\
\text { behavior } \\
1 \text { yes } \\
0 \text { no }\end{array}$ \\
\hline 1 & Immediately run away from the coast after receiving the warning & & & & & \\
\hline 2 & Hiding in the house because its safe & & & & & \\
\hline 3 & Wait first for evacuation instruction after receiving tsunami warning & & & & & \\
\hline 4 & $\begin{array}{l}\text { Assuring tsunami occurrence by running to the coast and observe tsunami } \\
\text { indications }\end{array}$ & & & & & \\
\hline 5 & Observe and follow what the neighbors do & & & & & \\
\hline 6 & $\begin{array}{l}\text { Gather all family members and evacuate together, does not matter how long } \\
\text { it takes }\end{array}$ & & & & & \\
\hline 7 & Help my neighbors and friends to evacuate themselves & & & & & \\
\hline 8 & Let children and women evacuate first & & & & & \\
\hline
\end{tabular}




\section{Self-Efficacy for Evacuation (How do people judge on their own capabilities to deal with tsunami risk)}

\begin{tabular}{|l|l|l|}
\hline \multicolumn{2}{|l|}{ Do you know / understand about the following-related to evacuation? } & $\begin{array}{l}1 \text { Yes } \\
\text { 0 No } \\
88 \text { Doubt }\end{array}$ \\
\hline 1 & I know high buildings suitable for evacuation close to home/workplace/school & $\square$ \\
\hline 2 & I know higher ground close to home/workplace/school & $\square$ \\
\hline 3 & $\begin{array}{l}\text { I know evacuation places designated by } \\
\text { government/authorities : }\end{array}$ & $\square$ \\
\hline 4 & I know and understand evacuation signs placed along the streets & $\square$ \\
\hline 5 & I know evacuation routes given by the government & $\square$ \\
\hline 6 & $\begin{array}{l}\text { Based on my own knowledge, I know routes to reach any evacuation place } \\
\text { (apart from what government design) }\end{array}$ & $\square$ \\
\hline
\end{tabular}

\begin{tabular}{|c|c|c|c|c|c|c|}
\hline \multicolumn{2}{|r|}{$\begin{array}{l}\text { Do you think you can manage to accomplish the following issues in an } \\
\text { emergency situation? } \\
4 \text { easily accomplished - } 1 \text { not possible to accomplish }\end{array}$} & 4 & 3 & 2 & 1 & $\begin{array}{l}88 \\
\text { Don't } \\
\text { know }\end{array}$ \\
\hline 1 & $\begin{array}{l}\text { I and my HH-members will manage to successfully find a safe place before } \\
\text { the tsunami could hit me }\end{array}$ & & & & & \\
\hline 2 & $\begin{array}{l}\text { Gathering my family members and still appropriately evacuate together to } \\
\text { a safe place }\end{array}$ & & & & & \\
\hline 3 & Helping others who need help while evacuating & & & & & \\
\hline \multicolumn{2}{|r|}{$\begin{array}{l}\text { According to your opinion, how long would you need to collect your most } \\
\text { important items / documents and gather family members before you } \\
\text { evacuate? }\end{array}$} & \multicolumn{5}{|c|}{ Answer } \\
\hline & $\begin{array}{l}\text { 1. Less or equal } 15 \text { minutes } \\
\text { 2. } 16-30 \text { minutes } \\
\text { 3. } 31 \text { minutes }-1 \text { hour } \\
\text { 4. More then } 1 \text { hour }\end{array}$ & \multicolumn{5}{|c|}{ Code: $\square$} \\
\hline \multicolumn{2}{|r|}{$\begin{array}{l}\text { According to your opinion, how long would it take for you to reach the } \\
\text { nearest evacuation place from home? }\end{array}$} & \multicolumn{5}{|c|}{ Answer } \\
\hline & $\begin{array}{l}\text { 1. Less or equal } 15 \text { minutes } \\
\text { 2. } 16-30 \text { minutes } \\
\text { 3. } 31 \text { minutes }-1 \text { hour } \\
\text { 4. More then } 1 \text { hour }\end{array}$ & \multicolumn{5}{|c|}{ Code: $\square$} \\
\hline
\end{tabular}

\section{E. Cost of Evacuation}

\begin{tabular}{|c|c|c|c|c|c|c|}
\hline \multicolumn{2}{|r|}{$\begin{array}{l}\text { What would be the disadvantages of evacuating? (in case tsunami isn't } \\
\text { happen) } \\
4 \text { strongly agree }-1 \text { strongly disagree }\end{array}$} & \multirow[t]{2}{*}{4} & \multirow[t]{2}{*}{3} & \multirow[t]{2}{*}{2} & \multirow[t]{2}{*}{1} & \multirow[t]{2}{*}{$\begin{array}{l}88 \\
\text { Don`t } \\
\text { know }\end{array}$} \\
\hline 1 & Possibility of looting during evacuation & & & & & \\
\hline 2 & Loss of income during evacuation & & & & & \\
\hline 3 & Need to buy additional food, water during evacuation & & & & & \\
\hline 4 & Troubling friends / relatives while staying at their house & & & & & \\
\hline 5 & Staying too long away from home due to evacuation & & & & & \\
\hline 66 & Others & & & & & \\
\hline
\end{tabular}




\section{Evacuation Capability}

\begin{tabular}{|c|c|}
\hline How do you know an evacuation route? & Multiple answer \\
\hline A. EVACUATION MAP ON THE CITY BILLBOARD & $\square \square \square$ \\
B. EVACUATION MAP DISTRIBUTED AS LEAFLETS FROM THE CITY GOVERNMENT & $\square \square \square$ \\
C. EVACUATION SIGNS AT THE ROADS & \\
D. INFORMATION FROM THE LOCAL TV & \\
E. FROM FRIENDS/NEIGHBOURS/RELATIVES & \\
F. PARTICIPATION IN DRILL EXERCISE & \\
G. OWN CONSIDERATION & \\
88. HAVE NO IDEA & Answers \\
\hline Have you ever participated in tsunami simulation/socialization? & Code: \\
\hline Y Yes & \\
0 No & \\
\hline
\end{tabular}

\begin{tabular}{|l|c|}
\hline $\begin{array}{l}\text { What kind of vehicles do the HH members have, which are still } \\
\text { functional }\end{array}$ & $\begin{array}{c}\text { If a-d, } \\
\text { 66:How many }\end{array}$ \\
\hline A. Bicycle & $\square \square \square$ \\
B. Motorcycle & $\square \square$ \\
C. Car & \\
D. Wheel chair for elderly/disabled & \\
66. Others & \\
0. Nothing or they are not functioning & Multiple answer \\
\hline According to your opinion, what are the constraints of & \\
successful evacuation? & $\square \square$ \\
\hline A. Not all the household members know the evacuation & $\square$ \\
B. Traffic jam & \\
C. The location is too far away & \\
D. No transportation or no vehicle & \\
E. Panic & \\
66. Others:............ & \\
\hline
\end{tabular}




\section{Risk Communication}

We suppose that there have been discussions about tsunami in the city of Padang and your living area. We would like to know more about the discussions.

\begin{tabular}{|l|c|}
\hline $\begin{array}{l}\text { If you require information about tsunami risk in your everyday life, which } \\
\text { source would you use? }\end{array}$ & Maximal $\mathbf{4}$ answers \\
\hline A. MEDIA (TELEVISION/RADIO/NEWSPAPER) & $\square \square$ \\
B. SOCIALIZATION FROM THE CITY GOVERNMENT & \\
C. SOCIALIZATION FROM NGO & \\
D. KECAMATAN / RT / RW & \\
E. RELIGIOUS LEADER & \\
F. ANOTHER HOUSE MEMBER & \\
G. SCHOOL & \\
H. NEIGHBOURS & \\
66. OTHERS & \\
\hline
\end{tabular}

\begin{tabular}{|c|c|c|c|c|c|c|}
\hline \multicolumn{2}{|r|}{$\begin{array}{l}\text { If the respondent is aware of the tsunami problem in the area, do you agree } \\
\text { to the following statements with regard to the topics discussed about } \\
\text { tsunami and how this discussion is going on? } \\
\text { 4strongly agree - } 1 \text { strongly disagree }\end{array}$} & \multirow[t]{2}{*}{4} & \multirow[t]{2}{*}{3} & \multirow[t]{2}{*}{2} & \multirow[t]{2}{*}{1} & \multirow[t]{2}{*}{$\begin{array}{c}88 \\
\text { Don't } \\
\text { know }\end{array}$} \\
\hline 1 & $\begin{array}{l}\text { Discussing about tsunami is not a public topic, only family members } \\
\text { discuss about tsunami }\end{array}$ & & & & & \\
\hline 2 & $\begin{array}{l}\text { The youngsters take the lead in the overall discussion, they are less } \\
\text { afraid to talk about tsunami risk and how to prepare for it }\end{array}$ & & & & & \\
\hline 3 & $\begin{array}{l}\text { Religious leaders have a significant influence on the topics to be } \\
\text { discussed amongst us }\end{array}$ & & & & & \\
\hline 4 & $\begin{array}{l}\text { The media and the religious leaders are discussing very different things } \\
\text { concerning aspects of the tsunami threat }\end{array}$ & & & & & \\
\hline 5 & These discussions about tsunami create conflict amongst the people & & & & & \\
\hline 6 & $\begin{array}{l}\text { People don't like to discuss, because it is not in our hands, whether a } \\
\text { tsunami will occur }\end{array}$ & & & & & \\
\hline 7 & $\begin{array}{l}\text { People don't like to discuss because we don't want to make ourselves } \\
\text { worry about it every day }\end{array}$ & & & & & \\
\hline 8 & $\begin{array}{l}\text { A lot of discussion is related on how the warning should be } \\
\text { disseminated to the people }\end{array}$ & & & & & \\
\hline 9 & $\begin{array}{l}\text { A lot of discussion is related to whether resettlement to a safe place is } \\
\text { necessary }\end{array}$ & & & & & \\
\hline 10 & $\begin{array}{l}\text { It is mostly discussed whether evacuation during a tsunami event is } \\
\text { nearly impossible and that one cannot do anything about it }\end{array}$ & & & & & \\
\hline 66 & Others & & & & & \\
\hline
\end{tabular}




\section{XII.3 Acknowledgement}

At this point I would like to express my utmost gratitude to all the colleagues, friends and family members who have helped me to navigate through this dissertation.

First of all, I would like to express my gratitude to Prof. Dr. Jörn Birkmann on behalf of the United Nations University - Institute for Environment and Human Security (UNU-EHS), who gave me the opportunity to work on this interesting field of applied research, to join the group of scientists contributing to establishing the Indonesian tsunami early warning system, and who secured continuous funding to finalize my dissertation. Furthermore, I am highly thankful for Prof. Dr. Heiko Faust to host my PhD, for his patience, carefulness, trust and effort to guide the finalization process of this piece of work.

This dissertation could not have been accomplished without the cooperation with the personnel of the German Aerospace Centre (DLR), notably Prof. Dr. Günter Strunz, Dr. Joachim Post, Matthias Mueck, and Stefanie Wegscheider, who had the work package lead on Risk and Vulnerability Assessment within the German-Indonesian Tsunami Early Warning System Project (GITEWS) and with whom I had a pronounced professional, sympathetic and harmonic collaboration during the entire period of the project, guided by trust and respect within an interdisciplinary research team.

Within this project I have been working together with a lot of very responsible Indonesian colleagues, especially Dr. Agus and his team from the Andalas University of Padang, as well as Dr. Agus Dwiyanto and his team from the Gadjah Mada University of Yogyakarta, who were assisting in managing my empirical work. Moreover, it was a pleasure and very helpful to closely collaborate with very friendly Dr. Herryal Anwar, the project coordinator from the Indonesian Government from the Lembaga IImu Pengetahuan Indonesia (LIPI) who was always helpful to arrange and prepare for important steps in the entire research process.

On a personal note, I would like to thank my dearest friends Neysa Setiadi, Joachim Post, Michael Hoppe, and Norbert Binternagel, as well as my root family who were always listening to share thoughts, and discuss major and minor aspects of my PhD. And finally, my deepest gratitude I want to attribute to my new core family which has meanwhile risen in numbers from 
two to five. I am especially thankful for the support of my dearest wife Sophia Baumert, and for her incredible patience, suffering, love, and encouragement throughout the PhD.

\section{XII.4 Declaration of Originality and Certificate of Ownership}

I, Niklas Baumert, hereby declare that I am the sole author of this dissertation entitled

„Advancing Risk and Vulnerability Assessment for Decision-Making and Research - Case Study from the German-Indonesian Tsunami Early Warning System (GITEWS) Project "

All references and data sources that were used in the dissertation have been appropriately acknowledged. I furthermore declare that this work has not been submitted elsewhere in any form as part of another dissertation procedure.

Maputo, July 21, 2015

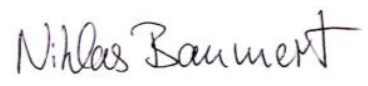

(Niklas Baumert) 